RECEIVED

JAN 131998

OSTI

\title{
Review of the Integrated Thermal and Nonthermal Treatment System Studies
}

\author{
Topical Report \\ July 1996
}

By:

Habib A. Durrani; Lanny J. Schmidt Thomas A. Erickson; Everett A. Sondreal John Erjavec; Edward N. Steadman Wolter J. Fabrycky; John S. Wilson Mark A. Musich

Work Performed Under Contract No.: DE-FC21-94MC31388

For

U.S. Department of Energy

Office of Environmental Management Office of Technology Development 1000 Independence Avenue Washington, DC 20585
U.S. Department of Energy

Office of Fossil Energy

Federal Energy Technology Center

Morgantown Site

P.O. Box 880

Morgantown, West Virginia 26507-0880

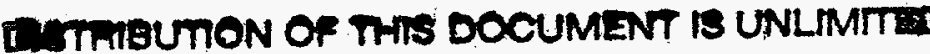

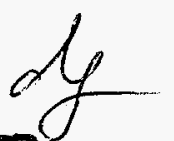

By

Energy \& Environmental Research Center

University Of North Dakota

P.O. Box 9018

Grand Forks, North Dakota 58202-9018

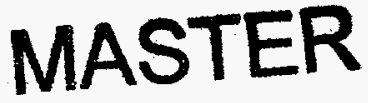




\section{Disclaimer}

This report was prepared as an account of work sponsored by an agency of the United States Government. Neither the United States Government nor any agency thereof, nor any of their employees, makes any warranty, express or implied, or assumes any legal liability or responsibility for the accuracy, completeness, or usefulness of any information, apparatus, product, or process disclosed, or represents that its use would not infringe privately owned rights. Reference herein to any specific commercial product, process, or service by trade name, trademark, manufacturer, or otherwise does not necessarily constitute or imply its endorsement, recommendation, or favoring by the United States Government or any agency thereof. The views and opinions of authors expressed herein do not necessarily state or reflect those of the United States Government or any agency thereof. 


\section{DISCLAIMER}

Portions of this document may be illegible electronic image products. Images are produced from the best available original document. 


\section{DISCLAMMER}

This report was prepared as an account of work sponsored by an agency of the United States Government. Neither the United States Government, nor any agency thereof, nor any of their employees makes any warranty, express or implied, or assumes any legal liability or responsibility for the accuracy, completeness, or usefulness of any information, apparatus, product, or process disclosed or represents that its use would not infringe privately owned rights. Reference herein to any specific commercial product, process, or service by trade name, trademark, manufacturer, or otherwise does not necessarily constitute or imply its endorsement, recommendation, or favoring by the United States Government or any agency thereof. The views and opinions of authors expressed herein do not necešsarily state or reflect those of the United States Government or any agency thereof.

\section{EERC DISCLAIMER}

LEGAL NOTICE This research report was prepared by the Energy \& Environmental Research Center (EERC), an agency of the University of North Dakota, as an account of work sponsored by U.S. Department of Energy. Because of the research nature of the work performed, neither the EERC nor any of its employees makes any warranty, express or implied, or assumes any legal liability or responsibility for the accuracy, completeness, or usefulness of any information, apparatus, product, or process disclosed, or represents that its use would not infringe privately owned rights. Reference herein to any specific commercial product, process, or service by trade name, trademark, manufacturer, or otherwise does not necessarily constitute or imply its endorsement or recommendation by the EERC.

\section{ACKNOWLEDGMENTS}

Because of the short time line involved in producing this review, the rapid acquisition of information was essential. The authors would like to acknowledge the contributions of the following individuals in providing the necessary information to conduct this study: Tom Bechtold (LITCO), Chuck Biagi (MK), Jan Brown (WPI), H.P. Loh (METC), Shawn Looney (VT), and Gary Knight (WPI). 


\section{TABLE OF CONTENTS}

LIST OF FIGURES $\ldots \ldots \ldots \ldots \ldots \ldots \ldots \ldots \ldots \ldots \ldots \ldots \ldots \ldots$ iii

LIST OF TABLES $\ldots \ldots \ldots \ldots \ldots \ldots \ldots \ldots \ldots \ldots \ldots \ldots \ldots$ iii

EXECUTIVE SUMMARY $\ldots \ldots \ldots \ldots \ldots \ldots \ldots \ldots \ldots \ldots \ldots \ldots$

ABSTRACT $\ldots \ldots \ldots \ldots \ldots \ldots \ldots \ldots \ldots \ldots \ldots \ldots \ldots \ldots \ldots \ldots \ldots \ldots \ldots \ldots \ldots$

$1.0 \quad$ INTRODUCTION $\ldots \ldots \ldots \ldots \ldots \ldots \ldots \ldots \ldots \ldots \ldots \ldots \ldots \ldots \ldots \ldots$

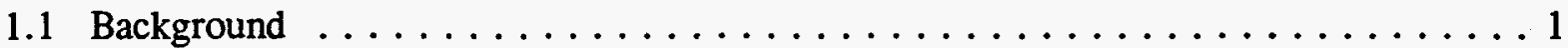

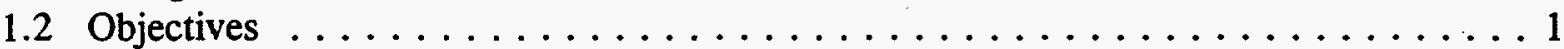

1.3 Review Process and Report Content .................... 2

2.0 SYSTEMS ENGINEERING APPROACH $\ldots \ldots \ldots \ldots \ldots \ldots \ldots \ldots \ldots$

2.1 Template for Evaluating the Technical Approach $\ldots \ldots \ldots \ldots \ldots \ldots \ldots \ldots$

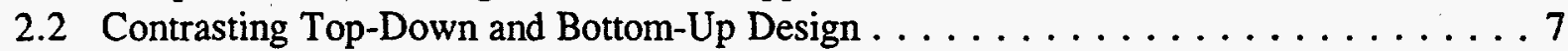

2.3 Inclusion of Performance Measures in Systems Engineering Studies . . . . . . 8

$3.0 \quad$ REVIEW OF REPORTS $\ldots \ldots \ldots \ldots \ldots \ldots \ldots \ldots \ldots \ldots$

3.1 Technical Approach $\ldots \ldots \ldots \ldots \ldots \ldots \ldots \ldots \ldots \ldots \ldots \ldots \ldots$

3.1.1 The Systems Engineering Process $\ldots \ldots \ldots \ldots \ldots \ldots \ldots \ldots \ldots$

3.1.2 Top-Down/Bottom-Up Design $\ldots \ldots \ldots \ldots \ldots \ldots \ldots \ldots \ldots \ldots$

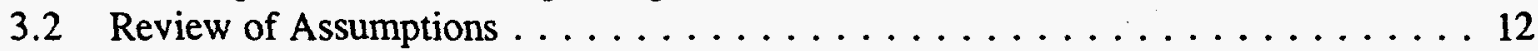

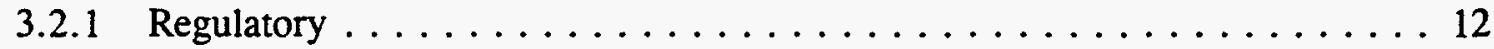

3.2.2 Waste Characteristics . . . . . . . . . . . . . . . . . 12

3.2 .3 General Operating . . . . . . . . . . . . . . . . . . . 14

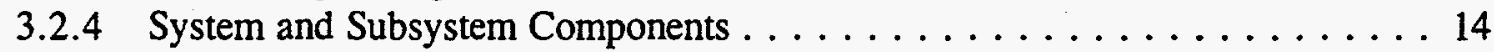

3.3 Economic Predictions and Sensitivities to Predictions . . . . . . . . . . 14

3.4 Performance Evaluation of Phase 2 Technologies $\ldots \ldots \ldots \ldots \ldots \ldots$

4.0 CONCLUSIONS AND RECOMMENDATIONS $\ldots \ldots \ldots \ldots \ldots \ldots \ldots \ldots \ldots$

EXPANDED DISCUSSION OF SYSTEMS ENGINEERING APPROACH $\ldots \ldots \ldots$ Appendix A

UTILIZATION OF THE SYSTEMS ENGINEERING TEMPLATE IN REVIEW OF THE TECHNICAL APPROACH OF THE ITTS AND INTS REPORTS $\ldots . \ldots$ Appendix B

EXPANDED DISCUSSION OF THE TOP-DOWN VERSUS

BOTTOM-UP APPROACH $\ldots \ldots \ldots \ldots \ldots \ldots \ldots \ldots \ldots \ldots \ldots \ldots \ldots \ldots \ldots$ Appendix $C$

IDENTIFIED ASSUMPTIONS FOR THE ITTS STUDY - PHASE $1 \ldots \ldots \ldots$ Appendix D

IDENTIFIED ASSUMPTIONS FOR THE ITTS STUDY - PHASE $2 \ldots \ldots \ldots$ Appendix E 
IDENTIFIED ASSUMPTIONS FOR THE INTS STUDY $\ldots \ldots \ldots \ldots \ldots$ Appendix F ASSUMPTIONS FROM THE ITTS PHASES $1 \& 2$ REPORTS AND

THE INTS REPORT WITH HIGH COST SENSITIVITY AND UNCERTAINTY . A Appendix G

ASSUMPTIONS OF INTEREST FROM THE ITTS PHASE 2 ANALYSIS OF

PERFORMANCE MEASURES

Appendix $\mathrm{H}$ 


\section{LIST OF FIGURES}

ES-1 Systems engineering template displaying the eight elements for evaluating

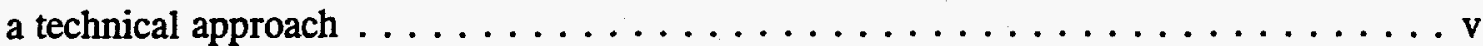

ES-2 Ranking of cost and performance for Phase 2 thermal subsystems . . . . . . . vii

2.1-1 Systems engineering template displaying the eight elements for evaluating

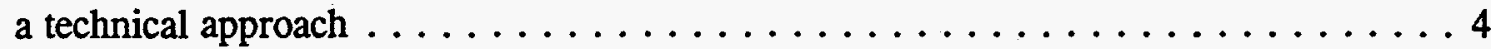

3.4-1 Comparison of cost sensitivity for Phase 2 systems and thermal subsystems . . . . . 23

3.4-2 Distribution of performance scores for regulatory compliance assumptions . . . . . . 24

3.4-3 Comparison of implementability for Phase 2 systems and thermal subsystems . . . . 25

3.4-4 Comparison of flexibility for Phase 2 systems and thermal subsystems . . . . . . . 25

3.4-5 Comparison of operability for Phase 2 systems and thermal subsystems $\ldots \ldots \ldots 27$

3.4-6 Comparison of maintainability for Phase 2 systems and thermal subsystems . . . . 27

3.4-7 Comparison of availability for Phase 2 systems and thermal subsystems $\ldots \ldots \ldots 28$

3.4-8 Comparison of ease of decontamination and decommissioning for Phase 2 systems

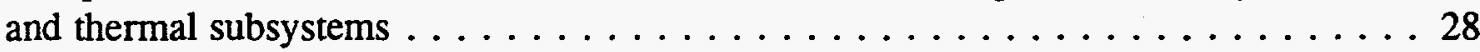

3.4-9 Comparison of weighted performance scores for Phase 2 systems and thermal subsystems . . . . . . . . . . . . . . . . . . . . . . 29

3.4-10 Ranking of cost and performance for Phase 2 thermal subsystems . . . . . . . 30

\section{LIST OF TABLES}

ES-1 $\quad E S-1 \ldots \ldots \ldots \ldots \ldots \ldots \ldots \ldots \ldots \ldots \ldots \ldots \ldots \ldots \ldots$

ES-2 $\quad \mathrm{ES}-2 \ldots \ldots \ldots \ldots \ldots \ldots \ldots \ldots \ldots \ldots \ldots \ldots \ldots \ldots \ldots \ldots \ldots$

3.1-1 Review of the Approach Used in the ITTS and INTS Reports Using the Systems Engineering Template $\ldots \ldots \ldots \ldots \ldots \ldots \ldots \ldots \ldots \ldots$

3.2-1 DOE Orders Governing the Regulatory Assumptions Used in the Study . . . . . . . 13 
3.3-1 Sensitivity of PLCC to Changes in Assumptions: System A1 - Baseline

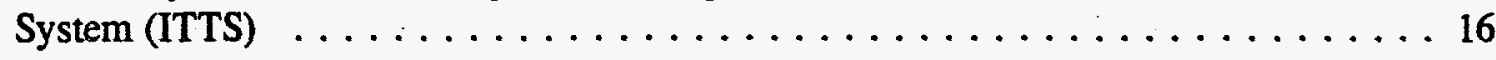

3.3-2 Sensitivity of PLCC to Changes in Assumptions: ITTS Phase 1 Systems . . . . . . 17

3.3-3 Sensitivity of PLCC to Changes in Assumptions: ITTS Phase 2 Systems

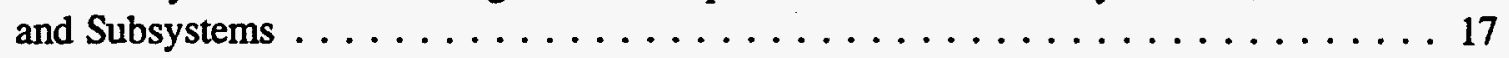

3.3-4 Sensitivity of PLCC to Changes in Assumptions: INTS - System $1 \ldots \ldots \ldots \ldots$

3.3-5 Sensitivity of PLCC to Changes in Assumptions: INTS Systems and Subsystems $\ldots 19$

3.4-1 Comparison of Performance Scores for Total Systems: Baseline and

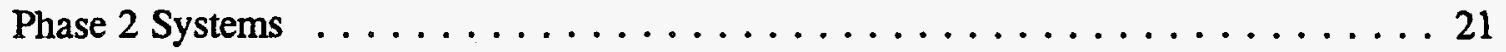

3.4-2 Comparison of Cost and Performance Scores for Thermal Subsystems: Baseline and Phase 2 Systems . . . . . . . . . . . . . . . . 22 


\section{EXECUTIVE SUMMARY}

This report analyzes three systems engineering (SE) studies performed on integrated thermal treatment systems (ITTSs) and integrated nonthermal treatment systems (INTSs) for the remediation of mixed low-level waste (MLLW) stored throughout the U.S. Department of Energy (DOE) weapons complex. The review was performed by an independent team of nine researchers from the Energy \& Environmental Research Center (EERC), Science Applications International Corporation (SAIC), the Waste Policy Institute (WPI), and Virginia Tech (VT). The three studies reviewed were as follows:

- Integrated Thermal Treatment System Study, Phase 1 - issued July 1994

- Integrated Thermal Treatment System Study, Phase 2 - issued February 1996

- Integrated Nonthermal Treatment System Study - drafted March 1996

The analysis was performed under Cooperative Agreement DE-FC21-94MC31388 for the DOE Morgantown Energy Technology Center. The purpose of this review was to 1) determine whether the assumptions taken in the studies might bias the resulting economic evaluations of both thermal and nonthermal systems, 2) identify the critical areas of the studies that would benefit from further investigation, and 3) develop a standard template that could be used in future studies to produce sound SE applications.

A common framework or template for SE was used to examine the three studies and evaluate the validity and completeness of the approach taken in each. This template is shown below (Figure ES-1).

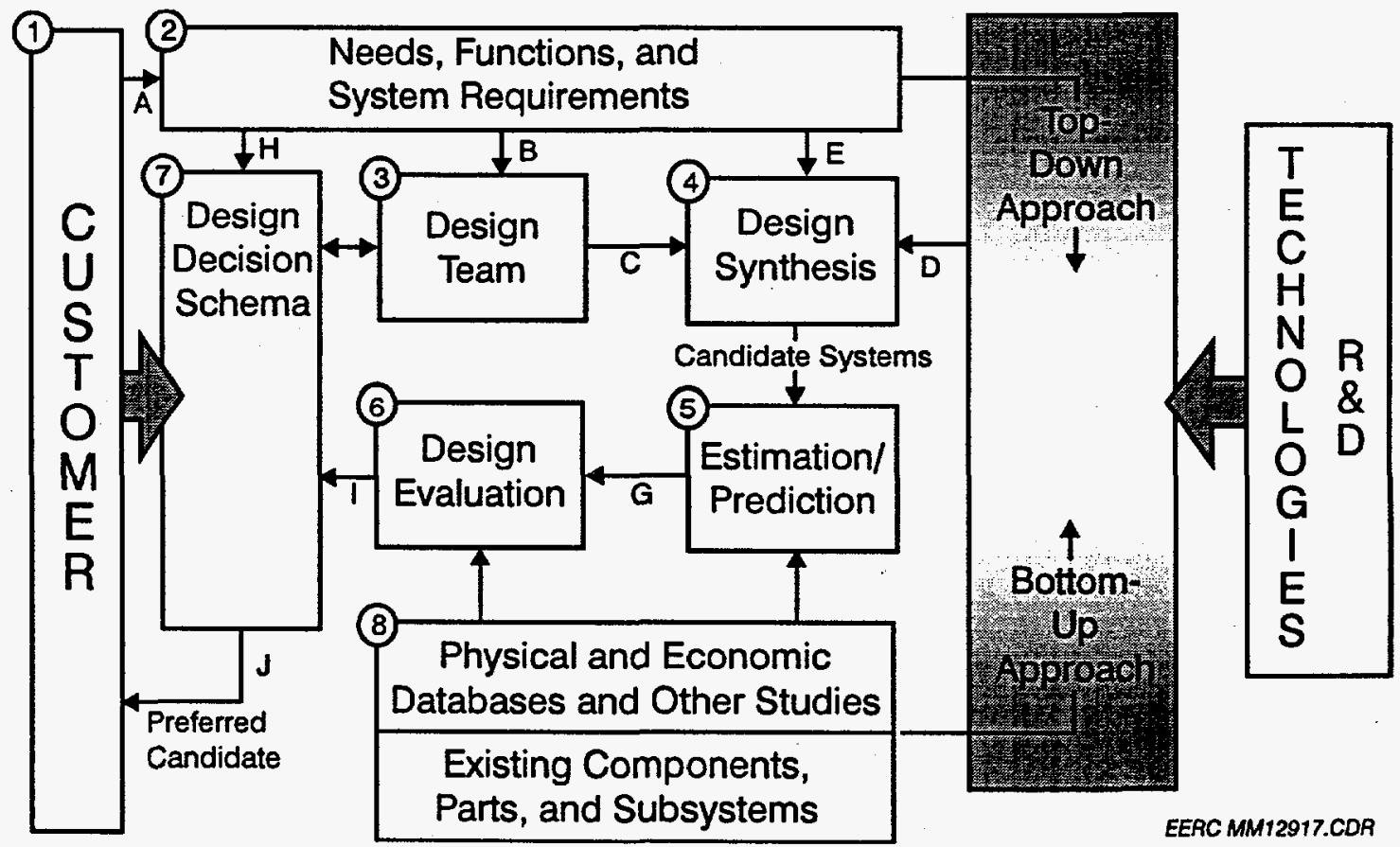

Figure ES-1. Systems engineering template displaying the eight elements for evaluating a technical approach. 
The ITTS and INTS reports represent a great stride forward in the use of a systems approach to the evaluation of waste remediation technologies. Not only were technologies put in a systems setting so as to allow upstream and downstream consequences of the use of the technologies to be judged, but total life-cycle costs were used, so that technologies at different stages of development could be compared. Nevertheless, there are still improvements that can and should be made. The main issue is that the studies do not reflect a complete adherence to the normal steps in the SE process as outlined in the template, and the study approaches varied (albeit improved) from study to study, as indicated in the following table (Table ES-1).

\begin{tabular}{|c|c|c|c|}
\hline & $\begin{array}{c}\text { ITTS Phase } 1 \\
\end{array}$ & ITTS Phase 2 & INTS \\
\hline $\begin{array}{l}\text { The } \\
\text { Customer } \\
\text { (Block 1) }\end{array}$ & $\begin{array}{l}\text { Customer not adequately described. } \\
\text { Customer inadequately considered in } \\
\text { synthesis, analysis, and evaluation. } \\
\text { Special interests (excluding federal } \\
\text { regulatory) incidentally mentioned; not } \\
\text { directly represented in voice of } \\
\text { customer; not part of evaluation } \\
\text { process. }\end{array}$ & $\begin{array}{l}\text { Special interests broader in definition } \\
\text { but still not represented as customer } \\
\text { or included in evaluation process. }\end{array}$ & $\begin{array}{l}\text { Study much more } \\
\text { responsive to } \\
\text { special interests (i.e., } \\
\text { Tribal and Stakeholder } \\
\text { Working Group } \\
\text { [TSWG]). Tribal and } \\
\text { public participation in } \\
\text { each stage of technology } \\
\text { assessment was the goal. } \\
\text { Final report designed to } \\
\text { be more understandable } \\
\text { to nontechnical readers. }\end{array}$ \\
\hline $\begin{array}{l}\text { Need, } \\
\text { Functions, } \\
\text { and System } \\
\text { Requirements } \\
\text { (Block 2) }\end{array}$ & $\begin{array}{l}\text { Studies lack adequate requirements and } \\
\text { Partial functional analysis attempted for } \\
\text { No evidence of functional analysis and }\end{array}$ & $\begin{array}{l}\text { ed analyses. } \\
\text { lection and definition of subsystems. } \\
\text { sequent allocation of system requireme }\end{array}$ & \\
\hline $\begin{array}{l}\text { Design Team } \\
\text { (Block 3) }\end{array}$ & $\begin{array}{l}\text { No details provided for areas of } \\
\text { expertise, areas of responsibility, } \\
\text { criteria for addition to team. } \\
\text { Panel of engineers for system down- } \\
\text { selecting not described }\end{array}$ & $\begin{array}{l}\text { DOE internal review panel reviewed } \\
\text { draft report, but contributions not } \\
\text { discussed. } \\
\text { Larger study team than before. }\end{array}$ & $\begin{array}{l}\text { Many members of study } \\
\text { team have changed. } \\
\text { TSWG could indirectly } \\
\text { be considered part of the } \\
\text { design team. }\end{array}$ \\
\hline $\begin{array}{l}\text { Design } \\
\text { Synthesis } \\
\text { (Block 4) }\end{array}$ & $\begin{array}{l}\text { Adequate description of alternative } \\
\text { systems, but inadequate traceability to } \\
\text { system requirements. } \\
\text { Heavy reliance on bottom-up approach } \\
\text { for system synthesis. } \\
\text { Little documentation for selection of } \\
\text { most technologies. } \\
\text { Documentation provided for down- } \\
\text { selecting from } 12 \text { to } 10 \text { systems. }\end{array}$ & $\begin{array}{l}\text { No documentation provided for } \\
\text { down-selecting systems. }\end{array}$ & $\begin{array}{l}\text { TSWG developed list of } \\
\text { nontechnical criteria to } \\
\text { assist TSWG in } \\
\text { technology down- } \\
\text { selecting. } \\
\text { Evidence for } \\
\text { incorporating } \\
\text { nontechnical criteria into } \\
\text { down-selecting not } \\
\text { adequate. }\end{array}$ \\
\hline $\begin{array}{l}\text { Estimation } \\
\text { and } \\
\text { Prediction } \\
\text { (Block 5) }\end{array}$ & $\begin{array}{l}\text { Lacks performance acceptability criteria } \\
\text { Lacks consideration for customer (specia } \\
\text { All systems presumed to meet performa }\end{array}$ & $\begin{array}{l}\text { nd target values. Lacks set of metrics } \\
\text { interest) input into acceptability measu. } \\
\text { e requirements. }\end{array}$ & measure merit of systems. \\
\hline $\begin{array}{l}\text { Design } \\
\text { Evaluation } \\
\text { (Block 6) } \\
\end{array}$ & $\begin{array}{l}\text { PLCC estimates calculated using the sou } \\
\text { money, which could impact relative cost } \\
\text { Sensitivity analysis with respect to desig }\end{array}$ & $\begin{array}{l}\text { engineering approach (except no cons } \\
\text { of the systems). } \\
\text { and operating assumptions is lacking. }\end{array}$ & ration of time value of \\
\hline $\begin{array}{l}\text { Design } \\
\text { Decision } \\
\text { Schema } \\
\text { (Block 7) }\end{array}$ & $\begin{array}{l}\text { Study results do not facilitate decision } \\
\text { making. } \\
\text { No attempt to organize and present } \\
\text { technical decision criteria. } \\
\text { Systems qualitatively evaluated with. } \\
\text { respect to technology risk. } \\
\text { A quantitative figure-of-merit system } \\
\text { comparison started but not finished. }\end{array}$ & $\begin{array}{l}\text { Systems qualitatively evaluated with } \\
\text { respect to technology risk but using } \\
\text { different criteria from Phase } 1 \text {. } \\
\text { No attempt at quantitative system } \\
\text { comparison. }\end{array}$ & $\begin{array}{l}\text { An attempt was made to } \\
\text { present technical decision } \\
\text { criteria in an organized } \\
\text { (tabular) manner. } \\
\text { No attempt at } \\
\text { quantitative system } \\
\text { comparison. }\end{array}$ \\
\hline $\begin{array}{l}\text { Physical and } \\
\text { Economic } \\
\text { Databases } \\
\text { and Other } \\
\text { Studies } \\
\text { (Block 8) } \\
\end{array}$ & \multicolumn{2}{|c|}{$\begin{array}{l}\text { No discussion on regulation changes and impact on the systems. } \\
\text { The apparently large technology database was not adequately referenced. }\end{array}$} & $\begin{array}{l}\text { Considerably more } \\
\text { referencing of technology } \\
\text { database. }\end{array}$ \\
\hline
\end{tabular}


The three studies aimed to develop life-cycle costs of various technical approaches to treatment of MLLWs. Design assumptions used in the studies produced results that are essentially equivalent for all the technical options, thus limiting the usefulness of the output in decision making about the development prospects for the technologies being considered. The evaluation of noneconomic performance criteria-cost sensitivity, cost uncertainty, regulatory compliance, implementablity, flexibility to handle variable waste, operability, maintainability, availability, and decontamination and decommissioning-using expert judgment and methods such as the Kepner-Tregoe approach, could provide additional differentiation among technologies. An example of such an analysis for the ITTS Phase 2 systems was carried out, and the combined performance score for each system is plotted versus the system's normalized cost (PLCC) in Figure ES-2. This analysis shows clear differences between the Phase 2 systems, and therefore its (more thorough) application to all systems allows differentiation of technology options when life-cycle costs do not provide significant differences (Figure ES-2). This additional study step is recommended for the analysis of all developmental technologies to assist in decisions about the viability of technology options. While the ITTS Phase 1 study considered the application of such an approach, it was not carried out as part of the study.

Within the life-cycle cost analyses on the ITTS and INTS, many design assumptions were necessarily made to develop the final results. Over 1200 assumptions were identified in the review. Among these assumptions, a few critical ones had major impacts on overall life-cycle costs. These major assumptions have been subjected to sensitivity analysis to determine their impacts on the overall plant costs defined in the studies. Significant design conservatism was inherent in the studies. For example, all systems were designed for Category 1 seismic region construction, adding 11 to 16 percent to overall plant life-cycle costs. Facility operation was assumed to be only about half time, adding about 20 percent to life-cycle cost. Conversely, many developmental systems were assumed to be able to perform; the penalty associated with system failure could add 5 to 10 percent to life-cycle cost. The summary of the impacts of major assumptions (with $>10$ percent impact on life-cycle costs [LCC]) is shown in the following table (Table ES-2).

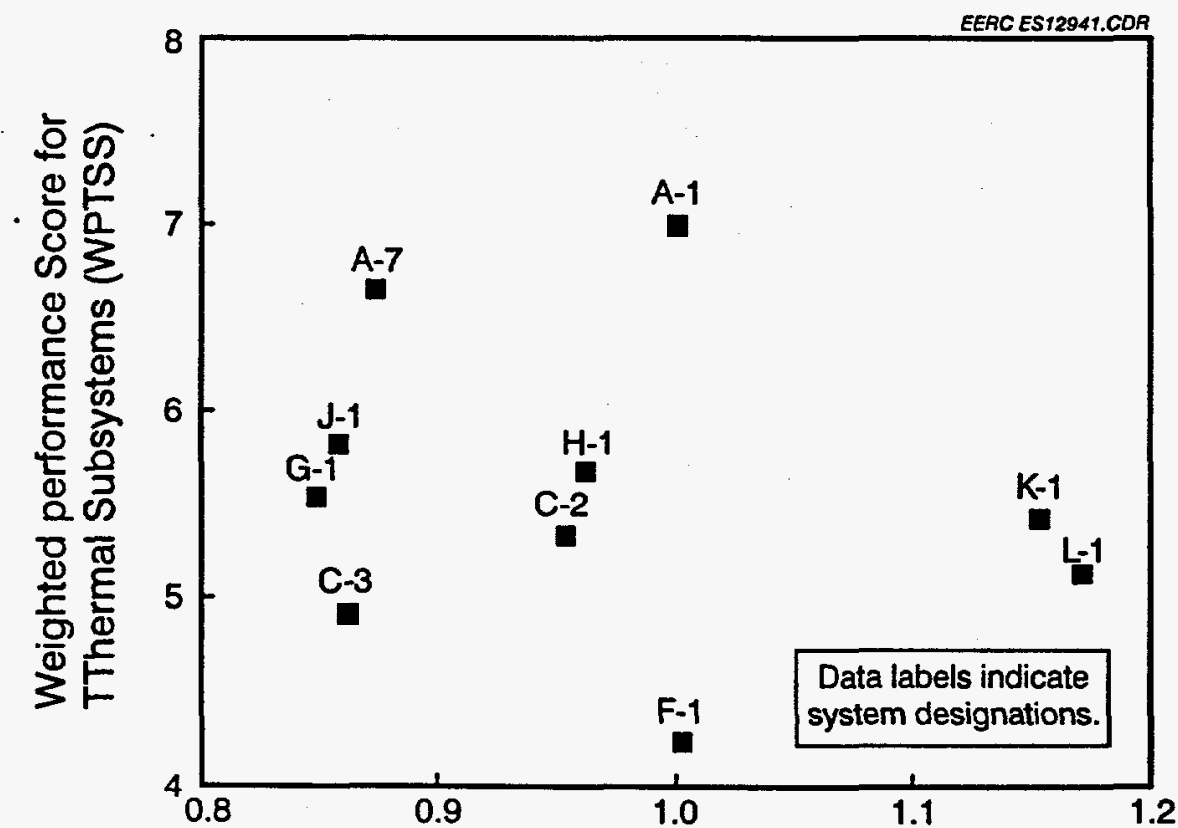

Normalized Planned Life-Cycle Cost (NPLCC), System A-1 Equals 1

Figure ES-2. Ranking of cost and performance for Phase 2 thermal subsystems. 
TABLE ES-2

\section{ITTS Baseline}

\begin{tabular}{ccc} 
Assumption & Change in Assumption & Percent Change in LCC \\
\hline Seismic Category 1 & Seismic Category 2 & -15.8 \\
$50 \%$ waste sorted & $75 \%$ waste sorted & +12.3 \\
$4032 \mathrm{hr} / \mathrm{yr}$ operation & $8064 \mathrm{hr} / \mathrm{yr}$ operation & -19.3 \\
Minimum shielding & More extensive shielding & +11.3 \\
GOCO *operation & Private operation & -17.5 \\
INTS & & -11.7 \\
\hline Seismic Category 1 & Seismic Category 2 & -13.0 \\
$75 \%$ waste sorted & $50 \%$ waste sorted & -17.0 \\
$4032 \mathrm{hr} / \mathrm{yr}$ operation & $8064 \mathrm{hr} / \mathrm{yr}$ operation & \pm 10.2 \\
Unit disposal cost $\$ 243 / \mathrm{ft}^{3}$ & Assume $\$ 243 \pm \$ 100 / \mathrm{ft}^{3}$ & +12.5 \\
Minimum shielding & More extensive shielding & -15.9 \\
GOCO *operation & Private operation & \\
\hline
\end{tabular}

* Government-owned-contractor-operated.

The conclusions of this analysis are as follows:

- A consistent approach among the studies would have enhanced their comparability. Future such studies should adopt a consistent SE approach similar to the template defined in this report.

- Noneconomic factors must be considered in a quantitative manner to gain full value from the analysis of system alternatives, especially those involving developing technologies that are being considered in competition for scarce funding. An approach like that outlined by example in this report should be required for all such systems analysis studies.

- Absolute system costs defined in the three studies should be seriously reexamined with special emphasis on the reasonableness of the major cost sensitivities identified in this report. 


\begin{abstract}
This report contains a review and evaluation of three systems engineering studies performed, by LITCO on integrated thermal treatment systems and integrated nonthermal treatment systems for the remediation of mixed low-level waste stored throughout the U.S. Department of Energy weapons complex. The review was performed by an independent team of nine researchers from the Energy \& Environmental Research Center, Science Applications International Corporation, the Waste Policy Institute, and Virginia Tech. The three studies reviewed were as follows:

- Integrated Thermal Treatment System Study, Phase 1 - issued July 1994

- Integrated Thermal Treatment System Study, Phase 2 - issued February 1996

- Integrated Nonthermal Treatment System Study - drafted March 1996

The purpose of this review was to 1) determine whether the assumptions of the studies were adequate to produce an unbiased review of both thermal and nonthermal systems, 2) to identify.the critical areas of the studies that would benefit from further investigation, and 3) to develop a standard template that could be used in future studies to assure a sound application of SE.
\end{abstract}




\section{REVIEW OF THE INTEGRATED THERMAL AND NONTHERMAL TREATMENT SYSTEM STUDIES}

\subsection{INTRODUCTION}

\subsection{Background}

The U.S. Department of Energy (DOE) Environmental Management Office of Technology Development (EM-50) commissioned Lockheed Idaho Technologies Company/Idaho National Engineering Laboratory (LITCO) to carry out a series of studies to evaluate system alternatives for treating contact-handled, alpha and nonalpha mixed low-level radioactive waste (MLLW). The MLLW within the DOE complex comprises various organic and inorganic liquids and solids contaminated with radioactive wastes and Resource Conservation and Recovery Act (RCRA) metals. The systems are intended to destroy the organic materials and stabilize the remaining material, including radioactive wastes, for long-term storage. The purpose of LITCO's systematic engineering evaluation of a variety of MLLW treatment system alternatives was to help DOE in down-selecting its sponsorship of research, development, and demonstration of remediation technologies. The reports resulting from these studies are listed below:

- Integrated Thermal Treatment System (ITTS) Study, Phase 1 - issued July 1994

- Integrated Thermal Treatment System (ITTS) Study, Phase 2 - issued February 1996

- Integrated Nonthermal Treatment System (INTS) Study - drafted March 1996

This report provides a review of these three studies to further aid DOE in its current and future decision-making processes. Since a systems engineering (SE) approach was reportedly used by LITCO in producing the studies, the methodology in the studies was compared to a sound SE approach in reviewing them. Although not stated explicitly within the LITCO reports, the authors of this review assumed that all three studies intended the following purpose: the SE evaluation was to result in an estimate of future cleanup costs, as well as to aid in deciding which technologies should receive future funding.

\subsection{Objectives}

The goal of this review was to provide DOE with the necessary information to determine whether a more detailed review of the LITCO studies is warranted and to identify the areas of the studies that would warrant future attention.

To achieve the above-mentioned goal, the following objectives were identified: 1) determine whether the assumptions of the reports were adequate to produce an unbiased review of thermal and nonthermal systems, 2) to identify areas of the study that could be expanded/enhanced to produce a better decision-making product, and 3) provide a template to guide future SE studies.

The specific issues outlined by the DOE Morgantown Energy Technology Center to be included within this review were as follows:

- Review facility designs as well as engineering and operating assumptions 
- Review cost estimation methods, bases, and assumptions

- Evaluate uncertainty of assumptions

- Review submodels for both baseline and alternative technologies to assess sensitivity of planning life-cycle costs (PLCCs) to the assumptions

- Determine which assumptions were critical in determining PLCCs for a given technology and which were critical to the relative technology rankings

- Review improvements on the systems engineering/systems analysis approach used.

\subsection{Review Process and Report Content}

This review was conducted by a team of nine individuals employed by four different organizations (the Energy \& Environmental Research Center [EERC], Science Applications International Corporation [SAIC], the Waste Policy Institute [WPI], and Virginia Tech [VT]). The review evaluated the data and findings in the three study reports and performed limited spreadsheet calculations to aid in determining economic sensitivities and performance measures.

This review was initiated in late April of 1996 and concluded approximately 8 weeks later. Because of the extremely short time line, further review of the LITCO studies and further analysis of thermal and nonthermal treatment systems is warranted.

This report covers two primary topics: a description of a technical approach to SE and a review of the ITTS and INTS studies. The technical approach section presents a recommended template for future SE studies to ensure more consistent, traceable, and rank-classified results. The review section contains specific comments on the LITCO studies reviewed. It was the authors' intent to produce an easily readable version of the review by relegating the lengthy discussions on approaches and assumptions to the appendices.

\subsection{SYSTEMS ENGINEERING APPROACH}

Systems engineering is a management tool that provides a framework for decision making in planning for implementing and controlling the development and application of new technologies. The recommended SE approach is outlined in detail in Appendix A.

The SE approach is a logical implementation process that compares alternative system designs against input requirements by means of a top-down functional analysis. The resulting synthesis can be continuously evaluated for adequacy. Decisions are made on recommended solutions, which can become input for subsequent cycles of SE analysis, leading to final selection and application. A critical element is the ability to feed back SE results to refine input information by verifying and validating input requirements as the results of trade-off studies become available. Cost drivers should be identified early so that they can be evaluated against operational benefits. This continuous review process serves to identify problem areas before they become "embedded" and create significant cost, schedule, or performance impacts. 


\subsection{Template for Evaluating the Technical Approach}

Broadly defined, SE is "the effective application of scientific and engineering efforts to transform an operational need into a defined system configuration through the top-down iterative process of requirements definition, functional analysis and allocation, synthesis, optimization, design, test, and evaluation." The SE process, in its evolving of functional detail and design requirements, has as its goal achieving the proper balance between operational (i.e., performance), economic, and disposal factors. Inherent in the SE process are the concepts of life cycle and concurrent engineering. The design of systems depends greatly on the effective use of SE as well as traditional design methods that are essentially bottom-up in nature.

As part of the evaluation of the technical approach of the LITCO studies, a SE template was developed to guide the review of the studies. The resulting template was meant to prompt critical questions about the design process utilized in the LITCO studies and to enable a fair evaluation of those studies. The elements of the template are illustrated in Figure 2.1-1, with a description of the respective blocks and the questions addressed by the model below. Refer to Appendix B for a more complete utilization of the template in evaluating the LITCO studies.

\section{BLOCK 1 - The Customer}

The purpose of any system design is to satisfy customer and stakeholder needs. The success of a particular system design is ultimately determined by the customer. During the design process, all requirements and decisions should be determined from that perspective. Stakeholders and special interests must be represented in "the voice of the customer" in a way that reflects their needs and concerns.

Questions to ask:

- Who is the customer?

- How is the "voice of the customer" captured?

- To what extent is the customer involved in decision-making?

- Are the study decisions traceable to the customer?

\section{BLOCK 2 - Need, Functions, and System Requirements}

The objective of the block is to define the system's functional mission. The SE study identifies a need to address an opportunity, problem, or deficiency. The identified need(s) are used to define the basic requirements of the system in terms of input criteria for design and operation. These criteria should be defined before system configurations are proposed. Definition of system requirements should include mission, performance and physical parameters, the operational environment, use requirements, effectiveness factors, deployment and distribution, and the operational life-cycle horizon. In Figure 2.1-1, Arrow A indicates customer inputs defining needs, functions, and requirements. The system should be defined only by function, not form, at this point.

\footnotetext{
'Blanchard. B.S.: Fabrycky, W.J. Systems Engineering and Analysis; Second Edition, Prentice Hall, 1990.
} 


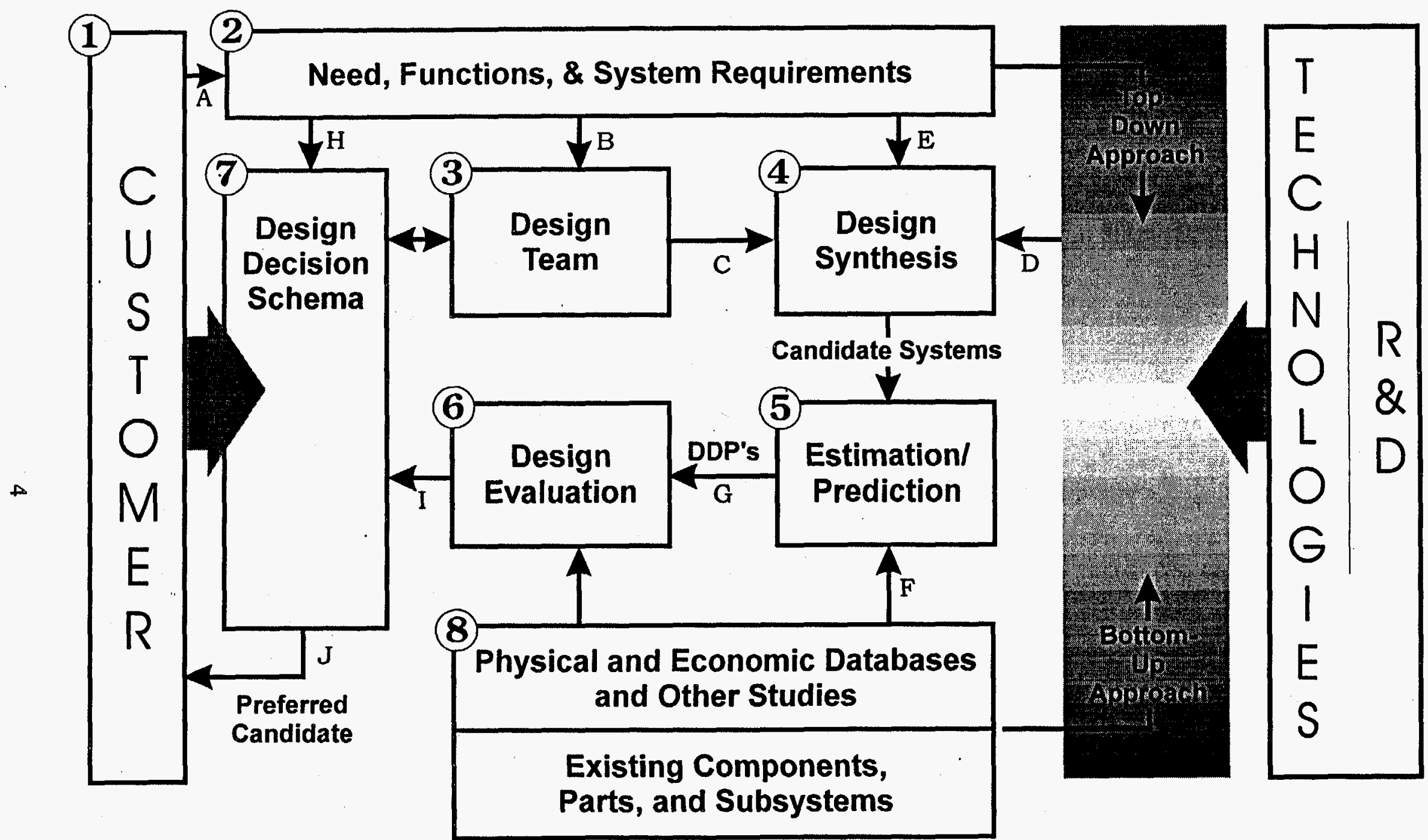

Figure 2.1-1. Systems engineering template displaying the eight elements for evaluating a technical approach. 
Questions to ask:

- What are the customer requirements?

- Have customer requirements been translated to system requirements?

- Do the requirements reflect a systems and life-cycle engineering point of view?

\section{BLOCK 3 - Design Team}

The design team selected must be balanced in terms of in-depth technical expertise and the broader methodology of SE. The team should include representation for each of the life-cycle elements contained in the set of system requirements. Measured consideration should be given to all aspects of the design, from the primary mission equipment to the supporting elements or attributes for achieving environmental compliance: flexibility, reliability, maintainability, availability, and disposibility. A diversity of perspectives on the design team facilitates consideration of all aspects of the system life cycle. Arrow B represents a relationship between the set of system requirements and the selection and makeup of the design team.

Questions to ask:

- What are the qualifications and expertise of the design team members?

- What method was used to select this design team?

- Are various aspects of the system life cycle represented on the design team?

- Are the motivations and desires of the design team(s) members/contractors consistent with those of the customer?

\section{BLOCK 4 - Design Synthesis}

Design synthesis is a creative process that relies on expert knowledge of state-of-the-art technology to describe a number of feasible design alternatives so that an analysis and subsequent evaluation and decision making can occur. Depending on the phase of system design, the synthesis can involve either conceptual elements or particular pieces of hardware at a very detailed level. Input by the design team is represented by Arrow $C$. The design team members must question their own preconceived vision of the end system when proposing candidate designs. The candidate system synthesis is driven by both a top-down functional definition of the need and by a bottom-up definition of the available technology for system elements. Arrow D represents the input of these two different, but complementary, approaches to system design. Adequate definition of each system alternative must allow for life-cycle analysis and evaluation to reflect the set of determined system requirements. Arrow $\mathrm{E}$ highlights the defining role of system requirements in the synthesis of candidate systems.

Questions to ask:

- How are the various alternatives selected?

- Are alternative selection methods based on stated customer and system requirements?

- Are the alternatives defined well enough such that meaningful analysis and evaluation can occur?

- Are all alternatives comparable? 


\section{BLOCK 5 - Estimation and Prediction}

In the estimation and prediction block, cost and effectiveness measures are generated using models and simulations to predict design-dependent parameter (DDP) values for each alternative. These models and simulations are based on assumptions, physical laws, and empirical data. Arrow F represents this available database of physical and economic models, as well as descriptions of existing components, parts, and subsystems. The DDP values provide the basis for comparing system designs against input criteria to determine the merit of each alternative. Alternatives that are found to be unacceptable in performance can be either discarded or reworked and new alternatives created. Alternatives that meet all or the most important performance criteria can then be evaluated based on life-cycle cost.

Questions to ask:

- What are the basic assumptions inherent in each estimation/prediction?

- By what means do we consider an alternative's performance acceptable?

- How are nonquantifiable parameters handled?

\section{BLOCK 6 - Design Evaluation}

Life-cycle cost is the basis used for comparing alternative systems that meet minimum requirements by performance criteria. The life-cycle cost of each alternative is determined based on the estimation and prediction activity just completed. Arrow $\mathrm{G}$ indicates the passing of the predicted DDP values to the evaluation step. The entire life cycle "from lust to dust" must be considered using a cost breakdown structure (CBS) developed for each alternative, including the time value of money. The selection of preferred alternative(s) can only be made after the life-cycle analysis is completed.

Questions to ask:

- What is the definition of the system's life cycle?

- By what means is the life-cycle cost calculated?

\section{BLOCK 7 - Design Decision Schema}

Given the variety of customer needs and perceptions included in the input criteria in Block 2, choosing a preferred alternative is usually not just the simple matter of picking the least expensive design. Input criteria derived from customer and system requirements are represented by Arrow $\mathrm{H}$ and the DDP values and life-cycle costs by Arrow I. The decision maker must now trade off lifecycle cost against other decision criteria subjectively. The result is one or more preferred alternatives that can be used to continue the design process to a more detailed level. These preferred alternatives are always ultimately judged by the customer; therefore, we show Arrow $\mathbf{J}$ returning the preferred candidate system for review by the customer.

Questions to ask:

- What method will be used to facilitate the decision-making process? 
- What are the established decision criteria and thresholds for each?

- How were the decisions reached?

\section{BLOCK 8 - Physical and Economic Databases and Other Studies}

This block represents a resource for the SE process rather than an actual step in the process flow. There exists a body of knowledge that engineers, economists, and scientists rely on to perform analysis and evaluation tasks. This body consists of known physical laws, empirical data, economic forecasts, and other studies and models. It also includes descriptions of existing system components, parts, and subsystems. It is very important to use existing databases in SE to avoid "reinventing the wheel." This body of knowledge and experience can be utilized both formally and informally in performance of SE studies and the decisions that follow.

Questions to ask:

- To what extent is reuse encouraged and past experience depended on?

- Where do assumptions made during the SE process originate?

- What effect does this body of knowledge or expert knowledge have on the alternative selection and decision-making process?

\subsection{Contrasting Top-Down and Bottom-Up Design}

Traditional engineering design methodology is based on a bottom-up approach. Starting with a set of known elements, design engineers synthesize the product or system by finding the most appropriate combination of system elements. However, unless the product is quite simple, it is unlikely that the functional need will be met on the first attempt. After determining the performance deviation from what is required (by prediction, simulation, measurement, or other means), the combination of elements is altered, and the system performance determined again.

A top-down approach to design is evoked by SE. Starting with requirements for the external behavior of any part of the system (expressed in terms of the function provided by that part externally or to other parts of the system), that behavior is analyzed to identify its functional characteristics. These functional behaviors are then described in more detail and made more specific through a process of refinement. Next, the appropriateness of this choice of functional components is verified by synthesizing the original part.

There are two main differences between the bottom-up and top-down approaches: In bottomup design, physical realizability in terms of known elements is assured, whereas at the end of the top-down design process, the systems elements are still functional entities. Their physical realizability is not guaranteed. In the top-down approach, the requirements are ideally always satisfied through every step of the design process (as an inherent part of the methodology), whereas in the bottom-up approach, the methodology provides no assurance that this will occur. Most projects will employ both methodologies-first SE to reduce the complexity by partitioning the system into its elements and then bottom-up design to realize the elements. 
The LITCO studies were evaluated with respect to the relative usage of top-down versus bottom-up design synthesis. A more thorough discussion contrasting top-down and bottom-up methodology is presented in Appendix $\mathrm{C}$.

\subsection{Inclusion of Performance Measures in Systems Engineering Studies}

It is important when performing a systems analysis study to include the ability to measure both economics and performance. The economic measure commonly used, preliminary life-cycle cost, is easy to grasp, but the measure of performance for a system becomes more subjective and complicated. Evaluation of noneconomic performance criteria of the system technologies, to be discussed in Section 3.4, was performed using an adaptation of a form of decision analysis described by Kepner and Tregoe. ${ }^{2}$ This systematic approach to assist decision making produces a quantitative ranking of alternatives based on the experiences and facts available to the decision maker(s).

The first step is to establish the relative importance of each objective, or, in this case, performance criteria, with respect to all other objectives. This is accomplished through numerical weighting. The lowest-weight, or least important, objective is taken as the baseline standard against which all other objectives are ranged or ranked. The second step is to judge the performance of each alternative, in this case systems and subsystems, against the objectives (performance criteria). This is done by numerically scoring each alternative with respect to each objective using any suitable scale, with the best alternative(s) receiving the highest score and all other alternatives scored relatively. The third step consists of multiplying the weight of each objective by the score assigned to each alternative. The fourth step consists of adding up the weighted scores to generate a total for each alternative. The results serve to quantify the alternatives and help to identify the best course of action.

\subsection{REVIEW OF REPORTS}

This section of the review discusses the approach used by LITCO for their studies relative to an ideal SE process, the validity of the assumptions made, the sensitivities of the economics to those assumptions, and the quantifications of performance measures. The studies performed have identified a wealth of qualitative information on pertinent environmental management (EM) cleanup technologies, but the systems evaluation performed was not carried to its logical conclusion of ranking systems based on explicit cost and performance criteria. This review concentrates on the quantitative application of SE and the generation of results that can be used to make decisions.

\subsection{Technical Approach}

This section summarizes the review of the technical approach of the LITCO studies. This review was directed from a SE perspective. The various aspects of SE, as well as comments and review of the LITCO studies are presented.

${ }^{2}$ Kepner. C.H; Tregoe, B.B. The Rational Manager; McGraw-Hill Book Company: New York, New York, 1965. 


\subsubsection{The Systems Engineering Process}

As already defined in Section 2.1, SE is the effective application of scientific and engineering efforts to transform an operational need into a defined system configuration through the top-down iterative process of requirements definition, functional analysis and allocation, synthesis, optimization, design, test, and evaluation. The SE process has as its goal achieving the proper balance between operational (i.e., performance), economic, and disposal factors. It is this balance of factors that this review examines. The LITCO studies do not achieve a balance among system factors sufficient to qualify them as "systems engineering" studies. (Appendix A goes into much greater detail about the nature and application of SE and how this balance is achieved.)

Inherent in the SE process are the concepts of life cycle and concurrent engineering. It is very important that all aspects of the system life cycle be represented in each phase of system design. Attention must be paid to all phases of the life cycle early in design to avoid problems and surprises later and to ensure that the operational need is fulfilled. Subsystem and life-cycle phases cannot be considered independently. It is also important that the design of various elements of the system be pursued and analyzed concurrently with each of the other elements. These principles, along with adherence to the functional, top-down definition of system elements, are the fundamentals of SE.

The LITCO studies do not adequately consider the systems viewpoint. Too much emphasis is placed on the technologies and not enough on the integration and the cost and performance (flexibility, operability, maintainability, etc.) of the system. Further, no discussion is provided of the maintenance life cycle and personnel requirements as these will effect system comparability.

A conceptual systems design study, or in this case a preconceptual study, has as its basis a need and requirements analysis. The problem and need to be filled must be fully understood. Any conceptual design study should begin with a complete needs analysis. The problem must be defined from a functional point of view. The LITCO studies did not devote enough effort or time to these fundamental activities. The "functional requirements" and "functional allocation diagrams" spoken of in the studies are not consistent with SE. In the studies, it is stated that "functional requirements" were developed for each alternative system. The inconsistency here is that there exists only one functional mission to perform, regardless of system alternatives. There should be only one set of functional requirements. The system needs to be defined from a functional point of view before physical realization of the system can occur.

The LITCO studies do define candidate systems and their developmental requirements quite well. However, there is no traceability during the synthesis of these alternatives. All candidate systems must derive from and be traceable back to the system operational and functional requirements. The studies are deficient in documentation of the candidate system synthesis process. Since the candidate systems are not readily traceable to these requirements, there is no insurance that the chosen "systems" actually perform the mission at hand.

Additionally, the LITCO studies did not fully explore an appropriate means of decision making. This approach was started in the ITTS Phase 1 study, but was entirely abandoned by the INTS study. A set of decision-making criteria must be developed and adhered to consistently from the initiation of any study. As it has been assumed that each of the systems performs nominally 
well, then the design decision making must be based on economics and other, subjective, criteria. The LITCO studies do not adequately spell out the design criteria or facilitate decision making. The life-cycle cost analysis in the LITCO studies, although prepared using a sound engineering approach, has limited application because there is no sizeable difference in the candidate systems as far as life-cycle cost goes.

The lack of customer involvement, principally in the ITTS studies, is of concern because without "the voice of the customer," the design and acceptance of any system may be compromised. Care must be taken to identify and consider "the customer" throughout the design process. There is insufficient evidence of consideration for special interest or stakeholder concerns in the ITTS studies. In contrast, and to the benefit of the study, the concerns of the customer are addressed in the INTS study. Although these studies were primarily a systems analysis of various MLLW remediation technologies, they represent a major step forward in the use of a SE approach to evaluating those technologies. Further, although the SE in the studies was far from complete, marked improvement in applying SE principles was noted for the INTS report. However, although a set of nontechnical principles was devised by a working group of the special interests, the documentation does not clearly show the incorporation of these principles into decision making.

The technical approach review of the ITTS and INTS studies, guided using the eight-block SE template discussed in Section 2, is summarized in Table 3.1-1. A summary of the base study review comments is given in the ITTS Phase 1 column. Subsequent changes or improvements in methodology or content for the ITTS Phase II and the INTS studies are indicated in the respective columns. These comments summarize a more detailed examination of the LITCO studies found in Appendix B.

\subsubsection{Top-Down/Bottom-Up Design}

Appendix $\mathrm{C}$ gives a more detailed description of the relationship between the top-down and bottom-up approaches to design. The LITCO ITTS and INTS studies primarily used a bottom-up methodology. In Section 1.2 of the ITTS study (Phase 1) and Section 1.8 of the INTS study, it is stated that "A key to accurate evaluation of the thermal treatment systems is using an integrated systems engineering approach." However, the SE design process depends on a rigorous, systematic approach to need and requirements definition followed by functional analysis. In using a bottom-up approach, as is the case with these studies, the functional analysis is often neglected, and expert judgment and creativity are relied upon as the sole method of design synthesis.

SE does not replace the need for bottom-up design. At some point in the design process there has to be a transition from the functional (or abstract) to the physical. Most development programs will employ both methodologies: first SE to reduce the complexity and partition the system into its elements and then bottom-up design to realize the elements. The two approaches must complement each other.

On balance, the ITTS and INTS studies do not sufficiently address the input requirements and functional analysis needed to ensure a system design that meets all performance requirements and fulfills the functional mission. These studies provide a good technical review of the various technologies that may be useful in a MLLW treatment system, but they do not adequately perform the type of functional analysis that is needed to select the preferred system warranting further development. 
TABLE 3.1-1

Review of the Approach Used in the ITTS and INTS Reports Using the Systems Engineering Template

\begin{tabular}{|c|c|c|c|}
\hline & ITTS Phase 1 & $\begin{array}{l}\text { ITTS Phase } 2 \\
\end{array}$ & INTS \\
\hline $\begin{array}{l}\text { The Customer } \\
\text { (Block 1) }\end{array}$ & $\begin{array}{l}\text { Customer not adequately described. } \\
\text { Customer inadequately considered in } \\
\text { synthesis, analysis, and evaluation. Special } \\
\text { interests (excluding federal regulatory) } \\
\text { incidentally mentioned, not directly } \\
\text { represented in voice of customer; not part of } \\
\text { evaluation process. }\end{array}$ & $\begin{array}{l}\text { Special interests broader in definition, but } \\
\text { still not represented as customer or } \\
\text { included in evaluation process. }\end{array}$ & $\begin{array}{l}\text { Study much more responsive to special } \\
\text { interests (i.e., Tribal Stakeholders } \\
\text { Working Group [TSWG]). } \\
\text { Tribal and public participation in } \\
\text { each stage of technology assessment was } \\
\text { the goal. } \\
\text { Final report designed to be more } \\
\text { understandable to nontechnical readers. }\end{array}$ \\
\hline $\begin{array}{l}\text { Need, Functions, and } \\
\text { System Requirements } \\
\text { (Block 2) }\end{array}$ & $\begin{array}{l}\text { Studies lack adequate requirements and need an } \\
\text { Partial functional analysis attempted for selecti } \\
\text { No evidence of functional analysis and subsequ }\end{array}$ & $\begin{array}{l}\text { alyses. } \\
\text { n and definition of subsystems. } \\
\text { ent allocation of system requirements. }\end{array}$ & \\
\hline $\begin{array}{l}\text { Design Team } \\
\text { (Block 3) }\end{array}$ & $\begin{array}{l}\text { No details provided for areas of expertise, } \\
\text { areas of responsibility, criteria for addition to } \\
\text { team. } \\
\text { Panel of engineers for system down-selecting } \\
\text { not described. }\end{array}$ & $\begin{array}{l}\text { DOE internal review panel reviewed draft } \\
\text { report, but contributions not discussed. } \\
\text { Larger study team than before. }\end{array}$ & $\begin{array}{l}\text { Many members of study team have } \\
\text { changed. } \\
\text { TSWG could indirectly be considered part } \\
\text { of the design team. }\end{array}$ \\
\hline $\begin{array}{l}\text { Design Synthesis } \\
\text { (Block 4) }\end{array}$ & $\begin{array}{l}\text { Adequate description of alternative systems, } \\
\text { but inadequate traceability to system } \\
\text { requirements. } \\
\text { Heavy reliance on bottom-up approach for. } \\
\text { system synthesis. } \\
\text { Little documentation for selection of most } \\
\text { technologies. } \\
\text { Documentation provided for down-selecting } \\
\text { from } 12 \text { to } 10 \text { system designs. }\end{array}$ & $\begin{array}{l}\text { No documentation provided for down- } \\
\text { selecting system designs. }\end{array}$ & $\begin{array}{l}\text { TSWG developed list of nontechnical } \\
\text { criteria to assist TSWG in technology } \\
\text { down-selecting. } \\
\text { Evidence for incorporating nontechnical } \\
\text { criteria into down-selecting not adequate. }\end{array}$ \\
\hline $\begin{array}{l}\text { Estimation and } \\
\text { Prediction } \\
\text { (Block 5) }\end{array}$ & $\begin{array}{l}\text { Lacks performance acceptability criteria and ta } \\
\text { Lacks set of metrics to measure merit of systen } \\
\text { Lacks consideration for customer (special inter } \\
\text { All systems presumed to meet performance reg }\end{array}$ & $\begin{array}{l}\text { get values. } \\
\text { s. } \\
\text { st) input into acceptability measures. } \\
\text { jirements. }\end{array}$ & \\
\hline $\begin{array}{l}\text { Design Evaluation } \\
\text { (Block 6) }\end{array}$ & $\begin{array}{l}\text { PLCC estimates calculated using sound engine } \\
\text { relative costs of systems). } \\
\text { Sensitivity analysis with respect to design and }\end{array}$ & $\begin{array}{l}\text { ring approach (except no consideration of tir } \\
\text { perating assumptions is lacking. }\end{array}$ & value of money, which could impact \\
\hline $\begin{array}{l}\text { Design Decision } \\
\text { Schema } \\
\text { (Block 7) }\end{array}$ & $\begin{array}{l}\text { Study results do not facilitate decision } \\
\text { making. } \\
\text { No attempt to organize and present technical } \\
\text { decision criteria. } \\
\text { Systems qualitatively evaluated with respect } \\
\text { to technology risk. } \\
\text { A quantitative figure-of-merit system } \\
\text { comparison started but not finished. }\end{array}$ & $\begin{array}{l}\text { Systems qualitatively evaluated with } \\
\text { respect to technology risk but using } \\
\text { different criteria from Phase } 1 \text {. } \\
\text { No attempt at quantitative system } \\
\text { comparison. }\end{array}$ & $\begin{array}{l}\text { An attempt was made to present technical } \\
\text { decision criteria in an organized (tabular) } \\
\text { manner. } \\
\text { No attempt at quantitative system } \\
\text { comparison }\end{array}$ \\
\hline $\begin{array}{l}\text { Physical and } \\
\text { Economic Databases } \\
\text { and Other Studies } \\
\text { (Block 8) }\end{array}$ & \multicolumn{2}{|c|}{$\begin{array}{l}\text { No discussion on regulation changes and impact on the systems. } \\
\text { The apparently large technology data bases is not adequately referenced. }\end{array}$} & $\begin{array}{l}\text { Considerably more referencing of } \\
\text { technology database. }\end{array}$ \\
\hline
\end{tabular}




\subsection{Review of Assumptions}

The assumptions used within the SE study are discussed broadly below. Over 1200 assumptions were identified by the review team as listed in Appendices D, E, and F. The discussion below does not attempt to address all of the specific assumptions, but rather the underlying themes. Section 3.3 addresses assumptions with economic consequences and examines the sensitivity of PLCC to the critical assumptions; Section 3.4 addresses assumptions based on performance criteria. It is noted that the origins of many of the assumptions were not traceable, but for this review it is immaterial whether any particular assumption was dictated by DOE, stakeholders, or LITCO (or Morrison-Knudson [MK])—-the effect on the SE study is still the same.

The following discussion is divided into regulatory, waste characteristics, general operating, and system and subsystem component assumptions. In general, the three LITCO studies do not aid in making decisions about which subsystems and systems are best based on cost. This is largely due to the broad assumptions that were made, such as assuming a single processing site and an average waste stream. The result is an averaging effect that tends to make most systems look similar and to deemphasize the differences that would warrant selection or rejection.

\subsubsection{Regulatory}

The treatment of regulatory assumptions in the LITCO studies was appropriate; however, the DOE orders have since been changed or canceled. But upon close examination, although many of the orders have changed in identification, they have not changed substantially in content. Table 3.2-1 lists the primary DOE orders cited in the studies and the currently applicable replacement DOE orders. Future studies should reference the new numbers. The moving regulatory targets (DOE regulations, disposal waste characterization, waste inventories, and others) can significantly influence the results of a large study. It is important that the study include a view of the future, so far as it can be reasonably predicted. The studies did show evidence of a futuristic view of the regulations for trace metal emissions by assuming more stringent limits than currently required by EPA.

\subsubsection{Waste Characteristics}

The waste characteristics discussed here include both the input and output (for disposal) waste streams, as well as the issues related to characterizing wastes. For this study, an average waste stream was assumed for designing all systems. This assumption provides a basis (although it is artificial) for designing and costing a waste treatment system, but it is not particularly meaningful. The notion of treating an "average" waste stream is problematic. The wastes that will be processed will have various ranges of radionuclides, inorganics, and organics. For an accurate comparison of technologies, the systems considered need to be designed to handle this waste variability. The variability of the waste stream will most likely have the largest effect on the nonthermal systems. This important operating characteristic, flexibility, is discussed in the Section 3.4. (for the ITTS Phase 2 systems). 


\section{TABLE 3.2-1}

DOE Orders Governing the Regulatory Assumptions Used in the Study

\begin{tabular}{|c|c|c|}
\hline $\begin{array}{l}\text { Old DOE } \\
\text { Order }\end{array}$ & $\begin{array}{l}\text { New DOE } \\
\text { Order }\end{array}$ & Title/Comments \\
\hline $5000.3 B$ & 0232.1 & Occurrence Reporting and Processing of Operations Information \\
\hline 15402 & 0460.1 & $\begin{array}{l}\text { Hazardous Material Packaging for Transportation - Administrative } \\
\text { Procedures }\end{array}$ \\
\hline $4330.4 \mathrm{~A}$ & 4330.4B & Maintenance Management Program \\
\hline 4700.1 & 0430.1 & Project Management System \\
\hline 5400.1 & O231.1 & $\begin{array}{l}\text { General Environmental Protection Program. Parts of Chapters } 2 \text { and } \\
3 \text { were canceled. }\end{array}$ \\
\hline 5400.3 & N1321.139 & $\begin{array}{l}\text { Hazardous and Radioactive Mixed Waste Program, which was further } \\
\text { replaced. }\end{array}$ \\
\hline 5480.13 & $5480.1 B$ & $\begin{array}{l}\text { Environmental, Safety \& Health (ES\&H) Program for DOE } \\
\text { Operations. The ES\&H Order } 5480.1 \mathrm{~B} \text { was canceled. }\end{array}$ \\
\hline 5480.4 & 0440.1 & $\begin{array}{l}\text { Environmental Protection, Safety, and Health Protection Standards, } \\
\text { DOE Order } 5480.4 \text { was canceled in part, and parts of Attachment } 2 \\
\text { and } 3 \text { were replaced. }\end{array}$ \\
\hline $5480.7 \mathrm{~A}$ & O420.1 & Fire Protection \\
\hline 5480.11 & 10CFR835 & Radiation Protection Program \\
\hline $5500.2 \mathrm{~A}$ & O151.1 & Planning and Preparedness for Operational Emergencies \\
\hline $5820.2 \mathrm{~A}$ & $5820.2 B$ & $\begin{array}{l}\text { Radioactive Waste Management. A new order will be issued in the } \\
\text { near future. }\end{array}$ \\
\hline $6430.1 \mathrm{~A}$ & O430.1 & General Design Criteria. \\
\hline
\end{tabular}

The waste inventory is another moving target that affected the outcome of this study. The data in the MLLW inventory report dated April 1993 indicated a total volume of 247,036 $\mathrm{m}^{3}$. Data collected for the Preliminary Site Treatment Plan (PSTP) in 1995 for MLLW indicate that the total amount of MLLW (debris, organic combustibles, sludges, soils, special group, and wastewaters) was $217,772 \mathrm{~m}^{3}$. The more current data should be used in any future analysis. The estimated rate of increase in MLLW (from the April 1993 report) is about 55,982 $\mathrm{m}^{3}$ per year.

Although they were not addressed during the review of these studies, a close look should be taken at the geographical distribution of the various wastes and their priority for cleanup. These issues should be addressed in more detail since they will have a large influence on the assumptions of input wastes, transportation, site location(s), and system designs.

The underlying assumption that current analytical techniques for characterizing input wastes and for determining the long-term stability (e.g., leachability) of the final waste form are adequate is highly uncertain. The currently accepted techniques, although accepted by regulatory agencies, are not sufficiently precise and accurate, and some do not adequately represent the disposal environment. A continuing effort to improve characterization methods is needed and is already ongoing. However, in the meantime, evaluation and application of cleanup technologies must proceed based on methods that are less than fully adequate. The effect of recognizing the 
limitations of current methods is to give additional weight to those performance criteria that enhance regulatory compliance (i.e., conservative design).

\subsubsection{General Operating}

The studies were based on a significant amount of overdesign. The principal assumptions concerned were that all equipment was to be designed for a Seismic Category 1 site, a high capacity factor of $125 \%$, only 4032 hours of operation/year, and all stainless steel construction. These assumptions are not typical of system designs that are commonly used in industry. If these assumptions are being used to ensure contingency, then they should be labeled as such. In future studies, general operating and design factors should be justified in greater detail.

The assumption of a single site to process all wastes leads to the blurring of the technology comparisons. Although this assumption provides a basis for these studies, it is an artificial basis, and therefore it does not allow technology comparisons in a realistic setting. Factors such as geographic distribution of wastes, areas closed to the transport of hazardous wastes, and the design of simpler, smaller systems for specialized purposes warrant far greater consideration.

\subsubsection{System and Subsystem Components}

The systems created and subsystems chosen for inclusion within a study greatly influence the results of the study. Although it is not practical to study every system that lays claim to being able to clean up MLLW, it is important that a thorough screening methodology be employed. The INTS studies used a technology selection group in making such decisions. Although a discussion of how selections were chosen was provided, an approach similar to the Kepner-Tregoe approach shown in Section 3.4 would be more advantageous for initial screening. If a single subsystem is chosen to represent a group of technologies, then it is important to discuss the sensitivity of the overall results to that assumption. Also, as already stated, simple and smaller systems should be considered for processing certain categories of waste where permitted.

\subsection{Economic Predictions and Sensitivities to Predictions}

Over 1200 assumptions were made in the three LITCO reports, all of which are listed in Appendix D (ITTS - Phase 1), Appendix E (ITTS - Phase 2), and Appendix F (INTS). The goals

of sifting out the critical assumptions and quantifying the sensitivity of the PLCC to each one were accomplished in two stages.

First, all the assumptions were evaluated using engineering judgement and given two scores (on a 1-10 scale): a score for uncertainty $(1=$ the assumption will almost certainly be true, and 10 $=$ the assumption will almost certainly turn out to be wrong) and a second score for sensitivity ( 1 = the PLCC for the system will change very little if the assumption is changed, and $10=$ the PLCC for the system will change dramatically if the assumption is changed). The long list of assumptions was then boiled down to a much shorter list of "critical assumptions," which are those assumptions having both high uncertainty $(\geq 5)$ and high sensitivity $(\geq 5)$. These assumptions are listed in Appendix G. The much reduced list has about 50 assumptions (or groups of closely related assumptions). 
The second stage was to examine each of the assumptions (or groups of assumptions) to determine quantitatively the sensitivity of the PLCC to a step change in the assumption. This analysis was carried out using the PLCC spreadsheets developed by Morrison Knudsen Corporation. The results of the sensitivity analyses are presented in Tables 3.3-1 to 3.3-5. The tables give the assumptions, the hypothetical changes in the assumptions, and the impacts of the changes on the PLCCs in both dollars (rounded to the nearest million) and as a percent of the baseline cost (total PLCC). Within each table, the assumptions are presented in order from the most beneficial change to the most harmful (costly).

Table 3.3-1 summarizes the assumptions in the ITTS studies that affect all systems similarly. For simplicity, the sensitivities were calculated for the baseline system (A-1) only. As shown in the table, there are three assumptions that have a very large impact on the PLCC of the system: 1) operating for only 4032 hours/year, 2) a government owned-contractor operated (GOCO) facility, and 3) a Seismic Category 1. If any or all of these assumptions could be changed to the extent indicated, the savings in PLCC could be up to $\$ 833$ million (38\%). It should be noted that the total savings is lower than the sum of the savings for the individual assumptions because there is an interaction between them. Of course, there are also some assumptions that are optimistic. For example, if $75 \%$ of the waste required sorting (rather than $50 \%$ ), the cost would increase substantially ( $\$ 267$ million).

Tables 3.3-2 and 3.3-3 list assumptions in the ITTS studies that are system-specific. The point was to look for assumptions that favor one system or technology over another. The only such assumption found for ITTS Phase 1 was the assumption of $100 \%$ sorting for Systems B1 and D1, while other systems require only $50 \%$ of the waste to be sorted. If that were relaxed to only $75 \%$ sorting, it would change the ranking of the systems, but neither of the two systems would become the best (cheapest). For ITTS Phase 2, no assumptions were found that would significantly alter the standing of any particular technology.

The assumptions in the INTS study that affect all systems similarly are given in Table 3.3-4. As with the ITTS systems, there is potential for substantial cost savings. The same three assumptions that were extremely important in the ITTS study were also important in the INTS study. If those three assumptions were changed to the extent indicated in Table $3.3-4$, the savings in PLCC could be up to $\$ 1078$ million (34\%). In addition, it was assumed that $75 \%$ of the waste for the INTS systems required sorting; if that alone were decreased to $50 \%, \$ 412$ million (13\%) would be saved. Likewise, there is also the potential for cost increases.

The assumptions that affected only specific INTS technologies are given in Table 3.3-5. None of them penalized any particular system in favor of another.

\subsection{Performance Evaluation of Phase 2 Technologies}

In selecting EM technologies for implementation, noneconomic performance factors need to be considered along with life-cycle cost. Noneconomic factors have particular importance where the costs of competing systems are similar and/or diverse regulatory requirements must be met, as is the case for the systems compared in the LITCO studies. Different sets of performance criteria are presented in each of the three reports for the LITCO studies (Phase 1 ITTS, Table 6-1; Phase 2 
TABLE 3.3-1

Sensitivity of PLCC to Changes in Assumptions: System A1 - Baseline System ITTS

\begin{tabular}{|c|c|c|c|c|c|}
\hline \multicolumn{2}{|c|}{$\begin{array}{l}\text { Assumption } \\
\text { No.* } \\
\text { Phase }\end{array}$} & \multirow[b]{2}{*}{ Assumption } & \multirow[b]{2}{*}{ Change in Assumption } & \multirow{2}{*}{$\triangle \$ P L C C$} & \multirow{2}{*}{$\triangle \mathrm{PLCC}, \%$} \\
\hline 1 & 2 & & & & \\
\hline 2 & 3 & $\begin{array}{l}\text { Operation of the facility is assumed to be } 4032 \text { hours } \\
\text { per year. }\end{array}$ & $\begin{array}{l}\text { Assume } 8064 \text { hours per year } \\
=0.63 \times \text { construction costs }+0.5 \times \text { receiving and } \\
\text { inspection labor. }\end{array}$ & -418 & -19.3 \\
\hline$\cdot$ & 16 & $\begin{array}{l}\text { Assume government owned-contractor operated } \\
\text { (GOCO). Indirect costs }=29 \%, \text { construction } \\
\text { management }=17 \%, \text { management reserve }=10 \% \text {, } \\
\text { contingency }=25 \% \text {, design }+ \text { inspection }+ \text { project } \\
\text { management }=42 \% \text { of construction cost. Contingency } \\
=25 \% \text { of operating and maintenance cost. }\end{array}$ & $\begin{array}{l}\text { Assume privately owned. } \\
\text { Assume indirect costs }=25 \% \text {, construction management }= \\
5 \% \text {, management reserve }=0 \% \text {, contingency }=10 \% \text {, design } \\
+ \text { inspection }+ \text { project management }=20 \% \text { of construction } \\
\text { cost. Contingency }=10 \% \text { of operating and maintenance } \\
\text { cost. }\end{array}$ & -379 & -17.5 \\
\hline 3 & 2 & $\begin{array}{l}\text { Facilities will be designed for a moderate-hazard } \\
\text { classification and Seismic Category } 1 .\end{array}$ & $\begin{array}{l}\text { Assume Seismic Category } 2 \\
=0.4 \times \text { construction costs. }\end{array}$ & -342 & -15.8 \\
\hline 12 & 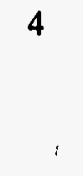 & $\begin{array}{l}\text { Triple containment will be used for all process steps } \\
\text { from waste sorting through waste stabilization. Double } \\
\text { containment is used for other processes if there is limit } \\
\text { potential for air emissions. }\end{array}$ & $\begin{array}{l}\text { Assume double rather than triple, and single rather than } \\
\text { double } \\
=0.5 \times \text { (building costs of all subsystems except } \\
\text { administration). }\end{array}$ & -120 & -5.5 \\
\hline 1 & 1 & $\begin{array}{l}\text { The same unit disposal cost of } \$ 243 / \mathrm{ft}^{3} \text { is used for all } \\
\text { waste disposal regardless of its form. }\end{array}$ & Assume $\$ 243 \pm \$ 100 / \mathrm{ft}^{3}$ & \pm 88 & \pm 3.7 \\
\hline 10 & & $\begin{array}{l}\text { A contingency of } 25 \% \text { is applied to all components in } \\
\text { production facility construction costs. }\end{array}$ & $\begin{array}{l}\text { Assume a contingency of } 10 \% \\
=0.4 \times \text { contingency costs for all components. }\end{array}$ & -77 & -3.6 \\
\hline 11 & & $\begin{array}{l}\text { Decontamination and decommissioning (D\&D) is } \\
\text { estimated at } \$ 450 / \mathrm{ft}^{2} \text {. }\end{array}$ & $\begin{array}{l}\text { Assume } \pm 50 \% \\
=D \& D \text { costs } \times(1 \pm 0.5)\end{array}$ & \pm 27 & \pm 1.2 \\
\hline 9 & & $\begin{array}{l}\text { Five low-temperature stabilization agents meet } \\
\text { implementability requirements. }\end{array}$ & $\begin{array}{l}\text { Assume technology fails } \\
=\text { cost of subsystem }+1 \text { year of operating costs. }\end{array}$ & +72.7 & +3.4 \\
\hline 5 & & $\begin{array}{l}\text { Vitrification technologies meet implementability } \\
\text { requirements. }\end{array}$ & $\begin{array}{l}\text { Assume technology fails } \\
=\text { cost of subsystem }+1 \text { year of operating costs. }\end{array}$ & +87.5 & +4 \\
\hline 4 & & System will incorporate minimum shielding: & $\begin{array}{l}\text { Requires more extensive shielding } \\
=2.0 \times \text { building construction costs. }\end{array}$ & +244 & +11.3 \\
\hline 6 & 13 & $50 \%$ of the waste requires sorting. & $\begin{array}{l}\text { Assume } 75 \% \text { of the waste requires sorting } \\
=1.5 \times \text { (construction costs }+ \text { annual operating costs }) \text {. }\end{array}$ & +267 & +12.3 \\
\hline
\end{tabular}

* See Appendix $\mathrm{G}$ for a more detailed description of the LITCO assumption. The "Assumption No." is the number of the assumption in Appendix $\mathrm{G}$ for ITTS. 
TABLE 3.3-2

Sensitivity of PLCC to Changes in Assumptions: ITTS Phase 1 Systems

\begin{tabular}{|c|c|c|c|c|}
\hline $\begin{array}{l}\text { Assumption } \\
\text { No.* }\end{array}$ & Assumption & Change in Assumption & $\begin{array}{l}\triangle \$ P L C C \\
\text { millions }\end{array}$ & $\begin{array}{c}\triangle \mathrm{PLCC} \\
\%\end{array}$ \\
\hline 7 & $\begin{array}{l}\text { For systems B1 and D1, it is assumed that } 100 \% \text { of the } \\
\text { waste requires sorting. }\end{array}$ & $\begin{array}{l}\text { Assume } 75 \% \text { rather than } 100 \% \\
=0.75 \times \text { construction costs }+0.75 \times \text { operating costs. }\end{array}$ & -157 & -7.0 \\
\hline 8 & $\begin{array}{l}\text { For systems A4 and D1, it is assumed that } 90 \% \text { of the } \\
\text { lime is recycled. }\end{array}$ & $\begin{array}{l}\text { Assume that } 10 \% \text { of the lime is recycled } \\
=2 \times \text { polymer }+1.5 \times \text { equipment cost for secondary } \\
\text { stabilization. }\end{array}$ & +31 & +1.4 \\
\hline
\end{tabular}

* See Appendix $\mathrm{G}$ for a more detailed description of the LITCO assumption. The "Assumption No." is the number of the assumption in Appendix $G$ for ITTS-Phase 1 .

\section{TABLE 3.3-3}

Sensitivity of PLCC to Changes in Assumptions: ITTS Phase 2 Systems and Subsystems

\begin{tabular}{|c|c|c|c|c|}
\hline $\begin{array}{l}\text { Assumption } \\
\text { No.* }\end{array}$ & Assumption & Change in Assumption & $\begin{array}{l}\triangle \$ P L C C \\
\text { millions }\end{array}$ & $\triangle \mathrm{PLCC}, \%$ \\
\hline 10 & $\begin{array}{l}\text { Joule-heated melter subsystem will meet } \\
\text { requirements. }\end{array}$ & $\begin{array}{l}\text { Subsystem fails to function properly and must be replaced } \\
=\text { construction cost of Joule-heated melter }+1 \text { year operating } \\
\text { cost. }\end{array}$ & +78.6 & +4.1 \\
\hline 12 & SCWO subsystem will meet requirements. & $\begin{array}{l}\text { Subsystem fails to function properly and must be replaced } \\
=\text { construction cost of SCWO }+1 \text { year operating cost. }\end{array}$ & +79.2 & +3.7 \\
\hline 14 & Incinerators will meet requirements. & $\begin{array}{l}\text { Subsystem fails to function properly and must be replaced } \\
=\text { construction cost of incinerator }+1 \text { year operating cost. }\end{array}$ & +88.2 & +4.2 \\
\hline 11 & MEO subsystem will meet requirements. & $\begin{array}{l}\text { Subsystem fails to function properly and must be replaced } \\
=\text { construction cost of } \mathrm{MEO}+1 \text { year operating cost. }\end{array}$ & +88.2 & +4.2 \\
\hline 9 & $\begin{array}{l}\text { Steam gasifier subsystem will meet } \\
\text { requirements. }\end{array}$ & $\begin{array}{l}\text { Subsystem fails to function properly and must be replaced } \\
=\text { construction cost of steam gasifier }+1 \text { year operating cost. }\end{array}$ & +94.3 & +4.3 \\
\hline 5 & Plasma furnace will meet requirements. & $\begin{array}{l}\text { Subsystem fails to function properly and must be replaced } \\
=\text { construction cost of plasma furnace }+1 \text { year operating cost. }\end{array}$ & +95 & +4.5 \\
\hline 8 & Molten metal subsystem will meet requirements. & $\begin{array}{l}\text { Subsystem fails to function properly and must be replaced } \\
=\text { construction cost of molten metal }+1 \text { year operating cost. }\end{array}$ & +96.2 & +5.1 \\
\hline 6 & Plasma gasifier will meet requirements. & $\begin{array}{l}\text { Subsystem fails to function properly and must be replaced } \\
=\text { construction cost of gasifier }+1 \text { year operating cost. }\end{array}$ & +96.8 & +5.0 \\
\hline 15 & APC subsystem will meet requirements. & $\begin{array}{l}\text { Subsystem fails to function properly and must be replaced } \\
=\text { construction cost of APC }+1 \text { year operating cost. }\end{array}$ & +107 & +4.9 \\
\hline 7 & $\begin{array}{l}\text { MSO meets DOE objectives for life-cycle cost } \\
\text { and schedule. }\end{array}$ & $\begin{array}{l}\text { Subsystem fails to function properly and must be replaced } \\
=\text { construction cost of } \mathrm{MSO}+1 \text { year operating cost. }\end{array}$ & +126 & +5.5 \\
\hline
\end{tabular}

* See Appendix G for a more detailed description of the LITCO assumption. The "Assumption No." is the number of the assumption in Appendix G for ITTS - Phase 2. 
TABLE 3.3-4

Sensitivity of PLCC to Changes in Assumptions: INTS - System 1

\begin{tabular}{|c|c|c|c|c|}
\hline $\begin{array}{l}\text { Assumption } \\
\text { No.* }\end{array}$ & Assumption & Change in Assumption & $\begin{array}{c}\triangle \$ P L C C, \\
\text { millions }\end{array}$ & $\triangle \mathrm{PLCC}, \%$ \\
\hline 3 & $\begin{array}{l}\text { Operation of the facility is assumed to be } 4032 \text { hours per } \\
\text { year. }\end{array}$ & $\begin{array}{l}\text { Assume } 8064 \text { hours per year } \\
=0.63 \times \text { construction costs }+0.5 \times \text { receiving and } \\
\text { inspection labor. }\end{array}$ & -542 & -17.0 \\
\hline 14 & $\begin{array}{l}\text { Assume GOCO. } \\
\text { Indirect costs }=29 \% \text {, construction management }=17 \% \text {, } \\
\text { management reserve }=10 \% \text {, contingency }=25 \% \text {, design } \\
+ \text { inspection }+ \text { project management }=42 \% \text { of } \\
\text { construction cost. Contingency }=25 \% \text { of operating and } \\
\text { maintenance cost. }\end{array}$ & $\begin{array}{l}\text { Assume privately owned. } \\
\text { Indirect costs }=25 \% \text {, construction management }=5 \% \text {, } \\
\text { management reserve }=0 \% \text {, contingency }=10 \% \text {, design } \\
+ \text { inspection }+ \text { project management }=20 \% \text { of } \\
\text { construction cost. Contingency }=10 \% \text { of operating and } \\
\text { maintenance cost. }\end{array}$ & -506 & -15.9 \\
\hline 12 & $75 \%$ of the waste requires sorting. & $\begin{array}{l}\text { Assume } 50 \% \text { of the waste requires sorting } \\
=0.67 \times \text { (construction costs }+ \text { annual operating costs } \\
\text { for receiving and inspection }) .\end{array}$ & -412 & -13.0 \\
\hline 1 & $\begin{array}{l}\text { Facilities will be designed for a moderate-hazard } \\
\text { classification and Seismic Category } 1 .\end{array}$ & $\begin{array}{l}\text { Assume Seismic Category } 2 \\
=0.4 \times \text { construction costs. }\end{array}$ & -372 & 11.7 \\
\hline 13 & $\begin{array}{l}\text { The same unit disposal cost of } \$ 243 / \mathrm{ft}^{3} \text { is used for all waste } \\
\text { disposal regardless of its form. }\end{array}$ & Assume $\$ 243 \pm \$ 100 / \mathrm{ft}^{3}$ & \pm 371 & \pm 10.2 \\
\hline 2 & $\begin{array}{l}\text { Triple containment will be used for all process steps from } \\
\text { waste sorting through waste stabilization. Double } \\
\text { containment is used for other processes if there is limit } \\
\text { potential for air emissions. }\end{array}$ & $\begin{array}{l}\text { Assume double rather than triple, and single rather than } \\
\text { double } \\
=0.5 \times \text { (building cost of all subsystems except } \\
\text { administration). }\end{array}$ & -181 & -5.7 \\
\hline 15 & $\begin{array}{l}\text { A contingency of } 25 \% \text { is applied to all components in } \\
\text { production facility construction costs. }\end{array}$ & $\begin{array}{l}\text { Assume a contingency of } 10 \% \\
=0.4 \times \text { contingency costs for all components. }\end{array}$ & -70 & -2.2 \\
\hline 16 & Equipment cost based on use of stainless steel. & $\begin{array}{l}\text { Assume equipment cost was based on mild steel } \\
=0.67 \times \text { equipment cost. }\end{array}$ & -64 & -2.0 \\
\hline 4 & $\begin{array}{l}\text { Stabilization formulas = } 1 \text { part polymer to } 1 \text { part waste; } 1 \\
\text { part ceramic additives to } 1 \text { part waste; and } 2 \text { parts grout to } \\
1 \text { part waste. }\end{array}$ & $\begin{array}{l}\text { Assume polymer is } 1.5: 1 \text {, grout is } 3: 1 \text {, and ceramic is } \\
1.5: 1 \text { : The capital cost for each secondary stabilization } \\
\text { method will be increased by } 28 \% \text {. Disposal costs are } \\
\text { increased by } 25 \% \text {. }\end{array}$ & +283 & +7.8 \\
\hline & System will incorporate minimum shielding. & $\begin{array}{l}\text { Requires more extensive shielding } \\
=2.0 \times \text { building construction costs. }\end{array}$ & +399 & +12.5 \\
\hline
\end{tabular}


TABLE 3.3-5

Sensitivity of PLCC to Changes in Assumptions for INTS Systems and Subsystems

\begin{tabular}{|c|c|c|c|c|}
\hline $\begin{array}{l}\text { Assumption } \\
\text { No. }\end{array}$ & Assumption & Change in Assumption & $\begin{array}{c}\triangle \$ P L C C \\
\text { millions }\end{array}$ & $\begin{array}{c}\triangle P L C C \\
\%\end{array}$ \\
\hline 10 & $\begin{array}{l}\text { Phosphate-bonded ceramic subsystem will meet } \\
\text { requirements. }\end{array}$ & $\begin{array}{l}\text { Subsystem fails to function properly and must be replaced } \\
=\text { C.C. } \dagger \text { of phosphate-bonded ceramic subsystem }+1 \text { year } \\
\text { operating cost. }\end{array}$ & +124 & +3.7 \\
\hline 9 & Acid digestion subsystem will meet requirements. & $\begin{array}{l}\text { Subsystem fails to function properly and must be replaced } \\
=\text { C.C. of acid digestion }+1 \text { year operating cost. }\end{array}$ & +126 & +3.7 \\
\hline 6 & Vacuum desorption subsystem will meet requirements. & $\begin{array}{l}\text { Subsystem fails to function properly and must be replaced } \\
=\text { C.C. of vacuum desorption }+1 \text { year operating cost. }\end{array}$ & +127 & +4.1 \\
\hline 7 & $\begin{array}{l}\text { Catalytic wet oxidation subsystem will meet } \\
\text { requirements. }\end{array}$ & $\begin{array}{l}\text { Subsystem fails to function properly and must be replaced } \\
=\text { C.C. of catalytic wet oxidation }+1 \text { year operating cost. }\end{array}$ & +129 & +3.8 \\
\hline 5 & $\begin{array}{l}\text { Mediated electrochemical oxidation subsystem will } \\
\text { meet requirements. }\end{array}$ & $\begin{array}{l}\text { Subsystem fails to function properly and must be replaced } \\
=\text { C.C. } \text { of MEO + } 1 \text { year operating cost. }\end{array}$ & +136 & +4.3 \\
\hline 8 & Aqueous washing subsystem will meet requirements. & $\begin{array}{l}\text { Subsystem fails to function properly and must be replaced } \\
=\text { C.C. of aqueous washing }+1 \text { year operating cost. }\end{array}$ & +139 & +4.2 \\
\hline 4 & $\begin{array}{l}\text { SYSTEM 4: Stabilization formulas = } 1 \text { part polymer } \\
\text { to } 1 \text { part waste; } 1 \text { part ceramic additives to } 1 \text { part } \\
\text { waste; and } 2 \text { parts grout to } 1 \text { part waste. }\end{array}$ & $\begin{array}{l}\text { Assume polymer is } 1.5: 1 \text {, grout is } 3: 1 \text {, and ceramic is } 1.5: 1 \text { : } \\
\text { The capital cost for each secondary stabilization method will } \\
\text { be increased by } 28 \% \text {. Disposal costs are increased by } 25 \% \text {. }\end{array}$ & +236 & +6.3 \\
\hline 4 & $\begin{array}{l}\text { SYSTEM 5: Stabilization formulas = } 1 \text { part polymer } \\
\text { to } 1 \text { part waste; } 1 \text { part ceramic additives to } 1 \text { part } \\
\text { waste; and } 2 \text { parts grout to } 1 \text { part waste. }\end{array}$ & $\begin{array}{l}\text { Assume polymer is } 1.5: 1 \text {, grout is } 3: 1 \text {, and ceramic is } 1.5: 1 \text { : } \\
\text { The capital cost for each secondary stabilization method will } \\
\text { be increased by } 28 \% \text {. Disposal costs are increased by } 25 \% \text {. }\end{array}$ & +250 & +6.6 \\
\hline 11 & SYSTEM 2: The excess water is discharged. & The excess water is grout stabilized. & +250 & +7.1 \\
\hline 4 & $\begin{array}{l}\text { SYSTEM 2: Stabilization formulas = } 1 \text { part polymer } \\
\text { to } 1 \text { part waste; } 1 \text { part ceramic additives to } 1 \text { part } \\
\text { waste; and } 2 \text { parts grout to } 1 \text { part waste. }\end{array}$ & $\begin{array}{l}\text { Assume polymer is } 1.5: 1 \text {, grout is } 3: 1 \text {, and ceramic } 1.5: 1 \text { : } \\
\text { The capital cost for each secondary stabilization method will } \\
\text { be increased by } 28 \% \text {. Disposal costs are increased by } 25 \% \text {. }\end{array}$ & +258 & +7.4 \\
\hline 4 & $\begin{array}{l}\text { SYSTEM 3: Stabilization formulas = } 1 \text { part polymer } \\
\text { to } 1 \text { part waste; } 1 \text { part ceramic additives to } 1 \text { part } \\
\text { waste; and } 2 \text { parts grout to } 1 \text { part waste. }\end{array}$ & $\begin{array}{l}\text { Assume polymer is } 1.5: 1 \text {, grout is } 3: 1 \text {, and ceramic is } 1.5: 1 \text { : } \\
\text { The capital cost of each secondary stabilization method will } \\
\text { be increased by } 28 \% \text {. Disposal costs are increased by } 25 \% \text {. }\end{array}$ & +295 & +7.9 \\
\hline
\end{tabular}

* See Appendix G for a more detailed description of the LITCO assumption. The "Assumption No." is the number of the assumption in Appendix G for INTS.

$\dagger$ Cost of construction. 
ITTS, Table 5-1; and INTS, Table 6-1). Only the Phase 1 study proposes numerical weighting factors for noneconomic performance criteria. No quantitative rating based on performance criteria was assigned to any of the 24 systems included in the ITTS and INTS studies, which would have allowed direct comparison leading to selection or rejection.

A structured evaluation of the nine Phase 2 systems and the baseline system was undertaken in the course of this review to illustrate the type of analysis that can be performed to deal quantitatively with the wealth of qualitative information presented in the LITCO studies. The comparisons generated may or may not be meaningful for selection purposes, considering the limited depth of the current review, but they do serve the intended purpose of illustrating the method. The method used is an adaptation of the Kepner-Tregoe approach applied to the 422 regulatory and design assumptions for Phase 2 technologies listed in Appendix E. Ratings on a scale of 1 to 10 were assigned to applicable assumptions relating to nine cost and performance criteria: 1) cost sensitivity, 2) cost uncertainty, 3) regulatory compliance, 4) implementability, 5) flexibility (to treat a variety of input waste), 6) operability, 7) maintainability, 8) availability, and 9) decommissioning and decontamination. The ratings were assigned in a once-through manner by a senior chemical engineer with process experience, based on engineering judgement applied to the information presented in the Phase 2 study report. The assumptions, with their respective scores, can be traced back to the related page in the LITCO Phase 2 study report by consulting Appendix E.

To facilitate comparison, ratings were sorted according to system and criteria using readily available spreadsheet software. The Lotus spreadsheet used for the analysis which follows is available for tracing or extending the analysis. Table 3.4-1 presents averaged rating scores on nine criteria for ten treatment systems (the baseline and nine Phase 2 systems, including all subsystems), and these summary data are used to compute the weighted comparison factors in the table that take into account both cost and performance. Table 3.4-2 presents a similar set of averaged rating scores for the primary thermal subsystems alone, which serves to accentuate differences that are masked by averaging over all of the subsystems in each system. Selected data from these tables have been graphed for illustrating the points that follow.

Observations can be derived from the rating summaries at different levels of detail, as illustrated by the following examples:

Analysis of Cost Assumptions. Out of the total of 422 design and regulatory assumptions identified from the Phase 2 report, 199 were rated for cost effect. The overall distributions of ratings for cost sensitivity and cost uncertainty were bimodal, with peaks at rating levels of 2-3 and 6-7, reflecting in part the proclivity indicated in Table 3.4-2 for certain thermal subsystems to have either high or low cost ratings for both sensitivity and uncertainty (e.g., high ratings for systems K-1 and L-1 based on thermal desorption with special oxidation systems and a low rating for the baseline rotary kiln system). In Figure 3.4-1, only the two kiln-based systems, A-1 and A-7, evidence a lower cost sensitivity for the thermal subsystem (the kiln) than for the total system, including air pollution control, waste stabilization, and other subsystems. The less fully developed thermal subsystems, such as K-1, L-1, and F-1 (F-1 uses molten salt oxidation), were characterized by high scores for both cost sensitivity and uncertainty (Table 3.4-2), reflecting a tendency in rating to assume that the costs associated with implementing unproven technologies, although not well known, will probably be high. As discussed in the previous section of this review, cost 
TABLE 3.4-1

Comparison of Performance Scores for Total Systems: Baseline and Phase 2 Systems

\begin{tabular}{|c|c|c|c|c|c|c|c|c|c|c|c|c|c|c|c|}
\hline & & & & & & & Criteri & & & & & & & & \\
\hline & & & & st & & & & forma & nce & & & & & & \\
\hline & & & 1 & 2 & 3 & 4 & 5 & 6 & 7 & 8 & 9 & Weig & ted Comp & arison $\mathrm{F}$ & Factors \\
\hline & & & & & & & Weig & ting $\mathrm{F}$ & actors & & & & & & \\
\hline & & System Description & & & $25 \%$ & $15 \%$ & $15 \%$ & $15 \%$ & $10 \%$ & $10 \%$ & $10 \%$ & WPS & NPLCC & $\mathrm{NC} / \mathrm{P}$ & NCU/P \\
\hline & A-1 & $\begin{array}{l}\text { Rotary Kiln with Air for } \\
\text { Combustion and Dry/Wet APC - } \\
\text { Baseline }\end{array}$ & 2.87 & 4.80 & 6.30 & 7.15 & 6.84 & 6.82 & 6.14 & 6.55 & 5.07 & 6.48 & 1.00 & 1.00 & 1.00 \\
\hline & A-7 & Slagging Rotary Kiln & 2.74 & 5.05 & 6.26 & 7.14 & 6.93 & 6.69 & 6.03 & 6.40 & 5.04 & 6.43 & 0.87 & 0.88 & 0.88 \\
\hline & $C-2$ & $\begin{array}{l}\text { Plasma Furnace with } \mathrm{CO}_{2} \\
\text { Retention }\end{array}$ & 3.20 & 5.33 & 6.22 & 5.81 & 6.96 & 5.68 & 5.17 & 5.63 & 4.95 & 5.90 & 0.95 & 1.05 & 1.06 \\
\hline & $C-3$ & Plasma Gasification & 3.00 & 5.11 & 6.09 & 6.21 & 6.96 & 6.00 & 5.32 & 6.26 & 5.05 & 6.06 & 0.86 & 0.92 & 0.93 \\
\hline & F-1 & Molten Salt Oxidation & 3.48 & 5.55 & 5.89 & 5.95 & 5.91 & 5.60 & 5.32 & 6.06 & 4.89 & 5.72 & 1.00 & 1.13 & 1.15 \\
\hline$\simeq$ & G-1 & Molten Metal Waste Destruction & 3.24 & 5.51 & 6.06 & 6.15 & 7.04 & 5.97 & 5.19 & 6.32 & 5.08 & 6.05 & 0.85 & 0.91 & 0.92 \\
\hline & $\mathrm{H}-\mathrm{I}$ & Steam Gasification & 2.98 & 5.29 & 6.17 & 6.51 & 6.24 & 6.39 & 5.80 & 6.37 & 5.04 & 6.14 & 0.96 & 1.02 & 1.03 \\
\hline & $J-1$ & Joule-Heated Vitrification & 3.03 & 5.16 & 6.20 & 6.71 & 6.93 & 6.32 & 5.17 & 6.07 & 5.26 & 6.19 & 0.86 & 0.90 & 0.90 \\
\hline & $\mathrm{K}-1$ & $\begin{array}{l}\text { Thermal Desorption and Mediated } \\
\text { Electrochemical Oxidation }\end{array}$ & 3.27 & 5.52 & 5.76 & 6.00 & 6.80 & 6.10 & 5.74 & 6.35 & 5.30 & 6.01 & 1.15 & 1.24 & 1.26 \\
\hline & L-1 & $\begin{array}{l}\text { Thermal Desorption and } \\
\text { Supercritical Water Oxidation }\end{array}$ & 3.61 & 5.61 & 5.96 & 5.88 & 6.84 & 5.96 & 4.96 & 6.04 & 5.32 & 5.92 & 1.17 & 1.28 & 1.30 \\
\hline & $\begin{array}{r}\text { Crite } \\
1\end{array}$ & $\begin{array}{l}\text { ia Definitions on a Scale of } 1 \text { to } 10 \text { : } \\
\text { Cost sensitivity }\end{array}$ & & Defi & ons & of Weig & ghted $C$ & Fimpar & ison $F$ & tors: & & & & & \\
\hline & 2 & Cost uncertainty & & & $P S-1$ & Weighte & ed pert & orman & ce crite & ria sco & res for & entir & rstems. & & \\
\hline & 3 & Regulatory compliance & & NPLC & $C-1$ & Vormali & ized $\mathrm{p}$ & anned & life-cy & le cost & $s$ for $s$ & ystems, & from Tabl & e 4-6 in & the \\
\hline & 4 & Implementability & & & & hase 2 & repor & & & & & & & & \\
\hline & 5 & Flexibility & & $\mathrm{NC}$ & $P-1$ & Normali & ized cc & st-to-p & erform & ance $r a$ & tio for & system & , NPLCC & /WPS, & \\
\hline & 6 & Operability & & & & cormali & ized to & 1 for $s$ & ystem & A-1. & & & & & \\
\hline & 7 & Maintainability & & $\mathrm{NCU}$ & $/ \mathrm{P}-\mathrm{I}$ & Vormali & ized sy & stem c & ost inc & eased & for unc & certaint & and ratioe & ed to & \\
\hline & 8 & Availability & & & & erform & lance: & NPLC & $C *(1$ & $0+2$ & $\% * c$ & cost un & tainty $/ 10$ & )/WPS, & \\
\hline & 9 & Decommissioning and & & & & 1ormali & zed to & 1 for 5 & ystem & A-1. & & & & & \\
\hline
\end{tabular}


TABLE 3.4-2

Comparison of Cost and Performance Scores for Thermal Subsystems: Baseline and Phase 2 Systems

Weighted Comparison

Factors

System Description

Performance Criteria

WPTSS

\begin{tabular}{|c|c|c|c|c|c|c|c|c|c|c|c|}
\hline & \multirow[t]{2}{*}{ System Description } & \multirow[t]{2}{*}{ I } & \multirow[t]{2}{*}{2} & \multicolumn{5}{|c|}{$\begin{array}{ccc}5 & 6 & 7 \\
\text { Weighting } & \text { Factors }\end{array}$} & 8 & $\mathbf{y}$ & \multirow[t]{2}{*}{ WPTSS } \\
\hline & & & & $25 \%$ & $15 \%$ & $15 \%$ & $15 \%$ & $10 \%$ & $10 \%$ & $10 \%$ & \\
\hline$A-1$ & $\begin{array}{l}\text { Rotary Kiln with Air for Combustion } \\
\text { and Dry/Wet APC - Baseline }\end{array}$ & 2.71 & 3.43 & 7.00 & 8.00 & 6.86 & 7.29 & 7.14 & 7.14 & 5.00 & 7.00 \\
\hline$A-7$ & Slagging Rotary Kiln & 2.17 & 4.67 & 7.38 & 7.44 & 7.29 & 6.30 & 5.75 & 5.88 & 4.83 & 6.64 \\
\hline C-2 & Plasma Furnace with $\mathrm{CO}_{2}$ Retention & 4.27 & 5.45 & 6.68 & 4.44 & 69.1 & 4.24 & 4.80 & 4.57 & 4.67 & 5.35 \\
\hline C-3 & Plasma Gasification & 4.20 & 4.60 & 6.20 & 3.78 & 6.80 & 3.50 & 3.00 & 4.75 & 4.75 & 4.91 \\
\hline F-1 & Molten Salt Oxidation & 5.40 & 6.70 & 5.12 & 3.85 & 3.60 & 3.46 & 3.88 & 5.00 & 4.38 & 4.24 \\
\hline G-1 & Molten Metal Waste Destruction & 4.08 & 6.17 & 6.12 & 4.81 & 7.11 & 4.73 & 4.15 & 6.00 & 5.00 & 5.54 \\
\hline $\mathrm{H}-1$ & Steam Gasification & 3.25 & 5.63 & 6.50 & 5.45 & 4.56 & 5.82 & 5.71 & 6.14 & 4.86 & 5.67 \\
\hline $\mathrm{J}-1$ & Joule-Heated Vitrification & 4.75 & 5.00 & 6.89 & 5.75 & 6.80 & 5.33 & 3.50 & 4.86 & 5.80 & 5.82 \\
\hline K-1 & $\begin{array}{l}\text { Thermal Desorption and Mediated } \\
\text { Electrochemical Oxidation }\end{array}$ & 6.80 & 7.40 & 5.44 & 4.62 & 6.43 & 4.80 & 5.14 & 5.83 & 5.83 & 5.42 \\
\hline L-1 & $\begin{array}{l}\text { Thermal Desorption and Supercritical } \\
\text { Water Oxidation }\end{array}$ & 7.00 & 7.13 & 6.17 & 4.17 & 6.57 & 4.00 & 2.88 & 4.86 & 6.00 & 5.13 \\
\hline
\end{tabular}

Criteria Definitions on a Scale of 1 to 10 :

Definition of Weighted Comparison Factors:

1 Cost sensitivity

2 Cost uncertainty

3 Regulatory compliance

4 Implementability

5 Flexibility

6 Operability

7 Maintainability

8 Availability

9 Decommissioning and decontamination 


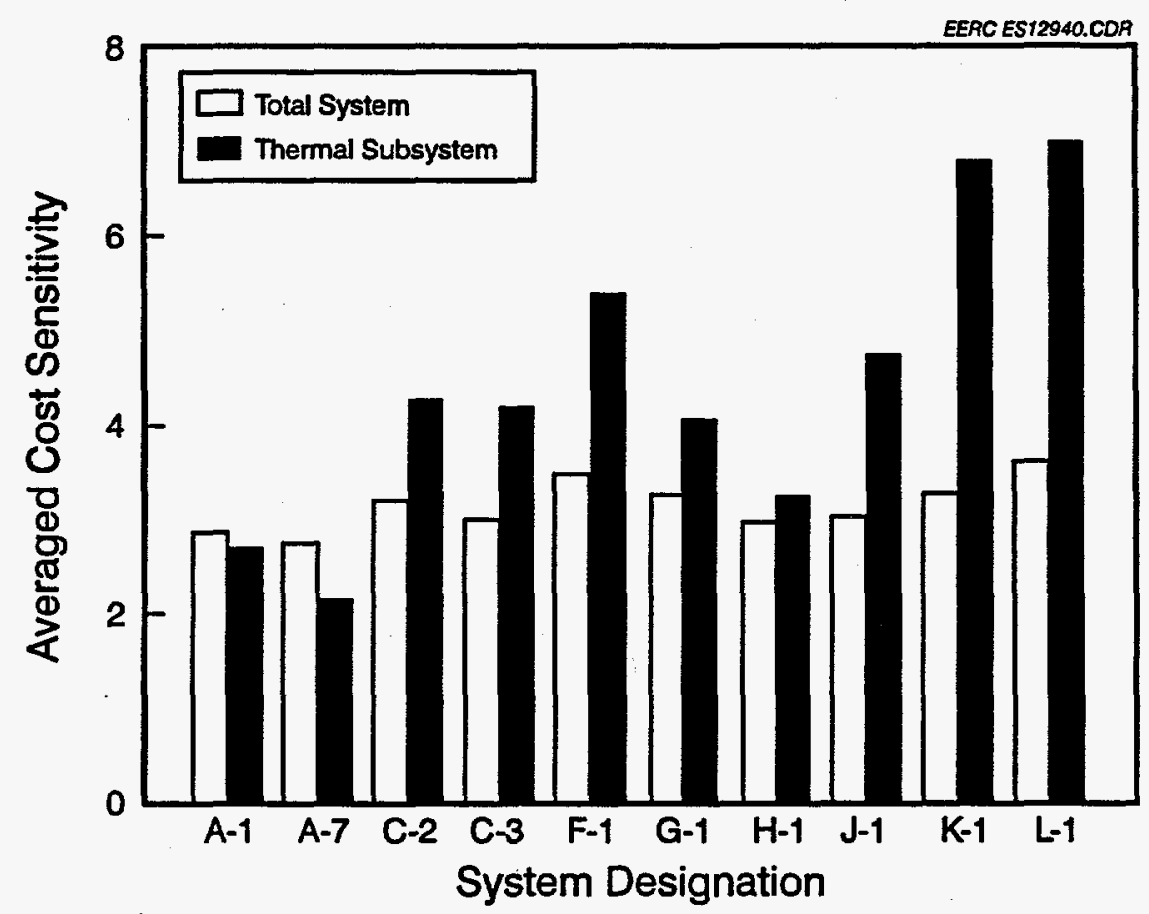

Figure 3.4-1. Comparison of cost sensitivity for Phase 2 systems and thermal subsystems.

assumptions that are rated high on both sensitivity and uncertainty require careful review. Out of the 199 assumptions rated for cost effects in the Phase 2 report, the 69 assigned ratings above 5 for both sensicivity and cost were incorporated with the critical cost assumptions in Appendix $G$.

Analysis of Regulatory Compliance Assumptions. The averaged ratings for regulatory compliance in Tables 3.4-1 and 3.4-2, respectively representing overall systems and thermal subsystems alone, show relatively small differences, in the range of 5 to 7 . Slightly lower average scores were observed for the less developed thermal treatment subsystems (F-1, K-1 and L-1) and for the systems relying on grouting instead of vitrification (K-1 and L-1). However, the more important differences affecting regulatory compliance are found at the level of the individual assumptions. In Figure 3.4-2, a histogram for the 265 assumptions rated for regulatory compliance indicates that most of the ratings are in a central range of 5 to 8, where it is assumed that they have little particular effect. Subsets of assumptions having low or high regulatory compliance ratings are listed separately in Appendix H. The low scores, from 1 to 4, are of special importance because of their appraised potential to interfere with achieving compliance. Examples include assumptions concerning: 1) waste characterization using drum assay procedures accurate to only $\pm 100 \%$, 2) the adequateness of the TCLP (toxicity characteristic leaching procedure) leaching test to demonstrate U.S. Environmental Protection Agency (EPA) compliance entailing long-term stability, and 3) the lack of information on thermal release of actinides in primary thermal treatment subsystems and their capture in air pollution modules, and 4) the untested designs used for recovering bulk mercury from the feed waste and subsequently capturing thermally volatilized mercury on carbon filters. Further review of all assumptions with low regulatory compliance scores is recommended. At the high end of the distribution, scores of 9 or 10 may indicate that costly measures are being used to achieve unneeded overcompliance; a possible example is the assumption that metals emissions will be controlled at levels that are one tenth of the EPA limits. 


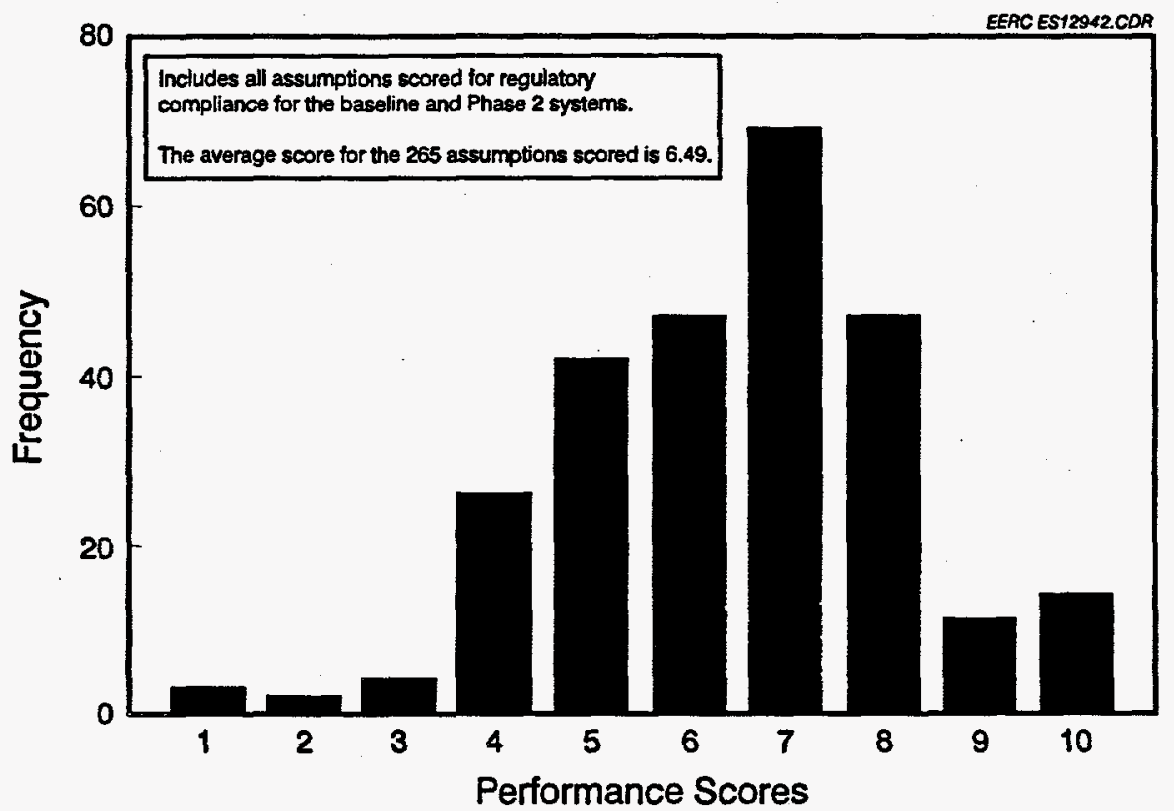

Figure 3.4-2. Distribution of performance scores for regulatory compliance assumptions.

Analysis of Implementability Rating. Averaged ratings for implementability presented in Figure 3.4-3 and Tables 3.4-1 and 3.4-2 indicate the highest scores for the kiln-based systems, A-1 and A-7. In these two cases alone, the implementability ratings for the thermal subsystems are higher than those for the total system, indicating that the kilns themselves are appraised as posing less difficulty than the related air pollution control and vitrification subsystems. All other thermal subsystems have implementability scores that are lower than those for the corresponding total system. The Joule-heated vitrifier (J-1), patterned after glass melter technology, was assigned the next highest score after the kiln-based systems. The lowest subsystem scores were assigned to plasma gasification and molten salt oxidation, followed by mediated electrochemical oxidation and supercritical water oxidation. Implementability was downgraded for a variety of process-related reasons that are documented in the assumption listings in Appendix E, which are organized by system and subsystem. Some of the principal reasons for downgrading thermal technologies were 1) an early stage of development, 2) high sorting requirements, 3) sensitivity to feed variations or system upsets (e.g., the potential for excess offgasing), 4) containment problems complicated in some cases by high pressure, 5) problems with seals for preventing leakage, 6) excessively high temperatures of $3000^{\circ} \mathrm{F}$ and higher, 7) limited lifetime for components such as plasma torches and refractory linings, 8) the effect of reducing conditions on construction materials and on the thermal volatility of nuclides, 9) complex flowsheets such as those involved in offgas recycling after $\mathrm{CO}_{2}$ retention or salt separation and recycling, and 10) conditions such as unburned carbon after primary thermal treatment that could adversely affect downstream vitrification.

Rating for Flexibility. The ratings on flexibility to treat a variety of input waste shown in Figure 3.4-4 and Tables 3.4-1 and 3.4-2 indicate low scores for the molten salt oxidation system (F-1) and the steam gasification system $(\mathrm{H}-\mathrm{l})$ because of the inability to treat wastes containing appreciable inorganic content and the consequent requirement for a high degree of sorting. 


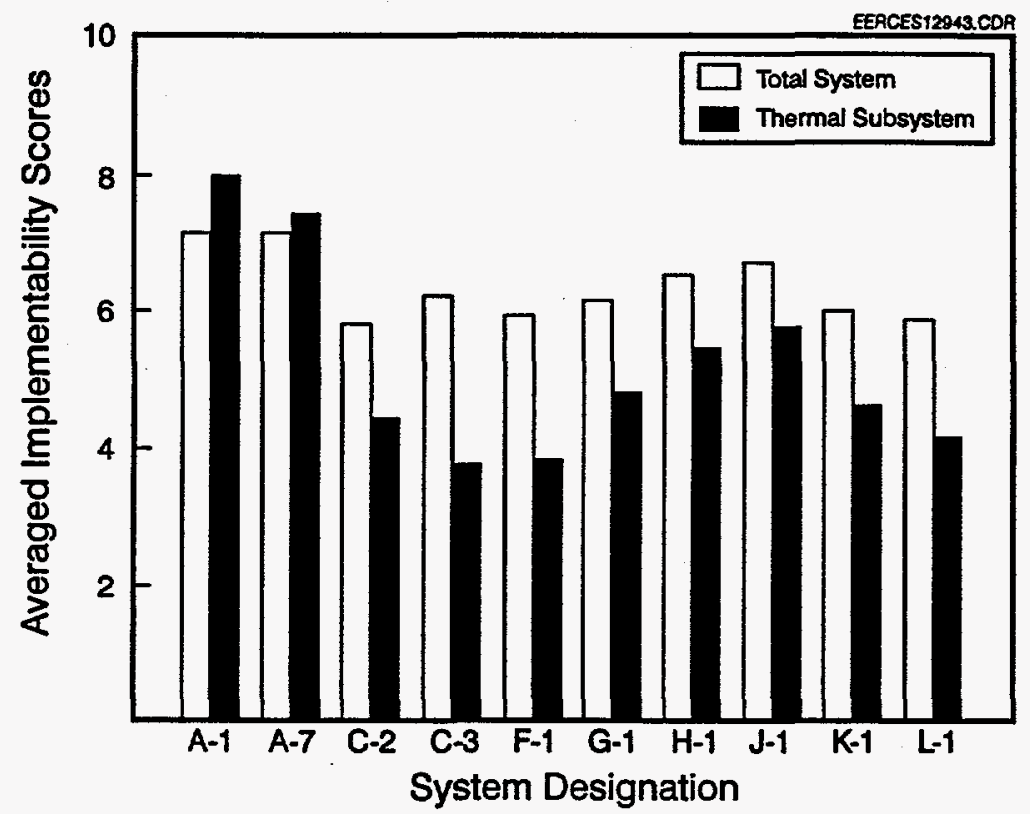

Figure 3.4-3. Comparison of implementability for Phase 2 systems and thermal subsystems.

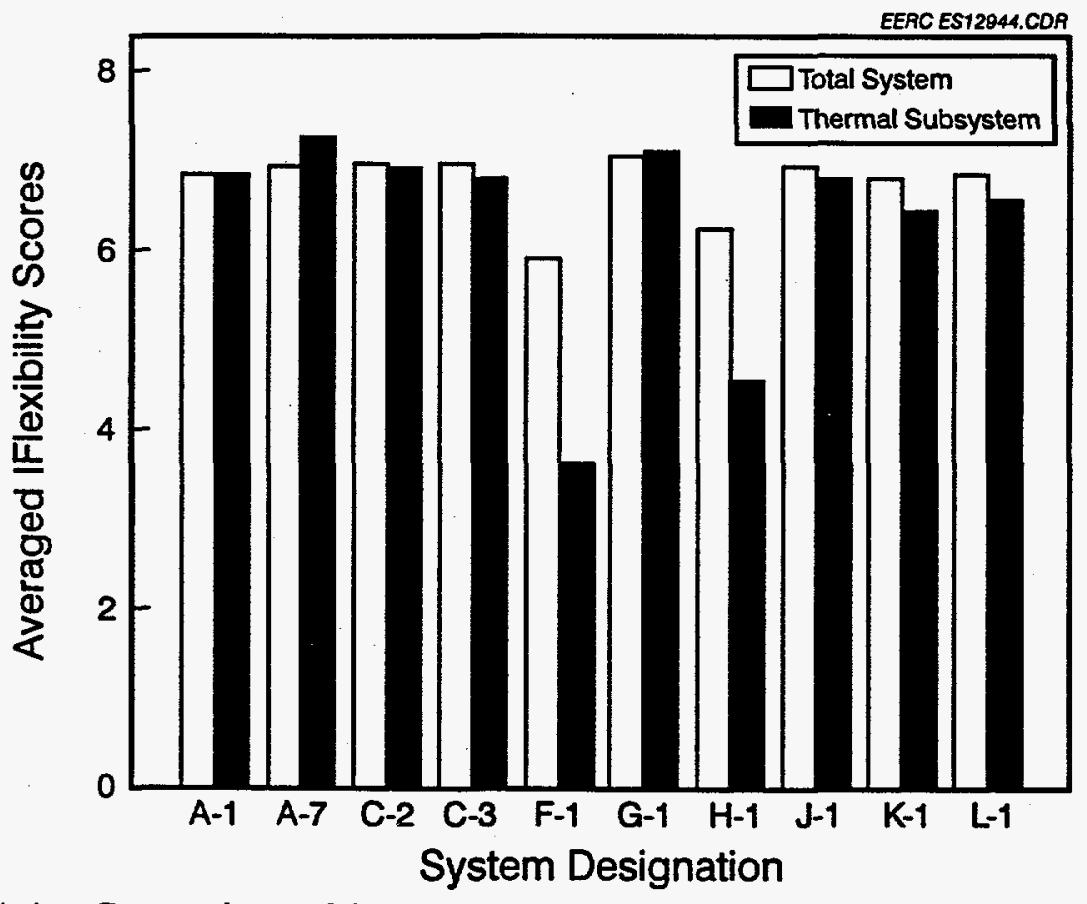

Figure 3.4-4. Comparison of flexibility for Phase 2 systems and thermal subsystems. 
Operability, Maintainability, and Availability. The ratings on these three criteria shown in Figures 3.4-5 through 3.4-7 tend to parallel each other for most of the systems, except that the appraised differences are smaller in the case of availability. Again, the differences among the systems as a whole are small, but they are amplified for the thermal subsystems alone. Many of the reasons given above for downgrading implementability apply also to the criteria discussed here. Operability was particularly downgraded for component and materials problems and complexity, applying most prominently to systems involving plasma gasification (C-3), molten salt oxidation (F1), and supercritical water extraction (L-1), and to a slightly lesser degree to the plasma furnace with $\mathrm{CO}_{2}$ retention (C-2) and molten metal waste destruction (G-1). Maintainability was downgraded for similar reasons, with the supercritical water extraction system (L-1) receiving the lowest score because of the difficulty of maintaining seals at high pressures. The lowest score for availability was given to the plasma furnace with $\mathrm{CO}_{2}$ retention $(\mathrm{C}-2)$ because of the appraised difficulties involved in the combination of the plasma hearth and the gas recycle system.

Ratings for Decommissioning and Decontamination. The ratings for this criterion were perhaps the most difficult to judge based on general engineering experience. The scores shown in Figure 3.4-8 are similar for most of the systems and their corresponding thermal subsystems. The systems given the highest scores were the two thermal desorption systems, K-1 and L-1, that did not involve vitrification in either the primary thermal subsystem or in a separate vitrifier, and which therefore did not involve adherent slag residues. The vitrification system given the highest score was the Joule-heated melter because of its relative simplicity, involving fewer processing units.

Weighted Performance Scores. The weighted performance scores (WPS) shown in Figure 3.4-9 were calculated for each of the systems and for their respective thermal subsystems (WPTSS) using the weighting factors shown in Table 3.4-1. It should be noted that the weighting considered only the seven performance criteria and not the two cost criteria. The highest weighting factor among the seven criteria considered was given to regulatory compliance, which was $25 \%$. Implementability, flexibility, and operability were each weighted at $15 \%$; and maintainability, availability and decommissioning/decontamination were each weighted at $10 \%$. Combining the criteria, even with weighting, served to average out some of the differences among systems. As in the case of the implementability criteria, the two kiln-based systems rank highest, and for these two alone, the thermal subsystem scores are higher than those for the total system. The ranking of systems suggested by the weighted scores will be discussed below in relation to life-cycle cost.

Weighted Comparison Factors Based on Cost and Performance. Table 3.4-1 presents the normalized planned life-cycle costs (NPLCC) determined in the Phase 2 study report and ratios these relative costs to the weighted scores for system performance, represented by WPS. The additional column titled NCU/P adjusts the ratioed costs upward to take into account the cost uncertainty scores, using the calculation footnoted in the table. The cost increment added to each system for uncertainty was $20 \%$ of its NPLCC times the score for cost uncertainty, normalized to account for the criteria scale of 10 . The $20 \%$ of PLCC is an estimate of the added cost of retrofitting a different primary thermal treatment subsystem if the first design fails, taking into account allowances for additional studies, demonstration, construction, and operation in reference to Table 4-1 in the Phase 2 report, or alternatively taking into account the ripple effect of having to modify other subsystems in reference to Table 4-2 in the Phase 2 report. The $20 \%$ is a crude value and can be fine-tuned later, but it is the methodology that is important here, not the specific number. 


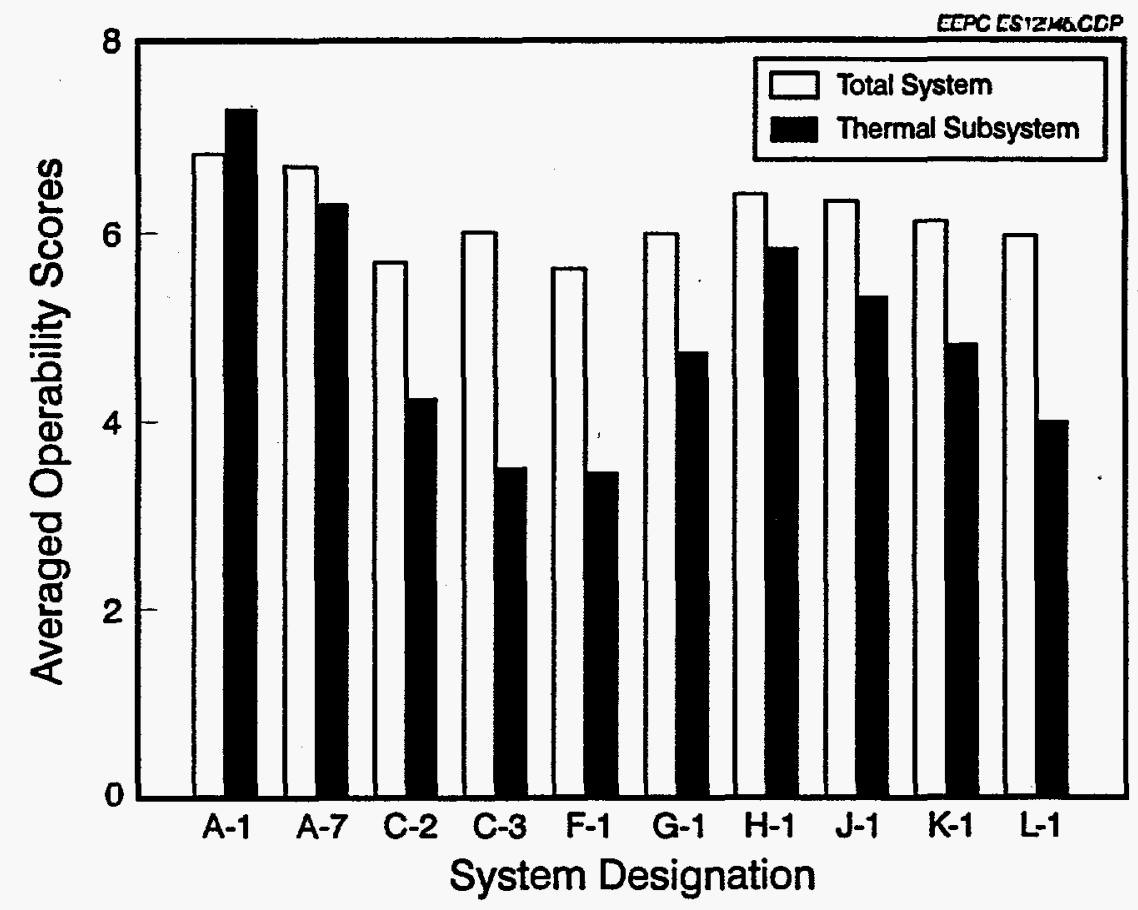

Figure 3.4-5. Comparison of operability for Phase 2 systems and thermal subsystems.

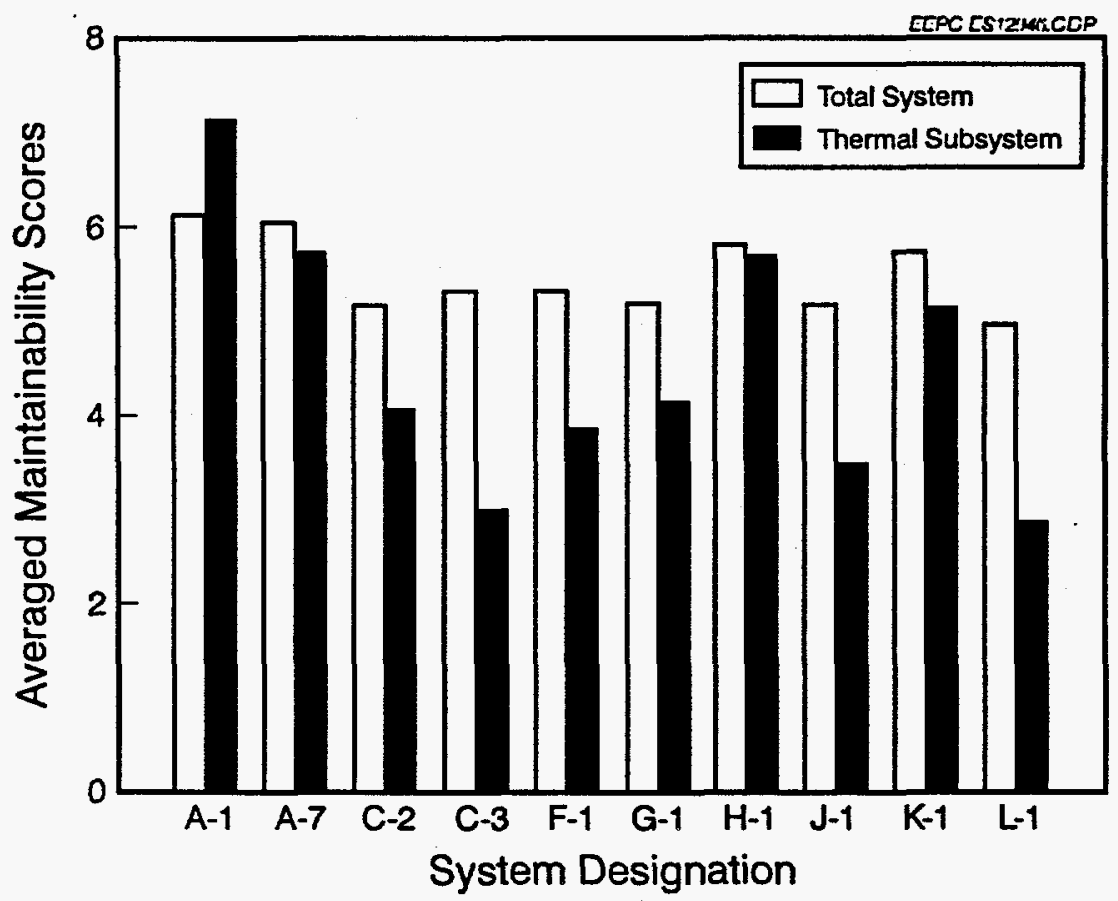

Figure 3.4-6. Comparison of maintainability for Phase 2 systems and thermal subsystems. 


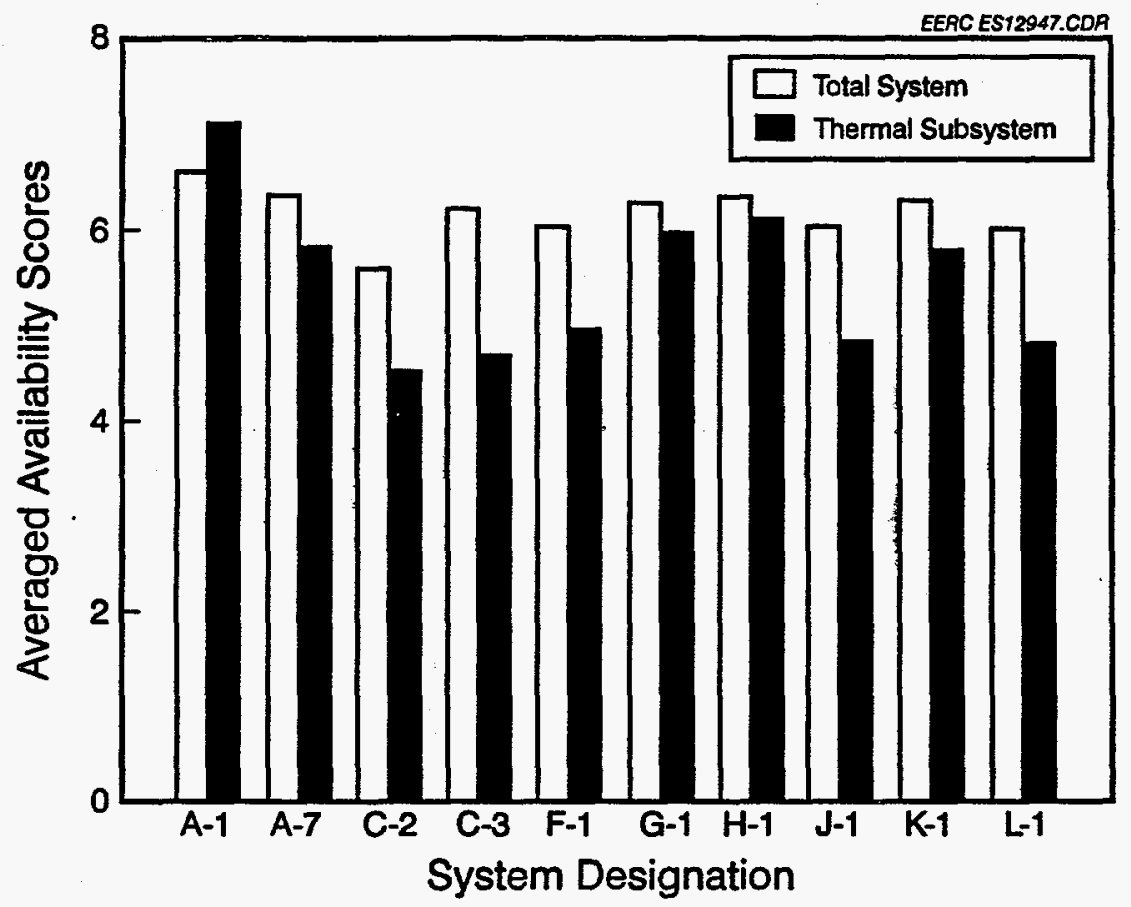

Figure 3.4-7. Comparison of availability for Phase 2 systems and thermal subsystems.

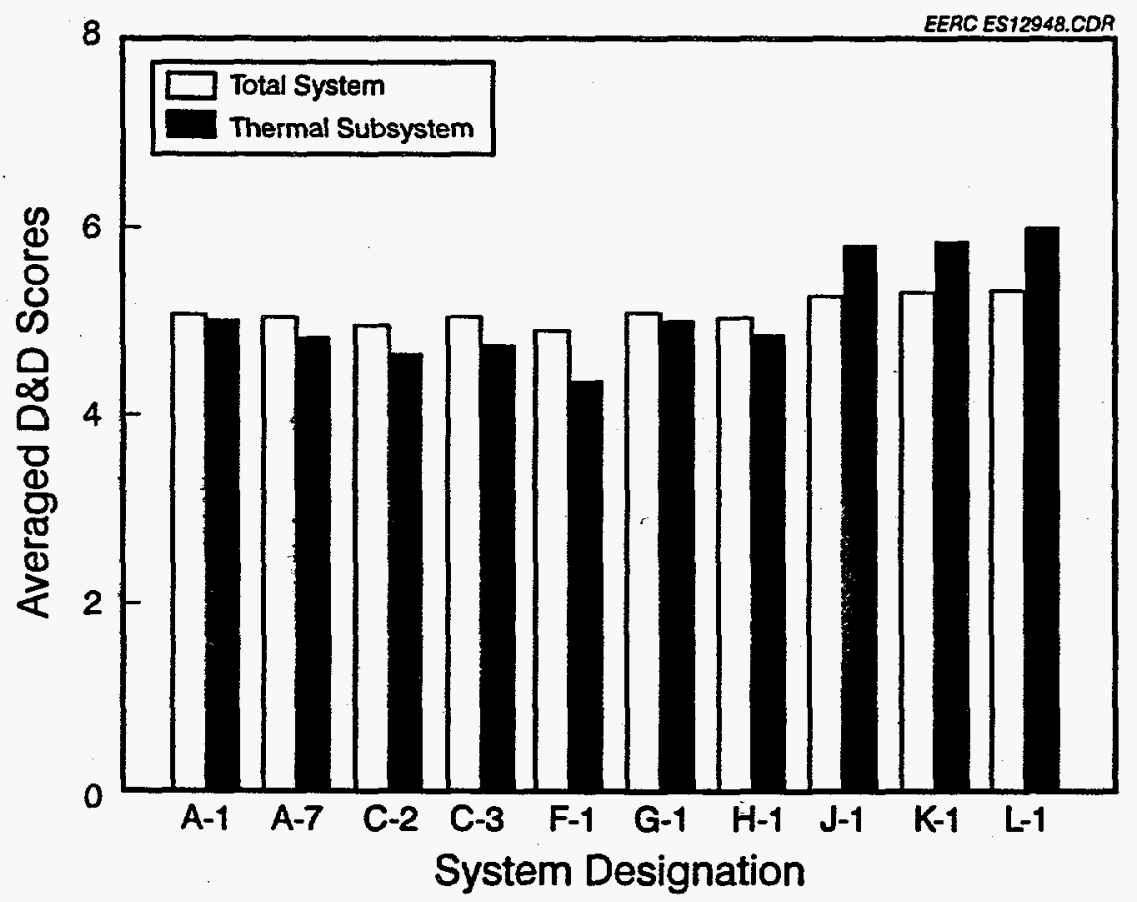

Figure 3.4-8. Comparison of ease of decontamination and decommissioning for Phase 2 systems and thermal subsystems. 


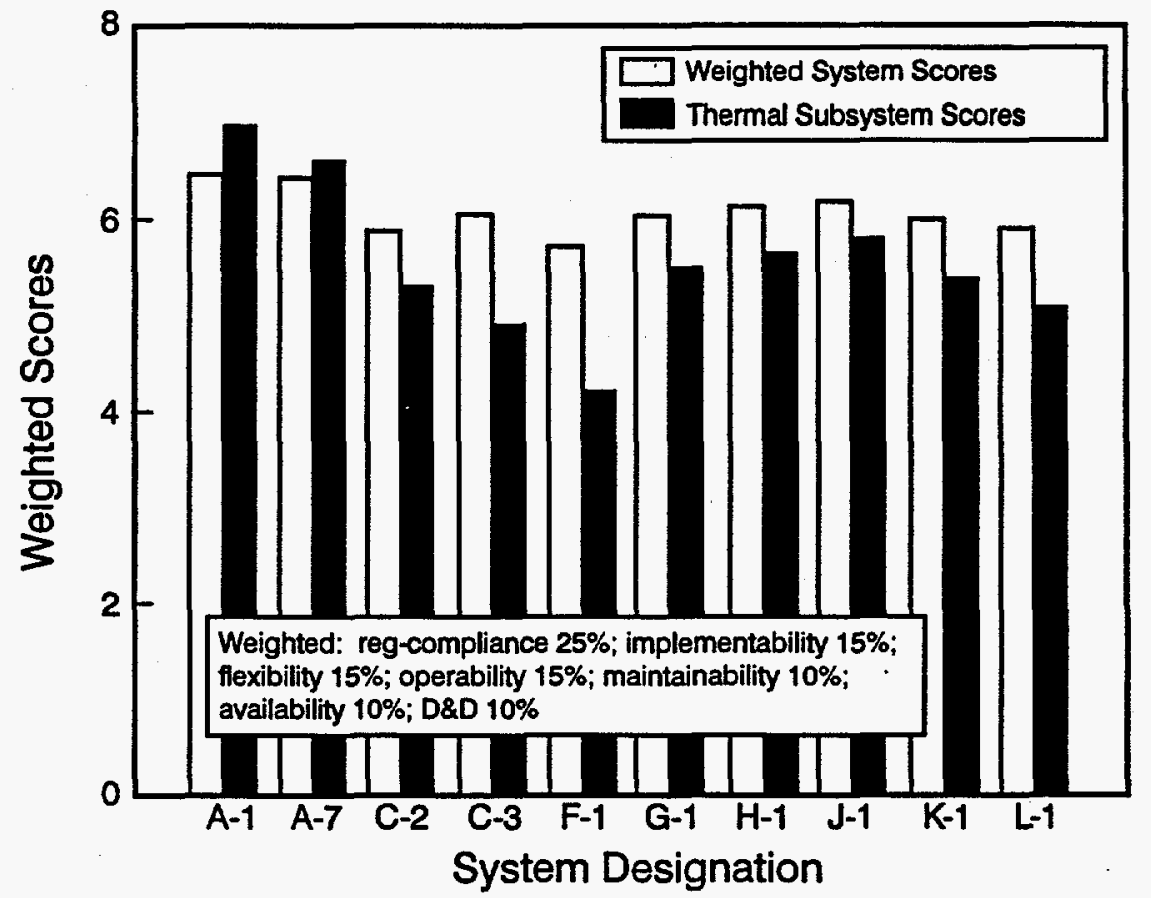

Figure 3.4-9. Comparison of weighted performance scores for Phase 2 systems and thermal subsystems.

Ranking Based on Performance Ratings and Cost. The primary purpose of this review is not to rank the systems under study. However, for sake of illustration and perhaps to shed some light on the merit of the systems, the following observations are offered:

- First of all, certain critical regulatory or design assumptions need to be considered individually, since their effect will be lost in averaging and combining scores across subsystems and criteria. For example, if the capture of volatile nuclides and mercury from high-temperature thermal systems cannot be adequately resolved, then most of the Phase 2 systems would be eliminated, with the possible exception of steam gasification ( $\mathrm{H}-1)$ and the two thermal desorption systems (K-1 and $\mathrm{L}-1$ ), which operate at lower temperatures. Or, if grouting proved to be environmentally inadequate, then K-1 and L-1 would be the systems eliminated. Similarly, if the problems of implementing some of the more complex or intensive systems proved unresolvable at reasonable time and cost, then systems such as $\mathrm{CO}_{2}$ with gas recycle (C-2), molten salt oxidation with salt recycle (F-1), or high-pressure supercritical water oxidation (L-1) might be ruled out. The comparisons that follow take account of these individual critical criteria only by assigning them low scores that bring the weighted score down marginally.

- Ranking based on averaged and weighted performance scores is useful where it can be assumed that all systems will meet minimum criteria and the question is only which is better, assuming similar cost. In order to focus on important differences, it appears preferable to compare systems based on the weighted performance of their thermal subsystems alone (WPTSS in Table 3.4-1 and Figure 3.4-9), which avoids averaging 
across less critical subsystems. This is warranted by the indication that the thermal subsystems scored lower (more critical) than the corresponding total system in all cases except the kiln-based systems. The three thermal subsystems with the highest weighted performance scores are the kiln systems A-1 and A-2 followed by the Joule-heated vitrifier $\mathrm{J}-1$. The three thermal subsystems with the lowest ranking are molten salt oxidation (F-1), the plasma furnace with $\mathrm{CO}_{2}$ retention (C-2), and supercritical water oxidation (L-1), which are the systems that were downgraded for complexity and high pressure.

- Ranking would normally be performed on the basis of both performance and cost, which is sometimes accomplished by ratioing. The ratios of normalized cost to performance in Table 3.4-1 identify the same rankings either with or without the added uncertainty factor, which indicates only that the appraised cost uncertainties for the different systems when averaged across all applicable assumptions were too similar to make a difference. By plotting the data, it is possible to visualize three rank groupings of cost versus performance (Figure 3.4-10). In the low-cost grouping, between 0.85 and 0.9 NPLCC, the preferred systems based on performance are the slagging rotary kiln (A-7) and the Joule-heated vitrifier $(\mathrm{J}-1)$, which also score among the top three on performance alone.

In the intermediate grouping, between 0.95 and 1.0 , the baseline rotary kiln (A-1) ranks highest, as it did on performance alone. In the high-cost grouping, above 1.15, the thermal desorption systems $\mathrm{L}-1$ and $\mathrm{K}-1$ received lower performance scores that would not warrant their higher cost.

Reproducibility of Method. The Kepner-Tregoe method as applied in this review has been shown to facilitate the quantitative evaluation of a large body of qualitative technical information on competing systems and to allow objective comparisons to be made that could not otherwise easily

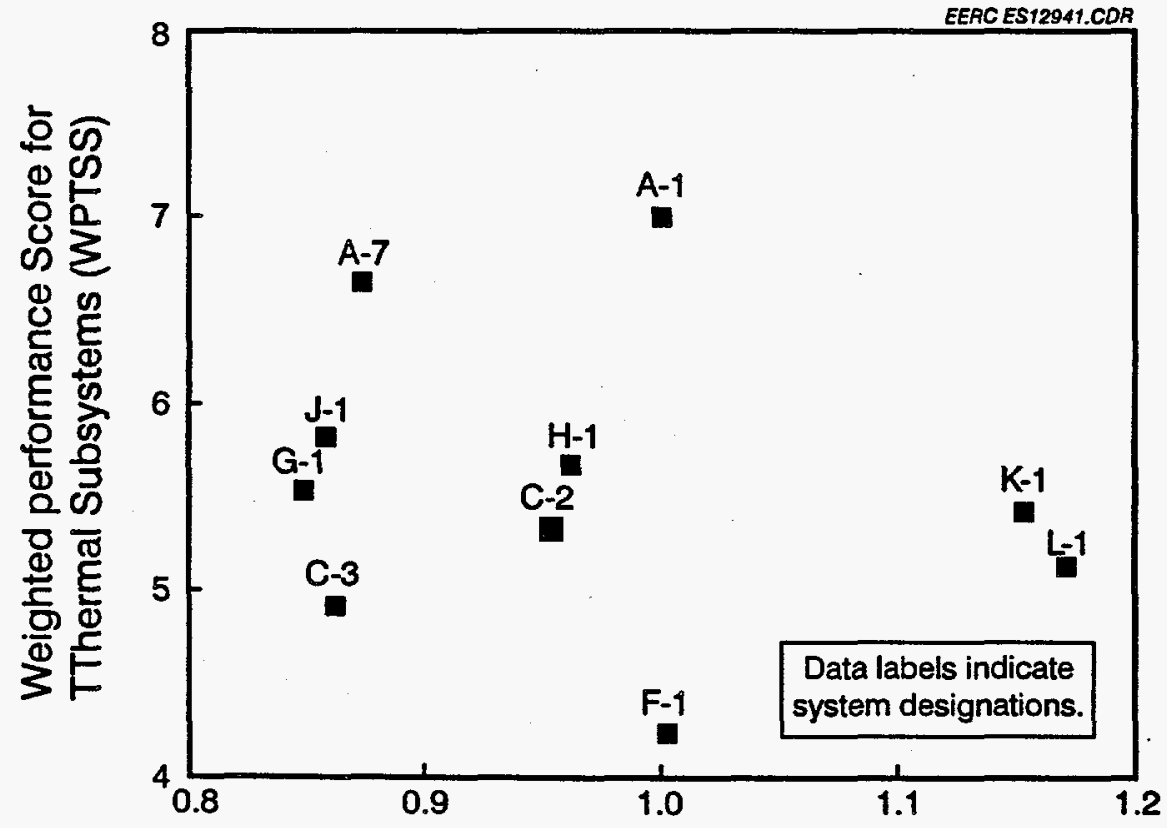

Normalized Planned Life-Cycle Cost (NPLCC), System A-1 Equals 1

Figure 3.4-10. Ranking of cost and performance for Phase 2 thermal subsystems. 
be accomplished. The review does not address the important question of the reproducibility of the method, since only one reviewer assigned ratings to the Phase 2 assumptions considered. However, it is at least encouraging that the results expressed in the ranking are easily understandable in terms of certain broad considerations, including in particular the stage of technology development, concerns over regulatory compliance, and implementability in reference to the complexity and intensity of the system. The engineer who was engaged in this rating effort is of the opinion that generally similar results would be obtained by any technically competent reviewer using the method, provided that generally similar premises were used. The premises used in the current review strongly favored advanced development over early development and simplicity over complexity and downgraded significantly for risk of regulatory noncompliance. The complete record of the review is available to permit tracing of all ratings in reference to the study reports.

\subsection{CONCLUSIONS AND RECOMMENDATIONS}

The conclusions of this review are as follows:

- The authors of the LITCO studies have identified and evaluated a wealth of pertinent information on EM cleanup technologies.

- These studies represent a major step forward in the use of a systems approach to evaluating technologies for use in the remediation of waste sites.

- Although the systems analysis in the LITCO studies was done thoroughly (i.e., the evaluation of alternative systems), the systems engineering in the studies was not complete (but it did improve by the last report [INTS]).

- The PLCC estimates were calculated in the appropriate level of detail using a sound engineering approach. The only exception is that the time value of money (i.e., the use of an interest rate to discount future cash flows to their equivalent present value) should have been taken into account.

- The cost-estimating factors used under the GOCO assumption and other very conservative design assumptions (e.g., 4032 operating hours/year) resulted in PLCC estimates that were about one-third higher than in industrial practice.

- No assumptions were found that favored one technology over another. On the contrary, the PLCCs for all the thermal systems were within the accuracy of the PLCC estimates.

- A consistent approach among the studies would have enhanced their comparability.

The recommendations of this review are as follows:

- Future such studies should adopt a consistent SE approach similar to the template defined in this report. DOE would be well served to develop a Systems Engineering Standard, 
similar to those already in use by $\mathrm{DOD}^{3}$ and IEEE, ${ }^{4}$ which would serve as the guideline for any future SE studies.

- Noneconomic factors must be considered in a quantitative manner to gain full value from the analysis of system alternatives, especially those involving developing technologies that are being considered in competition for scarce funding. An approach like that outlined by example in this report should be required for all such systems analysis studies.

- Absolute system costs defined in the three studies should be seriously reexamined, with special emphasis on the reasonableness of the major cost sensitivities identified in this report.

- A number of design assumptions warrant further study: 1) one facility to process all MLLW, 2) a feed of "average" waste composition, and 3) the segregation of thermal and nonthermal technologies.

${ }^{3}$ DOD-AMSC. Draft Military Standard for Systems Engineering; Mil-std-499B, Version 2.0, May 1992.

${ }^{4}$ IEEE. IEEE Trial-Use Standard for Application and Management of the SE Process; IEEEstd, 1220-1994, 1995. 


\section{APPENDIX A}

\section{EXPANDED DISCUSSION OF SYSTEMS ENGINEERING APPROACH}




\section{EXPANDED DISCUSSION OF SYSTEMS ENGINEERING APPROACH}

Systems engineering (SE) is the powerful technical tool for program managers. SE must be applied properly and fashioned for the specific application.

The process of SE provides a framework for application and involves three steps:

- Planning for SE

- Implementing the SE process

- Controlling the SE effort

\section{Planning Systems Engineering}

In the concept exploration and definition phase, a large amount of trade-off study effort is required. This effort supports the translation of operational needs to technical system alternatives. The output of this phase is broad, high-level specifications defining system alternatives. As the program progresses through development and into the full-scale production and deployment phase, SE requirements remain. However, the scope of the effort changes significantly. At this time, a firm baseline should have been defined, and production or construction specifications should exist. $\mathrm{SE}$ is more a maintenance effort at this point and entails the development of system modifications as processes, procedures, or capabilities are revised. SE still performs the task of monitoring and managing systems integration activities. As system problems arise, SE is needed to perform tradeoff analysis and determine solutions.

A system engineering management plan (SEMP) is used to define the organization that will perform SE on the program. The SEMP should be prepared as early as practicable in the life cycle (normally during concept exploration and definition). As the program progresses through its life cycle, the SEMP should be updated to reflect tailoring of the SE effort. The SEMP has three basic sections, which should define the following:

- The methodology established for technical program planning and control.

- The detailed SE process to be utilized and the tailoring to be applied.

- The integration and coordination of engineering specialty efforts to achieve a best mix of technical and performance values.

The SEMP can either be a stand-alone document or it can be abbreviated. An abbreviated SEMP would incorporate, by reference, other plans (such as the reliability plan, interface agreements, logistics support plan, and program management documentation). These plans should collectively address all the necessary SE requirements. The goal is to minimize formal documentation while maximizing the benefits achieved from the SE process. 


\section{Implementing Systems Engineering}

The benefits of SE are realized through effective implementation. SE is a logical and iterative process that takes input requirements and functional analyses and then allocates them functionally. These functions are then traded off as alternative solution sets are developed. This process of synthesis results in candidate solutions that can be evaluated for adequacy. A decision is made on the recommended solution(s). This is documented and becomes the input on the next cycle of the SE effort.

A critical element of the SE process is the ability to feed back results of the process to refine input information. This provides a means of verifying and validating input requirements as the results of trade-off studies become available. Cost drivers are identified early so that they can be evaluated against operational benefits. This continuous review process should help identify problem areas before they become embedded and cause significant cost, schedule, or performance impacts.

In the concept exploration and definition phase, input requirements are in the form of highlevel operational needs. The SE process must translate these requirements into the conceptual functions that must be performed to satisfy the need. This translation is called functional analysis.

Functional analysis is a top-down process. Global requirements are broken down into ever smaller and more quantifiable functions. These functions represent a set of capabilities which, when properly combined, will satisfy user need. Once the functional analysis is completed, the process of synthesizing an alternative can begin.

Various combinations of functional elements are traded off against the requirements. These trade-off studies examine the allocation of responsibility and resources to the various functions. The results of this trade-off and allocation effort are sets of potential system solutions. These synthesized alternatives are then evaluated against quantifiable measures of effectiveness. The evaluation is used to weigh the various alternative approaches, which can then be selected for further definition. Efforts during the SE process are documented in trade-off studies and evaluations. System specifications are developed for the best alternatives. They become input data to the next life-cycle phase.

Work breakdown structures are a product of the functional analysis and allocation process. As the global requirements are broken down into smaller functions, definable work packets are identified and incorporated into the managerial work breakdown structure.

As a program goes through the remaining phases of the life cycle, the SE process described above is repeated. More and more refined outputs are provided as the system becomes better understood and defined. It is essential that progress toward detail be uniform.

During the demonstration and validation phase, the system specifications of alternative concepts are functionally analyzed. This results in more detailed subfunctions for trade-off analysis. The synthesis process yields engineering models that can be evaluated against the original requirements. Evaluation allows for the selection of a preferred technical approach. Finalized 
system specifications and subsystem performance specifications are developed for input to the next phase.

The development phase uses finalized system specification as inputs. Functional analysis is the process that translates these subsystem performance requirements into detailed product functions. Detailed system synthesis and design trade-off studies are performed. Various detailed designs are integrated and interfaced into a system prototype that can then be evaluated. Based on the prototype's success during evaluation, a decision can then be made to produce the final design. As a result of this SE effort, detailed system, subsystem, and product specifications, along with drawing packages and other engineering data required for production or construction, are developed.

As the construction and deployment phase begins, the SE process is used once again. Input data are functionally analyzed and synthesized to develop a set of production processes and work sheets, which provide producible end products. A configuration audit process is used to verify the suitability of this documentation.

The SE process (functional analysis, synthesis, evaluation, and decision) is applicable across all phases of the life cycle. The degree of focus and level of documentation detail will change, but the basic process remains. The SE process logically breaks the work task into definable and manageable subelements. It integrates and interfaces the design and build efforts of these subelements so that a total capability is provided in response to the original user requirements.

\section{Controlling Systems Engineering}

Depending on the phase of the life cycle, the SE effort can represent a significant portion of the overall cost.

Various tools are available to assist in controlling the SE process. These include the following:

- Systems engineering management plan - The SEMP provides a plan for establishing a SE effort. It defines the actual methods and procedures to be followed in the SE process. It also defines the control structure to ensure total system integration.

- Formal reviews - During the development phases of the life cycle, a series of reviews should be conducted. These reviews (systems requirements review, system design review, preliminary design specification, and critical design review) provide an opportunity to assess the state of the technical effort; review in detail the system functional analysis and synthesis process; determine the adequacy of the resultant alternatives in satisfying the requirements; and provide a vehicle for making and documenting program decisions.

- Informal technical reviews - Formal reviews present an opportunity for reviewing a project's technical status. However, they occur infrequently and will not provide the degree of interchange necessary to ensure that the SE process is adequate. They provide a 
snapshot in time, but do not provide real-time status information. Periodic and informal technical reviews can fill the need for real-time situation monitoring.

- Technical performance measurements - These represent a set of key parameters, which are monitored as the program progresses through the development cycle. These quantitative measures can be tracked against program goals and provide a way to assess overall technical status. They provide data for problem analysis and corrective action and act as early warning indicators.

- Management control systems - As the SE process progresses, one output is increasingly detailed work breakdowns. These work packets are the entities upon which cost and schedule status information is collected. Through management review, they provide visibility into the program's problem areas. These problem areas then become candidates for informal review and for development of alternative action plans.

\section{Systems Engineering Outputs} below.

Output benefits from a successful SE process may be expected. Some of these are listed

- Ensures fully integrated engineering effort throughout the entire system life cycle.

- Conducts system definition and design on a total-system basis to achieve required effectiveness within cost, schedule, performance, and risk limits.

- Establishes system requirements that meet user needs and priorities.

- Totally integrates all system and subsystem design and related requirements.

- Establishes effective interfaces within and between the system for maximum compatibility and interoperability.

- Establishes, integrates, and maintains an effective work breakdown structure throughout the system's life cycle.

- Evaluates, documents, and tracks system changes and technical decisions that affect the overall performance, schedule, effectiveness, logistics, and system life-cycle cost.

- Provides a framework of system requirements to be used as design, performance, support, and test criteria and provides source data for contract work statements, specifications, test plans, design drawings, and other engineering documentation.

- Identifies high-risk and problem areas early in development and throughout the system's life cycle, continuously evaluating the system design and other support areas. 
APPENDIX B

\section{UTILIZATION OF THE SYSTEMS ENGINEERING TEMPLATE IN REVIEW OF THE TECHNICAL APPROACH OF THE ITTS AND INTS REPORTS}




\section{UTILIZATION OF THE SYSTEMS ENGINEERING TEMPLATE IN REVIEW OF THE TECHNICAL APPROACH OF THE ITTS AND INTS REPORTS}

As part of the effort to evaluate the technical approach of the LITCO studies, a systems engineering (SE) template was developed to guide the review of the studies. The resulting template was meant to prompt critical questions about the design process utilized in the LITCO studies and to enable a fair evaluation of those studies. This appendix contains that template as well as questions and points considered in the evaluation of the studies.

The essence of this template and evaluation effort is the eight-block morphology presented in Figure B-1. Each block in this morphology is further specified on subsequent pages along with questions and points to be addressed.

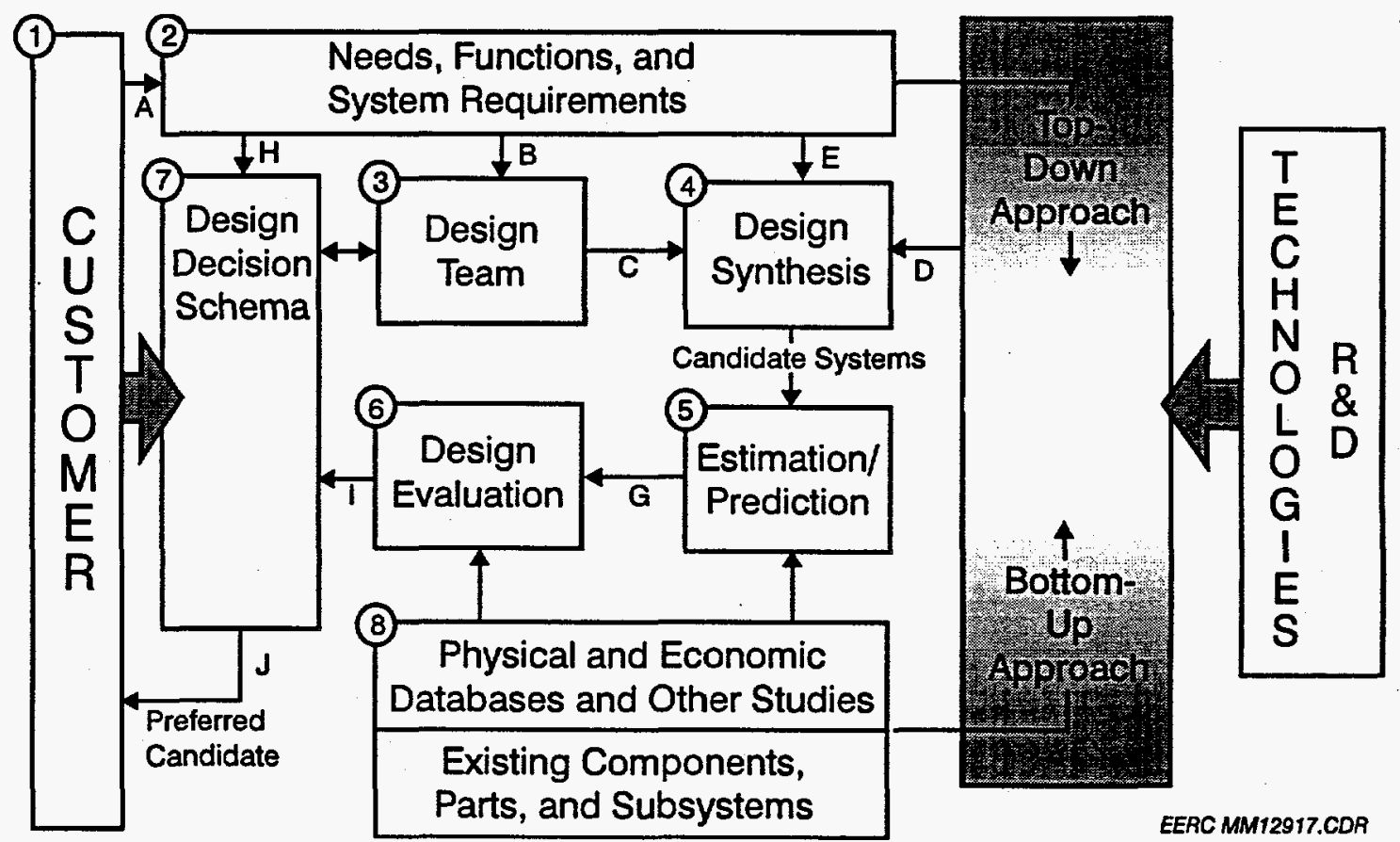

Figure B-1. Systems engineering template displaying the eight elements for evaluating a technical approach.

\section{BLOCK 1 - THE CUSTOMER}

\section{About This Block}

The purpose of any system design is to satisfy some customer and stakeholder need. The success of a particular system design is ultimately determined subjectively by the customer. During the design process, all requirements and decisions should be made from the customer's perspective. Even when the customer is relatively easy to identify, the concerns of "the customer" may not be readily accessible. Accordingly, the customer must be defined as an all-inclusive entity. 
Stakeholders and special interests must be represented in "the voice of the customer" in a way that reflects their needs and concerns.

\section{Questions and Points to Consider}

Who is the customer?

- Is the customer the U.S. Department of Energy (DOE), society as a whole, Native American tribes, engineering companies, etc., or some mixture thereof?

- Is the customer fully aware and educated as to the need for this treatment system?

- Where is this definition of the customer spelled out in the LITCO studies?

- Are customer interests generally in agreement or in opposition to each other?

- If the stakeholders and tribal interests are generally opposed to certain treatments and storage ideas, is this stated?

How is the "voice of the customer" captured?

- Can the customer make effective decisions and give valuable input based on the information available?

- Do the LITCO studies address this concern? How?

- How are the differing opinions of various interests resolved fairly in the LITCO studies?

- Are all identified interests being represented in the "voice of the customer"?

- What method is used to ensure this in the LITCO studies?

- To what extent are the LITCO studies responsible for obtaining and using information that represents the voice of the customer?

- What forum is used to capture this voice (surveys, polls, meetings, interviews, studies, etc.)?

\section{To what extent is the customer involved in decision-making?}

- Is the customer directly or indirectly involved in the decision-making process?

- Or, will only certain interests be active in decision-making, with the remaining interests acting as reviewers?

- Who defines this relationship (DOE, , etc.)? 
- Do the LITCO studies make this clear?

- What is the purpose of these studies? If the purpose is to eventually facilitate a decision about a preferred alternative system design, then do the studies consider their audience?

- That is, do the LITCO studies take into consideration the definition of the customer, i.e., who they are trying to satisfy when presenting the alternative systems?

- In which decisions does the customer participate (decisions at each major milestone, each design change, or when large costs are involved)?

- What weight is given to each interest?

- Is this weighting schema relatively more numerical or more subjective in nature?

- Who determines these weights (formally or informally)?

- Is this relationship between DOE, LITCO, Tribal Stakeholders Working Group (TSWG), etc., clearly defined?

Are the study decisions traceable to the customer?

- To what extent are the alternative designs and decisions traceable to the customer in the studies?

- Do the LITCO reports provide sufficient traceability to the customer?

- If the "customer" definition is not fully understood at the design level, what criteria are used to synthesize candidate systems in the studies?

\section{Evaluation of the LITCO Studies}

The integrated thermal treatment system (ITTS) and integrated nonthermal treatment system (INTS) studies inadequately consider the customer in the synthesis, analysis, and evaluation of the treatment technologies. In the ITTS studies, only incidental mention is made of stakeholder and customer considerations with regard to evaluation of alternative technologies. There is not adequate traceability in the design synthesis to say what motivated the particular synthesis based on needs of the customer.

The INTS study does a much better job of representing the customer interests than the ITTS Studies (Phases 1 and 2). The INTS study tries to document the input and concerns of the customer into the design synthesis portion of the report, but falls short. The INTS TSWG, which for the first time represented various tribal and nontribal interests, appeared to be a useful forum for DOE and tribal/stakeholder interaction. The INTS study report appeared to be somewhat more readable and understandable by the nontechnical reader. 


\section{BLOCK 2 - NEED, FUNCTIONS, AND SYSTEM REQUIREMENTS}

\section{About This Block}

The Systems Engineering (SE) approach stems from the identification of a need that develops as a result of a problem or deficiency and the subsequent desire for a system of some type. From the identification of a given need, one must define the basic requirements for the system in terms of input criteria for design. The need and requirements for operation should be clearly defined before problem solutions or system configurations are proposed. Definition of system requirements should include mission definition, performance and physical parameters, use requirements, deployment and dištribution of the system, operational life cycle (horizon), effectiveness factors, and definition of the operational environment. Additionally, any definition of system operational requirements should originate with the defined customer requirements. Arrow A illustrates the customer inputs to the need definition and requirements specification process. The "voice of the customer" should be the basis for all system requirements. Poorly defined customer requirements or an unclear identification of the customer can lead to a system that either does not satisfy the need or contains superfluous requirements. The definition of the system at this point is purely from a functional viewpoint. The objective is to capture what the system's overall mission is in a functional sense. At this point, designers should avoid overly constraining the design and should also resist the temptation to jump to the physical manifestation of these requirements.

\section{Questions and Points to Consider}

\section{What are the customer requirements?}

- Are all requirements from the customer point of view defined?

- Is the functional nature of the system specified in the LITCO studies?

- Are all the requirements related to the functional objective of the system?

- Each requirement must be related functionally to the mission objective. Which requirements are superfluous?

- Does the LITCO study relate these customer requirements in a functional sense?

- How well does the LITCO study address these requirements?

- Does the LITCO present these requirements so as to emphasize the main requirements and those that the design will be most driven by?

- How are these requirements obtained?

- Is an acceptable method used to extract these requirements from the customer and ensure the completeness of the set of requirements? 
- Do the LITCO studies analyze the requirements to determine whether they were appropriate and functionally correct?

- Do the LITCO studies point out any inconsistencies or problems with the customer requirements?

- Are the needs/desires of the tribes, general public, contractors, DOE, etc., fully represented in qualitative or quantitative terms?

- How are these incorporated into the given requirements in the studies?

\section{How are customer requirements translated into system requirements?}

- Do the studies show how the system meets customer requirements from an operational and functional perspective?

- Do the LITCO studies present a set of derived system requirements taken from, or translated from, the customer requirements?

- Do the studies contain a functional analysis of the system requirements?

- Are functional flow diagrams of the system generated and presented in the studies?

- Are system requirements traceable to the original customer requirements?

- Are performance parameters/requirements such as volume of waste treated per day, system environmental impact, safety, effectiveness of treatment, etc., adequately defined and quantifiable measures determined?

- Are the operational environment requirements well defined?

- Are these operational environment requirements sufficient or are there other questions that need to be answered?

- Are these operational environment requirements just assumptions or are they actual requirements?

- If they are not given as requirements, do the LITCO studies pursue various operating environment candidates along with the candidate systems developed?

Do the requirements reflect a systems and life-cycle engineering point of view?

- Do the requirements consider a time frame for design and development to allow for new, emerging technology refinement?

-What is the time frame? 
- What life-cycle horizon is used for planning?

- What are the available skill levels for operation, maintenance, support, and disposal?

- What role do maintenance and support factors play in the defined system requirements to the extent that they influence performance of the system?

- Is disposal of the actual system itself considered in the requirements?

- The LITCO studies claim an "integrated system engineering approach." Yet the "systems" they describe contain only prime mission equipment and processes. Where do the studies consider other life-cycle elements?

- Why do the LITCO studies refer to development of operational and functional requirements for each candidate system? All operational and functional requirements for the treatment system should be the same for all candidates. The only way to ensure a fair comparison is by maintaining consistency in requirements.

\section{Evaluation of the LITCO Studies}

Definition of the system from a functional viewpoint is necessary before the physical form is realized. In the technical approach section of each of the three studies, it is stated that "functional and operational requirements . . . were developed for each system." However, the functional need and requirements for the treatment system should not change whether thermal, nonthermal, or some as yet undiscovered option. There should be one set of requirements for the treatment of mixed low-level waste (MLLW), and these requirements should be the same and consistent across all system alternatives. These studies suffer from a lack of adequate requirements and need analyses. A significant portion of any preconceptual or conceptual design process is this analysis activity. These studies show little to no evidence of such activity.

The only evidence of functional analysis in the studies is the selection and definition of subsystems. The subsystems seem to have been separated along functional lines. However, this is simply a list of functions. A true, effective functional analysis would go into depth as to how these functional elements fit together and interact. What are the inputs and outputs? Finally, an appropriate functional analysis leads to an effective allocation of system requirements to functional elements. Only then can meaningful design synthesis occur. There is no evidence or traceability to a functional analysis and subsequent allocation of system requirements.

\section{BLOCK 3 - DESIGN TEAM}

The selection and qualifications of design team members are of utmost importance. It is not enough to have only technological expertise on the design team that relates to the stated need or deficiency represented. A design team that seeks to create a system using systems or life-cycle engineering methodology must have adequate representation from $S E$ as well as chemical engineers, operations engineers, actual users of the system, and others. A design team that is onesided in its makeup will tend to produce candidate systems that are likewise one-sided. That is, the 
design tends to focus too heavily on prime mission equipment and neglect elements such as support, environmental factors, reliability/availability, and disposability. The design team must have representatives for each of the life-cycle elements that are contained in the set of system requirements. A diversity of perspectives on the design team facilitates consideration of all aspects of the system life cycle. Arrow B in Figure B-1 represents a relationship between the set of system requirements and the selection and makeup of the design team.

\section{Questions and Points to Consider}

\section{What are the qualifications and expertise of the design team members?}

- Are the LITCO study design teams appropriately staffed?

- Are all design members qualified for their specific aspect of system design?

- Is the number of team members appropriate?

- Are there too many or too few design members representing a particular aspect of system design on each team?

- Does each of the requirements in the life cycle of the system have a representative on the design team?

- Do the LITCO studies justify and present the makeup of the design team, along with each team member's responsibilities?

- Are all design team members chemical or environmental engineers, or are a variety of system aspects represented?

What method was used to select this design team?

- What are the minimum qualifications and system elements represented on the teams?

- Is the makeup of each of the LITCO design teams consistent?

Are various aspects of the life cycle represented on the design team?

- Do the LITCO design teams include transportation expertise, support expertise, systems engineering expertise, etc.?

Are the motivations/desires of the design team(s) members/contractors consistent with that of the customer?

- Basically, are the concerns of the customer adequately represented on the design teams?

- How the customer represented on the design team? 
- Do the LITCO studies discuss how the customer perceptions and opinions were preserved and used by the design teams?

- Are the design teams one-sided? Are all the members from one discipline?

- Are teams similar in makeup such that meaningful comparison of alternatives can be made between multiple design teams?

- Are the LITCO studies consistent in their design team approaches?

- If not, are the differences known and understood so that the candidate systems from each study can be evaluated fairly against one another?

\section{Evaluation of the LITCO Studies}

Not much information is given regarding the design teams. The design team members and affiliations were listed, although no specific details were provided with regard to areas of expertise, specific areas of responsibility in the study, or criteria for selection to the study team.

Several additional questions arise. The size and composition of the study teams differed, and few design team members were consistent across all teams. Can the design alternatives be compared on an equivalent basis? What or who ensured that the level of effort was the same for the definition, analysis, and subsequent evaluation of all alternatives?

\section{BLOCK 4 - DESIGN SYNTHESIS}

Once a design team and the system operational and functional requirements have been defined, synthesis of various system design alternatives can begin. Depending on the particular phase of system design, design synthesis can consist of technology and system concept identification, in the case of conceptual design, or can be as detailed as compiling various designs for a particular piece of hardware at its most specific level. In any case, the objective is to sufficiently describe a number of feasible design alternatives so that an analysis and subsequent evaluation and decision-making can occur. Design synthesis is a highly subjective and creative process that relies on expert knowledge and state-of-the-art technology identification to synthesize alternative designs. The expert knowledge and experience that is utilized comes from the knowledge and experience of the design team members as represented by Arrow C in Figure B-1. It is important to realize that each design team member has his/her own vision of the end system. It is important that team members realize this and force themselves to question their own preconceived notions about the nature of the system design when proposing candidate systems. The candidate system synthesis is driven by a top-down functional definition of the need as well as a bottom-up definition of the set of available technology and system elements. Arrow D represents the input of the two different (but complementary) approaches to system design. It is important to note that the description of each alternative must include system factors and elements other than just the prime process or equipment. Adequate definition of each system alternative must allow for lifecycle analysis and evaluation to reflect the set of determined system requirements. Arrow E highlights the defining role that the system requirements play in the synthesis of candidate systems. 


\section{Questions and Points to Consider}

\section{How are the various alternatives selected?}

- Are all reasonable alternatives being explored?

- What resources are the design teams using to arrive at each alternative?

- Do the LITCO studies reveal the methods and sources for the selection of the various alternatives?

- Are the alternatives all existing designs or technologies?

- Are new, emerging technologies explored?

- In other words, does the design effort rely too heavily on either the bottom-up or topdown approach?

- Both approaches should be utilized in the design synthesis process. This ensures a mix of new ideas with proven processes.

- Does the statement of work or design team makeup bias or exclude otherwise reasonable design alternatives from consideration?

- Do the LITCO studies document the above?

- Do the design teams sufficiently document the origination of each system alternative?

- Do the LITCO studies give the reasons for including the candidate system for consideration?

Are alternative selection methods based on stated customer and system requirements?

- If any short listing or exclusion of alternatives occurred, is the justification rooted in customer and system requirements?

- Does each of the alternatives fit with the stated requirements?

- Do the LITCO studies give the criteria for selecting candidate systems?

- Are these criteria representative of the entire life cycle?

- Who makes the decision?

- Ultimately, each of the alternatives generated should be traceable to some or all of the requirements stated. 


\section{Are the alternatives defined well enough that meaningful analysis and evaluation can occur?}

- Is the set of alternatives defined well enough that some sort of analysis and evaluation can be made?

- Are the alternatives fully defined from a life-cycle and systems perspective in the studies?

- Do the LITCO studies include sufficient life-cycle information to estimate and predict parameter values and to evaluate life-cycle cost?

- Do they include at least preliminary ideas about how logistical support, operation, training, etc. will be accomplished?

- Can these life-cycle considerations be used as analyses and evaluated against one another?

\section{Are all alternatives comparable?}

- Is each of the alternatives able to be analyzed and evaluated fairly, on an equivalent basis?

- In other words, is each of the alternatives defined consistently the others?

\section{Evaluation of the LITCO Studies}

There is certainly adequate description of each of the alternative systems in the LITCO studies. However, neither the ITTS or INTS studies provide adequate traceability back to system requirements. The design teams relied too heavily on the bottom-up approach to synthesize system alternative designs. There appears to be little, if any, reliance on system requirements to dictate the design synthesis process. The ITTS studies do not document the reasoning behind the selection of each of the technologies. The INTS study provides a discussion of the technology and system selection process; this fulfilled the obligation to the TSWG to provide documentation of the process. However, there is not strong evidence that TSWG principles were used in the downselecting process.

The studies concentrated primarily on technology identification and selection. A true systems approach would have also considered many other factors such as facility configurations, geographic locations and trade-offs, transportation aspects, etc. It is important for the studies to identify and document the design synthesis process from the top-down perspective as well as the bottom-up perspective to ensure that the design alternatives produced can meet system requirements and satisfy the system need.

\section{BLOCK 5 - ESTIMATION AND PREDICTION}

After a set of candidate systems has been synthesized, each alternative must go through a process of estimation and prediction. Cost and effectiveness measures are generated for these alternatives using established criteria. This SE activity's purpose is to estimate and predict design 
dependent parameter (DDP) values for each alternative. Estimation and prediction rely on models and simulations to predict parameter values. These models and simulations are based on assumptions, physical laws, and empirical data. Arrow F in Figure B-1 represents this available database of physical and economic factors, as well as existing components, parts, and subsystems. These parameter values provide a basis for comparison with established design criteria to determine the merit of each alternative. Alternatives that are found to be unacceptable from a performance perspective can be reworked and new alternatives created. Those alternatives that meet all or the most important performance criteria can then be evaluated based on life-cycle costing methodologies.

\section{Questions and Points to Consider}

\section{What are the basic assumptions inherent in each estimation/prediction?}

- Are each alternative's DDP values estimated using a consistent set of assumptions?

- Do these assumptions match the assumptions stated in the requirements in the studies?

- Do the LITCO studies rely too heavily on assumptions? Which ones? This may indicate an area for further investigation.

- Are the models used to estimate values for one alternative consistent with models used on other alternatives?

- Are we sure we are not setting up an apples-to-oranges comparison later in the studies?

- Are the assumptions valid? Are they necessary? What overall impact do they have? Are the estimates derived from these assumptions important enough to cause possible decision reversal (e.g., assuming Seismic Category 1 in the nonthermal study)? If so, more work might be needed.

By what means do we consider an alternative's performance acceptable?

- There must be some minimum standard of performance to adhere to. What constitutes acceptable performance of the treatment system?

- Do the LITCO studies relate the acceptable performance criteria?

- Are any of the candidate systems not picked for consideration explained in the LITCO study?

- When an alternative fails to meet performance criteria, are the deficiencies and areas for improvement identified?

- Do the LITCO studies present this information?

- Are all alternatives held to the same level of performance criteria? 


\section{How are nonquantifiable parameters handled?}

- Is there some means for determining the "goodness" of an alternative design with respect to qualitative measures such as public confidence, ease of use, etc.?

- Are the methods used for determining the "goodness" of these measures acceptable?

- Do the parameters meet with the approval of the customer?

- Where in the LITCO studies are these parameters discussed? How are they to be handled?

- Do the measures represent the view of the customer?

- Since these qualitative measures are subjective, care must be taken to capture the opinions of the customer.

\section{Evaluation of the LITCO Studies}

The studies do a good job of collecting and describing each of the alternative system designs. What is lacking is a definitive set of metrics to measure the merit of each of the systems. Accordingly, the studies do not adequately organize and define the set of metrics that will be used to measure the system's effectiveness. Many characteristic metrics of the system alternatives are presented in the studies. However, the origins of many of the parameter values are not documented in enough detail. It is well understood that at the preconceptual design stage, many of the metrics used will have to rely on expert judgment and experience to assign values, but these need to be documented for future design efforts.

These studies lack consideration for the customer's input into acceptability measures, etc. The customer needs to be surveyed to obtain this information. Various qualitative measures need to be estimated. These types of measures are not given the same treatment as the readily quantifiable measures such as mass-flow rates, etc.

Additionally, the studies do not set forth a set of criteria by which the alternative systems can be judged from a performance acceptability perspective. Definitive measures for acceptable performance need to be set forth in the studies. These measures and their target values need to be listed and clearly stated so that each alternative's performance can be judged. In summary, a traceable set of performance criteria from which to make a statement as to the effectiveness of a particular system design is lacking.

The studies incorrectly assume that all alternative systems equally meet the prescribed regulatory and functional requirements. As a consequence, there are no minimum standards of performance to meet or exceed; i.e., all systems immediately meet or exceed (to an unspecified level) the performance criteria.

The studies do a reasonable job of defining deficiencies and areas of improvement. 


\section{BLOCK 6 - DESIGN EVALUATION}

The basis for the evaluation of candidate systems is life-cycle cost. Given that a set of alternatives minimally satisfies a set of performance criteria, a decision must be made between the alternatives. In order to do this, the cost-effectiveness of the designs needs to be evaluated. As a start, the life-cycle cost of each alternative is determined based on the estimation and prediction activity just completed. Arrow G in Figure B-1 indicates the passing of the estimation and prediction results, the DDP values, to the evaluation step. The entire life cycle "from lust to dust" must be considered in the life-cycle cost analysis. Some methodology must be utilized to estimate life-cycle cost. The cost breakdown structure (CBS) needs to be developed and used for each alternative. It should be obvious from the CBS whether a life-cycle approach to cost estimation is applied. Also, the time value of money principle is applied here. Only after performing a lifecycle cost analysis can a decision be made about the preferred alternative(s).

\section{Questions and Points to Consider}

\section{What is the definition of the system's life cycle?}

- Each phase of the life cycle must be considered.

Is there a life-cycle model contained in the LITCO studies?

- Do the LITCO studies contain a description of the life-cycle cost elements?

- Are all aspects of the system represented in the life-cycle model?

- Do the LITCO studies define the life-cycle cost estimation procedure?

- Are all system elements, i.e., support, operation, disposal, training, etc. represented in the life-cycle definition and/or CBS?

By what means is the life-cycle cost calculated?

- What method is used to calculate life-cycle cost in the studies? (activity-based costing, CBS, etc.)

- Is this method utilized consistently over the entire life cycle and across alternatives?

- What assumptions are made that affect life-cycle cost calculations in each study?

- Do the LITCO studies examine the effect of these assumptions on decision reversal?

- Which cost assumptions are critical enough to warrant further study?

- Identification of these critical assumptions and others is a fundamental part of the SE process, especially at the conceptual design level. Do the LITCO studies report or identify any assumptions, technologies, vague requirements, etc. for further investigation? 
- What interest rate, tax rate, depreciation rate, etc., is considered?

- Are rent versus buy options delineated as mutually exclusive alternatives? If not, design synthesis should be revisited and these alternatives considered.

\section{Evaluation of the LITCO Studies}

Largely, the methodology for calculating life-cycle cost from the system designs was consistent with sound engineering methods. However, there seems to be no consideration of the "time-value of money" principle in these life-cycle cost calculations. This is a consideration that can cause decision reversal in the selection of candidate systems.

The life cycle of the systems was not completely described; specifically, decontamination and decommissioning were neglected. The published life-cycle cost results are quite minimal, thus decision making or reconstruction by an independent reviewer is made difficult. Further, sensitivity analysis with respect to critical design and operating assumptions or parameters was not performed.

\section{BLOCK 7 - DESIGN DECISION SCHEMA}

After each alternative has been evaluated with respect to life-cycle cost, a decision can be made as to the preferred alternative(s). Given the variety of opinions represented by the customer and the number of decision criteria the customer will have, choosing a preferred alternative is usually not a simple matter of picking the least expensive design. Customer opinion and perception play a large role in this subjective decision-making process. Based on the definition and input from the customer about what is desirable in the system, a decision evaluation can be made. These design criteria are derived from the set of customer and system requirements and are represented by Arrow H in Figure B-1. This process of weighing multiple decision criteria against life-cycle cost is mostly subjective. The decision maker must now trade off life-cycle cost against other decision criteria subjectively. These parameter values are passed from the evaluation step along with DDP values, as seen in Arrow I. The result is one or more preferred alternatives that can be used to continue the design process to a more detailed level. These preferred alternatives are always ultimately judged by the customer; therefore, we show Arrow J returning the preferred candidate system for review by the customer.

\section{Questions and Points to Consider}

\section{What method will be used to facilitate the decision-making process?}

- The definition of the customer and ensuring all voices are heard plays a large part in determining what decision-making tool is used.

- Is the decision-making process facilitated by the work done to this point?

- Are the LITCO studies constructed to facilitate the decision-making process? 
- Is the ultimate goal of the studies to present many alternatives for a decision by the customer? Or, is the objective of the studies to select a preferred candidate system or set of candidate systems to proceed with?

- Are all design decision criteria identified and estimation and prediction completed?

- Do the decision criteria trace back to the customer requirements and concerns?

- Are the alternative systems developed, analyzed, and evaluated in enough detail so that a decision can be reached, or are the systems evaluated in a manner that does not allow for a decision to be made?

- If the LITCO studies do not evaluate the designs well enough, do they give reasons?

- Are there areas for further study identified in the studies before a decision can be made?

- Should the decision be to continue with multiple designs until a better evaluation can be done? What do the studies say?

- Is the customer, as defined, a major participant in the decision-making process?

- If not, what assures that the "voice of the customer" is represented in the decision-making process?

\section{What are the established decision criteria and thresholds for each?}

- Are the decision criteria and thresholds that define the goals and opinions of the decision maker documented?

- Do the selected criteria adequately reveal the deficiencies and differences between alternatives?

- Are there any customer concerns or opinions that are not addressed that are necessary to satisfy the customer? If so, then requirements and criteria must be added to the design process to correct this deficiency.

- Are the LITCO studies iterative in nature, or do they just complete one iteration of design synthesis, analysis, and evaluation?

\section{How were the decisions reached?}

- Is there traceability within the decision-making process?

- Do the LITCO studies provide traceability in decision making? How are the longer lists of candidate systems shortened? Where are the criteria for selection?

- Are the decisions made documented with the appropriate reasoning and criteria values? 
- If the decision makers are not the customer, how are they held accountable to the customer?

- How does the customer have input to the decision-making process? Is this role documented?

- Are the decisions made on a fair or equivalent basis?

\section{Evaluation of the LITCO Studies}

In the end, the ITTS and INTS studies do not provide the proper information to facilitate the decision-making process. The candidate systems cannot easily be compared, so there is no real basis for a decision. The ITTS Phase 1 report initiated, but did not conclude, a "quantitative systems comparison" of the system attributes using an approach the authors called figure-of-merit (FOM) analysis. There is no description, however, of how the weighting factors or scoring guidelines were developed. This approach, a valid methodology to assist decision making, was incorrectly abandoned in the ITTS Phase 2 and INTS studies.

The main problem with the ITTS and INTS study approach is that only technical criteria are presented. The decision between alternatives needs to be made in the face of multiple criteria, only a few of which are going to be technical in nature. Most of the design decisions will be made based on much more subjective criteria and characteristics. It is those criteria that these studies should concentrate on in the preconceptual stage of design.

\section{BLOCK 8 - PHYSICAL AND ECONOMIC DATABASES AND OTHER STUDIES}

This block represents a resource for the SE process rather than an actual step in the process flow. There exists a body of knowledge that engineers, economists, and scientists rely on to perform analyses and evaluations. This body consists of known physical laws, empirical data, economic forecasts, and other studies. It also comprises those existing system components, parts, and subsystems that have resulted from previous design efforts. This body of knowledge is great. To what extent it is utilized is a concern in SE. It is very easy in the design of a complex system to "reinvent the wheel." Reuse of existing systems and components is encouraged in the SE process. This body of knowledge and experience is utilized more informally than in a formal sense. There are, of course, useful formal treatments of this body of knowledge.

\section{Questions and Points to Consider}

\section{To what extent is reuse encouraged and past experience depended on?}

- Are all system components "new" designs, or do the selected alternatives build upon previously proven technologies and designs?

- Are these uses or reliance on past efforts documented in the LITCO studies?

- Are uses of past designs and work appropriate for this design effort? 
- Do the LITCO studies provide justification for these uses? Or, should more attention be devoted to new design work?

- Do the LITCO studies identify areas and potential for future and needed research and development?

Where do assumptions made during the systems engineering process originate?

- Do assumptions made in estimation and prediction have a basis in fact or in theory?

- Are there sufficient studies or data to support such assumptions?

- Are economic factors, i.e., interest rates, tax rates, depreciation, etc., forecast using sound economic principles?

- Where estimation occurs, are the appropriate assumptions consistent with the alternative design?

\section{What effect does this body of knowledge or expert knowledge have on the alternative} selection and decision-making process?

- Does the body of expert knowledge bias the alternative selection by the design team?

- What criteria are used in the LITCO studies to make decisions about selected alternatives?

- To what extent is engineering and expert judgment relied on to provide answers or estimates of design parameters?

- Is this documented?

- What effect do these assumptions have on decision making, and are they explored in the LITCO studies?

- Are decisions based on the estimation, prediction, and evaluation activities or solely on engineering judgment?

- Are these decisions documented and justified?

\section{Evaluation of the LITCO Studies}

The studies do a reasonable job of reviewing the technology and system deficiencies and required areas of development. References to regulations are numerous, but many of these are obsolete or have been superseded. Accordingly, it would be good if each cited regulation could be updated and the impact of the change on the MLLW treatment problem explained. Further, given the apparently large technology database, there was little referencing in the ITTS studies. The INTS study included more referencing with respect to the evaluated technologies. 


\section{APPENDIX C}

\section{EXPANDED DISCUSSION OF THE TOP-DOWN VERSUS BOTTOM-UP APPROACH}




\section{EXPANDED DISCUSSION OF THE TOP-DOWN VERSUS BOTTOM-UP APPROACH}

Traditional engineering design methodology is based on a bottom-up approach. Starting with a set of known elements, design engineers synthesize the product or system by finding the most appropriate combination of system elements. However, unless the product is quite simple, it is unlikely that the functional need will be met on the first attempt. After determining the performance deviation from what is required (by prediction, simulation, measurement, or other means), the combination of elements is altered and the system performance determined again.

\section{Top-Down versus Bottom-Up Design}

This bottom-up process is iterative, with the number of iterations (and design efficiency) determined by the experience and creativity of the designer, as well as by the complexity of the system or product. As the complexity of the product increases, it is less likely that the designer will come close to the required performance on the first try. It is also unlikely that an adjustment in the combination of elements will actually lead to an improvement. The effort involved in the iterative process, compared to the effort for the initial design, increases rapidly with increasing system complexity.

A top-down approach to design is evoked by systems engineering (SE). Starting with requirements for the external behavior of any part of the system (expressed in terms of the function provided by that part externally or to other parts of the system), that behavior is analyzed to identify its functional characteristics. These functional behaviors are then described in more detail and made more specific through a process of refinement. Next, the appropriateness of this choice of functional components is verified by synthesizing the original part.

Two characteristics of the top-down process are:

- The process is applicable to any part of the system. Starting with the system as a whole, repeated application of this process will result in a partitioning of the system into smaller and smaller elements.

- The process is self-consistent. External properties of the whole system, as described by the inputs and outputs and relations between parts, must be reproduced by the external properties of the set of interacting elements.

The first step of the analysis is to recognize the general functions involved in transforming inputs into outputs. That is, one must abstract from the particular case to the underlying generic case and represent this case by a number of interacting functional elements. The use of functional elements lies at the core of the SE methodology because:

- A particular functional element is applicable to a whole class of systems. Consequently, one needs only a limited number of such elements to represent a large number of real systems. 
- Functional elements inherently reflect the top-down approach. That is, a particular functional element is applicable or appropriate to a certain level of the top-down hierarchy.

- Functional elements provide a link in the specification of a system. Design-dependent parameters such as reliability, maintainability, producibility, performance, and others are related to functional elements of the system.

- Functional elements allow one to pursue system design work well before physical manifestations have been defined. This contrasts with designing a system by using the bottom-up methodology, where one starts out with a defined set of real elements (components) and synthesizes a system out of members from the set.

There are two main differences between the bottom-up and top-down approaches: In bottomup design, physical realizability in terms of known elements is assured, whereas at the end of the top-down design process, the systems elements are still functional entities. Their physical realizability is not guaranteed. In the top-down approach, the requirements are ideally always satisfied through every step of the design process (as an inherent part of the methodology), whereas in the bottom-up approach, the methodology provides no assurance that this will occur.

The extent to which the top-down process is applied as a complexity-reducing step depends on the complexity of the product or system to be designed. As products get more and more complex (i.e., consisting of more and more interacting elements and characterized by more and more parameters), the probability of selecting a combination of elements that will result in performance being anywhere near user requirements diminishes, as does the probability of picking a new combination that will result in an improvement.

SE is not likely to replace bottom-up design. In the end, every project must involve some physical object that meets the need. At some point in the design process, there must be a transition from the functional (or abstract) to the physical. Most projects will employ both methodologies: first $S E$ to reduce the complexity by partitioning the system into its elements, and then bottom-up design to realize the elements. This is best illustrated by the " $\mathrm{V}$ " system design and development model as illustrated below. 


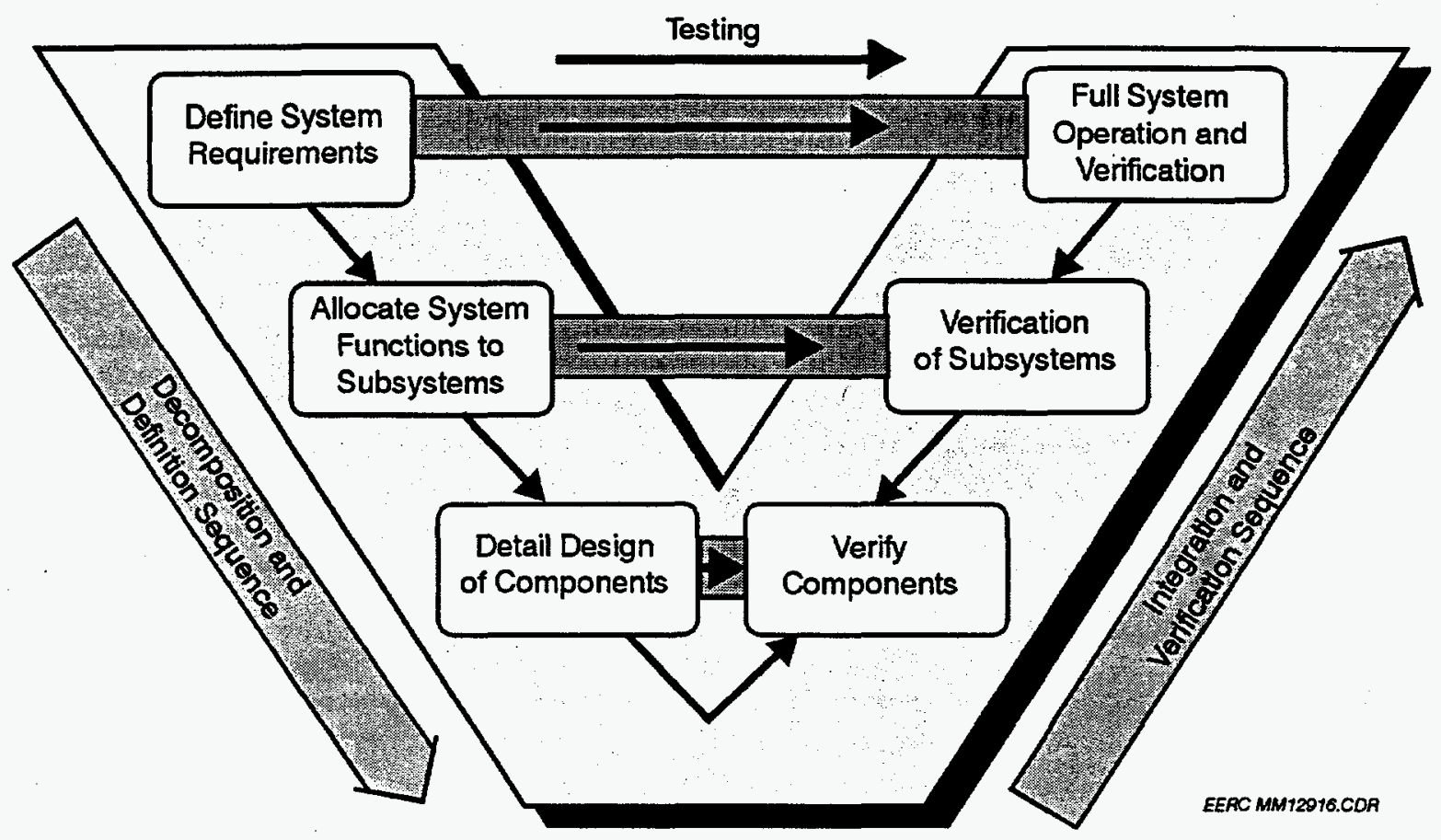

Figure C-1. V diagram representing both top-down and bottom-up systems engineering. 


\section{APPENDIX D}

\section{IDENTIFIED ASSUMPTIONS FOR THE ITTS STUDY - PHASE 1}


a) Regulations, Permitting and Stakeholder Input

$\begin{array}{ccc}19 & 1.2 .0 & 4 \\ 20 & \text { A-1.3 } & \text { A-5 } \\ 21 & \text { A-1.4 } & \text { A-5 }\end{array}$

Two major concerns of the public are control of hazardous stack emissions and safe disposal of hazardous solid residues, especially as it concerns radionuclides.

Main thermal treatment unit in ITTS must conform to TSCA; special consideration for PCB under 40 CFR $761.60-761.70$

: Limited quantities of CERCLA (buried) waste may be treated.; all RCRA (stored) waste will be treated

Permitting under RCRA is assumed to be for hazardous waste. General guidelines for all thermal processing of solid waste in the Code of Federal Regulation 40 CFR 240 will apply. RCRA permitting involves additional regulations applying to particular systems depending on the type of process used.

Listed (hazardous) waste as designated by the EPA is assumed to be treated.

The EPA has listed three categories of listed hazardous wastes under RCRA: 1) "F wastes" from nonspecific sources; 2) " $K$ wastes" from specific sources; and 3) "P and U wastes" from discarded and off-specification products, container residues and spills.

Wastes, whether listed or not, must be characterized by testing or prior process knowledge to determine if it exhibits any of the four characteristics of hazardous waste: 1) corrosivity, 2) ignitability, 3) reactivity, and 4) toxicity.

Management of secondary wastes shall be according to EPA "derived from" rule

Residue from treatment of all wastes is stabilized to meet concentration based extraction test (TCLP) (40 CFR 268.41); requirement is also part of DOE Order $5820.1 \mathrm{~A}$

Listed waste, after treatment, must be disposed of in an interim status or newly permitted RCRA conforming Subtitle $\mathrm{C}$ landfill

Some of the secondary waste streams are investigated for potential delisting to allow an exclusion pathway for the waste to become regulated as nonhazardous

Thermal units shall be permitted for RCRA regulations according to 40 CFR 270.62 which requires 1) description conditions operate compliance with performance standards $40 \mathrm{CFR}$ 264.343 , description of restrictions on waste constituents, waste feed rates, operating parameters according to 40 CFR 264.345, proposal for trial burn plan.

Thermal treatment shall be subject to RCRA permit trial burn plan and information to be provided is listed in 40 CFR $270.62(\mathrm{~b})(2)$

40 CFR 264.347 lists RCRA monitoring information requirements for thermally treating hazardous wastes

Section 112(c) of the Clean Air Act (CAA) requires that all source categories, including thermal treatment, be identified and that technology based emission standards be promulgated for each category; RCRA metal emission standards for boilers and industrial fumaces are risk based; the maximum achievable control standards are to be based on the best technology currently

Permits are now required for all major new sources; requires engineering justification of facility emission rates, new source air quality impacts, and assessment of other risks to the environment; specific operating limits might be imposed

Section 109(a) of the CAA (Ref 3) covers the National Ambient Air Quality Standards (40 CFR 50) shown in Table A-1

The Clean Water Act contains no standards for thermal treatment unit effluents; it will be several years 
a) Regulations, Permitting and Stakeholder Input (continued)

\begin{tabular}{|c|c|c|}
\hline 37 & $A-2.0$ & A-12 \\
\hline 38 & A-2.1 & $A-12$ \\
\hline 39 & $A-2.1 .1$ & $A-12$ \\
\hline 40 & A-2.1.2 & $A-12$ \\
\hline 41 & $A-2.1 .3$ & $A-12$ \\
\hline 42 & A-2.1.4 & A-12 \\
\hline 43 & A-2.1.5 & $A-12$ \\
\hline 44 & $A-2.1 .5 .1$ & A-16 \\
\hline 45 & $A-2.1 .5 .2$ & $A-16$ \\
\hline 46 & $A-2.2$ & A-16 \\
\hline 47 & $A-2.3$ & A-16 \\
\hline 48 & A-2.4 & A-16 \\
\hline 49 & A-2.5 & A-16 \\
\hline 50 & A-2.6 & A-16 \\
\hline 51 & $A-2.7$ & $A-17$ \\
\hline 52 & $A-2.8$ & A-17 \\
\hline
\end{tabular}

b) Input Waste Characteristics

Tables A-2 and A-3 show emission (current and proposed) for nonmetals and metals for the ITTS design

According to 40 CFR 264.343 thermal treatment units operated in accordance with permit requirements must meet the following performance standards:

Destruction removal efficiency (DRE) of $99.99 \%$ for each POHC designated in permit

DRE of $99.9999 \%$ for dioxin type waste; DRE demonstrated on difficult to treat surrogate POHC

Control of $\mathrm{HCl}$ when emission above $1.8 \mathrm{~kg} / \mathrm{hr}$, rate of emission no greater than larger of either 1.8 $\mathrm{kg} / \mathrm{hr}$ or $1 \%$ of $\mathrm{HCl}$ in stack gas before APC

Particulate emission must not exceed $180 \mathrm{mg} / \mathrm{dscm}(0.08$ grains/dscf); this will normally be held at 0.015 grains based on Municipal Waste Incinerator Standards and recent EPA policy

POHCs are primary indicators used by EPA in determining complete combustion; one or more POHCs will be specified in permit from those listed in 40 CFR Part 261 App VIl; EPA regulation of metal emissions will extend to hazardous waste $T T$ units under omnibus provision from ruling made for treating hazardous wastes in boilers and industrial furnaces

EPA requires no finite level for $C O$ provided that the concentration of hydrocarbons in stack gas does not exceed 20 ppmv (good operating practice) otherwise limit is 100 ppmv CO

No finite standard for dioxins had been set on hazardous waste $T$ units prior to the interim standard set May 1993

EPA Draft Strategy of 1993 - ?

DRE for POHCs - EPA generally believes that $99.99 \%$ "is protective of risks posed by emissions of organic constituents in the waste under vitually every scenario of which the agency is awaren; CAA interpreted by some states requiring aggregate risk for carcinogens of 1 in million, DRE of 99.999\% would allow spirit of new requirements to be easily met (Table A-2)

Carbon monoxide and HC - BIF rule FR 56 (35)7155 (1991) sets CO levels of 100 ppmv (technology based standard) and HC of $20 \mathrm{ppmV}$

Particulate matter smaller than 10 microns - EPA in May 1993 draft strategy document omnibus provision limits to $34 \mathrm{mg} / \mathrm{dscm}$

Metals - EPA intends to apply the BIF metal emission standards 56 FR 35 p. 7131 et seq. (1991) to hazardous waste TT units using omnibus provision

$\mathrm{HCl}$ - 40 CFR 264.343 restricts to $1.8 \mathrm{~kg} / \mathrm{hr}$ or $1 \%$ of value in stack before APC, whichever is larger; as a conservative measure the lower value was selected for ITTS (Table A-2)

Dioxins - German and Dutch governments limit dioxins and furans to $0.1 \mathrm{ng} / \mathrm{cm}$; technology based standard achievable using carbon filtration
Mixed low-level wastes (MLLW) to be treated are contact-handled, alpha and nonalpha materials consisting of organic and inorganic solids and liquids contaminated with radioactive substances.

Regulations promulgated by DOE and EPA govern the storage, treatment, and disposal of these wastes

The waste types treated are described in the DOE Mixed Waste Inventory Report (MWIR).

1.1 .0

A-19 87
ITTS shall treat the waste types described in Table A-4 Phase I report 
b) Input Waste Characteristics (continued)

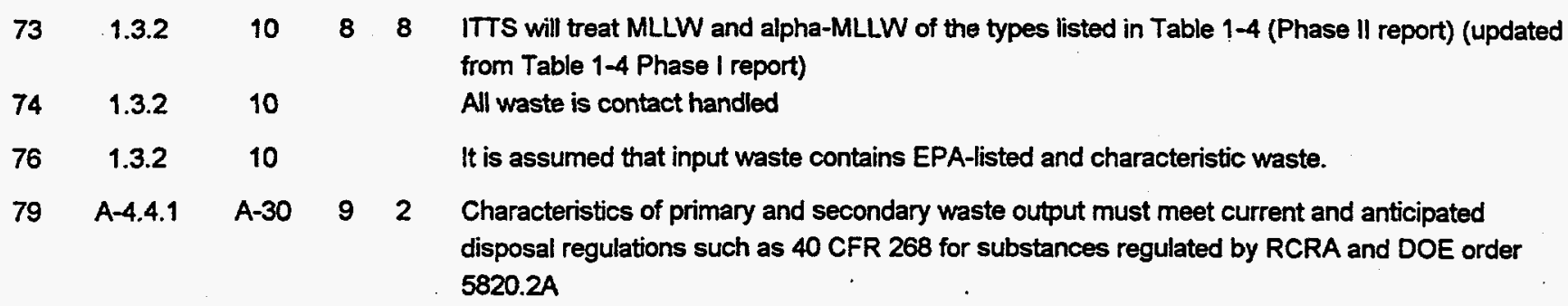

c) Waste Characterization

\begin{tabular}{|c|c|c|c|}
\hline 53 & A-3.0 & $A-17$ & $\begin{array}{l}\text { Proposed characterization requirements - Each step of } \Pi \text { will require characterization starting } \\
\text { with waste containers to final waste forms, offgas, scrubber solids }\end{array}$ \\
\hline 54 & A-3.1.1 & A-17 & $\begin{array}{l}\text { Non-destructive drum assay procedures for radionuclides having errors of }+\ldots 100 \% \text { at } 100 \\
\text { nanocuries per gram ( } \mathrm{nCi} / \mathrm{g} \text { ) are considered adequate for characterizing input. }\end{array}$ \\
\hline 55 & A-3.1.1 & $A-17$ & $X$-ray radiography can be used in presorting to determine physical characteristics. \\
\hline 56 & A-3.1.2 & $A-17$ & Chemical analysis for RCRA organics and hazardous metals according to the following: \\
\hline 57 & A-3.1.2 & $A-17$ & $\begin{array}{l}40 \text { CFR } 264.31 \text { for waste analysis states that "throughout normal operation sufficient analysis to } \\
\text { verify waste feed within physical and chemical limits specified in permit }\end{array}$ \\
\hline 58 & A-3.1.2 & A-17 & $\begin{array}{l}56 \text { FR } 35 p 7171 \text { addresses } 10 \text { metals under BIF rule and indicates analysis for if suspected in } \\
\text { waste }\end{array}$ \\
\hline 59 & A-3.1.2 & $A-17$ & During trial burn certain characterization requirement must be met \\
\hline 60 & A-3.1.2 & $A-17$ & $\begin{array}{l}47 \text { FR } 122 \text { p. } 27528 \text { provides guidance in terms of detection limits that might be needed for waste } \\
\text { characterization }\end{array}$ \\
\hline 61 & A-3.1.2 & A-18 & EPA does not discourage use of characterization to define waste feeds into various groups \\
\hline 62 & A-3.1.2 & $A-18$ & $\begin{array}{l}40 \text { CFR } 265.341 \text { for waste analysis requires (for feed) heating value, halogen and sulfur content, } \\
\text { lead and mercury (unless documentation shows their absence) }\end{array}$ \\
\hline 63 & A-3.1.2 & A-18 & $\begin{array}{l}40 \text { CFR } 265.13 \text { requires written analysis plan providing detailed chemical or physical analysis of } \\
\text { representative sample }\end{array}$ \\
\hline 64 & A-3.1.2 & A-18 & $\begin{array}{l}40 \text { CFR } 264.13 \text { for general waste analysis requires detailed chemical and physical analysis } \\
\text { before treatment of representative sample }\end{array}$ \\
\hline 65 & A-3.1.2 & A-18 & $\begin{array}{l}\text { For ITTS study, proposed that batches of waste for } 24 \text { hour campaign be shredded, composited, } \\
\text { mixed and complete suite of EPA SW- } 846 \text { analyses be performed on composite }\end{array}$ \\
\hline 66 & A-3.1.3 & A-18 & EPA SW-846 adopted for analysis of alpha contaminated mixed waste \\
\hline 67 & A-3.1.3 & $A-18$ & Stack gas sampling methods should comply with 40 CFR 60 App A \\
\hline 68 & A-3.2.1 & A-18 & $\begin{array}{l}\text { Methods of offgas characterization will be contained in DOE report "Characterization for } \\
\text { Treatment of Containerized Low-Level Wastes" May } 1993\end{array}$ \\
\hline 69 & A-3.2.2 & A-18 & EPA procedure SW-846 will be used for analyzing scrubber solutions. \\
\hline 70 & A-3.3.1 & A-19 & $\begin{array}{l}\text { Bottom ash and fly ash - radioassay of TRU required (routine methods available); analysis of } \\
\text { salt content may be needed (routine methods available); RCRA metals analysis not needed as } \\
\text { assumed waste will have levels of regulatory concern; analysis of TC may be required to show } \\
\text { absence of carbons }\end{array}$ \\
\hline
\end{tabular}


No. Sect. Page $U^{*} \mathbf{S}^{* *}$

c) Waste Characterization (continued)

$71 \quad$ A-3.3.1 A-19

Final waste form - TCLP leaching tests will be used to meet EPA requirements for burial in a mixed waste disposal facility.

d) General Design and Operating Assumptions

\begin{tabular}{|c|c|c|c|}
\hline 2 & 1.1 .0 & 1 & \\
\hline 4 & 1.1 .0 & 2 & \\
\hline 5 & 1.1 .0 & 2 & \\
\hline 6 & 1.1 .0 & 2 & \\
\hline 8 & 1.2 .0 & 3 & \\
\hline 9 & 1.2 .0 & 3,4 & \\
\hline 10 & 1.2 .0 & 4 & \\
\hline 11 & 1.2 .0 & 4 & 3 \\
\hline 12 & 1.2 .0 & 7 & \\
\hline 14 & 1.2 .0 & 7 & \\
\hline 15 & 1.2 .0 & 7 & \\
\hline 16 & 1.2 .0 & 7 & 9 \\
\hline 17 & 1.2 .0 & 7 & \\
\hline 75 & 1.3 .2 & 11 & 9 \\
\hline$\pi 7$ & 1.3 .2 & 11 & \\
\hline 78 & 1.3 .2 & 11 & \\
\hline 80 & $A-4.4 .1$ & $A-30$ & 9 \\
\hline 81 & $A-4.4 .2$ & A-31 & \\
\hline 82 & $A-4.4 .1$ & $A-31$ & \\
\hline 83 & A-5.2 & $A-27$ & \\
\hline
\end{tabular}

Treatment systems are required to destroy organic materials and stabilize inorganic residues and radionuclides prior to disposal in a MLLW disposal facility.

Thermal treatment is the most effective technique for destruction of toxic organic materials Incineration has been designated by EPA as BDAT for destroying a number of these organic waste constituents

Incineration is a mature and proven technology; technical risks are low and costs are well established

Focus of ITTS study was innovative, cost effective treatment systems that minimize short-, long-term adverse impacts to workers, public environment, health, safety

Twelve TT systems initially considered; panel of engineers with diverse experience, technical backgrounds in incineration and stabilization reduced to ten systems

Selection process preserved ability to evaluate costs and benefits for incinerator type, oxygen or air for combustion, $\mathrm{CO} 2$ retention, wet vs, dry/wet APC

Specific attention paid to APC design; intent to specify configuration to provide order of magnitude improvement in emission performance relative to EPA standards

Vitrification can provide greatest protection against environmental releases after disposal. provides margin against more stringent future release standards

Amalgamation presumed to be best stabilization method for mercury since listed by EPA as BDAT

All secondary residues processed in accordance with regulatory requirements, final volumes for disposal estimated

Costs estimated assuming system is government owned and contractor operated (GOCO)

Transportation and disposal costs applied to disposal volume for each system in PLCC estimate

The nominal capacity of the system shall be as shown in Table 1-4 (Phase II report) (updated from Table A-5 Phase ( report)

Solid and sludge waste will be shipped to the treatment facility in drums, metal bins, and wooden and fiberglass boxes.

Liquid waste is shipped to the facility by pipeline, tank truck, or in containers placed on wheeled vehicles

Shallow land burial assumed for LLW and treated MLLW, engineered shallow land disposal for alpha LLW and alpha MLLW

Final waste form is a stable and leach resistant solid produced by vitrification or solidification

Final waste form satisfies performance assessment requirements for alpha concentrations up to $99 \mathrm{nCi} / \mathrm{g}$ TRU

Waste pretreatment will include removing large bulk metal $(>10 \mathrm{~cm})$ and depressurizing or emptying temperature sensitive materials such as gas cylinders. 
No. Sect. Page $U^{*} \underline{S}^{* *}$

d) General Design and Operating Assumptions (continued)

85

86

87

88

89

90

91

92

93

94

95

96

97

$$
88
$$

Primary treatment to meet EPA requirements will include oxidation or decomposition of combustibles to reduce volume and destroy RCRA-controlled substances.

Noncombustibles will be treated to destroy RCRA controlled contaminants and remove moisture Engineered disposal facility used for costing

Output LLW, MLLW, alpha LLW, alpha MLLW shipped to and disposed at Nevada Test Site Design of final waste form based on surface disposal at site other then Nevada Processing sites for transportation purposes will be located at Oak Ridge Reservation and INEL Output waste will be packaged in 55 gallon drums meeting DOT requirements Vitrified waste will be placed in thick walled steel containers meeting DOT and TRUPACT II criteria

Final waste forms will meet contact handling requirements with no additional shielding besides the container

System will incorporate minimum shielding; shielding not a factor in system performance

Facility will be placed in Seismic Category 1 ; building will be classified as moderate hazard facility

Facility design will meet local, state, and federal regulations, including general design criteria for DOE facilities contained in DOE order 6430.1A

RCRA design constraints and performance specifications hold for storage and treatment facilities and waste stabilization

Primary design requirement is triple containment of alpha contamination; tertiary containment will be used for waste sorting through waste stabilization; two levels of containment for processes with limited potential for airborne materials

System will safely handle input waste over $100 \mathrm{nCi} / g$ radioactivity TRU material

Evaluated thermal treatment technologies are well developed

Technologies will be ready for pilot-scale demonstration in 2 years, incorporation into final design in 3 years, and construction in 5 years

Surge capacity for indoor storage of MLLW drums is 2 to 6 weeks

Final waste forms for LLW will be delistable to reduce the cost of disposal (Subtitle D versus Subtitle C).

TRU waste will comply with criteria for the Waste Isolation Pilot Plant (WIPP) and packaging under DOE TRUPACT $\|$ and 10 CRF 71 requirements.

Elemental mercury comprises $5 \%$ of stream designated as mercury contaminated; mercury concentration in remaining stream is $5 \%$

Stabilization formulas consist of 1 part soil or glass forming additive to 2 parts waste (vitrification), 1 part polymer to 1 part waste (polymer), 2 parts grout to 1 part waste (grout)

CO2 absorption, lime recycling is $90 \%$ and rejection is $10 \%$

Salt recovery process, sait cracking efficiency is $90 \%$ ( $10 \%$ is rejected)

Metal recovered from incinerator feed is $1 \%$ of input waste

Organics recovered in thermal desorption are $5 \%$ of feed 
d) General Design and Operating Assumptions (continued)

\begin{tabular}{|c|c|c|c|c|c|}
\hline 110 & 3.3 & 58 & 8 & 8 & $\begin{array}{l}\text { The ash content from combined combustible and noncombustible waste is } 54 \% \text { of feed, ash } \\
\text { from combustible waste is } 7 \% \text { of feed, lime discarded after calcining is } 10 \% \text { of feed }\end{array}$ \\
\hline 111 & 3.3 & 58 & 6 & 8 & $\begin{array}{l}\text { Feed rates (lb/hr) to primary treatment: A1 to A6 - } 2000 \text { consisting of } 1340 \text { noncombustibles and } \\
660 \text { combustibles; B1 and D1 - } 660 \text { combustibles; C1 - } 2149 \text { consisting of } 1340 \text { noncombustibles, } \\
660 \text { combustibles, } 149 \text { metal; E1 - } 1340 \text { noncombustibles to desorber, } 660 \text { combustibles plus } 289 \\
\text { organics (from desorber) to rotary kiln }\end{array}$ \\
\hline 112 & 3.3 & 58 & 3 & 8 & $\begin{array}{l}\text { Organic liquid waste subsystems (lb/hr) - } 51 \text { organic liquid in combustible waste, } 16 \text { aqueous } \\
\text { organic liquid in aqueous waste, } 358 \text { recovered during desorption }\end{array}$ \\
\hline 113 & A-6.1 & A-34 & 3 & 7 & Process units will be designed for $125 \%$ of the expected mass flow rates. \\
\hline 114 & A-5.1 & $A-19$ & & & $\begin{array}{l}\text { System for treating alpha MLLW and alpha MLLW should accommodate input waste with } \\
\text { radioactivity levels of TRU waste which is waste exceeding } 100 \mathrm{nCilg}\end{array}$ \\
\hline 115 & A-6.4 & A-35 & 9 & 8 & $\begin{array}{l}\text { Operation of the treatment facility is assumed to be for } 24 \text { hours per day, } 5 \text { days per week, } 240 \\
\text { days per year, at } 70 \% \text { capacity during operation. This is equivalent to } 4032 \text { hours per year }\end{array}$ \\
\hline 116 & A-6.4 & A-35 & 8 & 7 & Fewer then three shift operation for small capacity facilities \\
\hline 317 & 5.1 & 107 & & & $\begin{array}{l}\text { Evaluation of technology risk assesses probability that system or subsystem meets established } \\
\text { objectives: technical; environmental, safety, and health; institutional; cost; schedule }\end{array}$ \\
\hline 318 & 5.2 .1 & 108 & & & $\begin{array}{l}\text { System A1: Composed of most well developed commercial technologies; majority of } \\
\text { components used in hazardous waste applications, available from several vendors }\end{array}$ \\
\hline 319 & 5.2 .1 .1 .1 & 909 & & & Technical objectives: compliance with permitting - no problems \\
\hline 320 & 5.2.1.1.1 & 109,110 & & & $\begin{array}{l}\text { Technical objectives: compliance with emissions - expected to meet standards; areas of } \\
\text { development include mercury removal, lead removal, actinides, dioxins, nitrogen oxides }\end{array}$ \\
\hline 321 & 5.2 .1 .1 .1 & 111 & & & $\begin{array}{l}\text { Technical objectives: compliance with characterization - feedstock characterization unit needs } \\
\text { engineering development and demonstration for integration }\end{array}$ \\
\hline 322 & 5.2.1.1.1 & 111,112 & & & $\begin{array}{l}\text { Technical objectives: compliance with functional and operational requirements - technologies } \\
\text { are well developed but some design concerns; not detrimental to system effectiveness and can } \\
\text { be resolved through systems engineering: concept for mercury management, temperature } \\
\text { profile (APC) for optimum performance }\end{array}$ \\
\hline 323 & 5.2.1.1.1 & 112 & & & $\begin{array}{l}\text { Technical objectives: compliance with facility design requirements - system complies with } \\
\text { majority; major area concern is alpha confinement, proposed approach seldom used by DOE } \\
\text { and further evaluation needed }\end{array}$ \\
\hline 324 & 5.2 .1 .1 .2 & 112,113 & & & $\begin{array}{l}\text { Safety and health objectives: two main concerns when processing alpha waste are acceptability } \\
\text { of rotary kiln and volatilization of actinides }\end{array}$ \\
\hline 325 & 5.2 .1 .1 .2 & 112,113 & & & $\begin{array}{l}\text { Safety and health objectives: acceptability of rotary kiln - concerns with maintenance, leaking } \\
\text { seals; solutions described for both }\end{array}$ \\
\hline 326 & 5.2 .1 .1 .2 & 112,113 & & & $\begin{array}{l}\text { Safety and health objectives: volatilization of actinides - potential release to atmosphere is } \\
\text { greatest ES\&H concern; further study required. }\end{array}$ \\
\hline 327 & 5.2 .1 .1 .3 & 113 & & & $\begin{array}{l}\text { Institutional objectives: Experience in similar rotary kiln application (ORNL, Savannah River Site), } \\
\text { leach resistant, high integrity waste form should help gain public acceptance }\end{array}$ \\
\hline 328 & 5.2 .1 .1 .3 & 113 & & & $\begin{array}{l}\text { Institutional objectives: Recognized that public and state and local permitting agencies not } \\
\text { receptive to incinerators; site selection is critical }\end{array}$ \\
\hline 329 & 5.2 .1 .1 .4 & 113 & & & ves: Cost risk low for nonalpha waste, risk of cost overruns high for alpha waste \\
\hline
\end{tabular}

Cost objectives: Cost risk low for nonalpha waste, risk of cost overruns high for alpha waste 
No. Sect. Page $U^{*} \underline{S}^{* *}$

d) General Design and Operating Assumptions (continued)

\begin{tabular}{|c|c|c|}
\hline 330 & 5.2.1.1.4 & 113 \\
\hline 331 & 5.2 .1 .1 .5 & 114 \\
\hline 332 & 5.2.1.2.1 & 114 \\
\hline 333 & 5.2.1.2.1 & 114 \\
\hline 334 & 5.2 .1 .2 .2 & 115,116 \\
\hline 335 & 5.2 .1 .2 .2 & 115,116 \\
\hline 336 & 5.2 .1 .2 .3 & 116,117 \\
\hline 337 & 5.2 .1 .2 .3 & 116,117 \\
\hline 338 & 5.2 .1 .2 .4 & 118 \\
\hline 339 & 5.2 .1 .2 .4 & 118 \\
\hline 340 & 5.2.1.2.5 & 118 \\
\hline 341 & 5.2.1.2.5 & 118 \\
\hline 342 & 5.2 .1 .2 .6 & 118 \\
\hline 343 & 5.2 .1 .2 .6 & 118 \\
\hline 344 & 5.2 .1 .2 .7 & 118,119 \\
\hline 345 & 5.2 .1 .2 .7 & 118,119 \\
\hline 346 & 5.2.1.2.7 & 118,119 \\
\hline 347 & 5.2.1.2.8 & 119 \\
\hline 348 & 5.2.1.2.8 & 119 \\
\hline 349 & 5.2.1.2.8 & 119 \\
\hline 350 & 5.2 .1 .2 .9 & 119 \\
\hline 351 & 5.2 .1 .2 .9 & 119 \\
\hline 352 & 5.2 .1 .2 .10 & 119,120 \\
\hline 353 & 5.2 .1 .2 .10 & 119,120 \\
\hline & 5.2 .1 .2 .11 & 120 \\
\hline
\end{tabular}

Cost objectives: most system components need development for maintenance and decontamination for alpha environment

Schedule objectives: expected to be ready for detailed design within specified schedule, no significant development problems or delays expected

Receiving and preparation: moderate technical, ES\&H, cost, schedule risks associated with 1) assay and nondestructive waste container examination, 2) decapping, dumping, sorting

Development needs: Real time radiography, alpha radiation assay, sorting table, container decapping

Incineration (primary treatment): low technology risk for processing nonalpha and moderate technology risk for alpha waste;

Development needs for: shredders and other feed preparation equipment, solids separation, rotary kiln incinerators, characterization (incinerator feed and bottom ash)

Air Pollution Control: most equipment (except monitoring) well developed and widely used (industry) but extensive development for system integration

Development needs for: induced fan limitations, baghouse temperature limitations, activated carbon filter temperature limitations, stack monitoring equipment, back flushable stainless steel HEPA filters,

Lead Recovery: most equipment well developed and widely used (industry); technology risk is low

Development needs for: many similar to incinerator APC; treatment of lead gloves

Mercury amalgamation: well developed and widely used (industry); technology risk is low

Development needs: primarily system integration

Metal decontamination: well developed with many units used in nuclear industry; technology risk is low

Development needs: some equipment requires system integration

Metal Melting: Need for subsystem in question; could be viable if single unit with equipment for fabrication of recovered steel is built for entire DOE complex waste

Equipment is well developed (operating units in US and Germany); technology risk is low

Development needs: fluxing agents, system integration of some equipment

Special waste treatment: designed and developed on case by case basis

Waste list must be developed and candidate processes studied

Anticipated waste is reactive metal (e.g. sodium contaminated debris)

Aqueous waste treatment: Commercially available processes and equipment; low technology risk

Development needs: minor, approach of precipitation, filtration, ion exchange, activated carbon for mercury removal must be finalized

Primary stabilization: Technology risk is moderate, minor technical uncertainties remain

Development needs: melt chemistry and vitrification formulations, melter furnace design, capturing volatilized metais and actinides, impact of carbon in ash

Secondary stabilization: commercially available equipment; low technology risk 
No. Sect. Page $U^{*} \underline{S}^{* *}$

\section{d) General Design and Operating Assumptions (continued)}

\begin{tabular}{|c|c|c|}
\hline 355 & 5.2.1.2.11 & 120 \\
\hline 356 & 5.2.1.2.12 & 120,121 \\
\hline 357 & 5.2.1.2.12 & 120,121 \\
\hline 358 & 5.2 .2 & 121 \\
\hline 359 & 5.2.2.1.1 & 121 \\
\hline 360 & 5.2.2.1.2 & 121 \\
\hline 361 & 5.2 .2 .1 .2 & 121 \\
\hline 362 & 5.2 .2 .2 & 121,122 \\
\hline 363 & 5.2 .2 .2 & 121,122 \\
\hline 364 & 5.2 .3 & 122 \\
\hline 365 & 5.2 .3 .1 .1 & .122 \\
\hline 366 & 5.2 .3 .1 .2 & 122 \\
\hline 367 & 5.2 .4 & 123 \\
\hline 368 & 5.2 .4 .1 .1 & 123 \\
\hline 369 & 5.2 .4 .1 .1 & 123,124 \\
\hline
\end{tabular}

$\begin{array}{ccc}370 & 5.2 .4 .1 .2 & 124 \\ 371 & 5.2 .4 .1 .3 & 124 \\ & & \\ 372 & 5.2 .4 .1 .3 & 124 \\ 373 & 5.2 .4 .2 .1 & 124.125 \\ & & \\ 374 & 5.2 .4 .2 .1 & 124.125 \\ & & \\ 375 & 5.2 .4 .2 .2 & 125 \\ 376 & 5.2 .4 .2 .2 & 125 \\ 377 & 5.2 .5 & 125 \\ 378 & 5.2 .5 .1 .1 & 126\end{array}$

Development needs: selecting polymer agent to stabilize salt and meet EPA TCLP

Certify and ship: commercially available equipment except assay unit; technology risk is low Development needs: assay unit (same as receiving and preparation)

System A2: Same as A1 except uses oxygen to minimize offgas volume

Technical objectives: compliance with emissions - NOX a concern; reduction of pollutant mass emission rate by using oxygen (lower offgas velocities)

Institutional objectives: better acceptance of thermal treatment by public, state and local agencies due to reduced offgas volume

Institutional objectives: concerns with concentration of pollutants in offgas

Incineration (primary treatment): additional risk over A1; limited application in treating hazardous waste

Development needs: oxygen control, leaky seals (appears controllable), burner design, flame propagation and control, prevention of ash slagging, NOX control

System A3: Same as A1 except uses all wet filtration APC; minor differences in technology risk

Technical objectives: mercury management - APC scrubber liquor may need additional treatment step; larger aqueous waste treatment

Safety and health objectives: less desirable than A1 due to higher final waste volume (all scrubber solids to polymer solidification instead of vitrification)

System A4: Same as A1 except 1) incinerator uses oxygen burner, 2) APC uses only dry filtration, 3) $\mathrm{CO} 2$ retention added; higher system technology risk than $A 1$

Technical objectives: compliance with emission limits - concern with fate of RCRA metals

Technical objectives: compliance with functional and operational requirements - development for zero air inleakage (greatest obstacle to delayed release), sampling methods for detecting EPA controlled pollutants in spent lime, methods for separating and releasing inert gases and solids, determining radionuclide fate, process control integration

Institutional objectives: possible positive reception by public, etc. due to significantly reduced offgas and delay feature

Cost objectives: $\mathrm{CO} 2$ retention in infancy, cost of system and waste disposal not accurately estimated

Schedule objectives: $\mathrm{CO} 2$ retention in infancy, many uncertainties in process development timing Incineration (primary treatment): main concern is potential for air inleakage although kiln vendors have significantly advanced technology

Development needs: seals, oxygen burner design, flame control, combustion oxygen control, ash slagging prevention

APC (CO2 retention): considered to have high technological risk; first of a kind application in ITTS Development needs: many (undefined) in prototype environment

System A5: Same as A1 but vitrification eliminated and all residues stabilized by polymers

Technical objectives: reduced technical uncertainty by eliminating vitrification but acceptability of polymerized waste form for long term alpha waste a concern 
d) General Design and Operating Assumptions (continued)

$\begin{array}{ccc}379 & 5.2 .5 .1 .2 & 126 \\ 380 & 5.2 .5 .1 .3 & 126 \\ 381 & 5.2 .5 .1 .3 & 126 \\ 382 & 5.2 .5 .2 & 126 \\ 383 & 5.2 .6 & 126\end{array}$

\begin{tabular}{|c|c|c|}
\hline 385 & 5.2.6.1.2 & 127 \\
\hline 386 & 5.2 .6 .1 .3 & 127 \\
\hline 387 & 5.2 .6 .1 .3 & 127 \\
\hline 388 & 5.2.6.2 & 127 \\
\hline 389 & 5.2.6.2.1 & 127 \\
\hline 390 & 5.2 .6 .2 .1 & 127 \\
\hline 391 & 5.2.6.2.2 & 127 \\
\hline 392 & 5.2 .6 .2 .2 & .127 \\
\hline 395 & 5.3.1.1 & 128,129 \\
\hline 396 & 5.3 .1 .2 & 129 \\
\hline 397 & 5.3 .2 & 129 \\
\hline 398 & 5.3.2.1 & 129 \\
\hline 399 & 5.3.2.2 & 129 \\
\hline 400 & 5.3 .2 .3 & 129,130 \\
\hline 401 & 5.3.2.2 & 129 \\
\hline 402 & 5.3.2.3 & 129,130 \\
\hline 403 & 5.4 .0 & 130 \\
\hline
\end{tabular}

Safety and health objectives: less desirable than baseline due to higher waste volume, less stable and more leachable waste

Institutional objectives: may be viewed less favorable than A1 because of higher waste volume Institutional objectives: lower total offgas volume (no vitrifier)

Subsystems: slightly lower technology risk, relative to $A 1$, due to elimination of vitrification

System A6: Same as A6 except for 1) activated carbon in APC is recycled, 2) metal solids separation unit added to incinerator feed preparation, 3) APC salt recovery process; higher technology risk than $\mathrm{A} 1$

Technical objectives: compliance with functional and operational requirements - development needed for metal recovery devices (complicated when processing alpha waste), mercury capture from spent carbon, concept for salt cracking (electrolytic process proposed but needs evaluation)

Institutional objectives: may be received more positively due to waste minimization

Cost objectives: salt recovery process, yet to be defined, small part LCC

Schedule objectives: many uncertainties in development timing

Subsystems: higher technology risk than A1

Incineration: concern is complicated front end

Development needs: feed preparation to remove metals

Salt recovery: very little known (process efficiency, waste volumes, key process parameters)

Development needs: evaluation of salt recovery options

temperature operation; greater technology risk than A1 although components commercially complicate process control; lower reliability and availability

Technical objectives: concerns are drying of noncombustibles (mechanical and control complexity, trace organics), vitrifier operation with residual organics in ash

Institutional objectives: better acceptance due to lower (1/6) offgas volume relative to $A 1$

Subsystems: greater technology risks relative to $\mathrm{A1}$

Receiving and preparation: higher sorting demand that increases size and complexity

Incineration: pyrolyzer in advanced development stage and reasonably flexible; concerns are consistent feedstock (combustibles only), oxygen control in pyrolyzer, minimizing carbon in ash

Incineration: for vitrifier, no data on limit on carbon in ash before quality of vitrified waste affected

Development needs: seal design (probably easier because of lower temperatures); further investigation of low temperature pyrolysis and elimination of refractory (benefits)

Development needs: pyrolysis and vitrification tests to determine carbon in ash limits and how to oxidize carbon in vitrification unit (e.g. oxygen lance)

System C1: technology currently used in metallurgical industry, differs from $A 1$ in that combustion and vitrification in same unit, and metal melting eliminated; higher risk than A1 due to lack of commercial experience, components readily available but require development and demonstration for integration

Technical objectives: compliance with emissions - development to determine fate of volatilized metals and actinides in APC and methods of capture; solutions include moving sand filter 
No. Sect. Page $U^{*} S^{* *}$

d) General Design and Operating Assumptions (continued)

$405 \quad 5.4 .1 .1 .2 \quad 13$

406

$5.4 .2 \quad 131,132$

407

$5.4 .2 \quad 131,132$

408

$5.4 .2 \quad 131,132$

409

5.5 .0

132

410

5.5.1.1.1 132

411

5.5.1.1.2 133

412

5.5.1.2

413

5.5 .1 .3

133

41

5.5.1.4

133

$415 \quad 5.5 .2 \quad 134$

$417 \quad 5.5 .2 .2 \quad 134$

$418 \quad 5.5 .2 .2 \quad 134$

$419 \quad 5.5 .2 .3 \quad 134$

$420 \quad 5.5 .2 .3 \quad 134$

$421 \quad 5.6 .0 \quad 134,135$

$422 \quad 5.6 .1 .1$

Technical objectives: compliance with functional and operational requirements - technology is in advanced development stage but can not be considered commercial; system will be commercially available within required time frame

Subsystems: overall technology risks lower than baseline; higher technology risk for primary treatment

Incineration (primary treatment): simpler, in principle relative to rotary kiln (A1), easily adapt to changes in feedstock heating value, precise combustion oxygen control, compact configuration; many units used in precision metallurgical melting

Incineration: concerns with electrode life ( $<100 \mathrm{hrs}$ on surrogate waste), type of refractory lining

System D1: differs from A1 in 1) fixed hearth air controlled incinerator, oxygen firing, treats only combustible waste, noncombustible waste sorted and sent to vitrifier, $\mathrm{CO} 2$ retention for offgas discharge delay; higher technology risk compared to A1

Technical objectives: compliance with emission limits - same as A4 with $\mathrm{CO} 2$ retention

Technical objectives: compliance with functional and operational requirements - APC same as A4, acid gas removal in vitrifier APC due to treatment of noncombustibles (with potential residual organics), vitrifier scrubber to capture volatilized salts, effective air locks around feed chute to prevent air inleakage

Institutional objectives: may result in better acceptance due to lower (1/10) offgas volume, delay feature that prevents release of pollutants

Cost objectives: $\mathrm{CO} 2$ retention in infancy, cost of system and final waste disposal can not be estimated accurately

Schedule objectives: $\mathrm{CO} 2$ retention in infancy, many uncertainties in process development timing Subsystems: higher technology risks than $\mathrm{A} 1$; components are commercially available but require development, demonstration, system integration

Receiving and preparation: higher sorting demands causes more complex and larger system Incineration: concerns are minimizing air inleakage

Development needs: selection of fixed hearth furnace design

APC $\mathrm{CO} 2$ retention: same concerns as $\mathrm{A} 4$

Development needs: lime recycling efficiency, other $\mathrm{CO} 2$ capture methods

System E1: characterized by minimal processing, differs from A1 in 1) thermal desorber for treating EPA debris, 2) offgas from desorber to rotary kiln incinerator, 3) grout stabilization of desorber solids; higher technology risk than A1

Technical objectives: compliance with functional and operational requirements - overall larger and more complex facility due to large sorting requirements of desorption, larger final waste volume, final waste form less stable

Institutional objectives: possible lower acceptability due to higher final waste volume, less stable waste form, even though less offgas

Subsystems: Adding thermal desorber produces higher technology risks; components are commercially available but require development and demonstration on integrated level

Receiving and preparation: uncertainties with requirements for extensive sorting

Primary treatment: concerns with melting plastic in desorber 
d) General Design and Operating Assumptions (continued)

\begin{tabular}{|c|c|c|c|c|c|}
\hline 427 & 5.6 .2 & 135 & & & Development needs: operating temperature of desorber to get good organic desorption \\
\hline 428 & A-5.2 & A-27 & & & Lead in any form to be removed as best as reasonably possible, sent to appropriate treatment \\
\hline 429 & A-5.2 & A-27 & & & Bulk mercury and all waste suspected of mercury contamination sorted, sent to mercury treatment \\
\hline 430 & A-5.2 & A-27 & & & Containers potentially temperature sensitive, set aside, depressurized, made safe for treatment \\
\hline 431 & A-5.2 & A-27 & & & Containers of waste not requiring sorting should be processed intact, if appropriate for system \\
\hline 432 & A-5.2 & A-27 & & & Waste containers decontaminated or processed with bulk metals if not processed with waste \\
\hline 433 & A-5.2 & A-28 & & & $\begin{array}{l}\text { Drums should be nondestructively monitored to determine plutonium content (desirable but not } \\
\text { yet possible) and gross liquid content }\end{array}$ \\
\hline 434 & A-5.2 & A-28 & & & $\begin{array}{l}\text { Vapor samples to be taken on-line with direct readout of composition from shredded waste in } \\
\text { sampling bin }\end{array}$ \\
\hline 435 & A-5.2 & A-28 & & & Pretreatment blanketed with nitrogen or other inert gas \\
\hline 436 & A-5.2 & A-28 & & & In-leakage to primary thermal treatment should be estimated \\
\hline 437 & A-5.2 & A-28 & 6 & 2 & $\begin{array}{l}\text { Units for waste preparation, thermal treatment should tolerate some level of inadvertently fed } \\
\text { explosive materials }\end{array}$ \\
\hline 438 & A-5.3.1 & A-28 & 6 & 2 & $\begin{array}{l}\text { Levels of substances in offgas from primary treatment must meet requirements set forth in RCRA } \\
\text { and TSCA }\end{array}$ \\
\hline 439 & A-5.3.1 & A-28 & & & $\begin{array}{l}\text { Parts of system processing alpha waste should operate at slight negative pressure, tolerable in } \\
\text { leakage provided }\end{array}$ \\
\hline 440 & A-5.3.1 & A-28 & & & Combustion air should be taken from innermost containment \\
\hline 441 & A-5.3.1 & $A-28$ & & & $\begin{array}{l}\text { No liquid effluent should be generated with moisture discharged to building exhaust or process } \\
\text { stack }\end{array}$ \\
\hline 442 & A-5.3.1 & A-28 & & & $\begin{array}{l}\text { Process monitoring and control should be recorded and audited and be sufficiently responsive } \\
\text { to prevent upsets and excessive reactions }\end{array}$ \\
\hline 443 & A-5.3.1 & A-29 & 3 & 8 & $\begin{array}{l}\text { Air pollution control systems must meet or exceed current, anticipated regulations with } \\
\text { performance specifications set to meet or exceed current regulations by } 10 \text { times }\end{array}$ \\
\hline 444 & A-5.3.1 & A-29 & & & $\begin{array}{l}\text { Treatment and containment systems should be flexible to accommodate maximum process } \\
\text { upsets and failures }\end{array}$ \\
\hline 445 & A-5.3.1 & A-29 & & & $\begin{array}{l}\text { Bulk ferrous metals treated by decontamination to free release standards (DOE order } 5400.5 \text { ) or } \\
\text { by metal melting (to destroy RCRA contaminants, remove surface contamination) }\end{array}$ \\
\hline 446 & A-5.3.1 & $A-29$ & & & $\begin{array}{l}\text { Metal meeting free release standards should have scrap value; metal treated by melting } \\
\text { removed from disposal stream for ROE recycle purposes with zero value }\end{array}$ \\
\hline 447 & A-5.3.1 & $A-29$ & & & $\begin{array}{l}\text { Bulk lead should be treated by surface decontamination if reasonably determined to have no } \\
\text { activation products; other lead treated by melting (remove noncombustibles), cast into blocks for } \\
\text { DOE use; alternative is microencapsulation }\end{array}$ \\
\hline 448 & A-5.3.1 & $A-29$ & & & $\begin{array}{l}\text { Mercury with radioactive contamination treated by amalgamation, radioactivity free mercury } \\
\text { should be recovered (distillation and capture), sold as scrap }\end{array}$ \\
\hline 449 & A-5.3.1 & $A-29$ & & & $\begin{array}{l}\text { Aqueous waste treated to evaporate water, immobilize contaminants into final waste form; highly. } \\
\text { acidic or alkaline waste neutralized; organic liquids treated by oxidation; chloride salts treated in } \\
\text { same manner as offgas treatment salt residues }\end{array}$ \\
\hline 450 & A-5.3.1 & $A-29$ & 9 & 8 & $\begin{array}{l}\text { System designed for } 20 \text { year operating life; particular attention to ease of maintenance and } \\
\text { selection of materials to avoid corrosion failures }\end{array}$ \\
\hline
\end{tabular}


d) General Design and Operating Assumptions (continued)

$\begin{array}{lll}451 & A-5.3 .2 & A-29 \\ 452 & \text { A-5.3.2 } & \text { A-29 } \\ 453 & \text { A-5.3.2 } & \text { A-29 } \\ & & \\ 454 & \text { A-5.3.2 } & \text { A-29 } \\ 455 & \text { A-5.3.2 } & \text { A-29 } \\ & & \\ 456 & \text { A-5.3.2 } & \text { A-29 } \\ 457 & \text { A-5.3.2 } & \text { A-30 } \\ 458 & \text { A-5.3.2 } & \text { A-30 } \\ 459 & \text { A-5.3.2 } & \text { A-30 } \\ & & \\ 460 & \text { A-5.3.2 } & \text { A-30 }\end{array}$

Versatile systems that can handle waste type variations, minimum separate operations, are desirable

Five oxidation, thermal treatment technologies meet implementability requirements: fluidized bed, rotary kiln, plasma arc, controlled air stationary or moving hearth, indirectly heated pyrolyzer

Volume of offgas minimized to the extent possible: externally heated pyrolyzer, oxygen instead of air, recycling gases, long residence times.

Fluid bed systems should recycle inert heating material

Containment chamber should be used for sealing around rotary kiln; rotary kiln should use double seals with internal pressure adjustment;

Combustion air should be taken from secondary containment zone

Feasibility converting RCRA metals and oxides from chloride salts should be evaluated Volatilization of metals kept to minimum for systems designed to retain most metals in bottom ash

Toxic secondary waste from APC converted to nontoxic (non RCRA controlled) LLW if economically justified

APC should offer best decontamination factor for radioactive materials and best removal efficiency for toxic materials; should provide redundancy of select components to allow limited maintenance while on-line

Three stages of HEPA filters before gas is discharged; filters in prefilters and HEPA filters should be processable in thermal treatment unit

High vapor pressure metals should be captured by APC for high volatility systems.

APC should use dry or semi dry first step to minimize radioactive wet effluent

Salt removed by aqueous washing (salt $>3 \%$ ) if solid secondary wastes from APC to be vitrified

Solid effluents from APC may be stabilized by polymers; cement stabilization not feasible for high salt content (not yet determined)

Additives should enhance vitrification and simultaneously dispose of contaminated material (Superfund soil satisfies)

$467 \quad$ A-5.3.2 A-30

Final secondary residues, dried if wet, then consolidated into waste form for near surface disposal; waste form should allow easy movement ( 55 gallon drum)

Vitrification unit should consist of module to allow easy replacement over maintenance (if less costly) and allow easy expansion (by adding modules) rather than increasing size

Six vitrification technologies meet implementability requirements: joule, electric arc, direct current plasma torch, fossil fueled, slagging rotary kiln, high frequency induction melter; must meet 1450 to $1650 \mathrm{C}$ for aluminosilicate final waste form with minimal fluxing

Five low temperature stabilization agents meet implementability requirements: Portland cement, polymer (Dow Chemical), pozzolanic cement, polyethylene, sulfur cement

d-1) System A1 - Rotary Kiln with Air and DryWet APC

$\begin{array}{lll}117 & 2.1 .1 & 17 \\ 118 & 2.1 .1 & 17\end{array}$

System A1 (baseline): The system involves a rotary kiln, dry ash, air combustion, dry-wet APC

The rotary kin used in the A1 system is similar to the TSCA incinerator at Oak Ridge National Laboratory (ORNL). 

No. Sect. Page $\mathbf{U}^{*} \mathbf{S}^{* *}$
d-1) System A1 - Rotary Kiln with Air and DryWet APC (continued)

\begin{tabular}{|c|c|c|c|c|c|}
\hline 119 & 2.1 .1 & 17 & & & $\begin{array}{l}\text { The APC subsystem in the A1 is similar to the APC on the Scientific Ecology Group (SEG } \\
\text { incineration facility at Oak Ridge. }\end{array}$ \\
\hline 120 & 2.1 .1 & 17 & & & Solids residues are stabilized by a combination of vitrification and polymer solidification \\
\hline 121 & 2.1 .1 & 17 & 6 & 8 & $\begin{array}{l}\text { Contaminated soil from environmental restoration programs may be used as one of the } \\
\text { vitrification additives. }\end{array}$ \\
\hline
\end{tabular}

d-2) System A2 - Rotary Kiln with Oxygen and DryMet APC

$122 \quad 23 \quad 23 \quad$ System A2: Same as A1 except that the incinerator is equipped to use commercially pure oxygen as the combustion gas;

$123 \quad 2.1 .2 \quad 23$

APC subsystem has smaller capacity since oxygen combustion creates lower volumes and velocities of offgas relative to air combustion

d-3) System A3 - Rotary Kiln with Air and Wet APC
$124 \quad 2.1 .3 \quad 23$
System A3: Same as A1 except that APC subsystem uses all wet filtration and cleaning techniques

d-4) System A4 - Rotary Kiln with Oxygen and CO2 Retention

\begin{tabular}{|c|c|c|c|c|}
\hline 2.1 .4 & 23 & & & System A4: Same as A1 except incinerator uses oxygen as combustion gas \\
\hline 2.1 .4 & 23 & & & $\begin{array}{l}\text { APC uses conventional dry filtration with removal of } \mathrm{CO} 2 \text { by absorption onto lime (or dolomite) in } \\
\text { fluidized bed }\end{array}$ \\
\hline 2.1 .4 & 23 & & & Off gas enriched with oxygen and recycled to incinerator \\
\hline 2.1 .4 & 23 & 7 & 7 & Spent lime recycled as many as ten times by calcining \\
\hline 2.1 .4 & 23 & 7 & 7 & $\begin{array}{l}\text { CO2 is monitored and discharged; calcining can be done on or off site or spent lime can be } \\
\text { disposed }\end{array}$ \\
\hline 2.1 .4 & 23 & & & Receiving and preparation different from A1, bulk metals, slag and tar formers removed \\
\hline 2.1 .4 & 23 & & & Aqueous waste treatment larger than baseline in order to handle water condensed from off gas \\
\hline
\end{tabular}

d-5) System A5 - Rotary Kiln with Air and Polymer Stablization

$132 \quad 2.1 .5 \quad 24$

$133 \quad 2.1 .5 \quad 24$

d-6) System A6 - Rotary Kiln with Air and Maximum Recycling

$134 \quad 2.1 .6 \quad 24$

$135 \quad 2.1 .6 \quad 24$

$136 \quad 2.1 .6 \quad 24$

$137 \quad 2.1 .6 \quad 24$
System A6: Same as A1 except designed to minimize volume of disposed waste through enhanced feedstock preparation

Containers and some bulk metals recovered, decontaminated and recycled within facility

Aqueous secondary waste streams except scrubber blowdown treated in aqueous waste treatment

Blowdown from acid gas scrubber is processed through salt splitting (electrodialysis) system to produce caustic and $\mathrm{HCl}$ 
d-6) System A6 - Rotary Kiln with Air and Maximum Recycling (continued)

$\begin{array}{llll}138 & 2.1 .6 & 24 & \text { Caustic can be recycled to wet section of APC } \\ 139 & 2.1 .6 & 24 & \text { Activated carbon filters in offgas line are recycled using retorting for mercury recovery } \\ 140 & 2.1 .6 & 24 & \text { Stainless steel HEPA filters are cleaned and reused }\end{array}$

d-7) System B1 - Indirectly Heated Pyrolyzer with Oxygen and DryMet APC

\begin{tabular}{|c|c|c|c|}
\hline 2.2 & 24 & 56 & $\begin{array}{l}\text { System B1: Combines indirect fired, electrically heated, rotary kiln pyrolyzer, SCC, and } \\
\text { vitrification unit all fired on oxygen }\end{array}$ \\
\hline 2.2 & 24 & & $\begin{array}{l}\text { Electrical heating and burning in oxygen starved pyrolysis minimizes offgas which is then } \\
\text { oxidized in SCC with pure oxygen }\end{array}$ \\
\hline 2.2 & 24 & & Standard wet-dry APC and feedstock preparation subsystems \\
\hline 2.2 & 24 & & Solid residues from pyrolyzer vitrified, with oxygen injected via lance to assure carbon burnout \\
\hline 145 & 24 & & Offgas from pyrolyzer and vitrifier oxidized in same SCC and APC units \\
\hline 2.2 & 24 & & Organics from aqueous secondary waste treatment recycled to pyrolyzer \\
\hline 2.2 & 24 & & $\begin{array}{l}\text { Sludges from precipitation and filtration to primary stabilization or polymer stabilization if } \\
\text { necessary }\end{array}$ \\
\hline
\end{tabular}

d-8) System C1 - Plasma Hearth with Air and DryMet APC

$\begin{array}{llll}148 & 2.3 & 26 & \text { System C1: Combines plasma arc furnace with SCC both fired on air and standard dry-wet APC } \\ 149 & 2.3 & 26 & \begin{array}{l}\text { Plasma furnace performs thermal treatment, vitrification, metal melting simultaneously } \\ \text { Removal of only bulk lead and mercury (for separate treatment) required }\end{array} \\ 150 & 2.3 & 26 & \begin{array}{l}\text { Boxes, large metals, debris reduced in size for feed handling system and plasma chamber } \\ 151\end{array} \\ 152 & 2.3 & 26 & \begin{array}{l}\text { Solids residues, including radionuclides, drawn off in molten glass stream containing vitrified } \\ \text { ash, and molten metal stream }\end{array} \\ 153 & 2.3 & 26 & \text { Organics and sludges from aqueous waste treatment to plasma furnace }\end{array}$

d-9) System D1 - Fixed Hearth with Oxygen and CO2 Retention

\begin{tabular}{|c|c|c|c|c|c|}
\hline 154 & 2.4 & 27 & & & $\begin{array}{l}\text { System D1: Combines substoichiometric, fixed hearth primary combustor (controlled air } \\
\text { incinerator) with SCC, both fired on oxygen }\end{array}$ \\
\hline 155 & 2.4 & 27 & & & Fluidized bed absorber used for $\mathrm{CO} 2$ removal after dry APC \\
\hline 156 & 2.4 & 27 & & & $\begin{array}{l}\text { Calcium carbonate monitored for RCRA materials, stored, then either calcined (on or off site) or } \\
\text { landfilled }\end{array}$ \\
\hline 157 & 2.4 & 27 & & & Released $\mathrm{CO} 2$ monitored for RCRA and radioactive compounds \\
\hline 158 & 2.4 & 27 & 7 & 7 & Lime recycled up to ten times; landfilling eliminates $\mathrm{CO} 2$ release \\
\hline 159 & 2.4 & 27 & & & Standard feedstock preparation with removal of large pieces of metal and noncombustibles \\
\hline 60 & 2.4 & 27 & & & Organics and sludges from aqueous waste treatment to fixed hearth \\
\hline
\end{tabular}

d-10) System E1 - Debris Desorption and Grouting with Rotary Kiln for Combustibles 


\begin{tabular}{|c|c|c|c|}
\hline No. & Sect. & Page $U^{*} \mathbf{S}^{* *}$ & ITTS PHASE 1 - ASSUMPTIONS OR DESIGN FEATURES \\
\hline$d-10)$ & System E1 & - Debris Desorp & otion and Grouting with Rotary Kiln for Combustibles \\
\hline 162 & 2.5 & 29 & Combines standard rotary kiln with air combustion with parallel operating rotary kiln desorber, \\
\hline 163 & 2.5 & 29 & Standard feedstock preparation and standard dry-wet APC \\
\hline 164 & 2.5 & 29 & Desorber separates VOC's from debris (and soil) as defined by RCRA \\
\hline 165 & 2.5 & 29 & $\begin{array}{l}\text { Organics from desorber to rotary kiln and treated debris to shredding and microencapsulation } \\
\text { by grouting }\end{array}$ \\
\hline 166 & 2.5 & 29 & Organics and sludges from aqueous waste treatment to rotary kiln \\
\hline 167 & 2.5 & 29 & Ash from rotary kiln to vitrification \\
\hline
\end{tabular}

\section{e) Subsystem Design and Operating Assumptions}

e-1) Receiving and Preparation

$\begin{array}{rrrrr}168 & 2.1 .1 .1 & 18 & & \\ 169 & 2.1 .1 .1 & 18 & & \\ 170 & 2.1 .1 .1 & 18 & & \\ 171 & 2.1 .1 .1 & 18 & & \\ 172 & 2.1 .1 .1 & 18 & & \\ 173 & 2.1 .1 .1 & 18 & 9 & 2 \\ & & & & \\ 174 & 2.1 .1 .1 & 18 & & \\ & & & & \\ 175 & 2.1 .1 .1 & 18 & 9 & 8 \\ & & & & \\ 176 & 2.1 .1 .1 & 18 & 9 & 8 \\ & & & & \\ 177 & 2.1 .1 .1 & 18 & 9 & 8 \\ 178 & 2.1 .1 .1 & 23,28 & 9 & 3 \\ 179 & 2.1 .1 .1 & 5.28,29 & 9 & 3 \\ 180 & 2.1 .1 .1 & 26 & & \end{array}$

e-2) Primary Treatment

$\begin{array}{lll}181 & 2.1 .1 .2 & 18 \\ 182 & 2.1 .1 .2 & 18 \\ 183 & 2.1 .1 .2 & 18\end{array}$

All Systems: Cranes and fork lift trucks unload waste containers from incoming vehicles The physical state of the input waste is identified by real-time radiography (RTR).

A passive/active neutron (PAN) assay unit determines the level of TRU contamination. A segmented gamma scanning (SGS) unit is used to assay beta and gamma radioactivity. Each unit of waste input is assigned a bar code for computer tracking.

Incoming waste is classified as either sorting required (SR) or sorting not required (SNR) depending on its characterization.

Containers decapped by saw on gantry, Sorting on a table by master-slave and hydraulic manipulators.

Systems $A 1, A 2, A 3, A 4, A 5, A 6, C 1$ : It is assumed that $51 \%$ of the waste requires sorting (Table 3-9 Phase II report)

Systems B1 and D1: It is assumed that $100 \%$ of the waste requires sorting (Table 3-9 Phase II report)

System E1: It is assumed that $71 \%$ of the waste requires sorting (Table 3-9 Phase II report)

Systems A4 and D1: Bulk metal, tar and slag formers removed

Systems B1, D1, E1: Most of noncombustible bulk material separated out

System C1: Minimal processing with removal only of bulk lead and mercury, large pieces of metal and debris reduced in size, metal not needing melting to decontamination

Systems A1, A3, A5: The primary treatment includes a feed shredder, a characterization unit, a natural gas/air fired rotary kiln, a secondary combustion chamber (SCC), and an air blower.

Input to the rotary kiln incinerator includes combustible and noncombustible solids, sludges (also from aqueous treatment), and organic liquids.

The unit shreds intact drums and boxes and feeds the shredded material to transport bins and hoppers 


\begin{tabular}{|c|c|c|c|c|c|}
\hline No. & Sect. & Page & $\mathbf{U}^{\prime \prime}$ & $\mathbf{S}^{\star \star}$ & ITTS PHASE 1 - ASSUMPTIONS OR DESIGN FEATURES \\
\hline e-2) & Primary & reatment & & ontinu & ued) \\
\hline 184 & 2.1.1.2 & 18 & & & $\begin{array}{l}\text { Empty wooden boxes shredded and sent to transport bins and hoppers; empty metal containers } \\
\text { to metal treatment. }\end{array}$ \\
\hline 185 & 2.1.1.2 & 18 & & & Bins and hoppers are sampled and analyzed before being fed to the incinerator. \\
\hline 186 & 2.1.1.2 & 18 & & & $\begin{array}{l}\text { Negative air pressure is maintained in the rotary kiln using special graphite and steel seals to } \\
\text { minimize air in-leakage. }\end{array}$ \\
\hline 187 & 2.1.1.2 & 18 & 3 & 6 & Secondary confinement is provided for the baseline incinerator by a metal housing. \\
\hline 188 & 2.1.1.2 & 23 & & & Systems A2, A4: Same as baseline except oxygen for combustion \\
\hline 189 & 2.1.1.2 & 25 & 5 & 6 & System B1: Pyrolyzer, SCC, dryer are integrated with vitrification unit (vitrifier type ?) \\
\hline 190 & 2.1.1.2 & 25 & & & Noncombustible waste fed to dryer along with soil or additives \\
\hline 191 & 2.1 .1 .2 & 25 & & & Combustible waste undergoes partial combustion at $1200 \mathrm{~F}$ in oxygen starved atmosphere \\
\hline 192 & 2.1.1.2 & 25 & & & Ash from pyrolyzer and output from dryer fed to vitrifier \\
\hline 193 & 2.1.1.2 & 25 & & & Pyrolyzer offgases treated at $2200 \mathrm{~F}$ in SCC with stoichiometric oxygen \\
\hline 194 & 2.1.1.2 & 26 & & & $\begin{array}{l}\text { Oxygen supplied to vitrifier to combust carbon residue; gas pockets from burning carbon makes } \\
\text { vitrified waste less dense }\end{array}$ \\
\hline 195 & 2.1.1.2 & 26 & & & $\begin{array}{l}\text { System C1: Plasma electric arc furnace operated in pyrolytic or starved air mode to minimize } \\
\text { formation of nitrogen oxides }\end{array}$ \\
\hline 196 & 2.1.1.2 & 26 & & & Off gases burned in SCC using air \\
\hline 197 & 2.1.1.2 & 28 & & & $\begin{array}{l}\text { System D1:Fixed hearth incinerator in which waste is transported over hearth by ram feeder or } \\
\text { other conventional feeder }\end{array}$ \\
\hline 198 & 2.1.1.2 & 28 & & & Screw conveyor stirs ash pile and moves to ash ports \\
\hline 199 & 2.1.1.2 & 28 & & & $\begin{array}{l}\text { Combustible waste heated in oxygen starved atmosphere to facilitate volatilization and partial } \\
\text { combustion }\end{array}$ \\
\hline 200 & 2.1.1.2 & 28 & & & Off gases are burned in SCC using excess oxygen \\
\hline 201 & 2.1.1.2 & 29,30 & & & $\begin{array}{l}\text { System E1: Same as baseline except smaller rotary kiln to treat only combustible waste } \\
\text { (process residues) }\end{array}$ \\
\hline 202 & 2.1 .1 .2 & 29,30 & & & $\begin{array}{l}\text { Indirectly heated calciner for thermal desorption separates VOC from noncombustible (RCRA } \\
\text { debris and soil) }\end{array}$ \\
\hline 203 & 2.9 .1 .2 & 29,30 & & & $\begin{array}{l}\text { Waste components vaporized in desorber are treated in APC consisting of stripper and } \\
\text { condensers }\end{array}$ \\
\hline 204 & 2.1.1.2 & 29,30 & & & Organic liquids from desorber sent to rotary kiln \\
\hline 205 & 2.1.1.2 & 29,30 & & & Solid residues from desorber are sent to debris grouting \\
\hline
\end{tabular}

\section{e-3) Air Pollution Control (APC)}

System A1: The air pollution control subsystem (APC) includes both dry gas filtration and wet scrubbing. Incoming gas is quenched by water jets and filtered through either a baghouse or a ceramic filter, followed by HEPA filters.

$\begin{array}{lll}207 & 2.1 .1 .3 & 19 \\ 208 & 2.1 .1 .3 & 19\end{array}$

An activated carbon filter is used in front of the HEPA filter to remove trace quantities of mercury.

The baseline wet scrubber includes a complete water quench followed by hydrosonic (venturi) and packed-bed scrubbers for acid gas removal. A system for NOx and dioxin is also included. 
No. Sect. Page $U^{*} \underline{S}^{* \star}$

e-3) Air Pollution Control (APC)

209

210

211

21

21

214

215

21

217

218

220

221

2.1.1.4 19

e-4) Primary Stabilization

$\begin{array}{lllll}222 & 2.1 .1 .10 & 21 & & \\ 223 & 2.1 .1 .10 & 21 & 7 & 7 \\ 224 & 2.1 .1 .10 & 21 & & \\ 225 & 2.1 .1 .10 & 21 & \\ & & & \\ 226 & 2.1 .1 .10 & 21 \\ 227 & 2.1 .1 .10 & 21 \\ 228 & 2.1 .1 .10 & 21 \\ 229 & 2.1 .1 .10 & 21 \\ 230 & 2.1 .1 .10 & 21 \\ 231 & 2.1 .1 .10 & 21 \\ & & & \\ 232 & 2.1 .1 .10 & 21 \\ 233 & 2.1 .1 .10 & 21 \\ 234 & 2.1 .1 .10 & 21 \\ 235 & 2.1 .1 .10 & 21 \\ 236 & 2.1 .1 .10 & 21 \\ \end{array}$

(continued)

The continuous emissions monitor (CEM) analyzes and records $\mathrm{CO}, \mathrm{CO} 2, \mathrm{O} 2$, particulate and "other compounds". A continuous radiation detector is included.

System A2: smaller capacity due to oxygen use in the former and

System A3: uses only wet filtration and cleaning as dry gas filtration has been eliminated

System A4: eliminates wet filtration, except for water condensation, and adds $\mathrm{CO} 2$ absorption

System A5: Same as A1

System A6: Same as A1 but includes salt splitting process

System B1: Smaller capacity than A1 due to indirect heating with oxygen combustion

System C1: Smaller capacity than A1 since the volume of offgas generated per unit mass of waste is smaller (?); capability to reduce nitrogen oxides required

System D1: Special delayed release APC using dry filtration followed by $\mathrm{CO} 2$ absorption into lime in fluidized bed

Water vapor from incinerator first condensed, remaining gas stored, sampled, released if meeting requirements

Lime or dolomite recycled up to ten times in calcining lime recovery system

Lime disposed by secondary stabilization after ten cycles on premise that it contains RCRA metals and is subject to disposal restrictions

System E1: Smaller than A1

System A1: Vitrification used to convert incinerator ash to waste form suitable for disposal

Soil (including contaminated soil from DOE installations) or chemical additives ( ) used as glass formers

Input waste must be properly characterized for proper incinerator ash prediction

Soil added to kin, discharged to storage hopper than melter; vitrified ash and soil discharged to container

Container cooled, capped, sent to swiping and decontamination

Decontamination if necessary by high pressure water jets

Inspected container to assay, certification, and shipped to storage or disposal

Melter has dry filtration APC

Systems A2, A3, A4, A6: Same as A1

System A5: Treats incinerator ash by polymer encapsulation using sulfur cement, polyethylene. or polymerizing agents

Dried powder and polymer metered into extruder that heats and mixes feed

Extruder feeds mixture to drum which is capped, sent to swiping and decontamination

Decontamination by high pressure water jets or blasts of dry ice

Inspected container to assay, certification, then shipped to storage or disposal

Systems B1 and C1: No separate primary stabilization as vitrification performed in primary treatment 
No. Sect. Page $U^{*} \underline{S}^{\star \star}$

e-4) Primary Stabilization (continued)

$237 \quad 2.1 .1 .10 \quad 21$

$238 \quad 2.1 .1 .10 \quad 21$

$239 \quad 2.1 .1 .10 \quad 21$

$240 \quad 2.1 .1 .10 \quad 21$

e-5) Secondary Stabilization

$241 \quad 2.1 .1 .11 \quad 22$

$242 \quad 2.1 .1 .11 \quad 22$

$243 \quad 2.1 .1 .11 \quad 22$

$244 \quad 2.1 .1 .11 \quad 22$

$245 \quad 2.1 .1 .11 \quad 22$

$246 \quad 2.1 .1 .11 \quad 22$

e-6) Metal Decontamination

$\begin{array}{lll}247 & 2.1 .1 .6 & 19 \\ 248 & 2.1 .1 .6 & 19\end{array}$

e-7) Metal Meiting

$249 \quad 2.1 .1 .7 \quad 20$

$250 \quad 2.1 .1 .7 \quad 20$

$251 \quad 2.1 .1 .7 \quad 20$

$252 \quad 2.1 .1 .7 \quad 20$

$253 \quad 2.1 .1 .7 \quad 20$

$254 \quad 2.3 \quad 26$

e-8) Lead Recomvery

$\begin{array}{lll}255 & 2.1 .1 .4 & 19 \\ 256 & 2.1 .1 .4 & 19 \\ 257 & 2.1 .1 .4 & 19 \\ 258 & 2.1 .1 .4 & 19 \\ 259 & 2.1 .1 .4 & 19\end{array}$

System D1: Same as A1 except noncombustibles are dried and soil is added to ash from incinerator

System E1: Same as A1 except only ash and soil from rotary kiln are vitrified

Debris from thermal desorber shredded mixed with grout (cement, water, sand), poured into drums and cured

Drums are capped, washed, sent to certify and ship

Receives treated residues not suitable for primary stabilization via vitrification (salts with low melting points or fly ash exceeding specified salt concentration)

Treats salts and fly ash by polymer encapsulation using sulfur cement, polyethylene, or polymerizing agents

Dried powder and polymer metered into extruder that heats and mixes feed

Extruder feeds mixture to drum which is capped, sent to swiping and decontamination

Decontamination by high pressure water jets or blasts of dry ice

Inspected container to assay, certification, then shipped to storage or disposal

All Systems: metal decontamination subsystem uses size reduction tools (plasma torch, saw and shear

Abrasive blasting (with dry ice to minimize liquid waste generation) to remove entrained and surface contamination.

All Systerns except $\mathrm{C} 1$ : metal melting, used when surface decontamination cannot be accomplished,

Inductive melter used to remove most of the radioactive material in the molten slag

Slag cast in container, cooled, inspected, assayed, and shipped to storage or disposal

Clean metal is poured into ingots, cooled, sent for DOE reuse

Induction melter used dry filtration APC

System C1: metal melting accomplished in primary treatment

All Systems: Subsystem consists of decontamination train and electrically heated roasting oven

Saws, shears, sanders cut lead waste and remove metal cladding

Scarfing and abrasive blasting booths for decontamination

Oven melts lead that can not be decontaminated by mechanical means

Oven uses dry filtration APC 
No. Sect. Page $U^{*} \underline{S}^{* *}$

e-9) Aqueous Waste Treatment

$\begin{array}{lll}260 & 2.1 .1 .9 & 20 \\ 261 & 2.1 .1 .9 & 20 \\ 262 & 2.1 .1 .9 & 20 \\ 263 & 2.1 .1 .9 & 20\end{array}$

$\begin{array}{lll}264 & 2.1 .1 .9 & 20 \\ 265 & 2.1 .1 .9 & 20 \\ & & \\ 266 & 2.1 .1 .9 & 20 \\ 267 & 2.1 .1 .9 & 20 \\ & & \\ 268 & 2.1 .1 .9 & 20\end{array}$

e-10) Mercury Amalgamation

$269 \quad 2.1 .1 .5 \quad 19$

e-11) Special Waste Treatment

$270 \quad 2.1 .1 .8 \quad 20$

e-12) Certify and Ship

$\begin{array}{lll}271 & 2.1 .1 .12 & 22 \\ 272 & 2.1 .1 .12 & 22 \\ 273 & 2.1 .1 .12 & 22 \\ 274 & 2.1 .1 .12 & 22 \\ 275 & 2.1 .1 .12 & 22\end{array}$

All Systems: Treats all aqueous waste including corrosive wastewater or contaminated with DS, SS, organics, heavy metals

Treats secondary aqueous waste - APC scrubber blowdown, abrasive blasting sludge, container rinse water,

Incoming aqueous waste is segregated and stored in three batch tanks: 1) high levels of total organic carbon (TOC), 2) high levels of total dissolved solids (TDS), and 3) low levels of TDS.

High TOC aqueous waste is treated by floatation or coalescence to remove gross organics, filtration for suspended solids and dissolved organics (carbon filtration or ozonation), and ion exchange for dissolved solids. Alternatively, high-TOC waste can be fed to the thermal treatment subsystem.

High TDS aqueous waste neutralized, filtered, and evaporated to concentrate dissolved solids.

Low TDS aqueous waste is filtered, treated using a carbon filter or ozonation to remove dissolved organics, and by ion exchange to remove dissolved solids.

Sludges from aqueous waste treatment are concentrated and send to the stabilization system(s).

Aqueous waste with mercury contamination is treated using sulfur-impregnated activated carbon and mercury-selective ion exchange resins.

Spent ion exchange resin dewatered and sent to primary treatment or stabilization

All Systems: mercury in contaminated solids recovered by retorting and condensation. Retorted solids are sent to primary stabilization. Offgas is treated in a secondary combustion chamber and a wet-dry APC system. Mercury is recycled if not radioactive. If radioactively contaminated, it is amalgamated with zinc or copper for stabilization and disposal.

All Systems: No conceptual design has be developed for "special wastes", which will be dealt with on a case-by-case basis. A cost allowance of $\$ 3$ million is included in cost estimates.

All Systems: Characterizes physical, radiological properties of final wastes to allow certification for transportation, storage, disposal

RTR examines for homogeneity, and free water

TRU or alpha processed waste measured by PAN for TRU concentration

SGS unit assays beta and gamma radioactivity

Waste to temporary storage or shipped to on-site or off-site disposal

f) Life Cycle Cost and Sensitivity Analysis

$\begin{array}{lll}276 & 4.0 & 76 \\ 277 & 4.0 & 76 \\ 278 & 4.0 & 76\end{array}$

Transportation costs included on generic basis, small fraction ( $-5 \%)$ of total LCC

For comparison, systems sized at $2927 \mathrm{lb} / \mathrm{hr}$ (up from $2000 \mathrm{lb} / \mathrm{hr}$ Phase l), treat over 20 year period For smaller capacity systems, use cost vs. capacity curve Waste Management Facilities Cost Information Report 
No. Sect. Page $U^{*} \mathbf{S}^{* *}$

7) Life Cycle Cost and Sensittilty Analysis (continued)

\begin{tabular}{|c|c|c|c|c|c|}
\hline 279 & 4.0 & 76 & 9 & 8 & One system used for entire inventory and thus designed for alpha waste \\
\hline 280 & 4.1 & 76 & & & $\begin{array}{l}\text { Cost information obtained during 3rd quarter 1993; based on currently available knowledge } \\
\text { about waste processing requirements, technology availability, cost data }\end{array}$ \\
\hline 281 & 4.1 & 76 & 9 & 2 & Facilities are government owned and contractor operated (GOCO) \\
\hline 282 & 4.1 & 76 & & & Treatment unit rates by dividing total PLCC estimate by total operating hours per year \\
\hline 283 & 4.2 & 76 & & & $\begin{array}{l}\text { PLCC estimate for each facility has six components each estimated separately: Studies and } \\
\text { Bench Scale Tests; Demonstration; Production Facility Costs; Operations Budget Funded } \\
\text { Activities; Operating and Maintenance Costs; Decontamination and Decommissioning }\end{array}$ \\
\hline 284 & 4.2.1 & 78 & & & $\begin{array}{l}\text { Costs for studies and bench scale tests, and demonstration obtained by estimating research } \\
\text { manpower, equipment, facility needs costs }\end{array}$ \\
\hline 285 & 4.2 .2 & 78 & & & $\begin{array}{l}\text { Production facility costs consist of design, inspection, project management, construction cost, } \\
\text { construction management }\end{array}$ \\
\hline 286 & 4.2.2.1 & 78 & & & $\begin{array}{l}\text { Design - includes Titie } 1 \text { preliminary design and Title } 2 \text { detailed design; } 25 \% \text { of facility } \\
\text { construction cost (FCC) for alpha facility }\end{array}$ \\
\hline 287 & 4.2.2.2 & 78 & & & Inspection - includes Title 3 engineering support during construction; $7 \%$ of FCC \\
\hline 288 & 4.2.2.3 & 78 & & & Project management - for both DOE and site management and operations contractor; $10 \%$ of FCC \\
\hline 289 & 4.2.2.4 & 78 & & & $\begin{array}{l}\text { Construction cost - based on preconceptual design package developed for subsystems and } \\
\text { integrated facilities; includes process functional diagram, mass flows, functional allocation } \\
\text { diagram, scoping study layout, summary of functional and operational requirements }\end{array}$ \\
\hline 290 & 4.2.2.4 & 78 & & & Three parts to construction cost - building and structures, equipment, indirect costs \\
\hline 291 & 4.2.2.4 & 78 & 9 & 6 & $\begin{array}{l}\text { Building and structures - estimated by multiplying building unit costs by square feet for each } \\
\text { subsystem }\end{array}$ \\
\hline 292 & 4.2.2.4 & 78 & 9 & 6 & $\begin{array}{l}\text { Assumed rates ( } \mathrm{sq} \mathrm{ft} \text { ) - } \$ 1700 \text { triple confinement alpha cells (alpha waste processing areas), } \\
\$ 800 \text { double confinement cells (alpha equipment pull out) and operating areas next to alpha } \\
\text { cells, } \$ 420 \text { packaged waste handling (truck or drum bay) and nonalpha process, operator and } \\
\text { packaged waste areas } \$ 180 \text { for office areas, } \$ 420 \text { for analytical lab }\end{array}$ \\
\hline 293 & 4.2.2.4 & 78 & & & Rates include materials and labor, utilities, lighting. HVAC, site development \\
\hline 294 & 4.2.2.4 & 78 & & & Utilities and access road assumed to be within 100 feet of treatment facility \\
\hline 295 & 4.2.2.4 & 78 & & & $\begin{array}{l}\text { Not included - special steel support, foundations, ventilation ducts and hoods for process } \\
\text { components }\end{array}$ \\
\hline 296 & 4.2.2.4 & 79 & 9 & 8 & Equipment - costs obtained from similar facility, soliciting suppliers, engineering judgments \\
\hline 297 & 4.2.2.4 & 79 & & & Installation costs based on individual equipment requirements \\
\hline 298 & 4.2.2.4 & 79 & & & $\begin{array}{l}\text { Electrical, instrumentation, mechanical bulks estimated as percentage of total purchased } \\
\text { equipment }\end{array}$ \\
\hline 299 & 4.2.2.4 & 79 & & & Indirect costs - include subcontractor overhead and fee; $29 \%$ of building. structures, equipment \\
\hline 300 & 4.2.2.5 & 79 & & & $\begin{array}{l}\text { Construction management - includes materials and services procurement and control activities; } \\
\text { estimated at } 17 \% \text { of construction costs }\end{array}$ \\
\hline 301 & 4.2.2.5 & 79 & & & Management reserve - $10 \%$ of construction costs \\
\hline 302 & 4.2.2.5 & 79 & 9 & 9 & $\begin{array}{l}\text { Contingency - } 25 \% \text { due to planning level estimate; applied to all components in production } \\
\text { facility construction cost }\end{array}$ \\
\hline
\end{tabular}


APPENDIX E

\section{IDENTIFIED ASSUMPTIONS FOR THE ITTS STUDY - PHASE 2}


NO. SEC PAGE .......... 'CRITERIA .........

$\begin{array}{lllllllll}1 & 2 & 3 & 4 & 5 & 6 & 7 & 8 & 9\end{array}$

ASSUMPTIONS OR DESIGN FEATURES

a) Regulations, Permitting and Stakeholder Input (WPI)

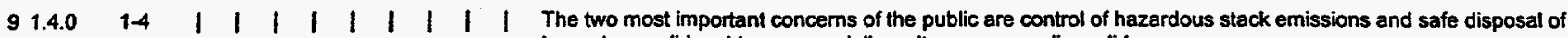 hazardous solid residues, especially as it concerns radionuclides.
$\begin{array}{llllllllllll}13 & 1.5 .1 & 1-11 & 3 & 1 & 10 & \mid & \mid & \mid & \mid & \mid\end{array}$ Conservation and Recovery Act (RCRA), and the Clean Air Act (CAA).
$\begin{array}{lllllllllllll}15 & 1.5 .1 & 1-11 & 3 & 6 & 3 & \mid & \mid & \mid & \mid & \mid\end{array}$ and Liability Act (CERCLA) may be retrieved for treatment.
$\begin{array}{lllllllllll}14 & 1.5 .1 & 1-11 & 3 & 1 & 10 & \mid & \mid & \mid\end{array} \mid$ it is assumed that permits will be required under the Toxic Substances Control Act (TSCA), the Resource
$\begin{array}{lllllllllll}16 & 1.5 .1 & 1-11 & 1 & 3 & 6 & \mid & \mid & \mid & 1 & \mid\end{array}$ solid waste in the Code of Federal Regulation 40 CFR 240 will apply. RCRA permitting involves additional regulations applying to particular systems depending on the type of process used.
$\begin{array}{lllllllllll}17 & 1.5 .1 & 1-11 & 2 & 2 & 8 & 1 & 1 & \mid\end{array}$ categories of listed hazardous wastes under RCRA: 1) "F wastes" from nonspecific sources; 2) "K wastes" from specific sources; and "P and U wastes" from discarded and off-specification products, container residues, and spills.
$\begin{array}{llllllllllll}19 & 1.5 .1 & 4-11 & 4 & 6 & 4 & \mid & \mid & \mid & \mid & \text { I Some regulatory guidelines have been published by the EPA, as for example in the document entitled Quality }\end{array}$ Assurance and Quality Control for Waste Containment Facilities, September 1993. However, specific permitting requirements may depend on the characterization of the final waste form obtained from pilot tests or demonstrations.
20 1.5.2 1-11 $\mid \begin{array}{lllllllll} & \mid & \mid & \mid & \mid & \mid & \mid & \text { DOE orders applicable to all systems include: }\end{array}$

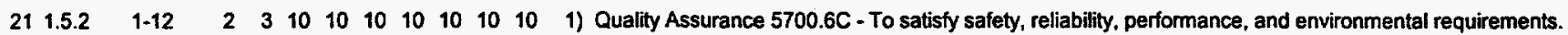
$221.5 .2 \quad 1-12 \quad|1| 1|1| 1|1| 1 \mid$
2) Occurrence Reporting 5000.3B - To inform DOE and contractor management of "reportable occurrences."
$231.5 .2 \quad 1-12|| 101|1| 1 \mid$
3) Conduct of Operations 5480.19 - To organize, operate and manage to assure safety.
$24 \begin{array}{llllllllll}24.5 .2 & 1.12 & \mid & 1 & 10 & \mid & \mid & \mid & 1 & 1\end{array}$
4) Hazardous Material Packaging for Transport 15402
$\begin{array}{lllllllllll}25 & 1.5 .2 & 1-13 & 2 & 2 & 1 & \mid & \mid & \mid & \mid & 1\end{array}$
5) Value Engineering $4010.1 \mathrm{~A}$ - To reduce nonessential costs and to improve productivity.
$\begin{array}{llllllllll}26 & 1.5 .2 & 1-13 & 3 & 3 & 10 & \mid & \mid & \mid & 1\end{array}$
6) Maintenance Management 4330.4A - To protect environment, health, safety and property by cost effective means.
$\begin{array}{lllllllllllll}27 & 1.5 .2 & 1-13 & 2 & 2 & 1 & \mid & \mid & \mid & \mid & \mid & \mid & \text { 7) Project Management } 41700.1 \text { - Systematic and coordinated project management and control. } \\ 28 & 1.5 .2 & 1-13 & \mid & \mid & 10 & \mid & \mid & \mid & \mid & \mid & \mid & \text { 8) General Environmental Protection } 5400.1 \text { - DOE's policy to comply with all applicable environmental } \\ \text { regulations. }\end{array}$

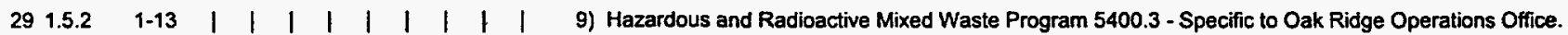

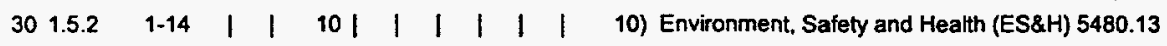
$\begin{array}{lllllllllll}31 & 1.5 .2 & 1.14 & 101 & \mid & \mid & \mid & 11) \\ \text { ES\&H Standards } 5480.4\end{array}$

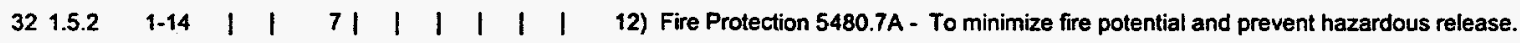
$339.5 .2 \quad 1.14|1 \quad 101| 1|1|$
13) Radiation Protection for Workers 5480.11 - To insure that radiation exposures are within standards.
$\begin{array}{lllllllllll}34 & 1.5 .2 & 1-14 & \mid & 1 & 7 & 1 & 1 & 1 & 1 & 1\end{array}$
$\begin{array}{llllllllll}35 & 1.5 .2 & 1-15 & 3 & 3 & 1 & 1 & \mid & 1 & 1\end{array}$
14) Planning and Preparedness for Operational Emergencies 5500.2A
$\begin{array}{lllllllllll}36 & 1.5 .2 & 1.15 & 3 & 3 & 10 & 1 & 1 & 1 & 1 & 1\end{array}$
$\begin{array}{lllllllllllllll}37 & 1.5 .2 & 1-15 & 2 & 3 & 1 & 1 & 1 & 1 & 1 & 1 & 1\end{array}$
15) Work Authorization System $5700.7 \mathrm{C}$
16) Radioactive Waste Management $5820.2 \mathrm{~A}$ - Over 50 DOE requirement and laws are attached.
38 1.5.3 1-15 $|1| 1|1| 1|1|$
17) General Design Criteria 6430.1A - To satisfy all applicable Executive Orders, Federal laws and regulations.
$\begin{array}{llllllllll}39 & \text { 1.5.3.1 } & 1.15 & \mid & \mid & 10 & 1 & \mid & \mid & \mid\end{array}$
1) Clean Air ACt - Emission limits used for ITTS design are listed in Tables 1-2 and 1-3 and Appendix A. The proposed emission limits for metals used by ITTS are 10-fold lower than EPA limits (Table 1-3).

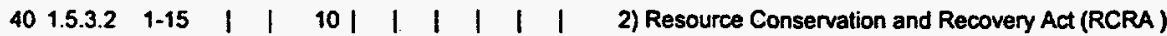

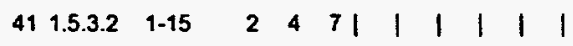
$\begin{array}{llllllllllll}42 & 1.5 .3 .2 & 1-17 & 3 & 8 & 5 & 1 & 1 & 1 & 1 & 1 & 1\end{array}$
Permitting for rotary kiln systems $A 1$ and $A 7$ is assumed to be under incinerator standards.
Systems C3 (plasma gasification). F1 (molten salt), $\mathbf{G} 1$ (molten metal), and H1 (steam gasification) are assumed to be permitted as either miscellaneous thermal units or as industrial furnaces.
$\begin{array}{lllllllllll}43 & 1.5 .3 .2 & 1.17 & 3 & 8 & 5 & \mid & \mid & \mid & \mid & 1\end{array}$
$\begin{array}{lllllllllll}44 & 1.5 .3 .2 & 1-17 & 4 & 9 & 2 & 1 & \mid & \mid & \mid & 1\end{array}$
Thermal desorption systems $K 1$ and $L 1$ will be classified as miscellaneous facilities.
System $\mathrm{G} 1$ (molten metal) may not require RCRA permitting if it can be classified as a recycling facility. The report casts doubt on this possibility, and it is presumed that the study does not treat it in that manner.

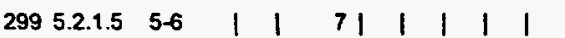

The public and permitting agencies are not receptive to incinerators, despite a high performance potential and 
NO. SEC PAGE $\ldots \ldots \ldots$. CRITERIA ...........

$\begin{array}{lllllllll}1 & 2 & 3 & 4 & 5 & 6 & 7 & 8 & 9\end{array}$

experience at ORNL and Savannah River. Siting selection is critical.

327 5.3.1.5 5-15 | | $\mid$ longer residence time, lesser sensitivity to variations in feed, higher destruction efficiency (including PCBs). reduced particulate loading, reduced dioxin formation, lower heat input requirement. and elimination of need for separate virtrification.

b) Input Waste Characteristics (WPI lead and EERC)

$\begin{array}{lllllllll}1 & 1.1 .0 & 1-1 & \mid & \mid & \mid & \mid & \mid\end{array}$ inorganic solids and liquids contaminated with radioactive substances.

5 1.2.0 1-2 $\quad|\quad| \quad|\quad| \quad|\quad| \quad|\quad|$ The waste types treated are described in the DOE Mixed Waste Inventory Report (MWIR).

$\begin{array}{lllllllllll}51 & 1.5 .3 .3 & 1-18 & 1 & 2 & 9 & \mid\end{array} \quad|\quad| \quad$ It is assumed that input waste contains EPA-listed hazardous organics or other RCRA-controlled substances.

52 1.5.3.3 1-18 $127|\quad| \quad|\quad| \quad \mid$ Input waste will be shipped to the treatment facility in drums, metal bins, and wooden and fiberglass boxes.

53 1.5.3.3 1-18 | | $\quad 7$ | | | | | Input waste will include alpha and nonalpha MLLW. Alpha low-level waste has more than 10 nCi/g and less than $100 \mathrm{nCi} g$.

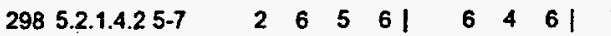

The proposed system for feedstock characterization is based on a remotely operated on-line grab sampler and the transportable hoppers and the incinerator feeder that controls the feeding sequence after characterization. The concept has not been tested and requires engineering development.

c) Waste Characterization (WPI lead and EERC)
18 1.5.1 1-11
$281|1| 11$
Wastes, whether listed or not, must be characterized by testing or prior process knowledge to determine if it exhibits any of the four characteristics of hazardous waste: 1) corrosivity, 2) ignitability, 3) reactivity, and 4) toxicity.
$\begin{array}{llllllllllll}45 & 1.5 .3 .3 & 1-18 & 1 & 9 & 2 & 1 & 1 & 1 & 1 & 1 & 1\end{array}$
Available drum assay procedures for radionuclides having errors of $+_{-} 100 \%$ at 100 nanocuries per gram (nCi/g) are assumed to be adequate for characterizing input.

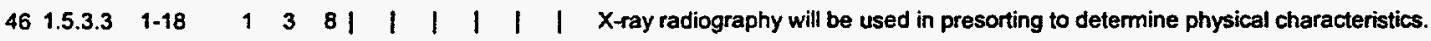
\begin{tabular}{llllll|lllll}
47 & 1.5 .3 .3 & $1-18$ & 1 & 3 & 8 & $\mid$
\end{tabular}
48 1.5.3.3 1-18 $1991 \mid$
$49 \quad 1.5 .3 .3 \quad 1-18$

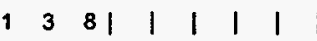
Screening analysis for total carbon will determine the need for organic speciation (e.g. GC/MS).
$501.5 .3 .3 \quad 1-18$
$\begin{array}{lllllllll}1 & 5 & 3 & 1 & 1 & \mid & 1 & \text { TCLP leaching } \\ \text { disposal facility }\end{array}$

d) General Design and Operating Assumptions (EERC)

2 4.1.0 $1-1 \quad|\quad| \quad|\quad| \quad|\quad| \quad|\quad|$ The general requirements of thermal treatment systems are to destroy organic materials and stabilize inorganic residues and radionuclides prior to disposal in a MLLW disposal facility

$\begin{array}{lllllll}3 & 1.1 .0 & 2 & 3 & 1\end{array}|\quad| \quad|\quad| \quad \mid$ Sources of study information included vendor catalogs providing technical data and prices, and direct contacts with developers and vendors of new technologies.

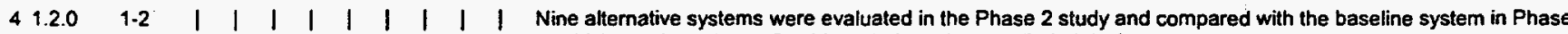
1 , which was based on a fixed-hearth dry-ash controlled-air incinerator.

$\begin{array}{llllllllllll}6 & 1.3 .0 & 1.3 & \mid & \mid & \mid & \mid & \mid & \mid & \mid\end{array}$ The systems evaluated in Phase 2 were based on new and innovative thermal technologies. whereas Phase 1 systems incorporated reasonably mature technologies.

\begin{tabular}{lll|l|l|l|l|l|}
71.4 .0 & $1-3$ & $\mid$
\end{tabular} minimize short- and long-term adverse impacts on worker and public environment, health and safety (EH\&.S).

$\begin{array}{lllllll}8 & 1.4 .0 & 1-4 & 8 & 8 & \mid\end{array}$ and waste stabilization. No details were provided in the Phase 2 study report to indicate the basis for selecting the systems studied.

\begin{tabular}{lll|l|l|l|l|l|}
10 & 1.4 .0 & 14 & $\mid$ & $\mid$ & $\mid$
\end{tabular} provide the greatest protection against future releases into the environment. and also to provide a margin against more stringent future release standards.

$121.4 .0 \quad 1.5 \quad|\quad| \quad|\quad| \quad|\quad| \quad \mid$ Phase 2 systems include: 1) Slagging rotary kiln, A7; 2) Plasma furnace with CO2 retention, C2; 3) Plasma

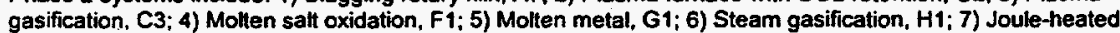
vitrification. $\mathrm{J1} ; \mathrm{B}$ ) Thermal desorption and mediated electrochemcial oxidation. K1; and 9) Thermal desorption and supercritical water oxidation, $\mathbf{L 1}$.

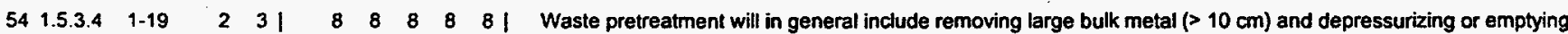
temperature sensitive materials such as gas cylinders. Additional pretreatment requirements apply to the various individual systems.

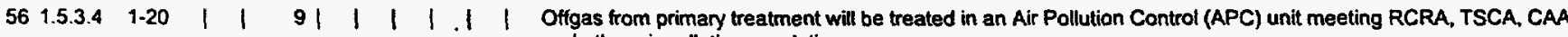
and other air pollution regulations.

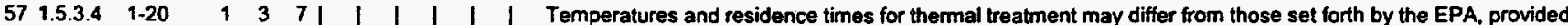


NO. SEC PAGE........ "CRITERIA ........

$\begin{array}{lllllllll}1 & 2 & 3 & 4 & 5 & 6 & 7 & 8 & 9\end{array}$

ASSUMPTIONS OR DESIGN FEATURES

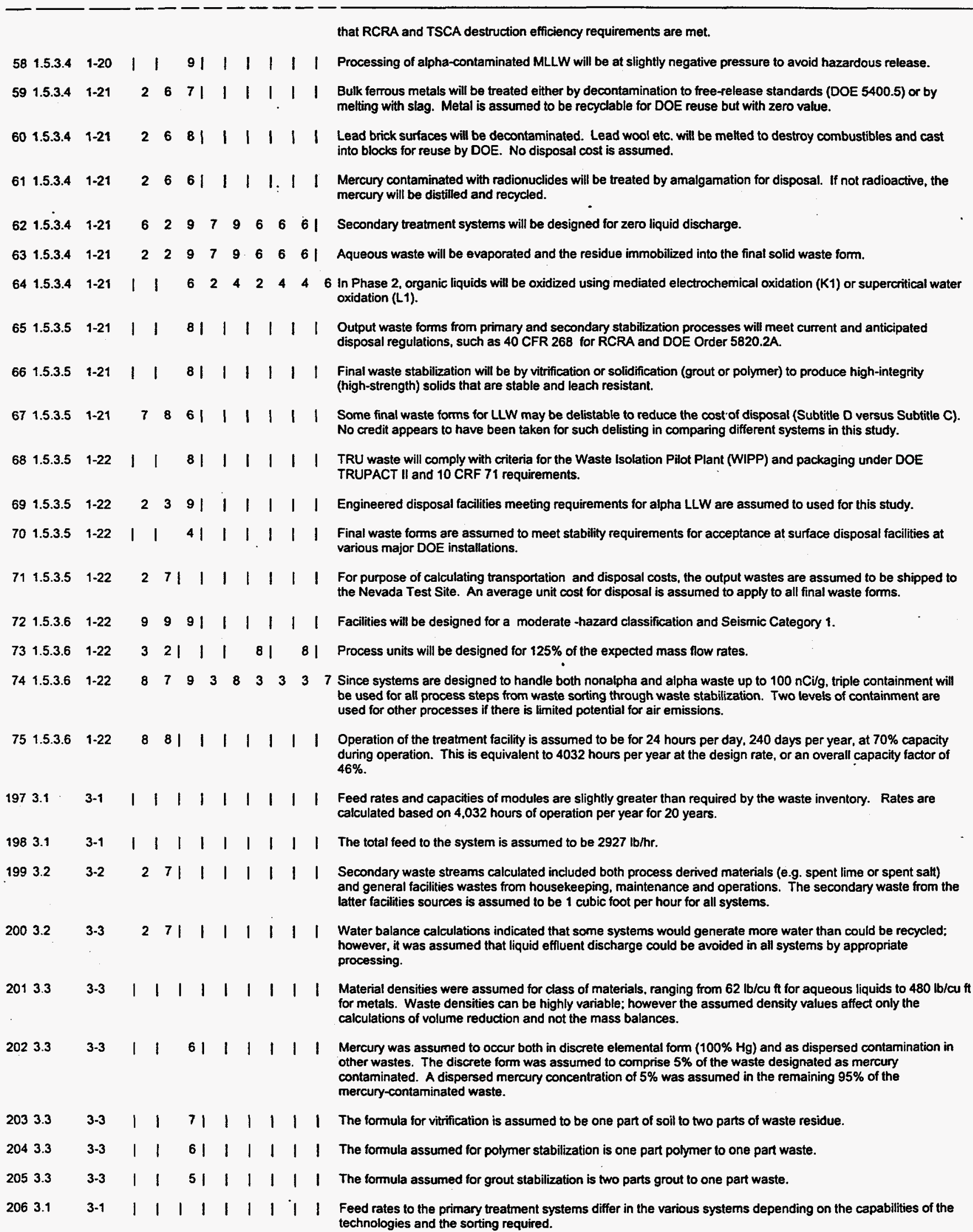


NO. SEC PAGE $\ldots \ldots \ldots \ldots$......... CRITERIA $\ldots \ldots \ldots$

$\begin{array}{llllllllll}1 & 2 & 3 & 4 & 5 & 6 & 7 & 8 & 9\end{array}$

2073 3-3 $221|1| 11$

2083.3 lb/hr combustible waste.

\section{$2093.3 \quad 3-4 \quad 2 \quad 2$ | | | | | | | The feed rate to thermal systems treating only presorted combustible waste (e.g. F1-molten salt oxidation and H1-steam gasification) is assumed to be $660 \mathrm{lb} / \mathrm{hr}$ of combustible waste. \\ $2103.3 \quad 3-4 \quad 22|| \quad|\quad| \quad|\quad|$. Feed rates to System G-1 (molten metal destruction) are assumed to be 1340 ib/hr noncombustible waste, 660 $\mathrm{lb} / \mathrm{hr}$ combustible waste, and $617 \mathrm{lb} / \mathrm{hr}$ of metal. \\ $\begin{array}{llllllll}211 & 3.3 & 3 & 2 & 2 & 4 & \mid\end{array}$ combustible and noncombustible waste combined, excluding any organic liquid streams. \\ rates to subsystems for organics oxidation (MEO in K1 and SCWO in L1) are assumed to include 51 to/h of separable organic liquid from the combustible waste stream, $16 \mathrm{lb} / \mathrm{hr}$ of organic liquid from the aqueous waste stream, and $358 \mathrm{lb} / \mathrm{hr}$ of organies recovered by thermal desorption. \\ $\begin{array}{lllllllllll}215 & 3.3 & 3-5 & 2 & 8 & 7 & \mid\end{array}$ waste. \\ $2963.3 \quad 3-5 \quad 4 \quad 5 \quad 7 \quad|\quad| \quad|\quad| \quad \mid$ The ash produced from combined combustible and noncombustible wastes (i.e. from the combined 2000 tb/hr) is assumed to comprise $54 \%$ of the feed. \\ $2173.3 \quad 3-5 \quad 3 \quad 5 \quad 7|\quad| \quad|\quad| \quad \mid$ The ash produced from combustible waste alone is assumed to comprise $7 \%$ of the combustible feed. \\ \begin{tabular}{llllll|l|l|}
218 & 3.3 & 2 & 2 & 3
\end{tabular} Vitrification System. This drying requirement includes systems designed to send unprocessed combustibles to the vitrifier (In Phase 2, F1- molten salt oxidation and H1-steam gasification).}

$2193.3 \quad 3-5 \quad 167 \quad|\quad| \quad|\quad| \quad \mid \quad$ The mass ratio of soil additive to waste input (inert) in vitrification subsystems is assumed to be $0.5: 1$ as a consistent design criteria. The soil additive is assumed to contain $10 \%$ moisture by weight.

The 0.5:1 mass ratio of soil to waste is assumed to apply to the Joule-heated melter despite the relatively narrower range of operating temperature for the borosilicate glass usually formed in this system (when compared to alumino-silicate based basalt).

$\begin{array}{lllllllll}221 & 3.4 & 3-6 & \mid & \mid & \mid\end{array} \mid$ various systems in the study, but this difference had little bearing on comparative life cycle costs.

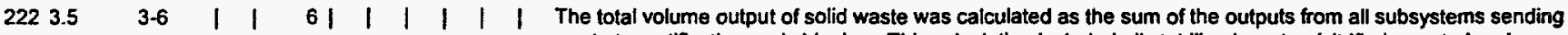
waste to certification and shipping. This calculation included all stabilized wastes (vitrified, grouted and polymer encapsulated) and outputs from one-step thermal processes producing a final waste form. A waste volume reduction factor was calculated.

$2233.5 \quad 3-5 \quad 141 \quad|\quad| \quad|\quad| \quad \mid$ Decontaminated metals that are recyclable are not included in the volume output sent to disposal

$2243.6 \quad 3-5 \quad|\quad| \quad 7|\quad| \quad|\quad| \quad \mid \quad$ Minimizing the volume of offgas is an objective that provides important benefits by reducing particulate carryover, reducing the size and cost of APC equipment, and possibly improving public acceptance of thermal treatment systems.

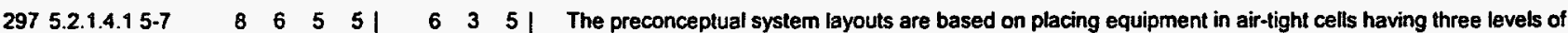
confinement. Personnel access is through airlock doors, with large corridors provided next to each cell for equipment pull-out and maintenance. This approach "has seldom been used by DOE" and it needs further evaluation.

d-0) Baseline System A-1: Dry-Ash Air-Fired Rotary Kiln

55 1.5.3.4 1-20 $\quad$ ～～$\quad 8 \quad|\quad| \quad|\quad| \quad \mid$ Attributes of the baseline system are as follows: Primary treatment to meet EPA requirements will include oxidation or decomposition of combustibles to reduce volume and destroy RCRA-controlled substances.

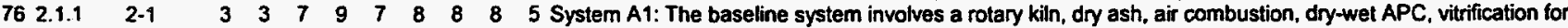
primary stabilization, and polymer solidification of secondary stabilization.

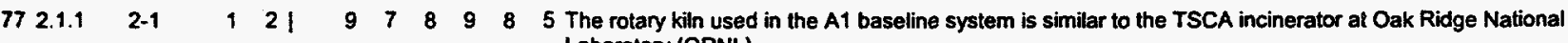
Laboratory (ORNL).

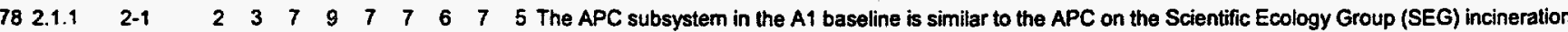
facility at Oak Ridge.

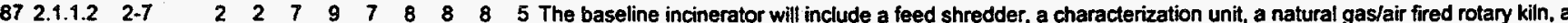
secondary combustion chamber (SCC), and an air blower.

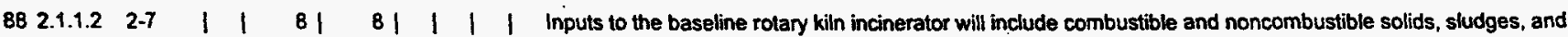
organic liquids. 
NO. SEC PAGE $\ldots \ldots \ldots . .$. CRITERIA $\ldots . . . .$.

$\begin{array}{lllllllll}1 & 2 & 3 & 4 & 5 & 6 & 7 & 8 & 9\end{array}$

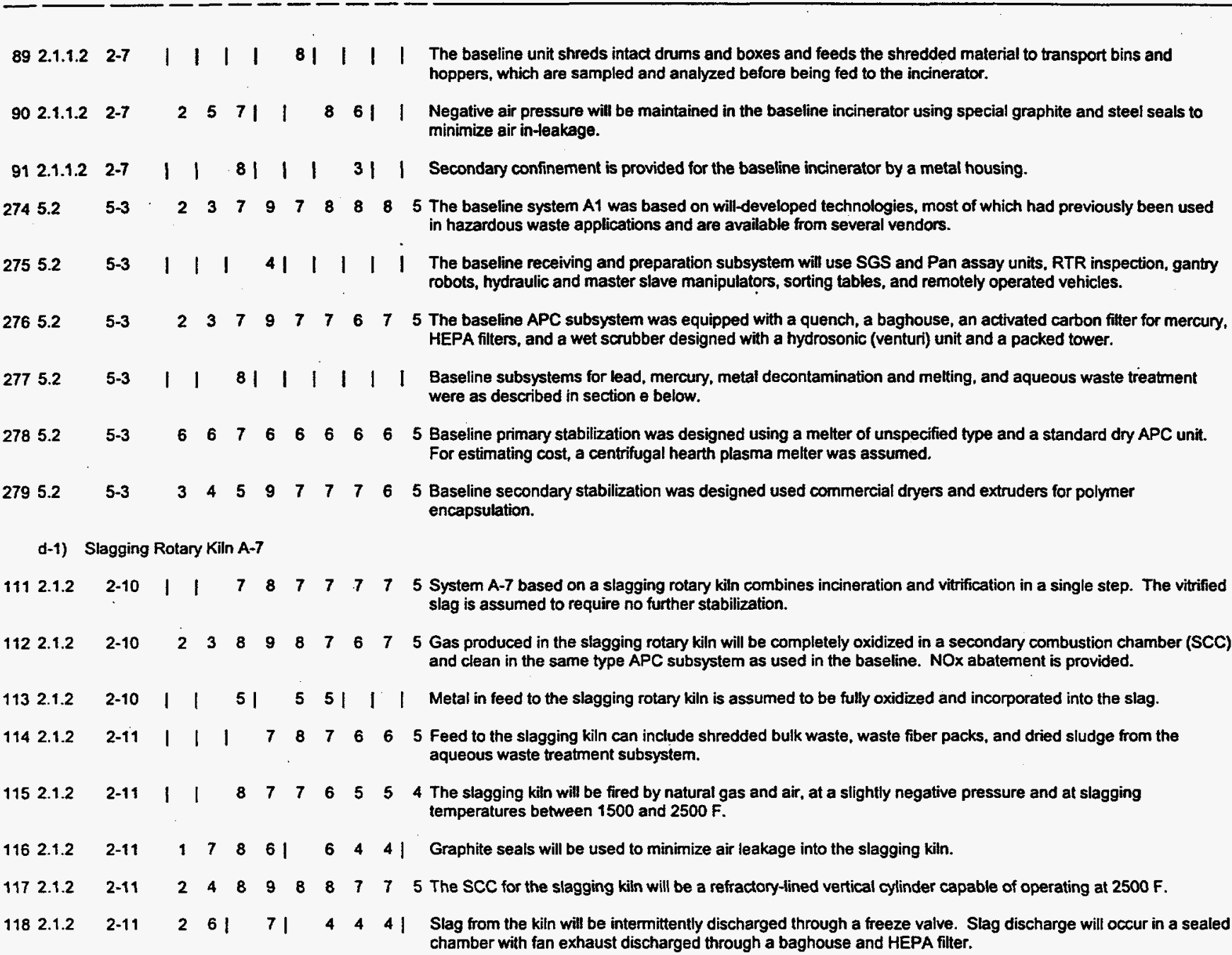

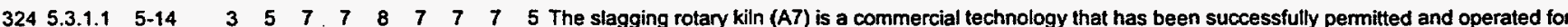
hazardous waste treatment in the U.S. and Europe (5.3.1.4). The final waste form is expected to meet LDR standards. Therefore the technology risk under regulatory compliance should be low.

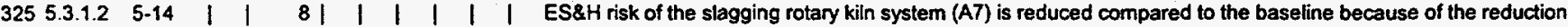
in worker exposure resulting from elimination of the vitrification subsystem.

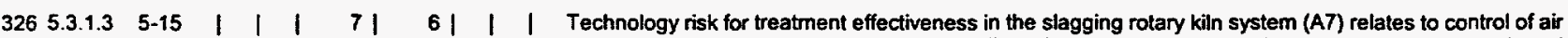
leakage and refractory maintenance. An additional issue is whether the slag produced will be consistently leach-resistant or will require further stabilization. Development work may be needed on fluxing/slagging agents in relation to leaching characteristics.

328 5.3.1.7 5-16 $\quad 3 \quad 3 \quad|\quad| \quad|\quad| \quad \mid \quad$ The slagging rotary kiln has minimal technology risks of cost or schedule overruns..

d-2) Plasma fumace, CO2 Retention C-2

$\begin{array}{lllllllllll}119 & 2.2 .1 & 2-12 & \mid & 8 & 4 & 5 & 4 & 4 & 4 & 4\end{array}$ The plasma furnace with oxygen combustion and $\mathrm{CO} 2$ retention (System $\mathrm{C2}$ ) is a variation of the conventional plasma fumace system (C-1) in the Phase 1 study. The plasma furnace combines the three functions of thermal treatment, vitrification and metal melting.

$\begin{array}{lllllllllll}120 & 2.2 .1 & 2-12 & \mid & \mid & 4 & 8 & 4 & 4 & 4 & 4\end{array}$ Using oxygen for combustion and removing CO2 from the offgas minimizes the amount of offgas. Remaining offgas, primarily oxygen, is recycled to the fumace, with a small blowdown stream discharged to the atmosphere.

$\begin{array}{llllllll}121 & 2.2 .1 & 2-12 & \mid & 5 & 5 & 5\end{array}$ removed and treated separately. and large pieces of metal and debris are reduced in size to fit into the feed system.

122 2.2.1 2-12 | | $\quad 7$ | | | | | Metals fed to the oxygen plasma furnace are assumed to be fully oxidized and incorporated into the slag. eliminating the need for a separate metal melting subsystem.

123 2.2.1 2-12 | | 4 | | | | | | | | | Contaminated soil or other additives are added to control the properties of the slag. 


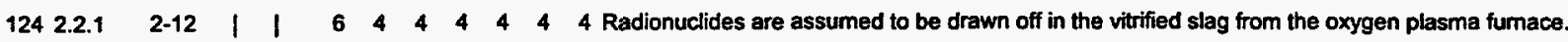

$\begin{array}{llllllllllll}125 & 2.2 .1 & 2-12 & 6 & 7 & 8 & 4 & 8 & 4 & 3 & 4 & 5\end{array}$ The APC subsystem for the oxygen plasma furnace will include a fluidized bed of lime to remove CO2, chlorides and water from the offgas. The spent lime will be calcined for recycling; the released $\mathrm{CO} 2$ will be discharged to the atmosphere.

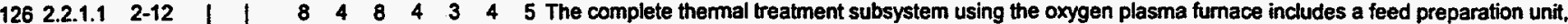
the plasma fumace and a secondary combustion chamber (SCC).

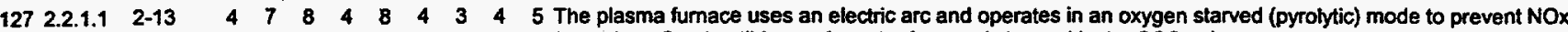
formation. Combustible gas from the furnace is bumed in the SCC using oxygen.

$\begin{array}{lllllllllll}128 & 2.2 .1 .1 & 2-13 & \mid & \mid & \mid & \mid & \mid & 4 & 4 & 4\end{array}$ The molten slag in the oxygen plasma furnace will be periodically drawn off. Feed to the furnace is suspended during slag discharge.

$\begin{array}{llllllllllll}129 & 22.12 & 2-13 & 3 & 4 & 7 & 8 & 6 & 6 & 5 & 6 & 5\end{array}$ Ahead of the $\mathrm{CO} 2$ retention unit, the APC subsystem for the oxygen plasma furnace is the same as that for System A4. Offgas from the SCC will be water quenched and sequentially fittered in a baghouse, carbon filter. and HEPA filter. Chlorides and acid gases are removed in a spray-dryer scrubber using lime.

$\begin{array}{lllllllllll}130 & \text { 2.2.9.2 } & 2-13 & \mid & \mid & 6 & \mid & \mid & \mid & \mid\end{array}$

$\begin{array}{lllllllllll}131 & 2.2 .1 .2 & 2-13 & 1 & 2 & 7 & 1 & 1 & 1 & 1 & 1\end{array}$

Gas from the spray dryer will be passed through a reheater ahead of the fluidized bed lime $\mathrm{CO} 2$ absorber, which operates at $650 \mathrm{C}$.

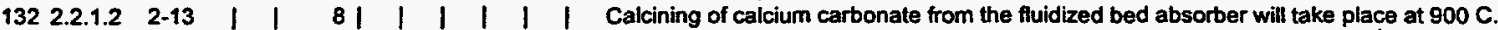

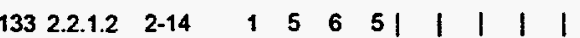

$90 \%$ of the recalcined lime will be recycled to the fluidized bed, with the remainder going either to the spray dryer or directly to (polymer) stabilization.

$\begin{array}{llllllllllll}134 & 2.2 .1 .2 & 2-13 & 2 & 3 & 9 & 8 & 8 & 7 & 6 & 8 & 5\end{array}$ The bleed stream from the (recycled) offgas stream from the fluidized bed absorber in system C-2 will be sent through a condenser and a delay tank before discharge

$3295.4 \quad 5-17 \quad|\quad| \quad|\quad| \quad|\quad| \quad|\quad| \quad$ The plasma fumace with $\mathbf{C O}$ retention (C2) is said to be a centrifugal design at one point the study report (sec. 5.4) and a fixed hearth design at another point (sec. 5.4.2.2).

$\begin{array}{llllllllllll}330 & 5.4 .1 & 5-17 & 6 & 6 & 8 & 4 & 8 & 4 & 3 & 4 & 5\end{array}$ The technology risk of the oxygen plasma furnace system (C2) is judged higher than the baseline due to lack of commercial experience, offgas recycling, short plasma torch lifetimes, problems of refractory lifetime, moving parts and complex seals in the centrifugal hearth.

\begin{tabular}{|c|c|c|c|c|c|c|c|}
\hline 315.4 .2 .2 & $5-20$ & 6 & 61 & 31 & 3 & 41 & $\begin{array}{l}\text { - No plasma arc system (C2) has yet operated for more than } 100 \text { hours on waste or surrogate waste. } \\
\text { Electrode lifetime is very limited. }\end{array}$ \\
\hline 0 & $5-20$ & 1 & 1 & 51 & 5 & 611 & $\begin{array}{l}\text { - The fixed hearth plasma furnace design has a double-walled shell with cooling water in the annulus, } \\
\text { aaking air leakage less likely than for a rotary design and allowing use of dependable, low-temperature } \\
\text { aterials. }\end{array}$ \\
\hline
\end{tabular}

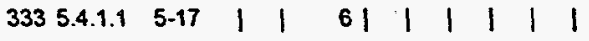
$3345.4 .1 .25-17 \quad|\quad| \quad 5 \mid$ $\begin{array}{lllllllll}335 & 5.4 .1 .3 & 5-18 & \mid & \mid & \mid & 3 & 3 & 3\end{array}$

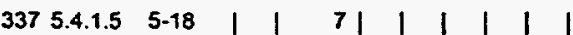

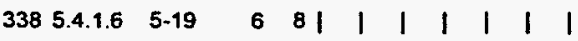
$\begin{array}{llllllllllll}339 & 5.4 .1 .7 & 5-19 & 6 & 6 & 1 & \mid & 1 & 1 & 1 & 1\end{array}$ $\begin{array}{llllllllllllllllll}340 & 5.4 .1 .7 & 5-19 & \mid & \mid & \mid & \mid & \mid & 1 & \mid & 1 & 1\end{array}$ $\begin{array}{lllllllllll}341 & 5.4 .2 .1 & 5-19 & \mid & \mid & \mid & 6 & 8 & 6 & 5 & 6\end{array}$ $3425.4 .2 .35-20 \quad|\quad| \begin{array}{llllll}4 & 2 & 2 & 2 & 1 & 1\end{array}$ d-3) Plasma Gasification C-3
- Regulatory compliance risk is favorable influenced by permitting requirements similar to an incinerator and a vitrified product expected to exceed LDR requirements.

- EH\&S risks are reduced by the small controlled gas discharge, but the fate of metals remains a concern with respect to volatilization in the plasma fumace, capture in the APC, absorption in the lime bed, revaporization from lime calcining, removal in condensed water, or recycle back to the furnace. The volume of final waste is increased.

- Treatment effectiveness in C2 involves significant technology risks related to plasma fumace design, air leakage prevention, and control of the $\mathrm{CO} 2$ retention and gas recycling functions. repair procedures (no repair experience for a radioactive environment exists), the near-zero air leakage requirement. separation of inert gases, and fate of radionuclides. baseline).

- Stakeholder risk for $\mathrm{C} 2$ is favorably affected by the greatly reduced offgas discharge (one tenth of the

- Life-cycle costs for C2 cannot be estimated accurately at this stage of development.

- The plasma furnace in $\mathrm{C}_{2}$ is at an early stage of development, but the involvement of several vendors and the high level of developmental effort indicates that plasma arc systems will be commercially available within the ITSS time frame.

- Aqueous based absorbents for $\mathrm{CO} 2$ are being studied as an alternative to lime absorption at Argonne National Laboratory.

- Sorting and size reduction are substantially reduced for $\mathrm{C} 2$ owing to the capability of the plasma furnace to accept bulk materials.

- APC concerns in system C2 are related to the fate of mercury and radionuclides that may be absorbed in the lime bed and released in the calciner.

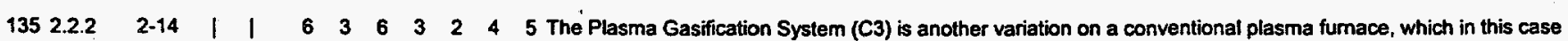


operates in an oxygen starved mode with an Scc. Air will be used as torch gas, and steam added for

$\begin{array}{lllllllllll}136 & 2.2 .2 & 2-14 & \text { | } & 1 & 4 & 4 & 4 & 4 & 4 & 4\end{array}$ material and drums provided that lead and mercury are removed and treated separately, and large pieces of metal and debris are reduced in size to fit into the feeder system.

$\begin{array}{llllllllll}137 & 2.2 .2 & 2-14 & 1 & 2 & 7 & 3\end{array}|\quad| \quad|\quad| \quad$ Cleaned ynthesis gas from plasma gasification can either be bumed in a steam boiler or burned in a thermal oxidation unit.

138 2.2.2.1 2-15 $\quad|\quad| \quad|\quad| \quad|\quad| \quad|\quad| \quad|\quad| \quad|\quad| \quad|\quad|$

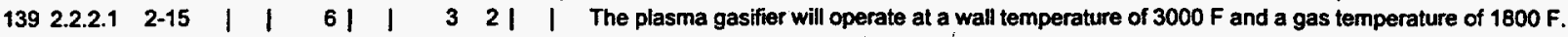

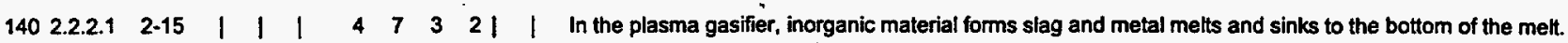

141 2.2.2.1 2-15 | | $\quad 7$ | | | | | The vitrified waste from the plasma furnace will be a metal-slag mixture. Melt discharge will take place in an air-sealed chamber exhausting through a baghouse and a HEPA filter.

$\begin{array}{llllllllllll}142 & 2.2 .2 .2 & 2-15 & 2 & 3 & 7 & 9 & 7 & 7 & 6 & 7 & 5\end{array}$ The APC subsystem for the plasma gasifier will include a water quench, baghouse filtration, wet scrubbing, activated carbon fittration, and HEPA filters. The process elements used are similar to those in the baseline.

$\begin{array}{llllllllllll}343 & 5.5 & 5-21 & 6 & 6 & 6 & 3 & 6 & 3 & 2 & 4 & 5\end{array}$ The technology risk of the plasma gasification system (C3) is higher than in the baseline owing to unproven operation for mixed organic/inorganic waste destruction, very limited electrode lifetime, volatilization of metals. uncertain refractory lifetime, and uncertainty concerning slag stability (5.5.2).

$3445.5 .1 .15-21|151| 1|1|$

$3455.5 .1 .25-21 \quad|\quad| \quad 531 \quad|\quad| \quad \mid$

- Regulatory compliance risk will be influenced by whether plasma gasification as a reforming process will be classified as an industrial furnace or a RCRA miscellaneous facility for permitting. The waste form is expected to meet L.DR requirements.

- EH\&S risks for C3 are favorable (low) for organics but uncertain for metals owing to the potential for increased metals volatilization under reducing conditions. NOx and dioxins should be less than the baseline. Worker exposure is reduced by eliminating separate vitrification.

$3465.5 .1 .35-22|||| 3|3| \mid$

- Treatment effectiveness in $\mathrm{C} 3$ depends on maintaining the desired processing atmosphere (reducing) by feeding an appropriate mix of organics and inorganics. The effect of a reducing atmosphere on the volatility of metals and the stability of the slag needs testing.

$\begin{array}{llllllllllll}347 & 5.5 .1 .5 & 5-22 & 6 & 6 & 1 & 1 & 1 & 1 & 1 & 1 & 1 \\ 348 & 5.5 .1 .6 & 5-22 & 1 & \mid & 7 & 1 & 1 & 1 & 1 & 1 \\ 349 & 5.5 .1 .7 & 5-22 & 6 & 6 & 6 & 2 & 1 & 21 & 1\end{array}$

- Accurate life cycle costs cannot be estimated for plasma gasification.

- Stakeholder risk for $\mathrm{C} 3$ is judged to be better than for the baseline (better public acceptance). Favorable aspects are the expectations for recyclable syngas and a stable vitrified product.

- Technology development risk for $\mathrm{C} 3$ is high owing to the early stage of development. A plasma reactor is being designed for hospital waste at a feed rate of $1000 \mathrm{tb} / \mathrm{hr}$. Only pilot studies and research have been performed to data. Further development using DOE wastes is necessary.

d-4) Molten Salt Oxidation F-1

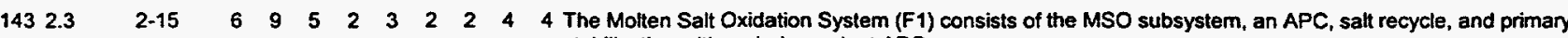
stabilization with an independent APC.

144 2.3.1 2-16 $\quad|\quad| \quad|\quad| \quad|\quad| \quad \mid \quad$ C Combustible waste will be oxidized in the molten sodium carbonate bed, which acts as a catalyst.

$\begin{array}{lllllllllll}145 & 2.3 .1 & 2-16 & 6 & 8 & 6 & 4 & 3 & 3 & 4 & 4\end{array}$ Inorganic ash in the MSO unit will collect in the molten salt and will subsequently be filtered from dissolved salt in the salt recycling subsystem and sent to primary stabilization.

$\begin{array}{llllllllll}146 & 2.3 .1 & 2-16 & 6 & 7 & 5 & 4 & 2 & 2 & \text { | }\end{array}$ going to the MSO unit.

$1472.3 .1 \quad 2-16 \quad|\quad| \quad 71 \quad|\quad| \quad|\quad|$ Noncombustibles are sent directly to a dryer and vitrification stabilization subsystem.

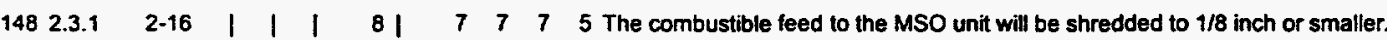

149 2.3.1 2-16 | | $\quad 5|\quad| \quad|\quad| \quad$ The molten bed of sodium carbonate operating at 1400 to $1800 \mathrm{~F}$ serves two functions: oxidation of organics and neutralization of acids.

$1502.3 .1 \quad 2-16 \quad|\quad| \quad \mid \quad 3 \quad 3 \quad 344$ Some molten salt will be continuously removed to prevent buildup of more than $20 \%$ ash and to control viscosity.

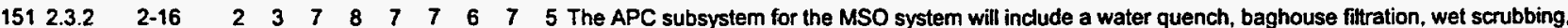
activated carbon filtration, and HEPA filters. A continuous emissions monitor (CEM) and radiation sampling device will record stack discharges.

\begin{tabular}{ll|l|l|l|l|l|l|}
152 & 2.3 .2 & $2-16$ & 5 & $\mid$
\end{tabular}

$\begin{array}{llllllllllll}153 & 2.3 .3 & 2-17 & 3 & 8 & 5 & 2 & 3 & 2 & 2 & 4 & 4\end{array}$ In the salt recycling subsystem, spent salt will be dissolved and filtered to separate the ash. The filtered salt solution will be evaporated in a crystalizer, with the supernate containing sodium chloride sent to the aqueous waste treatment subsystem.

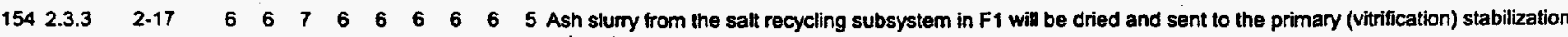
subsystem.

$\begin{array}{lllllllllll}350 & 5.6 & 5-23 & 6 & 6 & 4\end{array}$ 
NO. SEC PAGE

oxidizes low-ash combustibles in molten sodium carbonate, which catalyzes the oxidation and neutralizes acids. The viscosity of the melt must be controlled by removing ash and inert materials.

$\begin{array}{lllllllllll}351 & 5.6 & 5-23 & 6 & 6 & 4 & 2 & 3 & 2 & 2 & 4\end{array}$

- MSO technology has been developed over the last 30 years with little commercial application. Most of the available data were obtained in bench scale tests. Technology risks pertain to the removal of ash from the melt to control melt viscosity, the fate of radionuclides, and the effect of carbon in ash from the MSO process in subsequent vitrification stabilization (5.6.2).

$\begin{array}{lllllllllll}352 & 5.6 & 5-23 & \mid & \mid & 4 & 2 & 3 & \mid & 1\end{array}$

- Feed to the MSO consists of low-ash solid combustibles and organic liquids. Sorting the combustible from the noncombustible requires an extensive receiving and preparation subsystem. Large bulk items must be excluded. Because of the large heat sink, gradual changes in the feed's heating value can be tolerated (5.6.2).

353 5.6.1.1 5-23 | $\quad 4 \quad|\quad| \quad|\quad| \quad$ | treatment. Permitting is expected to be under industrial furnace or miscellaneous RCRA categories.

$3545.6 .1 .25-24 \quad 1 \quad 141111111$

- EH\&S risks of worker exposure are increased due to additional waste separation and processing for salt recycling. Small MSO systems have been operated at Oak Ridge and Lawrence Livermore. NOx is reduced and the volume of emissions is halved compared to the baseline. The tate of radionuclides remains to be evaluated.

$\begin{array}{lllllllllll}355 & 5.6 .1 .3 & 5-24 & 6 & 6 & 4 & 2 & 2 & 2 & 1\end{array}$

- Treatment effectiveness is reduced by the timitation of MSO to treat only combustibles. Corrosion of the vessel is a concern. Ash in the molten bath is limited to $20 \%$ to control viscosity. Excess ash is removed and the salt recycled by dissolution, fittration of ash, and evaporative recrystallization of the salt. The aqueous stream is recycled to avoid waste generation.

$\begin{array}{lllllllllll}356 & 5.6 .1 .3 & 5-24 & \mid & \mid & \mid & 2 & 2 & 2 & 1 & 1\end{array}$

$\begin{array}{lllllllllll}357 & 5.6 .1 .3 & 5-25 & 1 & \mid & 4 & 5 & 6 & 4 & 1 & 1\end{array}$

- Feed must be shredded to $1 / 8$ inch and the material dried in a calciner. Trace organics and plastics are a possible problem in the dryer.

- Both the separated noncombustible waste and the ash from the MSO are sent to the primary stabilization vitrifier. Vitrifier concerns include organics in the separated noncombustible material and carbon in the ash from the MSO.

$\begin{array}{lllllllllll}358 & 5.6 .1 .4 & 5-25 & 1 & \mid & 1 & 2 & 1 & 1 & 1 & 1\end{array}$

- Implementation risk is expected to be high for MSO due to its complexity. A commercial technology is available from at least one vendor.

- Features of MSO that favor stakeholder acceptance are its potential to retain heavy metals in the salt matrix, to retain chlorides in the bed, and and to minimize dioxin and furan formation.

- Life cycle cost and schedule for MSO may not meet DOE objectives. Further development will be needed to evaluate treatment of MLLW, organic destruction rate and efficiency, and gaseous emissions.

d-5) Molten Metal Waste Destruction G-1

$\begin{array}{lllllllllll}155 & 2.4 & 2-17 & 1 & 7 & 3 & 7 & 3 & 2 & 5 & 5\end{array}$ The Molten Metal Waste Destruction System (G1) will convert metal waste containing organics to recoverable metal, slag containing separated radionuclides, and syngas. It is assumed to accomplish organic destruction. primary stabilization, and metals recovery in a single process, thereby eliminating separate metal melting/decontamination and vitrification subsystems.

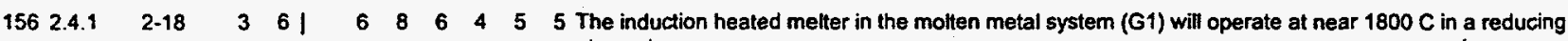
atmosphere.

$1572.4 .1 \quad 2-18 \quad 1 \quad 1 \quad 1 \quad 96777 \quad 7 \quad 6$ Feed to the molten metal bath will be coarse shredded to approximately 3 inches.

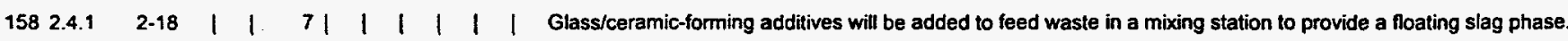

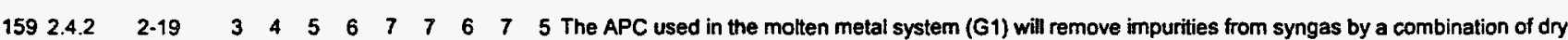
quenching, dry particulate filtration, and wet scrubbing.

$\begin{array}{lllllllllll}160 & 2.4 .2 & 2-19 & 2 & 6 & 4 & 4 & 5 & 4 & 5 & 4\end{array}$ Dry quenching in the molten metal APC will take place in a fluidized bed of silica sand or ceramic balls cooled by water-cooled coils. Cooling is from $1800 \mathrm{C}$ to $200-150 \mathrm{C}$.

$1612.4 .2 \cdot 2-19 \quad 1 \quad|31 \quad| \quad|\quad| \quad \mid$ Most of the volatile metals escaping the molten metal balh are assumed to be captured in the fluidized bed cooler.

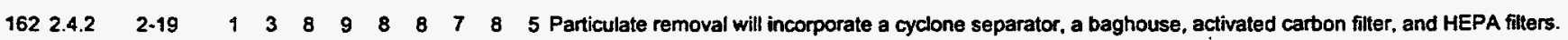

$\begin{array}{lllllllllll}163 & 2.4 .2 & 2-19 & 3 & 5 & 8 & 7 & 7 & 7 & 6 & 5\end{array}$ A wet scrubber with alkali scrubber backup will remove and neutralize acid gases from the molten metal reactor.

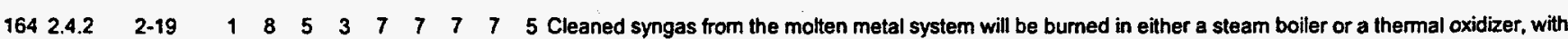
CEM and continuous radiation sampling.

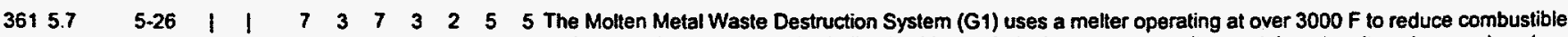
and noncombustible waste (including liquid and sludge) to syngas, molten metal, and mollen slag produced from inorganic waste, lime and flux.

$\begin{array}{llllllllllll}3625.7 & 5-26 & 6 & 8 & & 3 & & 3 & 2 & 1 & 1 \\ 3635.7 & 5-26 & 1 & 1 & 8 & 1 & 1 & 1 & 1\end{array}$
- The technology risk of $\mathrm{G} 1$ is higher than the baseline because of lack of commercial experience.

- The principal advantages of G1 are that themal destruction and vitrification are performed in one step. that the metal waste can be recycled for reuse by DOE, and that the volume of offgas is a order of magnitude less that that produced in the baseline system.

$\begin{array}{llllllll}364 & 5.7 .2 & 5-29 & \mid & \mid & 8 & \mid & \mid\end{array}$ 
NO. SEC PAGE

\begin{tabular}{llllllllllllll}
\hline 3655.7 .2 & $5-29$ & 6 & 6 & 1 & 3 & 1 & 3 & 2 & 1 & 1
\end{tabular}

- Technology risks of the molten metal melter in $\mathbf{G 1}$ concern the effect of changes in feed composition on the metal and slag produced, the residence time required to treat larger particles, and the ability of the melter to destroy organic without a secondary combustion chamber.

$\begin{array}{llllllllll}367 & 5.7 .1 .1 & 5-27 & \mid & 7 & \mid & \mid & 1 & 1\end{array}$

- The control of particulates, radionuclides, toxic metals and acid gases, and the leaching resistance of slag and metal products, remain to be demonstrated for MLLW.

- Regulatory compliance of $\mathrm{G} 1$ is favorable based on the expectation that the vitrified slag will meet LDR requirements and that metals can be recycled within DOE to reduce disposal volume. Permitting would be similar to that for an incinerator.

$\begin{array}{lllllllllll}368 & 5.7 .1 .2 & 5-27 & \mid & 1 & 7 & \mid & 1 & \mid\end{array}$

- The ES\&H risk of G1 is favorable based on the expectation that destruction efficiency will be high. Potentially high particulate emissions in the offgas are a concern. The low-volume offgas is primarily $\mathrm{H} 2$ and $\mathrm{CO}$, which can be burned in a boiler or themal oxidizer. NOx formation from oxygen and nitrogen camier gas (for additives) needs to be evaluated.

$\begin{array}{lllllllllll}369 & 5.7 .1 .2 & 5-27 & \mid & \mid & 7 & 1 & \mid & 1 & \mid & 1 \\ 370 & 5.7 .1 .3 & 5-27 & & 6 & 6 & 5 & 3 & 1 & 3 & 1\end{array}$

- A knowledge base concerning the tate of radionuclides is available based on vendor tests, but further development is needed on fluxes to control isotope partitioning in the molten bath.

- The applicability of the Gi technology to MLLW has not yet been determined. Principal technology risks for $\mathrm{GI}$ are in reference to melter design and the removal and cooling of slag and molten metal at high temperatures.

$\begin{array}{llllllllllll}374 & 5.7 .1 .4 & 5-26 & 6 & 6 & 3 & 7 & 3 & 2 & 4 & 5\end{array}$

- Implementation risk for the molten metal system (G1) is high and development is needed for reactor geometry, refractory, turbulence control, feeding. instrumentation, and slagimetal removal. Radionuclide partitioning requires additional study. These uncertainties adversely impact scaleup, cost and schedule.

$\begin{array}{lllllllllll}372 & 5.7 .1 .5 & 5-28 & \mid & 1 & 5 & 1 & 1 & 1 & 1\end{array}$

- EH\&S risks are posed by G1, including the high temperatures in the process, the possibility of explosion (e.g. hydrogen), confinement of the positive process pressure, particulate emissions, organic destruction without a secondary combustion chamber, and slag disposal properties.

$\begin{array}{lllllllllll}373 & 5.7 .1 .6 & 5-28 & 1 & \mid & 6 & 1 & \mid & 1 & 1 & 1\end{array}$

- Stakeholder acceptance for $\mathrm{G} 1$ is advanced by its one step design, low volume of combustible offgas. and potential for metals recycling. The vender claims that the technology will not require permitting as an incinerator.

\begin{tabular}{lllllll|}
374 & 5.7 .1 .7 & $5-28$ & 6 & 8
\end{tabular}

$3755.7 .1 .85-28|||4| 331 \mid$

- Technology development risks are increased by the fact that there are no operating commercial units. However, a number of molten metal facilities are planned, including a demonstration reactor at ORNL and a commercial unit at Rollins.

d-6) Steam Gasification $\mathrm{H}-1$

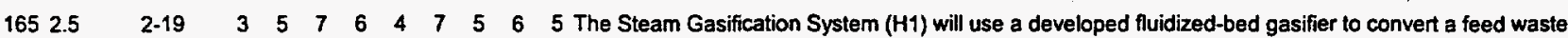
comprised primarily of combustible material into syngas. The gasifier will be indirectly heated to maintain an operating temperature of 1300 to $1400 \mathrm{~F}$ under reducing conditions, with steam fed at the bottom of the fluidized bed.

$\begin{array}{llllllll}166 & 2.5 & 2-20 & 7 & 8 & 2 & 3\end{array} \quad$ । Sorting requirements for the steam gasification system are larger than the baseline because of the inability of the gasifier to accept large amounts of noncombustible.

$\begin{array}{llllll}167 & 2.5 & 2-20 & \mid & 7 & \mid\end{array}$

$\begin{array}{lllllllll}168 & 2.5 .1 & 2-20 & \mid & 1 & 8 & 7 & 7 & 5\end{array}$ The sorted combustible feed to the gasifier is shredded to less than $1 / 4$ inch.

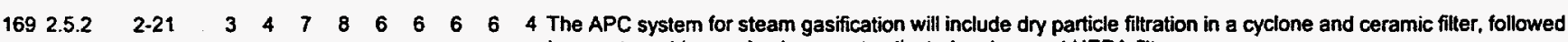
by a wet scrubber and subsequent activated carbon and HEPA fillers.

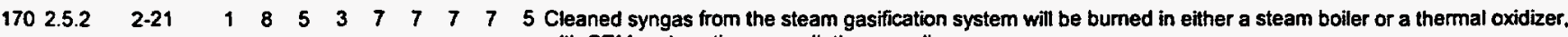
with CEM and continuous radiation sampling.

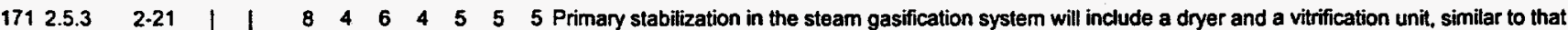
used in the mollen salt oxidation system. Fly ash from APC will be sent to primary stabilization, along with the initially separated inorganic waste.

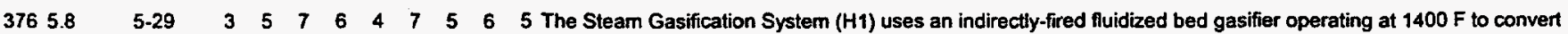
combustibles to syngas using steam as the reactant gas. Sorting requirements are extensive because noncombustibles must be removed from the gasifier feed and sent directly to the vitrifier.

$\begin{array}{lllllllll}377 & 5.8 .1 & 5-29 & 5 & 5 & 5 & 6 & 6 & 1\end{array}$

378 5.8.1.1 $5-30$ 1 $1171 \quad 1 \quad 1 \quad 1 \quad 1 \quad$

$\begin{array}{lllllllllll}379 & 5.8 .1 .2 & 5-30 & \mid & \mid & 6 & 1 & \mid & 1 & 1 & 1\end{array}$

$3805.8 .1 .35-30 \mid 16111111$

$3815.8 .1 .35-30 \quad 1 \quad 1 \quad|\quad| \quad 451 \quad 1$
- The technology risk for steam gasification (H1) in treating MLLW is judged to be higher than for the baseline despite the commercial use of the technology to treat biomass waste. General areas of concern are the fate of radionuclides and the destruction efficiency for organics without a secondary combustion chamber. regulations.

- Steam gasification is a commercial process that is expected to be permitted under industrial furnace

- EH\&S risks for $\mathrm{H} 1$ concem the destruction efficiency for organics in the gasifier, the explosion hazard of hydrogen containing offigas, and the volatility of metals and radionuclides in a reducing atmosphere.

- Steam gasification has not been used to treat MLLW, and treatment effectiveness is uncertain.

- Stearn gasification has a low tolerance for noncombustible material in the feed. The combustible feed 
must be sorted out and shredded to a particle size in a narrow range and less than $1 / 4$ inch to facilitate fluidization in the reactor.

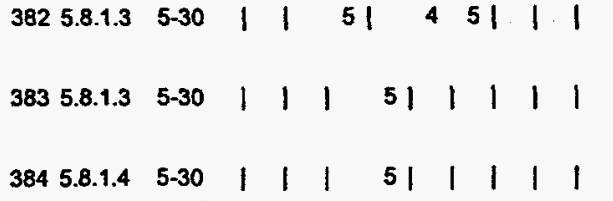

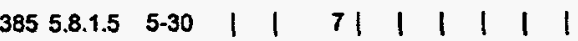

$\begin{array}{lllllllllll}386 & 5.8 .1 .6 & 5-31 & 3 & 5 & 1 & 1 & \mid & 1 & \mid & 1\end{array}$

$\begin{array}{llllllllllll}387 & 5.8 .2 & 5-31 & 5 & 5 & 6 & 6 & 4 & 7 & 5 & 6 & 5\end{array}$

d-7) Joule-Heated Vitrification J-1

- Noncombustible material separated from the feed waste must be shredded and dried in a calciner before being fed to the vitrifier. Trace organics and plastics are a concern in operating the dryer.

- Gasifier temperature must be optimized to achieve high destruction efficiency while avoiding slagging and pluggage in the reactor.

- Implementability of $\mathrm{H1}$ is lower than for the baseline owing to lack of prior operation on MLLW. The previous experience on biomass waste and the simplicity of the reactor tend to improve implementability and availability.

- Stakeholder acceptance of $\mathrm{H} 1$ should be better than for the baseline because of the reduced volume of offgas; the potential to use offgas to generate steam; low levels of NOx, dioxins and furans from the reducing conditions; and the lower temperature of the gasifier compared to the baseline incinerator.

- Life-cycle cost for the commercial equipment used in the Steam Gasification System ( $\mathrm{H} 1)$ can be well estimated, and cost and schedule objectives should be achievable.

- Technology risks for system $\mathrm{H1}$ are concemed with system integration and include: the higher demands placed on sorting; the destruction efficiency of low-temperature pyrolysis for MLLW: slagging and plugging in the fluidized bed; fate of metals and radionuclides; and the effect of carbon in ash on subsequent vitrification and the leaching properties of the disposed waste.

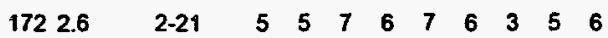

The Joule-Heated Vitrification System (J1) is a one-step oxidation/vitrification process for treating both combustible and noncombustible waste designed around a conventional glass-making melter. Oxygen is added to oxidize organics, and a plenum is provided to assist combustion.
\end{abstract}

$\begin{array}{llllllllll}173 & 2.6 & 2-21 & \mid & \mid & \mid & \mid & \mid & \mid\end{array}$ stable homogeneous product. The waste feed will be characterized to predict the level of required additives.

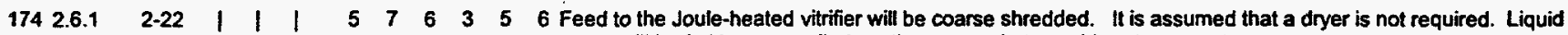
waste will be fed in a controlled continuous mode to avoid system upsets.

$\begin{array}{lllllllllll}175 & 2.6 .1 & 2-22 & \mid & 7 & 9 & 7 & 7 & 6 & 7 & 5\end{array}$ The APC subsystem for the Joule-heated vitrifier will use dry filtration followed by wet scrubbing, similar to the baseline.

$\begin{array}{lllllllll}176 & 2.6 .1 & 2-22 & \mid & \mid & 3 & 3 & 3 & 3\end{array}$ | The Joule-heated vitrifier will use a metering/freeze valve to accurately control glass draw off on an intermittent basis.

177 2.6.2 2-22 | $\quad$ | $\quad 8$ | | | | | | Cooling of the glass from the Joule-heated melter is carefully controlled to avoid both weakness due to rapid cooling or crystallization due to slow cooling.

$\begin{array}{llllllllllll}388 & 5.9 & 5-31 & 5 & 5 & 7 & 6 & 7 & 6 & 3 & 5 & 6\end{array}$ The Joule-Heated vitrification System (J1) uses an electrically-heated melter with a head space for organic oxidation operating at $2700-3000 \mathrm{~F}$ to accomplish both oxidation of combustibles and vitrification of the noncombustible waste.

$3895.9 .1 .15-32 \quad|\quad| 6||||||$

- Regulatory compliance for the joule-heated system $\mathrm{J1}$ requires that the leach resistance of the slag from MLLW be demonstrated. Permitting is expected to be similar to that for an incinerator, or it could be treated as a non-flame process. Permitting for commercial use is in progress in Tennessee and Washington.

$3905.9 .1 .25-32|| \quad 6|||1| 1$

- EH\&S risks for $\mathrm{J1}$ are concerned with organic destruction efficiency, particulate emissions, and the fate of radioactive metals. The volume of offgas is less than 1/3 of the baseline, and worker exposure is reduced by eliminating the separate vitrification unit.

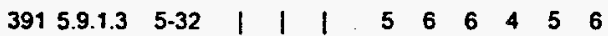

- The waste fed to system 11 must be shredded and dried in a calciner. Some melter designs do not require drying for wastes containing less than $20 \%$ moisture. More sorting well be required than in other one-step process using a slagging kiln or plasma vitrification. Metals are limited to $20 \%$ of feed, and metal drums cannot be fed to the melter.

\title{
392 5.9.1.3 5-32 problem can be alleviated by reactor design madifications or by installing an oxygen lance.

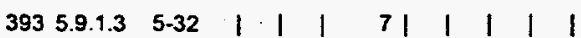 \\ - Risks of implementability are low for joule heated melters because of their commercial use in the glass industry. However, operability on MLLW is less certain. \\ 3955.9 .1 .45 .33|||||||| \\ - Electrode life for the joute-heated system could timit operability due to downtime for replacement. \\ - The availability of system J1 for MLLW cannot be predicted because of lack of experience. A commercial unit scheduled to begin construction in 1995 (?) will provide needed information.
}

$3965.9 .1 .5 \quad 5-33 \quad|1| 71|1| 1|1|$

$3975.9 .9 .6 \quad 5-33 \quad 451|1| 1|1| 1$

$398 \begin{array}{llllllllllll}5.9 .1 .7 & 5-33 & 5 & 5 & \mid & \mid & 1 & 1 & 1\end{array}$
- Stakeholder acceptance of system $\mathrm{J} 1$ will be enhanced by the simplicity of this one-step treatment and the possibility of producing useable syngas.

- Capital costs for the joule-heated melter system can be accurately estimated, but uncertainty exists for operating and maintenance costs because of the lack of commercial experience.

- Some developmental risk exists for the joule melter system. Bench-scale tests have been performed using surrogate waste, but full-scale test remain to be performed. The flexibility of the system to process a variety of MLLW types has not been demonstrated. 
NO. SEC PAGE $\ldots . . . .$. CRITERIA $\ldots \ldots \ldots$ leachability of the slag. operational control, ability to tolerate feed variations, and additives.

d-8) Thermal Desorption and Mediated Electrochemical Oxidation K-1

$1782.7 \quad 2-22 \quad|\quad| \begin{array}{lllllll}5 & 6 & 8 & 7 & 6 & 7 & 6\end{array}$ The Thermal Desorption and Mediated Electrochemical Oxidation (TDMEO) System (K1) is designed to heat combustible and noncombustible waste to vaporize low-boiling VOCs at temperatures below $600 \mathrm{~F}$.

$1792.7 \quad 2-22 \quad|\quad| \quad \mid \begin{array}{llllll}6 & 8 & 7 & 5 & 6 & 6\end{array}$ The rotary thermal desorber is indirectly heated.

$\begin{array}{llllllll}180 & 2.7 & 2-22 & \mid\end{array} \quad 4 \quad|\quad| \quad \mid \quad$ Feed to the themal desorber inciudes sludge and shredded waste solids. Physically separable organic liquids bypass the desorber and are sent directly to the organic liquid treatment subsystem.

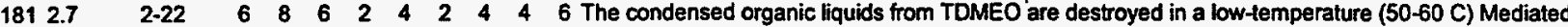
Electrochemical Oxidation (MEO) process using an aqueous sulfuric acid/cobalt sulfate electrolyte.

$\begin{array}{lllllllllll}182 & 2.7 & 2-22 & \mid & 4 & \mid & \mid\end{array}$

$\begin{array}{lllllllllll}183 & 2.7 .2 & 2-23 & \mid & 6 & 8 & 7 & 6 & 5 & 6 & 5\end{array}$ The APC for treating offgas from the desorber includes dry sintered metal filtration; two stages of condensation for mercury and water/organic liquids respectively; a carbon filter; and HEPA filters. Cleaned gas containing residual volatile organics will be burned in a thermal oxidizer and discharged to the atmosphere. CEM and continuous radiation sampling will be used.

\begin{tabular}{ll|l|l|l|l|l|l|}
184 & 2.7 .3 & $2-24$ & $\mid$ & 6
\end{tabular} hydroxyl radicals which oxidize the organics. Cathode offgas is primarily $\mathrm{H} 2$ and the anode offgas primarily $\mathrm{CO2}$, along with chlorine gas from chlorocarbons and small amounts of 02 .

\begin{tabular}{ll|l|ll|l|l|l|}
185 & 2.7 .3 & $2-24$ & 8 & 7 & $\mid$
\end{tabular} cathodes gases will be discharged through a thermal oxidizer.

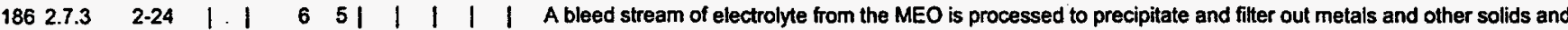
to distill and fractionate the liquid to recover the intermediate boiling point fraction containing recyclable sulfuric acid.

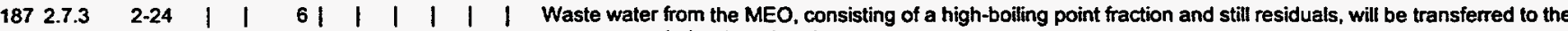
aqueous waste treatment system.

188 2.7.3 2-24 $\mid$

$1892.7 .4 \quad 2-25 \mid$ waste to grout of $50 \%$ by weight. The stabilized process residues will be required to pass the EPA TCLP test.

$\begin{array}{lllllllllll}400 & 5.10 & 5-34 & 7 & 8 & 5 & 3 & 6 & 4 & 5 & 5\end{array}$

6 Thermal Desarption (TD) and Mediated Electrochemical oxidation (MEO) in system K1 combine low-temperature technologies to remove and destroy volatile organics in MLLW. This system takes advantage of the EPS's debris rule for hazardous waste processing that allows minimum stabilization of a certain category of MLLW debris.

$\begin{array}{lllllllllll}401 & 5.10 & 5-34 & \mid & 5 & 6 & 8 & 7 & 6 & 7 & 6\end{array} \quad$ MLLW solids are treated in the TD unit to remove organics, and the organic liquid condensed is oxidized in the MEO unit.

$\begin{array}{lllllllllll}4025.10 & 5-34 & \mid & \mid & 4 & 1 & 1 & 1 & 1 & 1 & \mid\end{array}$

$403 \begin{array}{llllllll}5.10 .1 & 5-34 & 7 & 7 & 3 & 3 & 5\end{array}$

$4045.10 .1 .15-34|14||||| \mid$

$4055.10 .1 .25-35|1 \quad 7||||| \mid$

$4065.10 .1 .35-35 \quad|\quad| \quad 5 \quad 3|4|$

$\begin{array}{llllllllll}4075.10 .2 .1 & 5-36 & \mid & \mid & 5 & 4 & 4 & 4 & \mid\end{array}$

$4085.10 .2 .15-36 \quad|\quad| \quad 54|4|$

$4095.10 .1 .45-35 \quad 7 \quad 7|3||| \mid$
- Solids leaving the TD unit are stabilized by grouting.

- The technology risks for for the TDMEO system are much higher than for the baseline. The TD and APC subsystems are less complex than those in the baseline, but only limited small-scale experience exists for the approach used in this system.

- Regulatory Compliance depends on evaluating the acceplability of grout stabilization for TD residues under EPA and DOE standards. Grouting produces a less stable waste form than vitrification. "Permitting ... may not be possible." TD has been permitted for hazardous waste treatment, and MEO as an aqueous treatment method is a less sensitive technology.

- EH\&S risks for system K1 are reduced by low temperature processing. The gas emissions produced are an $\mathrm{H} 2$ offgas containing some volatile organics from the TD APC and offgas containing $\mathrm{CO} 2$ and chlorine from the MEO. Chlorine is removed by scrubbing, and the remaining offgases are sent to a themal oxidizer.

- Treatment effectiveness risks exist in reference to organics volatilization in the TD. melting of waste plastics in TD processing, removal of mercury from TD offgas. and scaleup of the MEO process.

- The operating temperature of the thermal desorber is a key parameter. To prevent release of chlorine gas from PVC plastic the desorber should operate below $540 \mathrm{~F}$; however, volatilization of PCBs may require about $800 \mathrm{~F}$. Since no organic destruction will occur in the grouting process, careful attention will need to be given to meeting waste disposal requirements.

- Mercury boils at $674 \mathrm{~F}$ and would be removed in the desorber only at the higher temperature required for PCB containing waste. Other RCRA metals have high boiling points and would not be removed in the desorber.

- Implementability risks for $\mathrm{K} 1$ are high due to high sorting requirements, questions on processing plastics and combustibles, and the early developmental status of MEO at LLNL. A number of prototypes have been built using commercial electrochemical cells, but electrolyte replacement and regeneration need further development (5.10.2.2)

Stakeholder acceptance is judged to be better than the baseline if effectiveness is demonstrated. Less 
NO. SEC PAGE $\ldots \ldots \ldots$. CRITERIA $\ldots \ldots \ldots$

offgas will be discharged, but the volume of solid waste requiring disposal will be greater than the baseline.

$4115.10 .1 .65-35 \quad 7 \quad 7|| 1|1|$

- Life cycle cost for system K1 cannot be accurately forecast at this stage of development. Disposal of a large volume of grouted waste adversely affects overall cost.

d-9) Themal Desorption and Supercritical Water Oxidation L-1
$\begin{array}{llllllllllll}190 & 2.8 & 2-25 & 7 & 8 & 6 & 6 & 8 & 7 & 6 & 7 & 6\end{array}$ combustible and noncombustible waste to vaporize low-boiling VOCs at temperatures below $800 \mathrm{~F}$. The Thermal Desorber, APC and Primary Stabilization subsystems are similar to those used in the K1 TDMEO System.

$\begin{array}{lllllllllll}191 & 2.8 .3 & 2-26 & \mid & 8 & 3 & 6 & 3 & 2 & 5 & 6\end{array}$ The Supercritical Water Oxidation (SCWO) subsystem is designed to accomplish feed preparation, reaction and air pollution control.

192 2.8.3 2-25 | | | $\quad$ - $1 \quad 7|\quad| \quad \mid$ Feed to the SCWO includes organic liquids and organic sludge that has been filtered to remove particles large than about 100 microns. The larger particles fittered out will be sent to primary stabilization.

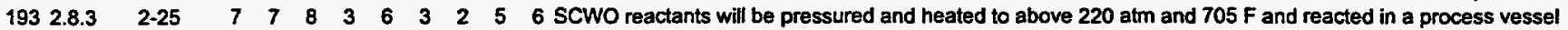
still being developed. Prototype reactors use metal alloys and may use ceramics.

194 2.8.3 2-25 | | $\quad 5 \quad 5 \quad|\quad| \quad|\quad|$ Products from SCWO include H2O, CO2, and inorganic salt precipitates. The precipitates are separated in a thin-film filter and evaporator and sent to secondary (polymer) stabilization.

$\begin{array}{llllllllll}195 & 2.8 .3 & 2-25 & \mid & 6 & 7 & \mid & \mid\end{array}$ either recycled or sent to the aqueous waste treatment subsystem.

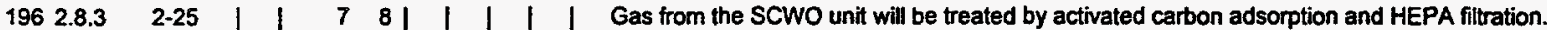

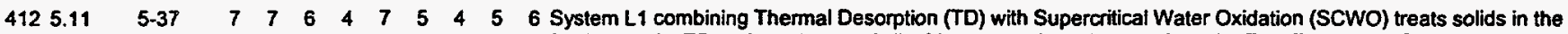
feed waste by TD and sends organic liquid waste and condensate from the TD offgas to the SCWO unit. Sludges and liquified waste prepared from finely ground solid waste can be treated by SCWO.

\section{$\begin{array}{lllllllllll}413 & 5.11 .1 & 5-39 & 7 & 7 & 3 & 5 & 4 & \mid\end{array}$ \\ $4145.11 .1 .15-39 \quad|\quad| \quad 4||||||$}

- Technology risk for the TDSCWO system (L1) is much higher than for the baseline.

- Regulatory compliance risk is increased by the less stabilized final waste form and the larger volume produced by grouting, compared to the baseline. TD has been permitted for hazardous waste treatment, and SCWO would be permitted as a simpler aqueous method.

\section{5.11.1.2 5-39 $|1| 6||||||$ \\ 416 5.11.1.3 5-39 $|1| 1|1| 1|1|$ \\ $4175.11 .1 .35-39 \quad$ | $1.73 \quad 3 \quad 6 \quad 3 \quad 2 \quad 56$ \\ $\begin{array}{llllllllllll}418 & 5.11 .1 .4 & 5-39 & 7 & 7 & 1 & 3 & \mid & \mid & \mid\end{array}$

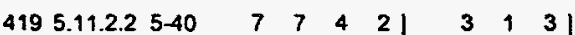

- EH\&S risks for system L.1 are reduced by low temperature processing and the simplified APC requirements need to meet regulatory standards. The high operating pressure of the SCWO is a major safety issue.

- Treatment effectiveness for TD in system $L 1$ is the same as in system $K 1$.

- SCWO has the potential to completely destroy organic wastes, but the technology is unproven for MLLW. SCWO can treat liquid organic waste and sludge, which represent about $3 \%$ of DOE's total MLLW.

- Scaleup and implementability of SCWO remain to be demonstrated. Operational issues regarding salt buildup, reactor corrosion, and high pressure negatively affect availability.

- The SCWO process operates at about $1000 \mathrm{~F}$ and $230 \mathrm{~atm}$, and significant problems with chloride-induced stress corrosion cracking are expected. Clogging of valves and lines with precipitated salts has hampered operation of pilot plants. Pressure reduction and gas/liquid/solid separations must be optimized.

$4205.11 .1 .55-39|1| 7|||||| \mid$

- Slakeholder acceptance is judged to be better than for the baseline because of the lower temperature compared to incineration and the reduced volume of offgas ( $15 \%$ of baseline). However, the volume of final waste is greater and the waste form is less stable.

$4215.11 .1 .65-39 \quad 7 \quad 71 \mid 1 \quad 1 \quad 1 \quad 1$

- Life cycle costs for system L1 cannot be accurately forecast because of the early stage of SCWO development.

- SCWO remains largely untested on DOE's MLLW. The first commercial SCWO plant was placed in operation in 1994 processing a petroleum based waste stream at the rate of 5 gallons per minute.

e-1) Receiving and Preparation

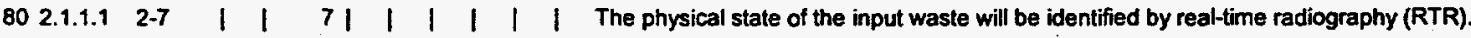
81 2.1.1.1 2-7 | $|41 \quad| \quad|\quad| \quad$ A passive/active neutron (PAN) assay unit will determine the level of TRU contamination.
82 2.1.1. 2-7 | | $\quad 5$ | | | | | | A segmented gamma scanning (SGS) unit will be used to assay beta and gamma radioactivity.
83 2.1.1.1 2-7
11
$91 \mid 1111$
$842.1 .1 .1 \quad 2-7$
\begin{tabular}{llllll|}
1 & 1 & 8 & 8 & 8 & 8
\end{tabular}
61
Each unit of waste input will be assigned a bar code for computer tracking. characterization.

85 2.1.1.1 $2-7$

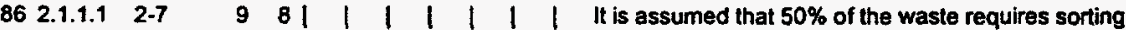


No. SEC PAGE ......... CRITERIA .......

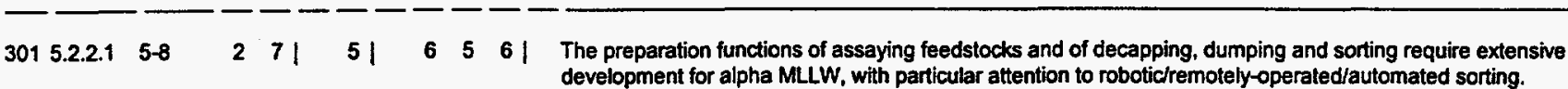

$\begin{array}{lllllllllll}302 & 5.2 .2 .1 & 5-8 & 1 & 6 & 4 & 6 & 7 & 6 & 6 & 7\end{array}$ data interpretation.

$\begin{array}{llllllllll}303 & 5.2 .2 .1 & 5-8 & 1 & 7 & 4 & \mid\end{array} \quad|\quad| \quad \mid$ Alpha-radiation assay based on PAN is the current technology bas for DOE facilities. The method is suitable for TRU waste $>100 \mathrm{nCi} / \mathrm{g}$, but the accuracy is questionable at lower levels.

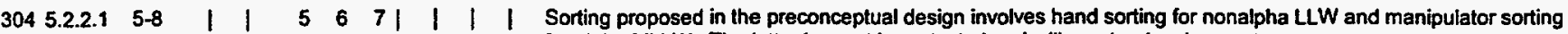
for alpha MLLW. The latter has not been tested and will require development.

305 5.2.2.1 5-9 | | | 67 | 6 is needed to select a workable concept.

306 5.2.2.2.15-9. $\quad|\quad|+81 \quad 7464$ A single-stage low-speed shredder will meet shredding requirements, but frequent maintenance will be a problem for alpha LLW. The potential for fire may require inert gas in the shredder housing.

307 5.2.2.2.2 5-9 | $|\quad| \quad|\quad| \quad|\quad| \quad \mid$ Post-shredder sorting to recover metals might offer an advantage for nonalpha MLLW. Since alpha waste is assumed, this is presumed not to be included in the preconceptural design.

e-2) Primary Treatment

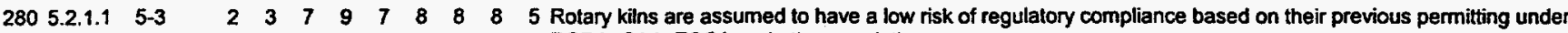
RCRA, CAA, TSCA and other regulations.

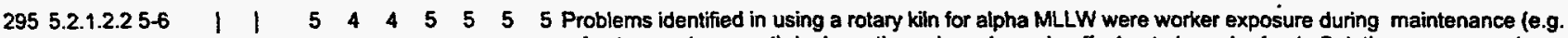
refractory replacement). leakage through seals, and puffs due to irregular feed. Solutions are secondary housing around seals, increased kiln volume (to reduce pressure variations), and fine shredding and mixing to provide a homogenous feed.

296 5.2.1.4 5-7 | | | | | | | | | Development work to improve the reliability and maintainability of rotary kilns may be needed to improve rotary seals and refractory lining life.

$3005.2 .1 .65-8 \quad 55|\quad| \quad|\quad| \quad|\quad|$ The risk of cost overruns for incinerators is low for nonalpha MLLW, but it is high for alpha MLLW. Equipment engineering development will be needed for alpha MLLW (5.2.2.2).

$\begin{array}{lllllllllll}308 & 5.2 .2 .2 .45-10 & 1 & 6 & 6 & 6 & 6 & 7 & 7 & 7 & \text { Although kiln leakage is a technical concern, available designs make leakage very controllable. }\end{array}$ Graphite/steel seals provide leak-tight operation with low maintenance and long life, based on Dow Chemical Corp. experience.

309 5.2.2.2.45-10 | | $\quad 6$ | $\quad$ | | | | Kiln leakage due to puffs will be minimized by fine shredding the feed and burning combustible liquids separately.

311 5.2.2.2.4 5-10 $\quad 3 \quad 5|\quad| \quad|\quad| \quad|\quad| \quad$ Refractory maintenance can be resolved by appropriate material selection and careful attention to minimizing rapid heating and cooling cycle. Bulk feeding can damage refractory, but less so than thermal cycling.

e-3) Air Pollution Control

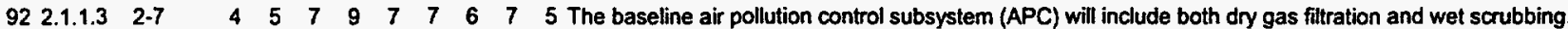
Incoming as is quenched by water jets and fittered through either a baghouse or a ceramic filter, followed by HEPA fitters.

93 2.1.1.3 2-7 | | 7 | | | | | An activated carbon fitter will be used in front of the HEPA filter to remove trace quantities of mercury.

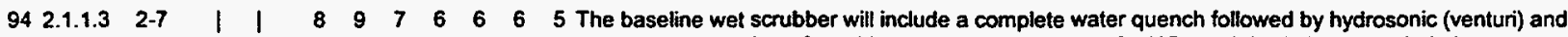
packed-bed scrubbers for acid gas removal. A system for NOx and dioxin is also included.

95 2.1.1.3 2-7 | | $\quad 7$ | | | | | A continuous emissions monitor (CEM) will analyze and record CO, CO2, O2, particulates and "other compounds". A continuous radiation detector is included.

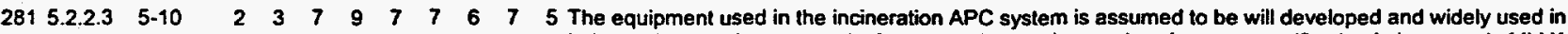
industry, but requirements exist for system integration, and performance verification in large-scale MLLW treatment units.

282 5.2.2.3.15-11 | | | | | | | | Pressure drop through the APC may exceed the capability of a single induced-draft fan and require a booster fan at a midpoint in the subsystem.

283 5.2.2.3.2 5-11 | | 6 | | | | | | Typical baghouse temperature limitations of $400-450 \mathrm{~F}$ may cause mercury to condense on the flyash collected, raising the need to consider high-temperature baghouse fitters or ceramic filters.

284 5.2.1.2.15-3 | | $\quad 4|\quad| \quad|\quad| \quad \mid$ The low temperature required for mercury capture on activated carbon (150 F) creates a design problem concerning removal of condensate from flue gas ahead of the HEPA fitters.

285 5.2.2.3.3 5-11 | | 6 | | | | | A heat exchanger was proposed ahead of the HEPA filter to reheat the offgas from mercury removal filters (150 F) to eliminate water from entering the HEPA filters. This solutions was not used in the preconceptual design.

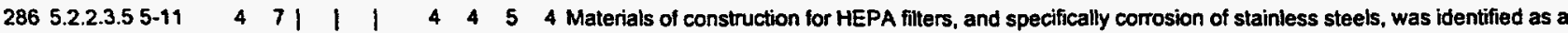
problem requiring study.

288 5.2.1.2.15-4 | | 6 | | | | | | A mercury capture efficiency of up to $90 \%$ is assumed for a carbon bed filter operated at 150 F downstream of the baghouse. 


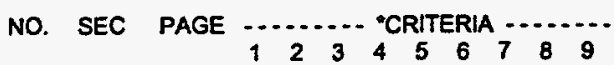

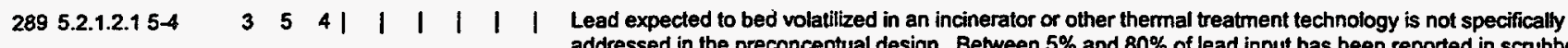
addressed in the preconceptual design. Between $5 \%$ and $80 \%$ of lead input has been reported in scrubber exit gas, indicating a need for further study.

290 5.2.1.2.3 5-6

771111111

Actinide volatilization and potential release is the greatest ES\&H concern when treating alpha MLLW, which may contain the toxic radionuclides uranium, plutonium and americium. Actinide volatilization and capture require further study.

$2915.2 .1 .2 .15-4$

68111111

Actinide removals in APC modules are unknown. For compliance, actinides discharge from APCs should be very low and perhaps below detection limits. Most of the actinides are thought to remain in the incinerator bottom ash, but they may be volatilized in the stabilization vitrifier. Aluminosilicates have been shown to decrease actinide volatility.

$2925.2 .1 .2 .15-5|1| 61|1| 1$

Dioxins and furans are not included in MLLW waste inventories, but they can be formed in thermal treatment process if offgases experience significant residence time between 400 and $600 \mathrm{~F}$. Rapid cooling by quenching ahead of the APC baghouse will minimize dioxin formation; carbon used for mercury removal may also remove dioxins.

293 5.2.1.2.1 5-5 | | $\quad 8$ | | | | | Nitrogen oxides will form in the secondary combustion chamber of thermal treatment systems. Abatement technology is commercially available and is being further developed for the fossil-fueled power industry. It is not clear that the preconceptual designs employ deNOx technology.

294 5.2.1.3.2 5-6 $\quad 2 \quad 7 \quad 5 \quad 6 \quad 6 \quad 6 \quad|\quad|$ The temperature profile for the incinerator and APC train rieeds further study to optimize control of dioxin, mercury and RCRA metals.

e-4) Primary Stabilization

$792.1 .1 \quad 2-1 \quad|\quad 8||\quad| \quad|\quad| \quad$ Contaminated soil from environmental restoration programs may be used as one of the vitrification additives.

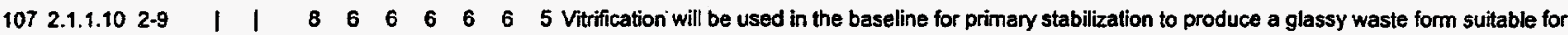
disposal.

108 2.1.1.10 2-9 | | $\quad 6|\quad| \quad|\quad| \quad \mid \quad$ Vitrification additives will include contaminated soil from DOE sites and other glass forming additives (e.g. SiO2. Al2O3, Fe2O3, etc.). INEL research has shown that $40 \%$ to $50 \%$ soil will form good glass or ceramic waste form. Work by EPA at RTP and by DOE at LLNL has shown that the volatility of some toxic metals and actinides is reduced by adding aluminosilicates or SiO2.

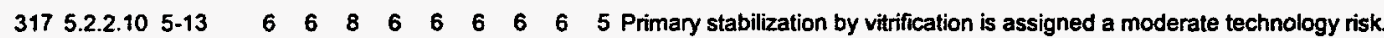

318 5.2.2.10.5-13 | | $|4| \quad|\quad| \quad \mid \quad$ - Melt chemistry and formulation requires additional work on a prototype unit to assure ;high-integrity, leach-resistant vitrified product.

$\begin{array}{lllllllllll}319 & 5.2 .2 .10 .5-13 & 3 & 5 & 6 & 5 & 7 & 6 & 3 & 5 & 6\end{array} \quad$ - Pilot scale testing is required an a plasmalelectric arc or Joule melter design for vitrification

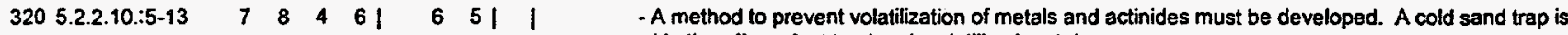
proposed in the offgas duct to absorb volatilized metals.

321 5.2.2.10.5-14 | | $\quad 5|\quad| \quad|\quad| \quad$ - Tests are needed to define the effect of high carbon ash on the vitrification process

e-5) Secondary Stabilization

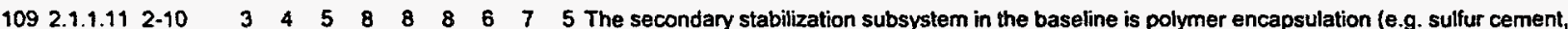
polyethylene, or polymerization agents). This method will be used to treat residues not suitable for vitrification. such as flyashes or other wastes containing low-melting salts. Bulk secondary waste, such as spent filters, will be compacted and stabilized by cement grouting.

$\begin{array}{llllllllll}322 & 5.2 .2 .11 & 5-14 & \mid & 5 & 8 & 8 & 8 & 6 & 5\end{array}$ Secondary stabilization by polymer solidification is assigned a low technology risk, but development is needed to select polymer agents that allow stabilized salts to pass the TCLP test.

e-6) Metal Decontamination

98 2.1.1.6 2-8 $\quad 267 \quad$ | | | | | The baseline metal decontamination subsystem will use size reduction tools (plasma torch, saw and shear) and abrasive blasting (with dry ice to minimize liquid waste generation).

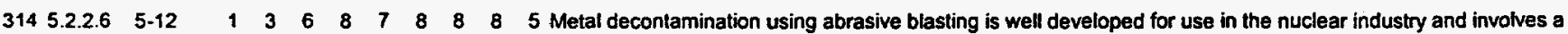
low level of technology risk.

e-7) Metal Melting

99 2.1.1.7 $2-8 \quad 4 \quad 6 \quad 6 \quad 5 \quad 6 \quad 5 \quad 4 \quad 6 \quad 5$ Baseline metal melting, used when surface decontamination cannot be accomplished, make use of an inductive meller. Most of the radioactive material is assumed to be separated from the metal in the molten slag. Clean metal is cast into ingots for DOE reuse. Solidified slag is characterized and sent to disposal.

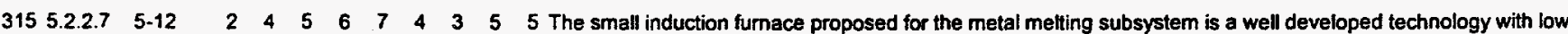
risk, but development is needed on fluxing agents to force radioactive isotopes into the slag phase.

e-8) Lead Recovery

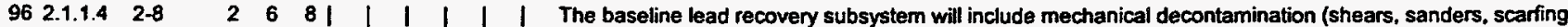
and abrasive blasting) and an oven to melt lead that cannot be surface decontaminaled. An APC unit similar to 


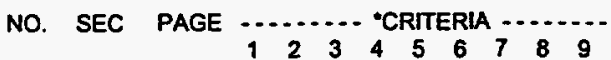

that for the incineralor is provided on the lead oven.

$\begin{array}{lllllllllllll}312 & 5.2 .2 .4 & 5-11 & 1 & 3 & 7 & 7 & 6 & 8 & 8 & 8 & 6\end{array}$ The lead recovery subsystem is well developed and will require only minor development. to address removal of radioactivity from molten lead in slag form and the APC treatment of acid gases from thermal destruction of synthetic rubber in lead gloves.

e-9) Aqueous Waste Treatment

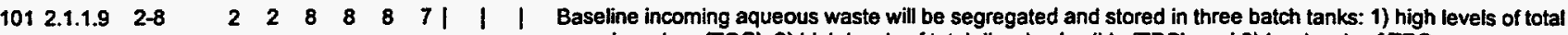
organic carbon (TOC), 2) high levels of total dissolved solids (TDS), and 3) low levels of TDS.

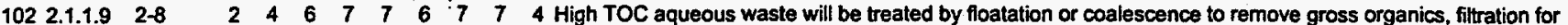
suspended solids and dissolved organics (carbon filtration or ozonation), and ion exchange for dissolved solids. Alternalively, high-TOC waste can be fed to the thermal treatment subsystem.

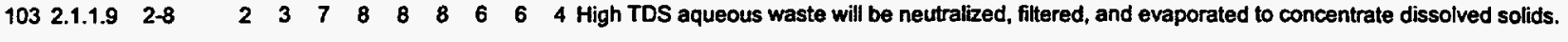

$\begin{array}{llllllllllll}104 & 2.1 .1 .9 & 2-8 & 2 & 2 & 6 & 8 & 8 & 8 & 7 & 7 & 5\end{array}$ Low TDS aqueous waste will be fittered, treated using a carbon fitter or ozonation to remove dissolved organics, and treated by ion exchange to remove dissolved solids.

$\begin{array}{lllllllllll}105 & 2.1 .1 .9 & 2-9 & 1 & 1 & 7 & 1 & 6 & 1 & \mid\end{array}$

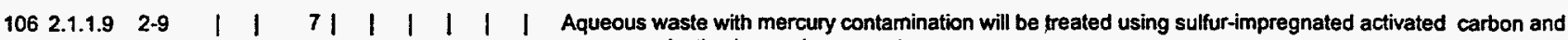
mercury-selective ion exchange resins.

$\begin{array}{llllllllllll}316 & 5.2 .2 .9 & 5-13 & 1 & 4 & 6 & 8 & 7 & 8 & 8 & 8 & 5\end{array}$ A low technology risk is assigned to the aqueous waste treatment subsystem, for which the preconceplual design involves precipitation and filtration followed by trace mercury removal using ion exchange or activated carbon. Better information on input properties is needed.
\end{abstract}

e-10) Mercury Amalgamation

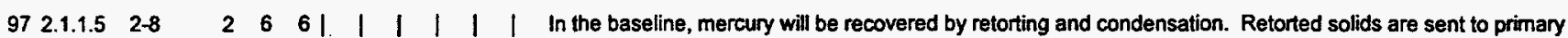
stabilization. Offgas is treated in a secondary combustion chamber and a wet-dry APC system. Mercury is recycled if not radioactive. If radioactively contaminated, it is amalgamated with zinc or copper for stabilization and disposal.

$\begin{array}{lllllllllll}287 & 5.2 .1 .3 .15-6 & 3 & 7 & 5 & 6 & 5 & 7 & 7 & 6 & 7\end{array}$ The concept of removing elemental bulk mercury from feed to the incinerator and subsequently capturing volatilized mercury from offgas using carbon filters, as used in the preconceptual design, is untested. Both the level of mercury contamination in feedstocks and the removal efficiency of mercury carbon filters are unknown.

$\begin{array}{llllllllllll}313 & 5.2 .2 .5 & 5-12 & 2 & 5 & 6 & 6 & 5 & 7 & 7 & 6 & 7\end{array}$ Mercury recovery and amalgamation subsystem involves a low technology risk. The subsystem employs a retort to vaporize mercury in a vacuum followed by condensation and separation from condensed organics.

e-11) Special Waste Treatment

$\begin{array}{lllllllllll}100 & 2.1 .1 .8 & 2-8 & 2 & 8 & 3 & \mid & \mid & \mid & \mid & \mid\end{array}$ basis. A cost allowance of $\$ 3$ million is included in cost estimates.

e-12) Certify and Ship

$\begin{array}{llllllllll}110 & 2.1 .1 .12 & 2-10 & 2 & 2 & 9 & 1 & \mid\end{array} \quad|\quad| \quad \mid \begin{aligned} & \text { The baseline certification and shipping subsystem will include physical and radiological characterization and } \\ & \text { cerification in accordance with transportation, storage and disposal requirements. Characterization will employ }\end{aligned}$ cerification in accordance with transportation, storage and disposal requirements. Chara
the same types of RTR, PAN, and SGS units as used for characterizing input wasles.

323 5.2.2.12 5-14 125 | | | | | | The Certify and Ship Subsystem is assigned a low technology risk. Equipment except for assay is commercially available, and the assay units will be the same as the receiving and preparation.

f) Life Cycle Cost and Sensitivity Analysis
$2254.0 \quad 4-1$
Cost versus capacity curves were taken from the Waste Management Facilities Cost Information Report.
$2274.1 \quad 4-1 \quad 6 \quad 7 / \quad|\quad| \quad|\quad| \quad \mid \quad$ PLCC estimates assume a government owned and contractor operated (GOCO) facility. Cost multipliers appropriate to this business relationship were used.
$2284.0 \quad 4-1 \quad 3 \quad 3|\quad| \quad|\quad| \quad|\quad|$ The ITTS capacity used for Planning Life-Cycle Cost (PLCC) estimation was based on processing the stored alpha and nonalpha MLLW inventory in a 20 -year period, using a rate of $2927 \mathrm{lb} / \mathrm{hr}$ for direct comparison of systems.
$2294.9 \quad 4-1 \quad 11111111111$
PLCC costs were estimated to represent one system handling 236 million pounds of waste over 20 years. The total processing rate was obtained by dividing the tolal inventory by 80,640 operating hours over the 20 years.
$\begin{array}{lllllllllllll}230 & 4.2 & 4-1 & \mid & \mid & \mid & 1 & \mid & \mid & 1 & \mid & \mid & \text { The PLCC estimates for each system were divided into six components: } \\ 231 & 4.2 .1 & 4-1 & \mid & \mid & \mid & 1 & 1 & 1 & 1 & \mid\end{array}$

$\begin{array}{llllllllllll}232 & 4.2 .2 & 4-2 & 1 & 1 & \mid & \mid & \mid & 1 & 1 & . & 1\end{array}$

3) Production Facility Capital Costs were estimated for five subcomponents -

233 4.2.2.1 4-2 $\quad 7 \quad 8|1| 1|1|$

- Design was estimated at $25 \%$ of construction cost. 
$234 \begin{array}{lllllllllll}4.2 .2 .2 & 4-2 & \mid & 1 & 1 & 1 & 1 & 1 & 1 & 1 & 1\end{array}$

$235 \quad 4.2 .2 .3 \quad 4-2$

$236 \quad 4.2 .2 .4 \quad 4-2$

$671 \mid 11111$

6 8 1111111 s million for EIS and permits, including NEPA, RCRA, TSCA, CAA, and other state and local cost.

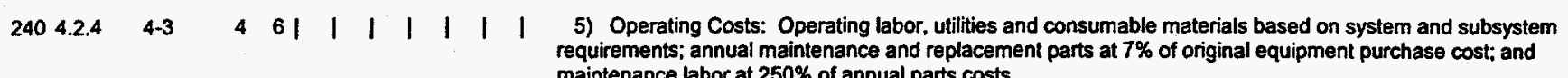
maintenance labor at $250 \%$ of annual parts costs.

\begin{tabular}{|c|c|c|c|c|c|c|c|c|}
\hline 2414.2 .5 & $4-3$ & 3 & 71 & 1 & 1 & 1 & 1 & 1 \\
\hline 2424.2 .6 & $4-4$ & 11 & 11 & 1 & 1 & 1 & 1 & 1 \\
\hline 2434.3 & $4-4$ & 8 & 71 & 1 & 1 & 1 & 1 & 1 \\
\hline 2444.3 & $4-4$ & 1.1 & 11 & 1 & 1 & 1 & 1 & 1 \\
\hline 2454.4 & $4-4$ & 5 & 51 & 1 & 1 & 1 & 1 & 1 \\
\hline 2464.4 & $4-5$ & 11 & 11 & 1 & 1 & 1 & 1 & 1 \\
\hline 2474.4 & $4-5$ & 11 & 11 & 1 & 1 & 1 & 1 & 1 \\
\hline 2484.4 & $4-5$ & 11 & 11 & 1 & I & 1 & 1 & 1 \\
\hline 2494.4 & $4-5$ & 11 & 11 & 1 & 1 & 1 & 1 & 1 \\
\hline 2504.4 & $4-5$ & 11 & 11 & 1 & 1 & 1 & 1 & 1 \\
\hline 2514.4 & $4-5$ & 11 & 11 & 1 & 1 & 1 & 1 & 1 \\
\hline 2524.4 & $4-5$ & 11 & 11 & 1 & 1 & 1 & 1 & 1 \\
\hline 2534.5 & $4-5$ & 11 & 11 & 1 & 1 & 1 & 1 & 1 \\
\hline 2544.5 & $4-5$ & 11 & 11 & 1 & 1 & 1 & 1 & 1 \\
\hline 2554.5 & $4-5$ & 6 & 71 & 1 & 1 & 1 & 1 & 1 \\
\hline 2564.5 & $4-5$ & 6 & 71 & 1 & 1 & 1 & 1 & 1 \\
\hline 2574.5 & $4-5$ & 6 & 71 & 1 & 1 & 1 & 1 & 1 \\
\hline 2584.6 & $4-6$ & 7 & 81 & 1 & 1 & 1 & 1 & 1 \\
\hline
\end{tabular}

6) Decontamination and Decommissioning (D\&D) at \$450/sq it for the total facility.

The Unit Cost of trealing waste was calculated in two ways: In the first case, all systems were considered to treat $2927 \mathrm{lt} / \mathrm{hr}$. In the second case, those systems that use contaminated soil for vitrification are assumed to treat $2927 \mathrm{lb} / \mathrm{hr}$ plus the added soil, which lowers the unit cost of treatment. based on the use of an engineered disposal facility, either above-ground or in a below-ground vault.

Systems producing a grout-stabilized waste form for disposal are more sensitive to unit disposal cost because of the added volume of grouting material. If disposal costs change (e.g. are lower), this effect is sufficient to change the break even comparison of different systems. the major cost components.

-PLCC increased by less than $5 \%$ for a doubling of testing and demonstration.

- Less than $15 \%$ for doubling equipment cost.

- About $10 \%$ for doubling building cost.

-About $5 \%$ for doubling "operating budget funded cost component."

$-65 \%$ for doubling operating and maintenance costs.

- Less than $5 \%$ for doubling D\&D costs.

- About $11 \%$ for doubling disposal costs.

Sensitivity to the state of technology development was addressed by assigning increased levels of cost for development, demonstration and preoperation activities. Four risk levels were considered in assigning added costs.

\section{- Risk level 1 for commercially available systems involved no added cost}

- Risk level 2 assumed full operation in two years and increased overall system costs by $4 \%$.

- Risk level 3 assumed full operation in three years and increased overall system costs by $7 \%$.

Sensitivity to the choice of stabilization technology was determined for vitrification, polymer solidification and
- Inspection was $7 \%$ of construction cost.

\section{- Project management was $10 \%$ of construction cost}

- Construction costs were estimated for buildings ( $\$ 180$ for offices to $\$ 1700 / 59$ ft for triple containment areas): equipment (suppliers cost plus allowance for installation, electrical, instrumentation and mechanical): and indirect cost ( $29 \%$ of buildings and equipment).

- Construction management was estimated as percent of equipment, building and indirect and included $17 \%$ for management and $10 \%$ for project scope changes and management reserve.

The same unit disposal cost of $\$ 243$ per cubic foot is used for all waste disposal regardless of form. This rate is

A sensitivity analysis was performed for the baseline system. A1, to determine the effect of doubling the cost of

- Risk level 4 for technologies in an earty stage of development increased overall system costs by $11 \%$. grouting. Under the assumption that all waste forms bear the same disposal cost, the effect on PLCC was in proportion to the amount of waste produced. which increased in the order of vitrification, polymer, and grout.

\begin{tabular}{|c|c|c|c|c|c|c|c|c|c|c|}
\hline 2594.7 & 4-7 & 7 & 81 & 1 & 1 & 1 & 1 & 1 & 1 & $\begin{array}{l}\text { Sensitivity to delisting was addressed for scrubber salts and for the entire vitrified waste. It was assumed that } \\
\text { delisted salts could be disposed in a shallow-land burial facility without stabilization. Delisted vitrified waste } \\
\text { was assumed to be disposed in a non-RCRA facility at a cost of } \$ 100 / \text { cu ft. }\end{array}$ \\
\hline 2604.5 & $4-5$ & 1 & 11 & 1 & 1 & 1 & 1 & 1 & 1 & Transportation cost was treated generically for all systems based on the following assumptions: \\
\hline 2614.5 & 4-5 & 1 & 41 & 1 & 1 & 1 & 1 & 1 & 1 & - $60 \%$ of the feed waste is shipped to the treatment facility from a distance of 1000 miles. \\
\hline 2624.5 & $4-5$ & 1 & 41 & 1 & 1 & 1 & 1 & 1 & 1 & - Disposal is at the treatment site. \\
\hline 2634.5 & 4-5 & 2 & 61 & 1 & I & 1 & 1 & 1 & 1 & $\begin{array}{l}\text { - Waste containers are contact handled, do no need special over-pack, and are shipped in enclosed } \\
\text { trailers. }\end{array}$ \\
\hline 644.5 & $4-5$ & 1 & 1 & 1 & & 1 & 1 & & & - The input waste has an average density of $35 \mathrm{lb} / \mathrm{cu} \mathrm{ft}$. \\
\hline
\end{tabular}




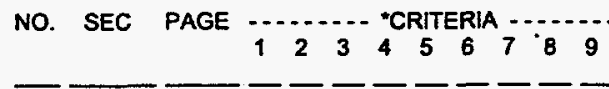

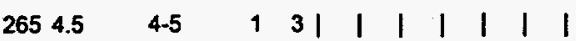

g) Criteria for Assessing Technology Risk

\begin{tabular}{|c|c|c|c|c|c|c|c|c|c|c|}
\hline 2665.0 & $5-1$ & 1 & 1 & 81 & 1 & 1 & 1 & 1 & 1 & $\begin{array}{l}\text { Technology risk was qualitatively evaluated to determine the probability that systems and subsystems will } \\
\text { meet objectives for 1) regulatory compliance, 2) environment, health and safety (EH\&S), 3) treatment } \\
\text { effectiveness, 4) implementability, 5) stakeholder concerns, 6) life cycle cost, and 7) technology development. }\end{array}$ \\
\hline 2675.1 .1 & $5-1$ & 1 & 1 & 81 & 1 & I & 1 & I & 1 & $\begin{array}{l}\text {-Risk for regulatory compliance concerns meeting land disposal restriction (LDR) standards for final } \\
\text { waste forms and complying with all EPA, DOT and other state or local requirements. Previously permitted } \\
\text { technologies were considered to pose lower risks. }\end{array}$ \\
\hline 2685.1 .2 & $5-2$ & I & 1 & 81 & 1 & 1 & 1 & 1 & 1 & $\begin{array}{l}\text { - EH\&S risks considered workers, the public and the environment during construction, operation and } \\
\text { decommissioning of treatment facilities. }\end{array}$ \\
\hline 2695.1 .3 & $5-2$ & 1 & 1 & 1 & I & 1 & 1 & 1 & 1 & $\begin{array}{l}\text { - Treatment effectiveness considered volume reduction; minimizing secondary waste; efficiency of } \\
\text { destruction, removal or demobilization; flexible response to input variations; and final waste form performance } \\
\text { under regulatory requirements. Areas of noncompliance were identified. }\end{array}$ \\
\hline 2705.1 .4 & $5-2$ & 5 & 5 & 1 & 1 & 1 & 1 & 1 & 1 & $\begin{array}{l}\text { - Implementability addressed the probability of bringing a technology into operation within the estimated } \\
\text { cost and schedule by considering ability to build, scaleup and scheduling concerns, and mechanical } \\
\text { availability/reliability. }\end{array}$ \\
\hline 2715.1 .5 & $5-2$ & 1 & 1 & 81 & 1 & 1 & 1 & 1 & 1 & $\begin{array}{l}\text { - Stakeholder issues concemed the local public near treatment and disposal facilities, state and local } \\
\text { governments, Native Americans, industry, and the Congress. The focus in the evaluation was on the offgas and } \\
\text { the final waste form. }\end{array}$ \\
\hline 2725.1 .6 & $5-2$ & 1 & I & 1 & I & I & 1 & 1 & 1 & $\begin{array}{l}\text { - Life-Cycle Cost should be reasonable and certain (low probability of overtuns). Systems that have } \\
\text { never been constructed have a high risk of cost overnun. }\end{array}$ \\
\hline 735.1 .7 & $5-2$ & I & 1 & 1 & 1 & I & 1 & 1 & 1 & ologies should be fully developed and ready for detailed design by 1996 . \\
\hline
\end{tabular}

- The waste volume in each shipment is $290 \mathrm{cu} / \mathrm{ft}$. 


\section{APPENDIX F}

\section{IDENTIFIED ASSUMPTIONS FOR THE INTS STUDY}


No. Sect. Page $\mathbf{U}^{*} \mathbf{S}^{* *}$

a) Regulations, Permitting and Stakeholder Input

$1 \quad 1.9 .1 \quad 15 \quad 2 \quad 6 \quad$ Facility design must meet DOE order 6430.IA for waste management facilities.

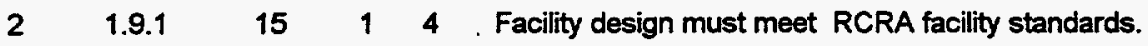

$\begin{array}{llllll}3 & 1.9 .1 & 15 & 7 & 8 & \text { Facilities are placed in seismic category } 1 .\end{array}$

$\begin{array}{lllll}4 & 1.9 .1 & 16 & 1 & 3\end{array}$ The facility that houses the treatment systems will use the canyon concept where hot cells are : separated from maintenance galleries and operating galleries.

$1.9 .1 \quad 16$

3

A system of airlocks and room ambient pressures are used to separate radiation zones.

$6 \quad 1.9 .1 \quad 16$

$7 \quad 1.9 .1 \quad 16$

1

Hot cells are designed as alpha hot cells.

$\begin{array}{llll}1.9 .1 & 16 & 6 & 6\end{array}$

The facility consists of four radiation zones that house the treatment subsystems and other support systems. These zones are as follows:

8

$\begin{array}{ll}6 & 6 \\ 6 & 6 \\ 6 & 6 \\ 6 & 6 \\ 2 & 6\end{array}$

Low hazard areas: the zone that houses offices. and packaged waste handling areas. Moderate hazard areas: the zone that houses operating galleries and analytical laboratory.

Double confined alpha cells: the zone that houses maintenance galleries.

Triple confined alpha cells: the zone that houses alpha MLLW processing equipment. Inside hot cells material handling will be accomplished by overhead cranes, and self or remotely guided vehicles.

Special design for radioactive criticality safety will not be required.

$\begin{array}{ll}2 & 6 \\ 1 & 5 \\ 3 & 6\end{array}$

The equipment must meet Nuclear Quality Assurance-l (NQA-1) standards.

The final waste form will have alpha concentrations below 100 nano-curies per gram $(\mathrm{nCi} / \mathrm{g})$ for transuranic (TRU) materials.

The treated solid waste output from the facility will meet all transportation and land disposal requirements (LDR).

Technologies selected are developed to an extent that is required to meet the system requirements for treating or otherwise handling MLLW.

The final waste form will meet disposal regulations as required by 40 Code of Federal Regulations (CFR) 268 and DOE Order $5820.2 \mathrm{~A}$.

There is no radiological transformation of waste from one radiation category to another.

23

Whenever vendor quotes are based on off-the-shelf equipment, they are multiplied by an appropriate adjustment factor to allow for NQA-1 and other more complex requirements of the specific process.

A full environmental impact statement will be required of the facility

The facility will process all of the RCRA waste stored at all DOE instaliations.

Treatment units used to process polychlorinated biphenyl's (PCB's) may require permitting under the Toxic Substances Control Act (TSCA).

Air emissions will be permitted under the Clean Air Act (CAA).

Water discharge will be permitted under local regulations to a publicly owned treatment works (POTW) or the National Pollutant Discharge Elimination System (NPDES) to surface waters. Residue from the treatment of all waste (except debris) is stabilized to meet the TCLP tests. Universal Treatment Standards (UTS) for land disposal and liquid effluents (40 CFR 168) will apply. 
a) Regulations, Permitting and Stakeholder Input (continued)

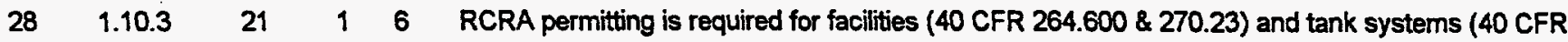
264.190).

$\begin{array}{llll}1.10 .3 & 21 & 2 & \end{array} \quad$ Non-thermal destruction technologies require demonstration of capability to achieve the contaminant level of thermal destruction technologies or standards in the UTS.

1.10.3 $21 \quad 5 \quad 5 \quad$ Debris is stabilized according to the debris rule (40 CFR Parts 148 and 268).

31

A-1.1 A-1 $\quad 4 \quad 5$

Nuclear Regulatory Commission authority (regulations) applies only to commercial facilities, therefore this facility would be exempt.

National Environmental Policy Act (NEPA) requirements are an integral part of the planning for this facility (see 42 USC 4330, 40 CFR 1500, and DOE Order 4700.1).

PCB waste should be treated in accordance with operating requirements (40 CFR 761.60-70).

The facility will process only limited quantities of the waste covered by the Comprehensive Environmental Response, Compensation, and Liability Act (CERCLA).

All source categories must be identified and technology-based emission standards be promulgated (CAA Section 112c).

DOE Value Engineering requirements (DOE 4010.1A) must be adhered to.

DOE Hazardous Material Packaging for Transport - Administrative Procedures (DOE 1540.2) must be adhered to.

DOE Occurrence Reporting and Processing of Operations Information requirements (DOE 5000.3B) must be adhered to.

DOE Conduct of Operations Requirements for DOE Facilities (DOE 5480.19) must be adhered to.

DOE Quality Assurance requirements (DOE 5700.6C) must be adhered to.

DOE Hazardous and Radioactive Mixed Waste Program requirements (DOE 5400.3) must be adhered to.

DOE Environmental, Safety \& Health Program (ES\&H) for DOE Operations requirements (DOE 5480.13) must be adhered to.

DOE General Environmental Protection Program requirements (DOE 5400.1) must be adhered to.

DOE Maintenance Management Program requirements (DOE 4330.4A) must be adhered to.

DOE Project Management System requirements (DOE 4170.1) must be adhered to.

DOE Environ
adhered to.

DOE Fire Protection requirements (DOE 5480.7A) must be adhered to.

DOE Radiation Protection for Occupational Workers requirements (DOE 5480.11) must be adhered to.

DOE Planning and Preparedness for Operational Emergencies requirements (DOE 5500.2A) must be adhered to.

DOE Work Authorization System requirements (DOE 5700.7C) must be adhered to. DOE Radioactive Waste Management requirements (DOE 5820.2A) must be adhered to. DOE General Design Criteria (DOE 6430.1A) must be satisfied. 
a) Regulations, Permitting and Stakeholder Input (continued)

54 A-2 A-9 35 The air emission limits for nonmetals and metals are the same as for the ITTS designs, and are more stringent than the requirements for misc. facilities or process vents.

55 A-2 A-12 35 The air emission limits for metals are 10x lower than required to anticipate EPA's long-term preference for adopting more rigorous, technology-based standards.

b) Input Waste Characteristics

$\begin{array}{llllll}56 & 1.6 & 12 & 9 & 4 & \text { Feed is based on SAIC mixed waste inventory estimate from August } 1993 . \\ 57 & 1.9 .1 & 15 & 3 & 8 & \begin{array}{l}\text { All waste considered is contact-handled mixed radioactive waste (including alpha-contaminated } \\ \text { MLLW). }\end{array} \\ 58 & 1.9 .2 & 17 & 2 & 5 & \text { All debris waste will be identified. } \\ 59 & 1.9 .2 & 17 & 2 & 6 & \begin{array}{l}\text { Liquid waste is shipped to the system either by a pipeline, in tank trucks, or in containers placed } \\ \text { on wheeled vehicles. }\end{array} \\ 60 & 1.9 .2 & 17 & 2 & 6 & \begin{array}{l}\text { The treatment system receives incoming solid and sludge waste in drums, metal bins, and } \\ \text { wooden or fiberglass boxes shipped to the treatment facility by onsite or offsite wheeled vehicles. }\end{array}\end{array}$

c) Waste Characterization

\begin{tabular}{|c|c|c|c|c|c|}
\hline 61 & 1.10 .3 & 21 & 2 & 7 & $\begin{array}{l}\text { Each step in the process will require waste characterization (starting with the input, and ending } \\
\text { with the final waste, offgas, and scrubber solids). }\end{array}$ \\
\hline 62 & 1.10 .3 & 22 & 2 & 7 & $\begin{array}{l}\text { Throughout normal operation, the operator of a treatment unit must analyze a waste to verify that } \\
\text { waste fed to the unit is within the physical and chemical limits specified in the permit. }\end{array}$ \\
\hline & 1.10 .3 & 22 & 2 & 6 & No attempt was made to provide shielding in any unit operation. \\
\hline
\end{tabular}

d) General Design and Operating Assumptions

\begin{tabular}{|c|c|c|c|c|c|}
\hline 64 & 1.3 & 4 & 3 & 8 & $\begin{array}{l}\text { Systems selected for evaluation were required to treat all types of RCRA waste stored in the } \\
\text { DOE complex. }\end{array}$ \\
\hline 65 & 1.7 & 12 & 9 & 9 & $\begin{array}{l}\text { Over } 200 \text { non-thermal technologies were screened; only five systems were selected (WPI, } 1966 \\
\text { - see Appendix D) }\end{array}$ \\
\hline 66 & 1.9 .1 & 16 & 3 & 3 & $\begin{array}{l}\text { Solid waste treatment operations within each subsystem may be continuous processes. } \\
\text { Transfer of solid wastes between subsystems are batch processes. }\end{array}$ \\
\hline 67 & 1.9 .1 & 16 & 5 & 2 & $\begin{array}{l}\text { Filling and discharge stations are equipped with interlocking flanges that produce a seal } \\
\text { between vessels. }\end{array}$ \\
\hline 68 & 1.9 .1 & 16 & 5 & 3 & Liquid and gaseous materials handling processes are continuous operations. \\
\hline 69 & 1.9 .1 & 16 & 3 & 2 & $\begin{array}{l}\text { Conveyor bins are used to transfer waste between subsystems. The conveyor bins employed } \\
\text { are loaded from the top and unloaded from the bottom. }\end{array}$ \\
\hline 70 & 1.9 .2 & 17 & 8 & 8 & $\begin{array}{l}\text { The facility is designed to operate three shifts per day, seven days per week, } 40 \text { weeks per year } \\
\text { at } 60 \% \text { operating efficiency for a total of } 4,032 \mathrm{hrs} \text { per year. }\end{array}$ \\
\hline 71 & 1.9 .2 & 17 & 7 & 2 & $\begin{array}{l}\text { The process controls and instrumentation used are capable of providing real time process } \\
\text { control data. No lag time is allowed. }\end{array}$ \\
\hline 72 & 1.9 .2 & 17 & 7 & 2 & Air emissions will be continuously monitored and will meet discharge requirements. \\
\hline
\end{tabular}


d) General Design and Operating Assumptions (continued)

\begin{tabular}{|c|c|c|c|c|c|}
\hline 73 & 1.10 .3 & 25 & 5 & 3 & Metals meeting DOE Order 5400.5 after decontamination are recycled within the DOE complex. \\
\hline 74 & 1.10 .3 & 25 & 2 & 3 & Lead that cannot undergo surface decontamination is grouted. \\
\hline 75 & 1.10 .3 & 25 & 2 & 7 & $\begin{array}{l}\text { Process residue, soil and debris will be treated to remove organic RCRA-controlled } \\
\text { contaminants. }\end{array}$ \\
\hline 76 & 1.10 .3 & 25 & 2 & 8 & Metals with entrained contamination are grouted. \\
\hline 77 & 1.10 .3 & 25 & 3 & 8 & Treated soil and debris will be stabilized in grout. \\
\hline 78 & 1.10 .3 & $25-$ & 3 & 8 & Treated process residues will be stabilized in polymer. \\
\hline 79 & 1.10 .3 & 25 & 2 & 7 & $\begin{array}{l}\text { Parts of the system that contain alpha-contaminated waste will be operated at slightly negative } \\
\text { pressure to avoid release of contamination outside the units. }\end{array}$ \\
\hline 80 & 1.10 .3 & 25 & 3 & 4 & Bulk lead undergoes surface decontamination (followed by recycling). \\
\hline 31 & 1.10 .3 & 26 & 3 & 8 & The output solid waste will be stabilized by one of three processes: polymer, ceramic or grout. \\
\hline 82 & 1.10 .3 & 26 & 3 & 7 & $\begin{array}{l}\text { Micro-encapsulation is used for debris that does not have a RCRA LDR or is subject to a } \\
\text { treatment variance. }\end{array}$ \\
\hline 83 & 1.10 .3 & 27 & 5 & 4 & $\begin{array}{l}\text { To be considered, technologies must be ready for pilot demonstration in } 2 \text { yrs, incorporated in } \\
\text { the final design in } 3 \text { yrs, and constructed in } 5 \text { yrs. }\end{array}$ \\
\hline 84 & 1.10 .3 & 27 & 5 & 4 & The operating period is 20 years. \\
\hline 85 & 1.10 .3 & 27 & 8 & 6 & The subsystems will handle at least $125 \%$ of the expected flow rates. \\
\hline 86 & 1.10 .3 & 27 & 5 & 3 & For small capacity unit operations, a single shift per day (or part-time shift) is assumed. \\
\hline 87 & 1.10 .3 & 27 & 5 & 6 & $\begin{array}{l}\text { The system for treating alpha LLW and alpha MLLW will accommodate TRU waste (triple } \\
\text { containment of contaminated waste). }\end{array}$ \\
\hline 88 & 1.10 .3 & 28 & 5 & 6 & $\begin{array}{l}\text { Double containment will be used for processes involving materiais with limited potential for } \\
\text { becoming airborne. }\end{array}$ \\
\hline 89 & 3 & 97 & 4 & 3 & Reaction rates, and consequent reactor sizes are based on data from vendors and developers. \\
\hline 90 & 3.1 & 97 & 5 & 4 & $\begin{array}{l}\text { The total feed to the INTS is always } 2,927 \mathrm{lb} / \mathrm{hr} \text { although the input to the various subsystems may } \\
\text { vary. }\end{array}$ \\
\hline 91 & 3.2 & 98 & 3 & 5 & $\begin{array}{l}\text { Secondary waste (from housekeeping trash, spent filters, carbon beds \& ion exchange resins, } \\
\text { etc.) is estimated to be } 1.0 \mathrm{ft} 3 \mathrm{hr} \text { for all systems }\end{array}$ \\
\hline 92 & 3.3 & 99 & 3 & 3 & Density of waste input $(\mathrm{lb} / \mathrm{tt} 3)$ : input waste $=64$, metal $=480$, aqueous liquid $=62$, soil $=67$. \\
\hline 93 & 3.3 & 99 & 3 & 6 & $\begin{array}{l}\text { Density of waste output (lb/ft3): polymer stabilized salts }=80 \text {, polymer stabilized } \\
\text { salts/residues/waste }=94, \text { phosphate ceramic stabilized waste }=80, \text { grout stabilized debris }= \\
126.6, \mathrm{Hg} \text { amalgam }=733 \text {. }\end{array}$ \\
\hline 94 & 3.3 & 99 & 8 & 3 & $\begin{array}{l}\text { Mercury content: Elemental mercury }(100 \% \mathrm{Hg}) \text { comprises } 5 \% \text { of the waste designated as } \\
\text { mercury contaminated. }\end{array}$ \\
\hline 95 & 3.3 & 99 & 8 & 3 & Mercury concentration in the remaining $95 \%$ of the mercury-contaminated stream is $5 \%$. \\
\hline 96 & 3.3 & 100 & 6 & 8 & $\begin{array}{l}\text { Stabilization formulas (mass basis): Polymer = } 1 \text { part polymer to } 1 \text { part waste; Phosphate } \\
\text { bonded ceramic = } 1 \text { part ceramic additives to } 1 \text { part waste; Grout = } 2 \text { parts grout to } 1 \text { part waste. }\end{array}$ \\
\hline 97 & 3.4 & 100 & 7 & 2 & $\begin{array}{l}\text { Calculations for one process unit (dryer for polymer stabilization input) showed that this unit could } \\
\text { require heating or cooling. Heating was included in the natural gas requirement; cooling was } \\
\text { ignored assuming that the polymer stabilization unit could accept a warmer input. }\end{array}$ \\
\hline
\end{tabular}


No. Sect. Page $U^{*} \mathbf{S}^{* *}$

d) General Design and Operating Assumptions (continued)

\begin{tabular}{|c|c|c|c|c|c|}
\hline 98 & 3.4 & 100 & 2 & 3 & $\begin{array}{l}\text { Cooling water is required for cooling all other unit operations, including acid gas scrubbers, } \\
\text { OH-generators, photolytic-UV reactors, CWO reactors, gas equilibration reactors, acid digestion } \\
\text { reactors, and HNO2 recovery reactors. }\end{array}$ \\
\hline 99 & 3.4 & 100 & 2 & 3 & $\begin{array}{l}\text { Those unit operations using electricity include mercury amalgamation, GPCR, ozone generation, } \\
\text { salt concentrator, and the MEO cells. }\end{array}$ \\
\hline 100 & 3.4 & 100 & 2 & 2 & $\begin{array}{l}\text { Operations that could utilize natural gas for process heat include the HEPA preheaters, vacuum } \\
\text { thermal desorbers, and dryers. }\end{array}$ \\
\hline 101 & 3.4 & $100-$ & 3 & 2 & $\begin{array}{l}\text { In this analysis, the energy requirements were based on heating and cooling needed for the } \\
\text { waste to be treated and organics broken down; the energy required is the net energy. }\end{array}$ \\
\hline 102 & 3.4 & 100 & 3 & 2 & $\begin{array}{l}\text { Calculations made with ASPEN provided overall energy requirements for all of the unit } \\
\text { operations within the models for the five systems. }\end{array}$ \\
\hline 03 & 3.6 & 102 & 3 & 5 & In all systems, offgas is less than 300 scfm and water discharge is less than $2 \mathrm{gpm}$. \\
\hline 104 & 5.1 .3 & 163 & 5 & 6 & $\begin{array}{l}\text { Process containment - Double or triple containment is standard for systems treating radioactive } \\
\text { waste and is not a significant discriminator between systems. }\end{array}$ \\
\hline 105 & 5.3 & 166 & 8 & 8 & $\begin{array}{l}\text { Issues regarding single versus multiple facility options and transportation of waste to such } \\
\text { facilities were not considered in this study ( they were addressed in the draft DOE Programmatic } \\
\text { Environmental Impact Statement (PEIS)). }\end{array}$ \\
\hline 106 & 5.3 & 166 & 8 & 8 & $\begin{array}{l}\text { Premise was that a single facility will treat all existing DOE mixed waste in } 20 \text { yrs (excluding } \\
\text { Hanford tank wastes and Rocky Flats pondcrete). }\end{array}$ \\
\hline 107 & 6.2 & 185 & 6 & 3 & $\begin{array}{l}\text { Mercury management in this system is untested: the removal efficiency of sulfur impregnated } \\
\text { activated carbon filters for volatile mercury and the effectiveness of the mercury debris leaching } \\
\text { process are unknown at this time. }\end{array}$ \\
\hline 108 & 6.2 & 185 & 8 & 3 & $\begin{array}{l}\text { Current DOE waste inventory indicates that a large part of the waste has mercury contamination, } \\
\text { but little is known about the concentrations or the chemical form. }\end{array}$ \\
\hline 109 & 6.7 & 223 & 5 & 4 & $\begin{array}{l}\text { The frequency of waste delivery to the site, assuming } 44,000 \text { pounds per truck, is } 268 \text { trucks per } \\
\text { year. }\end{array}$ \\
\hline 110 & 6.7 & 223 & 8 & 2 & The INTS study assumption is that wastes will be treated on-site and disposed of on-site. \\
\hline 111 & 6.7 & 224 & 9 & 7 & $\begin{array}{l}\text { Hybrid systems that combine the best elements of thermal and non-thermal technologies were } \\
\text { not considered. }\end{array}$ \\
\hline
\end{tabular}

d-1) System 1 - Grout Debris

\begin{tabular}{|c|c|c|c|c|}
\hline 112 & 31 & 7 & 6 & $\begin{array}{l}\text { System } 1 \text { (Grout Debris) uses mediated electrochemical oxidation (MEO) for primary organic } \\
\text { destruction }\end{array}$ \\
\hline 113 & 31 & 7 & 6 & $\begin{array}{l}\text { System } 1 \text { (Grout Debris) uses vacuum desorption for volatile organic separation of process } \\
\text { residue and soil. }\end{array}$ \\
\hline 114 & 31 & 3 & 3 & System 1 (Grout Debris) uses polymer stabilization of process residue and salt waste. \\
\hline 2 & 31 & 3 & 3 & System 1 (Grout Debris) uses grout stabilization of soil and untreated debris. \\
\hline 6.2 & 184 & 5 & 3 & $\begin{array}{l}\text { The grout debris case is designed to use the most well developed of the non-thermal treatment } \\
\text { technologies available. }\end{array}$ \\
\hline 6.2 & 185 & 8 & 4 & $\begin{array}{l}\text { The treatment of non-mercury contaminated debris, which is grouted without pretreatment, does } \\
\text { not remove the organics or metals prior to stabilization. This may not be sufficient to meet future } \\
\text { regulatory requirements. }\end{array}$ \\
\hline
\end{tabular}




\begin{tabular}{|c|c|c|c|}
\hline No. & Sect. & Page & $\mathbf{U}^{*}$ \\
\hline$d-2)$ & System 2 & - Des & ption \\
\hline 118 & 2 & 31 & 7 \\
\hline 119 & 2 & 31 & 7 \\
\hline 120 & 2 & 31 & 3 \\
\hline 121 & 4.8 & 132 & 7 \\
\hline 122 & 6.3 & 199 & 7 \\
\hline 123 & 6.3 & 199 & 7 \\
\hline 124 & 6.3 & 201 & 3 \\
\hline & $C-3$ & $C-4$ & 3 \\
\hline
\end{tabular}

System 2 (Desorption) uses vacuum desorption (followed by stabilization) for debris waste as well as process residue and soil.

System 2 (Desorption) uses catalytic wet oxidation (CWO) for primary organic destruction.

System 2 (Desorption) uses grout as the primary stabilization process and polymer as the secondary stabilization process.

The excess water generated by the system may need to be grout stabilized (rather than discharged), which would increase the grout system by $60 \%(\$ 450 \mathrm{k})$ and increase disposal cost by $\$ 250 \mathrm{M}$.

Sorting requirements for System 2 are more strenuous than System 1 because debris must be separated. BUT sorting and preparation was considered to be the same for all systems; this is not consistent.

The vacuum desorption tech. does not remove heavy and radioactive metals. Stabilization of these materials in grout in the presence of debris has not been demonstrated.

Process control of CWO will require robust safety features which will include additional features such as double containment for piping to provide adequate containment.

Vacuum desorption takes place at $250 \mathrm{~F}$ to prevent pyrolysis of organic material; it was assumed that no reactions of oxygen occurred during this step (no formation of $\mathrm{CO}, \mathrm{CO} 2$, or $\mathrm{H} 2 \mathrm{O}$ from organics in the debris).

d-3) System 3 - Wash

\begin{tabular}{|c|c|c|c|c|c|}
\hline 126 & 2 & 31 & 7 & 6 & $\begin{array}{l}\text { System } 3 \text { (Washing) uses aqueous wash for soil, process residue, and inorganic sludge } \\
\text { treatment; and high pressure wash for soft, open and complex debris. }\end{array}$ \\
\hline 127 & 2 & 31 & 3 & 2 & $\begin{array}{l}\text { System } 3 \text { (Washing) uses grout as the primary stabilization method and polymer as the } \\
\text { secondary stabilization method for secondary waste. }\end{array}$ \\
\hline 128 & 2 & 31 & 7 & 6 & System 3 (Washing) uses MEO for primary organic destruction. \\
\hline 129 & 2.3.1 & 49 & 2 & 2 & The washing system is operated in a continuous mode for one shift/day to minimize costs. \\
\hline 130 & 2.3.1 & 50 & 3 & 5 & $\begin{array}{l}\text { All water from the washing system is recycled (except during shutdown or cleanup); the only } \\
\text { water leaving exits with the wet treated waste, the metal froth or the organic contaminants. }\end{array}$ \\
\hline 131 & 2.3.1 & 51 & 3 & 2 & $\begin{array}{l}\text { In the second wash stage, the detergent solution is delivered through nozzles generating } 100 \text { psi; } \\
\text { the appropriate pressure for soft debris will have to be determined. }\end{array}$ \\
\hline 132 & 2.3.1 & 51 & 3 & 2 & $\begin{array}{l}\text { The surfactant solution is reconditioned by passing through an oil/water separator to remove oil } \\
\text { and solids. }\end{array}$ \\
\hline 133 & 2.3 .1 & 51 & 3 & 4 & The washed debris is sent to grout stabilization. \\
\hline 134 & 6.4 & 203 & 6 & 3 & Mercury removal from debris, soil and process residue via the wash water is assumed. \\
\hline 135 & 6.4 & 203 & 4 & 6 & $\begin{array}{l}\text { System } 3 \text { requires additional sorting of debris to separate the debris into open, soft and complex } \\
\text { streams; but sorting cost was the same as System } 1 .\end{array}$ \\
\hline 136 & 6.4 & 207 & 6 & 6 & $\begin{array}{l}\text { If surfactant cannot be recycled (due to poor partitioning) treatment of the surfactant would } \\
\text { increase the cost to the MEO organic destruction subsystem by approximately } 50 \%, \text { or } \$ 100 \\
\text { million in PLCC, and surfactant costs would increase by }<1 \text { million. }\end{array}$ \\
\hline 137 & C-3 & C-5 & 3 & 3 & $\begin{array}{l}\text { Aqueous wash removes } 95 \% \text { of the organics from the matrix and } 1 \% \text { of the silica and alumina are } \\
\text { entrained in the organic stream. }\end{array}$ \\
\hline
\end{tabular}


No. Sect. Page $U^{*} \mathrm{~S}^{*}$

d-4) System 4 - Acid Digestion

\begin{tabular}{|c|c|c|c|c|c|}
\hline 138 & 2 & 31 & 7 & 6 & System 4 (Acid Digestion) uses aqueous wash for soil. \\
\hline 139 & 2 & 31 & 3 & 2 & $\begin{array}{l}\text { System } 4 \text { (Acid Digestion) uses grout for stabilization of treated debris waste and complex } \\
\text { debris. }\end{array}$ \\
\hline 140 & 2 & 31 & 7 & 6 & $\begin{array}{l}\text { System } 4 \text { (Acid Digestion) uses vacuum thermal desorption for process residue and inorganic } \\
\text { sludge. }\end{array}$ \\
\hline 141 & 2 & 31 & 3 & 2 & System 4 (Acid Digestion) uses polymer for stabilization of soluble salts. \\
\hline 42 & 2 & 31 & 7 & 6 & $\begin{array}{l}\text { System } 4 \text { (Acid Digestion) uses phosphate bonded ceramic for stabilization of treated soil and } \\
\text { insoluble residues. }\end{array}$ \\
\hline 43 & 2 & 31 & 7 & 6 & $\begin{array}{l}\text { System } 4 \text { (Acid Digestion) uses phosphoric-nitric acid digestion for primary organic destruction } \\
\text { and soft debris treatment. }\end{array}$ \\
\hline 144 & 2 & 31 & 7 & 6 & System 4 (Acid Digestion) uses high pressure spray wash for open debris. \\
\hline 45 & 2.4 .1 & 52 & 3 & 4 & $\begin{array}{l}\text { The phosphoric acid results in very insoluble phosphate salts being formed as the byproducts of } \\
\text { the organic destruction process; these salts are easily removed and become part of the } \\
\text { phosphate bonded ceramic. }\end{array}$ \\
\hline 146 & 2.4 .1 & 53 & 5 & 3 & $\begin{array}{l}\text { The acid digestion of soft debris occurs at the same conditions as for organic destruction but it is } \\
\text { slower. (No residence times were given for either system.) }\end{array}$ \\
\hline 147 & 2.4 .1 & 54 & 5 & 2 & $\begin{array}{l}\text { Solid waste (soil) is blended with } \mathrm{MgO} \text { and process residues are mixed with } 50 \% \text { phosphoric } \\
\text { acid and } 15 \% \text { boric acid solution; these are combined to initiate the stabilization reaction. The } \\
\text { final product could be as high as } 70 \% \text { waste, but } 50 \% \text { was assumed. }\end{array}$ \\
\hline 148 & 6.5 & 208 & 7 & 6 & $\begin{array}{l}\text { Phosphate bonded cement stabilization (which uses the waste phosphoric acid) is a bench } \\
\text { scale process whose effectiveness needs to be determined. }\end{array}$ \\
\hline 149 & 6.5 & 208 & 7 & 6 & The response of the acid digestion system to complex feed streams is not known. \\
\hline 150 & 6.5 & 209 & 5 & 5 & $\begin{array}{l}\text { Failure of phosphate bonded ceramic waste may occur, with subsequent reprocessing required; } \\
\text { curing may be slower than anticipated which will impact production rate. }\end{array}$ \\
\hline 151 & 6.5 & 210 & 7 & 6 & Phosphate bonded ceramic is assumed to be as stable as polymer and more stable than grout. \\
\hline 152 & 6.5 & 211 & 5 & 3 & $\begin{array}{l}\text { Vendor costs were not available, and the costs were developed using commercial equipment } \\
\text { and anticipated utility needs. It was assumed that no additional secondary treatment was } \\
\text { needed. }\end{array}$ \\
\hline 153 & 6.5 & 212 & 7 & 6 & Volatile organics could vaporize prior to destruction. \\
\hline 154 & 6.5 & 213 & 4 & 3 & $\begin{array}{l}\text { Early tests on the resins indicate changeout of the acid media only every three months. For } \\
\text { debris or waste with a significant inorganic content, changeout may be necessary as often as } \\
\text { weekly. }\end{array}$ \\
\hline 155 & 6.5 & 213 & 5 & 2 & $\begin{array}{l}\text { Pretreatment of the phosphate waste may be necessary, or the stabilization process may not } \\
\text { work. }\end{array}$ \\
\hline 56 & 6.5 & 213 & 4 & 2 & $\begin{array}{l}\text { Acid digestion has the ability to treat plastics by complete decomposition, but the temperature } \\
\text { may cause plastics to melt and fuse together rather than dissolve. }\end{array}$ \\
\hline
\end{tabular}

d-5) System 5 - Catalyzed Wet Oxidation

$\begin{array}{llllll}157 & 2 & 31 & 7 & 6 & \begin{array}{l}\text { System } 5 \text { (Catalytic Wet Oxidation) uses CWO for primary organic destruction and soft debris } \\ \text { treatment. }\end{array} \\ 158 & 2 & 31 & 7 & 6 & \text { System } 5 \text { (Catalytic Wet Oxidation) uses aqueous wash for soil. }\end{array}$

System 5 (Catalytic Wet Oxidation) uses aqueous wash for soil. 
No. Sect. Page $\mathbf{U}^{*} \mathbf{S}^{\star *}$

d-5) System 5 - Catalyzed Wet Oxidation (continued) $\begin{array}{llllll}159 & 2 & 31 & 3 & 2 & \text { System } 5 \text { (Catalytic Wet Oxidation) uses grout for stabilization of treated debris and soil. } \\ 160 & 2 & 31 & 7 & 6 & \begin{array}{l}\text { System } 5 \text { (Catalytic Wet Oxidation) uses vacuum thermal desorption for process residue and } \\ \text { inorganic sludge. }\end{array}\end{array}$

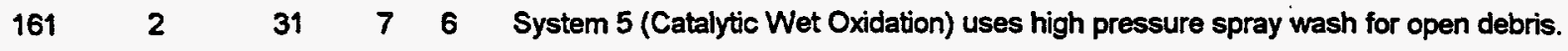

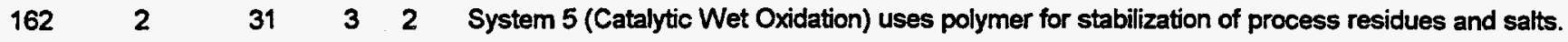

$\begin{array}{lllll}163 & 2.5 .3 & 55 & 7 & 6\end{array}$ The CWO subsystem for treating soft debris is the same as for treating organics except that an extra shredder in needed and a larger ( $2500 \mathrm{gal})$ vessel is used since a slower reaction is expected

$\begin{array}{lllll} & 6.6 & 214 & 7 & 6\end{array}$ The organic destruction efficiency of CWO is $99.99 \%$ for organics, and soil rinsed with CWO solution has metal removal to nondetect levels.

e) Subsystem Design and Operating Assumptions

$\begin{array}{llllll}165 & 2 & 30 & 3 & 5 & \begin{array}{l}\text { No thermal subsystems, such as metal melting, were included in these systems. } \\ 166\end{array} \\ 2 & 30 & 3 & 3 & \begin{array}{l}\text { The subsystems which are consistent for all five systems are: administration, receiving and } \\ \text { preparation, aqueous waste treatment, metal decontamination, mercury, lead, special waste } \\ \text { treatment, air pollution control, grout stabilization, polymer stabilization, certification \& shipping, } \\ \text { and support. }\end{array}\end{array}$

e-1) Receiving and Preparation

$\begin{array}{lllll}167 & 1.10 .3 & 24 & 5 & \text { Extensive sorting is required to divide the waste into appropriate categories (as given in Table }\end{array}$ 3-1).

$\begin{array}{lllll}168 & 2 & 30 & 5 & 8\end{array}$ All systems use extensive characterization and sorting.

$\begin{array}{lllll}169 & 2.1 .2 & 34 & 6 & 8\end{array} \quad$ The Receiving and Preparation subsystem (the highest cost subsystem) is the same for all alternative INTS systems.

$\begin{array}{lllll}170 & 1.9 .2 & 17 & 6 & 8\end{array}$

$75 \%$ of all the waste received by the facility will require sorting to meet the Waste Acceptance Criteria (WAC) for the processes.

$\begin{array}{lllll}171 & 1.9 .2 & 17 & 6 & 8\end{array}$

$25 \%$ of all the waste received by the facility meets the WAC of the treatment processes and will not require further sorting.

$\begin{array}{llllll}172 & 6.2 & 187 & 8 & 8 & \text { The feedstock characterization and preparation process has not been tested; it will require }\end{array}$ further engineering development and demonstration.

Assay \& non-destructive examination of incoming containers and decapping, dumping, \& sorting of the waste require extensive concept development, component development, hardware engineering and system integration.

e-2) Organic Destruction
$\begin{array}{llll}1.10 .3 & 25 & 7 & 6\end{array}$
Organic liquid and sludge waste will be oxidized or decomposed at temperatures below $660 \mathrm{~F}$ to achieve destruction of RCRA controlled materials.
The design of the MEO equipment is based on an expected destruction removal efficiency of $90 \%$ for each pass through the MEO cells.
The recirculation rate for the MEO cells (a typical feed molecule will pass through the cell 25 times) will degrade the organics by $99.99 \%$. 


\begin{tabular}{|c|c|c|c|c|c|}
\hline No. & Sect. & Page & & $\mathbf{S}^{* *}$ & INTS - ASSUMPTIONS OR DESIGN FEATURES \\
\hline e-2) & Organic & Jestructior & & contir & lued) \\
\hline 177 & 6.2 & 187 & 7 & 6 & $\begin{array}{l}\text { The organic destruction subsystems may be affected by the presence of non-organic } \\
\text { compounds present in DOE wastes; the impact of non-organics on performance, reliability and } \\
\text { availability must be addressed. }\end{array}$ \\
\hline 178 & 6.2 & 188. & 6 & 2 & $\begin{array}{l}\text { The MEO system developers claim a recovery of } 99.9 \% \text { of the silver, but a recovery of } 90 \% \text { was } \\
\text { used for the study. }\end{array}$ \\
\hline 179 & C-3 & C-6 & 5 & 3 & $\begin{array}{l}\text { Mediated Electrochemical Oxidation, MEO, (used for Systems } 1 \text { and 3) treats organic liquids } \\
\text { and sludges at } 176 \text { F and } 35 \text { psi; the reactions taking place are assumed to go to } 99 \% \\
\text { completion. The recovery of HNO2 is also assumed to operate at a conversion of } 99 \% \text {. }\end{array}$ \\
\hline 180 & C-3 & C-7 & 7 & 6 & $\begin{array}{l}\text { Catalytic Wet Oxidation, CWO, (used for Systems } 2 \text { and } 5 \text { ) treats organic liquids and sludges at } \\
302 \mathrm{~F} \text { and } 35 \text { psi; the reactions taking place are assumed to go to } 99 \% \text { completion. The liquid } \\
\text { stream is neutralized, which is also assumed to operate at a conversion of } 99 \% \text {. }\end{array}$ \\
\hline 181 & c-3 & C-8 & 7 & 6 & $\begin{array}{l}\text { Phosphoric Acid Digestion, (used for System 4) treats organic liquids and sludges at } 392 \mathrm{~F} \text { and } \\
1 \text { atm; the reactions taking place are assumed to go to } 95 \% \text { completion. The recovery of HNO3 } \\
\text { is also assumed to operate at a conversion of } 99 \% \text {. }\end{array}$ \\
\hline
\end{tabular}

e-3) Air Pollution Control

\begin{tabular}{|c|c|c|c|c|c|}
\hline 182 & 2.1 .13 & 42 & 5 & 3 & $\begin{array}{l}\text { The Air Pollution Control (APC) subsystem includes filters, a GPCR unit, a wet gas scrubber, a } \\
\text { mist eliminator, and activated carbon (plus sulfur impregnated activated carbon). }\end{array}$ \\
\hline 183 & 2 & 30 & 7 & 3 & $\begin{array}{l}\text { All systems use Gas Phase Corona Reactor (GPCR) for destruction of residual organics in the } \\
\text { offgas. }\end{array}$ \\
\hline 184 & 2.1.13 & 43 & 8 & 2 & The APC subsystem includes a system for continuous emissions monitoring (CEM). \\
\hline 185 & 6.2 & 188 & 7 & 4 & $\begin{array}{l}\text { Airborne releases - volatile mercury is not expected to pass the condensers in the APC } \\
\text { subsystem. }\end{array}$ \\
\hline 186 & A-2 & A-9 & 8 & 3 & $\begin{array}{l}\text { The emission limits for nonmetals and metals used for the INTS design were developed for } \\
\text { ITTS work and are more stringent than required, but they were retained for consistency. }\end{array}$ \\
\hline 187 & A-3 & A-18 & 8 & 3 & $\begin{array}{l}\text { The APC subsystem performance specifications should be set to meet or exceed current } \\
\text { regulations by } 10 \text { times. }\end{array}$ \\
\hline 188 & $\mathrm{C}-2$ & $C-1$ & 8 & 4 & $\begin{array}{l}\text { In the APC, it is assumed that } 100 \% \text { of the solid metals are trapped by the filter and that } 100 \% \text { of } \\
\text { the aqueous and gaseous stream is allowed to pass through the filter. }\end{array}$ \\
\hline 189 & $\mathrm{C}-2$ & $C-1$ & 4 & 3 & $\begin{array}{l}\text { The gas scrubber introduces caustic solution ( } \mathrm{NaOH} \text { and water, } 1 \% \text { excess) to remove the acid } \\
\text { gases that remain in the offgas. A conversion of } 99 \% \text { is assumed for these reactions. }\end{array}$ \\
\hline 190 & C-2 & $C-1$ & 8 & 4 & $\begin{array}{l}\text { The reactions in the GPCR are assumed to occur at } 1,832 F\left(1000^{\prime} \mathrm{C}\right) \text { and I atm pressure and with } \\
\text { a power input of } 56.49 \mathrm{~W} / \mathrm{cfm} \text {, and a conversion of } 95 \% \text { is assumed for all the reactions. }\end{array}$ \\
\hline 191 & C-2 & $C-2$ & 7 & 3 & $\begin{array}{l}\text { Complete }(100 \%) \text { removal of the salts in the offgas stream is assumed. If sufficient water is } \\
\text { available, it is removed to give a water/solids ratio of } 0.3 \text {. }\end{array}$ \\
\hline
\end{tabular}

e-4) Primary Stabilization (Grout)

\begin{tabular}{|c|c|c|c|c|c|}
\hline 192 & 2 & 30 & 3 & 2 & All systems use grout for debris stabilization. \\
\hline 193 & 2.1.14 & 43 & 6 & 6 & $\begin{array}{l}\text { The Grout Stabilization subsystem mixes two parts of grout (cement, sand, \& water) with one part } \\
\text { of waste. }\end{array}$ \\
\hline 194 & 6.2 & 186 & 7 & 4 & $\begin{array}{l}\text { The effectiveness of grout stabilization for debris (in preventing organics, RCRA metals and } \\
\text { radionuclides from migrating out) must be established for a wide range of DOE waste. }\end{array}$ \\
\hline
\end{tabular}




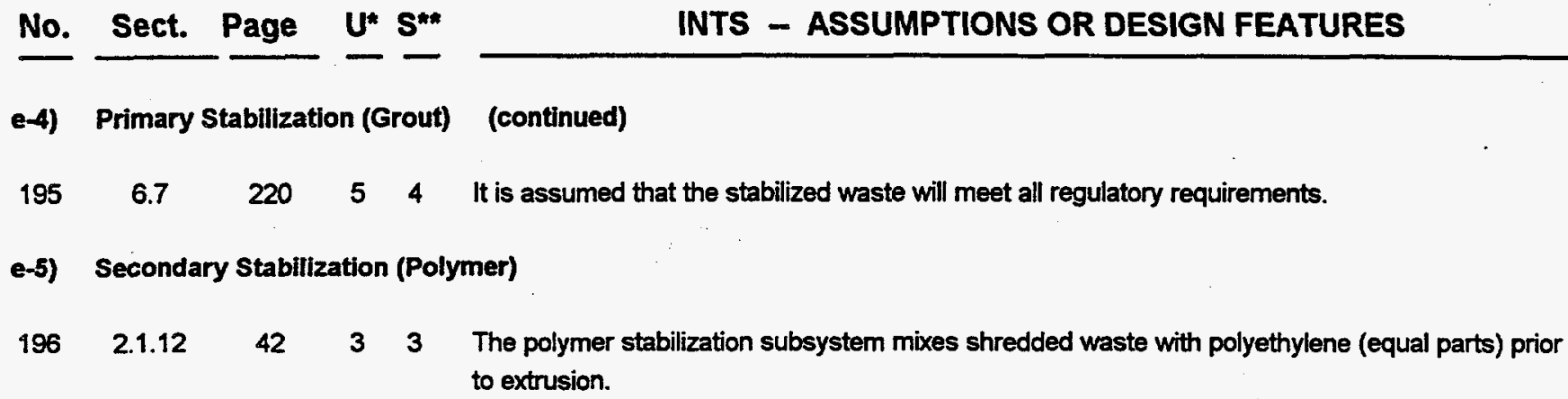
to extrusion.

e-6) Metal Decontamination

\begin{tabular}{|c|c|c|c|c|c|}
\hline 197 & 1.10 .3 & 25 & 3 & 3 & $\begin{array}{l}\text { Mercury contaminated debris will be treated (by vacuum desorption or aqueous washing) } \\
\text { followed by amalgamation. }\end{array}$ \\
\hline 198 & 2 & 30 & 3 & 2 & All systems use surface decontamination of bulk metals and recyclable drums. \\
\hline 199 & 2.1 .8 & 40 & 3 & 2 & $\begin{array}{l}\text { Metal decontamination is done in blasting booths to remove entrained and surface } \\
\text { contamination. }\end{array}$ \\
\hline 200 & $\mathrm{C}-2$ & $\mathrm{C}-3$ & 4 & 2 & $\begin{array}{l}\text { In the metal decontamination subsystem, it was assumed that } 99 \% \text { of the contaminants on } \\
\text { incoming metal debris was removed; the aqueous stream was routed to aqueous waste } \\
\text { treatment, and the metal was to be recycled offsite. }\end{array}$ \\
\hline
\end{tabular}

e-7) Metal Melting (Not used in INTS's)

e-8) Lead Recovery
$201 \quad 2.1 .10 \quad 41 \quad 3 \quad 2 \quad$ The Lead Recovery subsystem decontaminates lead which can be recycled by mechanically removing a thin surface layer.
$202 \quad 2.1 .10 \quad 41 \quad 3 \quad 2 \quad$ Lead which cannot be decontaminated is sent to be grouted without treatment.
$203 \quad \mathrm{C}-2 \quad \mathrm{C}-3 \quad 7 \quad 2$ It is assumed that hydrogen, carbon, silica, and alumina in the lead-contaminated waste stream ( $5 \mathrm{lb} / \mathrm{hr}$ leaded-gloves $+21 \mathrm{lb} / \mathrm{hr}$ lead bricks) partition in the same proportion as the lead.

e-9) Aqueous Waste Treatment

\begin{tabular}{|c|c|c|c|c|c|}
\hline 204 & 1.10 .3 & 26 & 4 & 8 & Treated water will be further treated to remove trace contaminants and recycled or discharged. \\
\hline 205 & 1.10 .3 & 26 & 6 & 3 & Aqueous waste will be treated to destroy organics and to separate and immobilize contaminants. \\
\hline 206 & 2 & 30 & 6 & 4 & $\begin{array}{l}\text { All systems use photo-oxidation destruction of any residual organic materials in the aqueous } \\
\text { treatment system. }\end{array}$ \\
\hline 207 & 2 & 30 & 6 & 4 & $\begin{array}{l}\text { The aqueous waste treatment subsystem includes photo-oxidation (for organic destruction) } \\
\text { along with neutralization, precipitation, filtration, and evaporation. }\end{array}$ \\
\hline 208 & 2.1 .3 & 35 & 4 & 4 & $\begin{array}{l}\text { The aqueous waste subsystem must be extremely flexible in order to treat the wide range of } \\
\text { aqueous wastes. }\end{array}$ \\
\hline 209 & 2.1 .3 & 35 & 6 & 4 & $\begin{array}{l}\text { The aqueous waste subsystem treats input aqueous waste as well as the system's secondary } \\
\text { aqueous wastes. }\end{array}$ \\
\hline 210 & 2.1 .3 & 35 & 6 & 3 & $\begin{array}{l}\text { For waste with high total organic carbon (TOC), the primary processing occurs at the organic } \\
\text { destruction subsystem. }\end{array}$ \\
\hline 211 & 2.1 .3 & 36 & 7 & 3 & $\begin{array}{l}\text { Dissolved organics removal is accomplished in an ultraviolet (UV) reactor using an oxidizing } \\
\text { agent. }\end{array}$ \\
\hline
\end{tabular}




\begin{tabular}{|c|c|c|c|c|c|}
\hline No. & Sect. & Page & $\mathbf{U}^{\star}$ & $\mathbf{S}^{\text {**t }}$ & INTS - ASSUMPTIONS OR DESIGN FEATURES \\
\hline$e-9)$ & Aqueous & Waste Tre & atm & & (continued) \\
\hline 212 & 2.1 .3 & 36 & 4 & 6 & $\begin{array}{l}\text { The aqueous waste subsystem removes radionuclides, RCRA-controlled metals and trace } \\
\text { organic concentrations to regulatory discharge levels. }\end{array}$ \\
\hline 213 & 2.1 .3 & 36 & 4 & 3 & $\begin{array}{l}\text { Sludge from the aqueous waste subsystem is concentrated via evaporation and sent to polymer } \\
\text { stabilization. }\end{array}$ \\
\hline 214 & 7.3 & 234 & 4 & 6 & $\begin{array}{l}\text { Not considered in the INTS study was the need for some wastewater treatment facilities in the } \\
\text { COE complex to meet new permitting requirements which mandate extremely low levels for } \\
\text { some metals. }\end{array}$ \\
\hline 215 & $\mathrm{C}-2$ & $\mathrm{C}-2-$ & 5 & 3 & $\begin{array}{l}\text { The aqueous waste stream coming out of the photolytic reactor is separated into three different } \\
\text { substreams (sludge, offgas, and aqueous); it is assumed that the separation of these streams is } \\
\text { complete ( } 100 \%) \text {. }\end{array}$ \\
\hline
\end{tabular}

e-10) Mercury Amalgamation

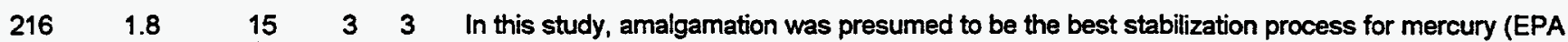 listed as BDAT).

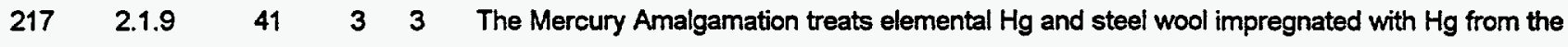 leaching process via amalgamation with copper (or zinc).

$\begin{array}{lllll}218 & 6.7 & 218 & 7 & 3\end{array}$
It was assumed that trace concentrations of mercury, too small to affect the mass balance, are present. Five pounds $/ \mathrm{hr}$ of $\mathrm{Hg}$ goes directly from receiving to amalgamation. In System 2, an additional $82 \mathrm{lbs} / \mathrm{hr}$ of $\mathrm{Hg}$ is recovered.
$219 \quad \mathrm{C}-2 \quad \mathrm{C}-1 \quad 6 \quad 2$
In the mercury amalgamation subsystem, a Cu: $\mathrm{Hg}$ weight ratio of 0.7 is used and a conversion of $100 \%$ is assumed.

e-11) Special Waste Treatment
$220 \quad 2.1 .11$
41 44 44
2.1 .11

$\begin{array}{lllll}221 & 2.1 .11 & 41 & 4 & 4 \\ 222 & \text { C-2 } & \text { C-3 } & 4 & 4\end{array}$
It is assumed that there will be special wastes that require capabilities not in the basic system.
Building space and utilities (including a crane) are provided for special processing, but no equipment.
Approximately $153 \mathrm{lb} / \mathrm{hr}$ of the incoming waste (total of $2927 \mathrm{lb} / \mathrm{hr}$ ) was designated as special waste. No specific treatment of this waste was proposed.

e-12) Certify and Ship

223

$1.10 .3 \quad 26$

52

$\begin{array}{llll}224 & 1.10 .3 & 26 & 5 \\ 225 & 2.1 .15 & 43 & 4\end{array}$

Outgoing
surveys.

e-13) Administrative

$\begin{array}{lllll}226 & 2.1 .1 & 34 & 1 & 1\end{array}$ The Administrative Subsystem is the same for all alternative INTS systems. 
No. Sect. Page $\mathbf{U}^{*} \mathbf{S}^{* *}$

e-14) Process Residue and Inorganic Sludge

$\begin{array}{llllll}227 & 2.1 .5 & 39 & 7 & 6 & \text { The Process Residue and Inorganic Sludge Treatment subsystem employs vacuum desorption }\end{array}$ at $500 \mathrm{~F}$ to remove volatile compounds.

$228 \quad 2.1 .5 \quad 40 \quad 6 \quad 3 \quad$ Solids from the desorber are washed, filtered, and routed to polymer stabilization.

$229 \quad 2.1 .5 \quad 40 \quad 6 \quad 3 \quad$ Offgas from the desorber goes through three condensers (the last at $O F$ ) and is then routed to the :air pollution control subsystem.

$230 \quad 6.2 \quad 195 \quad 3 \quad 5 \quad$ Process residues are anticipated to be homogeneous and are not to require sorting.

e-15) Bulk Soil

$231 \quad 2.1 .6 \quad 40 \quad 7 \quad 6 \quad$ The bulk soil is treated (in campaigns) in the vacuum desorption process, and then sent to the grout stabilization subsystem.'

e-16) Debris

$232 \quad 2.1 .7 \quad 40 \quad 7 \quad 6 \quad$ in System 1, all debris (complex, open, and soft) is grouted; no pretreatment is performed.

$233 \quad 2.1 .7 \quad 40 \quad 76$ In Systems 2-5, the debris is segregated (complex, open, and soft), the debris requiring treatment is shredded, and then the debris is treated prior to grouting.

e-17) Support

$\begin{array}{lllll}234 & 2.1 .16 & 4 & 3 & 3\end{array}$ The Support subsystem includes facilities to ensure continuous functioning of the treatment facility including a main control room, maintenance, HVAC, motor control center (MCC) and electrical rooms.

$\begin{array}{llllll}235 & 2.1 .16 & 4 & 3 & 3 & \text { The Support subsystem includes equipment to maintain the confinement zones (primary }\end{array}$ confinement around process enclosures, secondary confinement, and non-confinement.

$\begin{array}{lllll}236 & 2.1 .16 & 45 & 4 & 3\end{array}$ The confinement system consists of dust collection, process vents, building ventilation, and nuclear grade HEPA filtration units.

e-18) Disposal

$\begin{array}{llllll}237 & 1.10 .3 & 27 & 7 & 2 & \text { Transportation and disposal costs were based on shipping the LLW, MLLW alpha LLW, and }\end{array}$ alpha MLLW to the Nevada Test Site for disposal.

$\begin{array}{llllll}238 & 1.10 .3 & 27 & 7 & 2 & \text { All wastes from other sites will be transported to the same site for disposal; an average cost of }\end{array}$ disposal is used for all shipments.

$\begin{array}{llllll}239 & 1.10 .3 & 27 & 5 & 6 & \text { Costs for shallow land disposal facilities have been used for all wastes. }\end{array}$

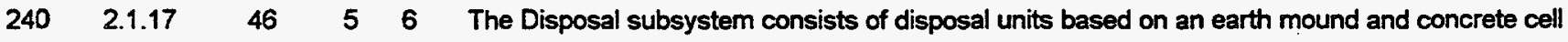
concept.

f) Life Cycle Cost and Sensitivity Analysis

$\begin{array}{llllll}241 & 15 & 15 & 8 & \text { Costs have been estimated assuming the system is a government owned and contractor }\end{array}$ operated (GOCO) facility.

$\begin{array}{lllll}242 & 1.9 .3 & 18 & 8 & 9\end{array}$

Design, inspection, project administration, indirect, construction management, and contingency costs subcomponents are developed using percentage guidelines provided by INEL. 
No. Sect. Page $\mathbf{U}^{*} \mathbf{S}^{* *}$

7) Life Cycle Cost and Sensitivity Analysis (continued)

$\begin{array}{lllll}243 & 1.9 .3 & 3 & 2 & \text { Planning studies and tests include three subcomponents: manpower, test equipment, and }\end{array}$ equipment installation.

$\begin{array}{llllll}244 & 1.9 .3 & 18 & 5 & 5 & \text { Equipment cost estimates are based on the use of stainless steel material for process vessels }\end{array}$ selected for ease of decontamination and maintenance, unless otherwise discussed.

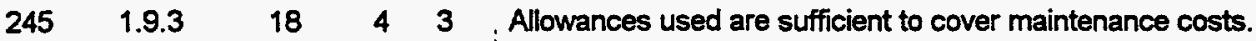

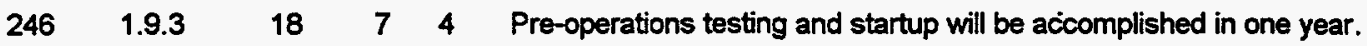

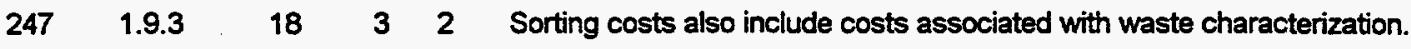

$\begin{array}{llllll}248 & 1.9 .3 & 18 & 8 & 8 & \text { PLCC estimates for facility construction are based on conditions at ldaho National Engineering }\end{array}$ Laboratory (INEL), in Idaho Falls, Idaho, including utilities, labor and related design, construction, operation, and management factors.

$\begin{array}{lllll}249 & 1.9 .3 & 18 & 1 & 1\end{array}$

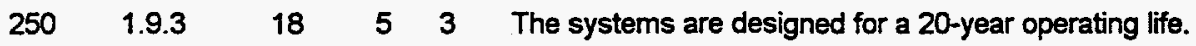

$\begin{array}{lllll}251 & 1.9 .3 & 2 & 2 & \text { Demonstration costs consist of nine subcomponents: manpower during demonstration, building }\end{array}$ structure, equipment, design, inspection, project administration, indirect, construction management (CM), and contingency.

$\begin{array}{lllll}252 & 1.9 .3 & 18 & 3 & 4\end{array}$ Technologies must be ready for pilot scale demonstration in 2 years, incorporation in a final design in 3 years, and construction in 5 years.

The costs for each facility are divided into these six components: studies and bench scale tests, demonstration, production facility construction, pre-operation costs, operating and maintenance (O\&M), and decontamination and decommissioning (D\&D).

The allowance percentages are historical averages experienced by DOE contractors at INEL for the types of activities covered by waste management facilities.

The maintenance cost subcomponent is divided into maintenance labor and maintenance replacement equipment cost. The annual maintenance equipment cost is $7 \%$ of the original equipment capital cost for most subsystems. The annual maintenance labor cost is $250 \%$ of the maintenance equipment cost.

For subsystems with corrosives, $10 \%$ of the equipment cost is estimated as the annual maintenance equipment cost. For subsystems with simple requirements, such as grout and metal decontamination, a factor of $4 \%$ is used.

\begin{tabular}{|c|c|c|c|c|c|}
\hline 257 & 3.4 & 27 & 2 & 2 & Costs for monitors are included in each treatment subsystem. \\
\hline 258 & 3.4 & 100 & 4 & 1 & $\begin{array}{l}\text { Cooling water costs were assumed to be negligible by comparison and were ignored in this } \\
\text { simple analysis. }\end{array}$ \\
\hline 259 & 3.4 & 100 & 5 & 2 & $\begin{array}{l}\text { A price of } \$ 0.05 \text { per } k W h \text { was used for electricity, and } \$ 2.00 \text { per million British thermal units } \\
\text { (MMBtu) was used for natural gas. }\end{array}$ \\
\hline 260 & 4 & 125 & 8 & 6 & $\begin{array}{l}\text { The facility includes alpha confinement rather than build two smaller facilities (one for alpha and } \\
\text { one for non-alpha MLLW). }\end{array}$ \\
\hline 261 & 4 & 125 & 4 & 3 & $\begin{array}{l}\text { Transportation costs were not included as part of the PLCC since they were small }(-1 \%) \text { and the } \\
\text { same for all systems. }\end{array}$ \\
\hline 262 & 4.1 & 125 & 8 & 6 & The time value of money was ignored in this analysis. \\
\hline 263 & 4.1 & 126 & 7 & 2 & Cost information obtained during second half of 1995. \\
\hline
\end{tabular}


No. Sect. Page $\mathbf{U}^{*} \mathbf{S}^{* *}$

f) Life Cycle Cost and Sensitivity Analysis (continued)

$\begin{array}{lllll}264 & 4.2 .1 & 126 & 3 & 2 \\ 265 & 4.2 .2 & 126 & 8 & 6 \\ 266 & 4.2 .2 & 126 & 8 & 6 \\ 267 & 4.2 .2 & 126 & 1 & 1 \\ 268 & 4.2 .2 & 126 & 8 & 6 \\ 269 & 4.2 .2 & 126 & 1 & 1 \\ & & & & \\ 270 & 4.2 .2 & 126 & 6 & 3 \\ 271 & 4.2 .2 & 126 & 6 & 3 \\ 272 & 4.2 .2 & 126 & 6 & 3 \\ & & & & \\ 273 & 4.2 .2 & 126 & 5 & 3 \\ 274 & 4.2 .2 & 127 & 2 & 6 \\ 275 & 4.2 .2 & 127 & 2 & 6\end{array}$

Costs for Studies, Bench Scale Tests and Demonstrations were estimated from research manpower, equipment, and facility needs.

Design (preliminary plus detailed) is estimated at $25 \%$ of facility construction costs (FCC).

Project management for construction (DOE and M\&O) is estimated at $10 \%$ of FCC

Construction costs include buildings, equipment and indirect costs.

Inspection (engineering support during construction) is estimated at $7 \%$ of FCC

Building and structure costs are estimated by multiplying building unit costs by the space square footage allocated to each subsystem in the scoping study layouts (SSL's).

$\$ 1,700 /$ sq-ft for triple confinement alpha cells

$\$ 800 /$ sq-ft for double confinement alpha cells and operating areas next to alpha cells

$\$ 420 / s q-f t$ for packaged waste handling areas, non-alpha process areas, and analytical laboratories

\begin{tabular}{|c|c|c|c|c|c|}
\hline 276 & 4.2 .2 & 127 & 1 & 1 & $\begin{array}{l}\text { Building unit rates include all material and labor needed for constructing the building shell } \\
\text { including utilities, lighting, HVAC, and site development costs. }\end{array}$ \\
\hline 277 & 4.2 .2 & 127 & 1 & 1 & $\begin{array}{l}\text { To estimate the additional costs of the supporting equipment, allowances are estimated as a } \\
\text { percentage of the total equipment purchase cost. }\end{array}$ \\
\hline 278 & 4.2 .2 & 127 & 3 & 3 & $\begin{array}{l}\text { Subsystems which involve processing equipment: } 15 \%=\text { electrical; } 30 \%=\text { mechanical; } 30 \%= \\
\text { instrumentation' }\end{array}$ \\
\hline 279 & 4.2 .2 & 127 & 3 & 3 & $\begin{array}{l}\text { For subsystems where material handling is the major processing activity: } 15 \%=\text { electrical; } 5 \%= \\
\text { mechanical; } 5 \%=\text { instrumentation. }\end{array}$ \\
\hline 280 & 4.2 .2 & 127 & 3 & 3 & $\begin{array}{l}\text { For non processing areas (administration and support): } 15 \%=\text { electrical; } 1 \%=\text { mechanical; } 1 \%= \\
\text { instrumentation. }\end{array}$ \\
\hline 281 & 4.2 .2 & 127 & 3 & 3 & $\begin{array}{l}\text { Major equipment costs are based on similar facility costs, costs from suppliers, or by making } \\
\text { engineering judgments. }\end{array}$ \\
\hline 282 & 4.2 .2 & 127 & 6 & 4 & $\begin{array}{l}\text { In the case of acid digestion, which is highly immature, an extra factor of } 1.5 \text { was applied to } \\
\text { account for potential unidentified requirements. }\end{array}$ \\
\hline 283 & 4.2 .2 & 127 & 3 & 3 & $\begin{array}{l}\text { Equipment was added to all subsystems for alpha containment (e.g. shield windows and closed } \\
\text { circuit television). }\end{array}$ \\
\hline 284 & 4.2 .2 & 128 & 8 & 6 & $\begin{array}{l}\text { A } 25 \% \text { contingency was added to the total construction cost (because the costs are a planning } \\
\text { level estimate). }\end{array}$ \\
\hline 285 & 4.2 .2 & 128 & 8 & 6 & Allowances for project scope change $=10 \%$ of construction cost. \\
\hline 286 & 4.2 .2 & 128 & 8 & 6 & Construction management $=17 \%$ of construction costs (equipment + buildings + indirect costs). \\
\hline 287 & 4.2 .2 & 128 & 3 & 6 & $\begin{array}{l}\text { Indirect costs (including subcontractor overhead and fees) }=29 \% \text { of the total building, structure, } \\
\text { and equipment costs. }\end{array}$ \\
\hline
\end{tabular}


7) Life Cycle Cost and Sensitivity Analysis (continued)

\begin{tabular}{|c|c|c|c|c|}
\hline 4.2 .2 & 128 & 1 & 1 & $\begin{array}{l}\text { In cases where the technology developer provided the total cost, no additional allowances were } \\
\text { added. }\end{array}$ \\
\hline 4.2.3 & 128 & 8 & 3 & Conceptual design is estimated at $1.5 \%$ of construction cost. \\
\hline 4.2 .3 & 128 & 4 & 6 & Pre-operation costs are assumed equal to one year of total facility operating costs \\
\hline 4.2 .3 & 128 & 7 & 4 & Safety assurance is estimated at $1 \%$ of construction cost. \\
\hline 4.2.3 & 128 & 7 & 3 & $\$ 7$ million is the estimated cost for all permits. \\
\hline 4.2 .4 & 129 & 3 & 7 & $\begin{array}{l}\text { Operating labor, utilities, and consumable materials were estimated from the requirements of } \\
\text { each subsystem. }\end{array}$ \\
\hline 4.2 .4 & 129 & 4 & 6 & Maintenance labor is estimated at $250 \%$ of the cost of the spare parts. \\
\hline 4.2 .4 & 129 & 4 & 4 & $\begin{array}{l}\text { Annual maintenance equipment costs are estimated to be about } 7 \% \text { of the original equipment } \\
\text { costs ( } 10 \% \text { for subsystems with corrosion). }\end{array}$ \\
\hline 4.2 .5 & 129 & 7 & 4 & The cost of D\&D is estimated at $\$ 450 /$ sq- $t$ for the total facility. \\
\hline 4.2 .6 & 129 & 1 & 1 & The PLCC cost estimate is the sum of the component costs. \\
\hline 4.3 & 129 & 8 & 6 & Disposal costs are based on a unit rate of $\$ 243 / t t 3$ for burial in an engineered disposal facility \\
\hline 4.4 & 129 & 1 & 1 & Total PLCC is the PLCC plus the disposal costs. \\
\hline 4.5 & 130 & 1 & 1 & The Total PLCC increases by $50 \%$ if the Operating and Maintenance cost is doubled. \\
\hline 4.5 & 130 & 1 & 1 & The Total PLCC increases by $23 \%$ if the Disposal cost is doubled. \\
\hline 4.6 & 131 & 8 & 6 & $\begin{array}{l}\text { Uncertain subsystems (receiving and prep, organic destr. [MEO, CWO, and acid digestion], } \\
\text { process residue [vacuum desorption, aqueous washing], soil treatment [aq. washing], and } \\
\text { debris treatment [high press washing, agitation washing, acid digestion, CWO]) were given a } \\
50 \% \text { contingency. }\end{array}$ \\
\hline
\end{tabular}

It was found that all systems were equally sensitive to pre operations cost. An increase in pre operation duration from 1 year to 4 years will result in an increase of $12 \%$ in the PLCC.

$\begin{array}{lllll}304 & 4.7 & 132 & 1 & 1 \\ 305 & 4.9 & 132 & 3 & 2 \\ 306 & 4.9 & 134 & 3 & 2\end{array}$

Analysis of stabilization technology ignored the stability of final waste. Polymer is most stable @ $\$ 14 / \mathrm{lb}$. Ceramic and grout are less stable and cost $\$ 15 / \mathrm{b}$.

Transportation costs have not been included in the PLCC.

$$
30
$$

Transportation costs could be calculated: Trans. Cost $=$ (lbs waste/44,000 lbs/shipment $)(\$ 880+$ rate $x$ one-way miles), where rate $=\$ 5.94 / \mathrm{mi}$ ( $<30$ miles), $\$ 4.98 / \mathrm{mi}(30-200$ miles), or $\$ 4.00$ (>200 miles).

A contingency of $25 \%$ was added for O\&M costs.

Analysis indicates that research and development costs are small relative to implementation costs.

$\begin{array}{lllll}310 & 5.1 .5 & 165 & 6 & 3 \\ 311 & 5.1 .5 & 165 & 6 & 3\end{array}$

The uncertainties in total PLCC are estimated to be $-35 \%$ to $+75 \%$. The maximum difference in INTS's is $9 \%$ which is not significant. requirements (which depend upon the next use of the facility) were not determined.

Environmental restoration - all INTS's were assumed to require approximately the same amount of site restoration; specific requirements (which depend upon the next use of the land) were not determined. 
No. Sect. Page $\underline{U^{*}} \underline{\mathbf{S}^{* \hbar}}$

f) Life Cycle Cost and Sensitivity Analysis (continued)

$312 \quad A-4 \quad$ A-20 $6 \quad 3$ For calculating transportation and disposal costs, it was assumed that the stabilized waste will be shipped to and disposed of at the Nevada Test Site.

313 A-6 A-24 $4 \quad 3$ The Scoping Study Layout, SSL, for each facility is based on a surge capacity of 2-6 weeks for the indoor storage of MLLW drums and on a triple confinement system for areas process alpha-contaminated MLLW.

314 A-6 A-24 $8 \quad 6$ The facilities' process units were designed to handle at least $125 \%$ of the expected mass flow rates.

g) Criteria for Assessing Technology Risk

$\begin{array}{lllll}315 & 5.1 .1 & 2 & 2 & 2\end{array} \quad$ Flexibility - This study did not evaluate variations in waste throughput or concentrations, and developed the systems to treat the wastes at the given throughput

$\begin{array}{lllll}316 & 5.1 .1 & 2 & 2 & 2\end{array} \quad$ Effectiveness - Based on available vendor data, all systems were assumed capable of treating the organic contaminants to the EPA UST.

Versatility - Was taken care of in the selection process. By combining the selected technologies, it was considered that the non-thermal systems could treat all the waste in the waste profile used in this study.

Maintainability - Assessment of maintainability was beyond the scope of this study.

$319 \quad 5.1 .1 \quad 160$

Hazardous waste generation - Details of potential contaminant carryover cannot be determined.

Volume reduction - Volumes of waste inputs and outputs were estimated for all systems.

Byproducts and residuals - Byproducts from the subsystems were estimated.

Availability - Judgment of availability was highly qualitative in this study. Long-term operational experience is not available, and a detailed analysis of the reliability of each component was not done.

Reliability - Judgment of reliability was highly qualitative in this study. Long-term operational experience is not available, and a detailed analysis of the reliability of each component was not done.

Hazardous waste generation - Secondary waste streams generated by the
been characterized, and the volumes of effluents have been estimated. were assumed to be the same as for the ITTS study.

Final waste form performance - Developer data appear to verify that the waste forms selected can meet EPA TCLP leaching criteria.

Airborne releases - Technologies that were thought to minimize gaseous effluent were selec
however determination of contaminant carryover requires testing at operating conditions. available.

Wastewater releases - Systems were designed to recycle
determination of contaminant releases requires testing.

Hazardous operating conditions - Determination of off-normal modes of operation and their consequences was beyond the scope of this study. 
No. Sect. Page $\underline{U^{*}} \underline{S^{* *}}$

\section{g) Criteria for Assessing Technology Risk (continued)}

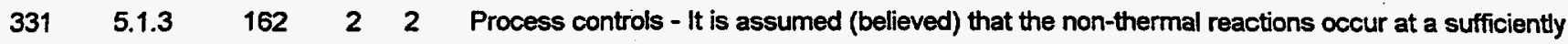
slow rate that the controls can prevent upset and/or accident conditions.

$\begin{array}{llllll}332 & 5.1 .3 & 162 & 2 & 2 & \text { Hazardous reagents - all non-thermal systems use hazardous reagents; processes were }\end{array}$ selected based on using the least hazardous material that would still perform the function.

Hazardous process equipment -Technologies that operate under extremely hazardous conditions (such as high pressures, or the use of flammable materials) were eliminated from consideration. Upset and accident conditions - upsets are assumed to be rare.

Maintenance worker exposure - The potential for worker exposure is not defined due to the early stage of system development; it is believed that the maintenance requirements will be similar for all systems.

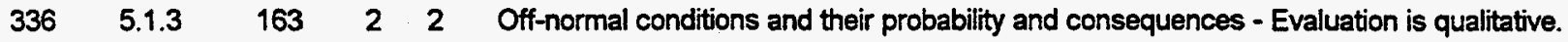

$\begin{array}{lllll}337 & 5.1 .5 & 2 & 2 & 2\end{array} 2$ Complexity - The simplest systems that would meet the treatment requirements were selected.

$\begin{array}{lllll}338 & 5.1 .5 & 2 & 2 & 2\end{array}$ Schedule - The systems studies are estimated to require 7 to 10 years of development demonstration, construction, and permitting before they can be implemented for treatment of DOE mixed waste.

All final waste forms are expected to conform to LDR's (requires verification).

NOTE: $\quad U$ The uncertainty in an assumption

(on a scale of 1 - 10 with 10 being the most uncertain)

* $\mathbf{S}$ The sensitivity of the Total PLCC to changes in the assumption

(on a scale of $1-10$ with 10 being the most sensitive)

Both Uncertainty and Sensitivity were based on engineering judgement; no quantitative evaluations were made at this stage of the review of the reports. 


\section{APPENDIX G}

\section{ASSUMPTIONS FROM THE ITTS PHASES $1 \& 2$ REPORTS AND THE INTS REPORT WITH HIGH COST SENSITIVITY AND UNCERTAINTY}


App D

No. No. Sect. Page $\mathbf{U}^{*} \mathbf{S}^{*}$.

ITTS Phase 1 - Critical Assumptions or Design Features

a) Regulations, Permitting and Stakeholder Input

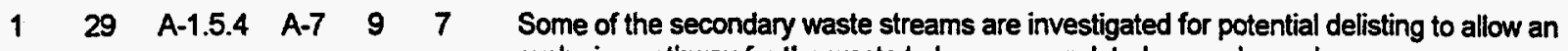

exclusion pathway for the waste to become regulated as nonhazardous

$1 \quad 102$ A-4.4.2 A-31 $7 \quad 7 \quad$ Final waste forms for LLW will be delistable to reduce the cost of disposal (Subtitle D versus

b) Input Waste Characteristics

\begin{tabular}{|c|c|c|c|c|c|}
\hline 110 & 3.3 & 58 & 8 & 8 & $\begin{array}{l}\text { The ash content from combined combustible and noncombustible waste is } 54 \% \text { of feed, ash } \\
\text { from combustible waste is } 7 \% \text { of feed, and lime discarded after calcining is } 10 \% \text { of feed }\end{array}$ \\
\hline 121 & 2.1 .1 & 17 & 6 & 8 & $\begin{array}{l}\text { Contaminated soil from environmental restoration programs may be used as one of the } \\
\text { vitrification additives. }\end{array}$ \\
\hline 223 & 2.1 .1 .10 & 21 & 7 & 7 & $\begin{array}{l}\text { Soil (including contaminated soil from DOE installations) or chemical additives used as glass } \\
\text { formers }\end{array}$ \\
\hline 72 & A-5.1 & A-19 & 8 & 7 & The ITTS shall treat the waste types described in Table A-4 of Phase 1 report \\
\hline
\end{tabular}

d) General Design and Operating Assumptions

2115 A-6.4 A-35 $9 \quad 8 \quad$ Operation of the treatment facility is assumed to be for 24 hours per day, 5 days per week, 240

days per year, at $70 \%$ capacity during operation. This is equivalent to 4032 hours per year.

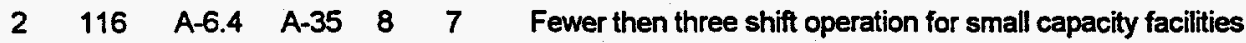

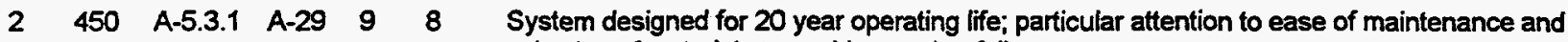
selection of materials to avoid corrosion failures

$\begin{array}{llllll}3 & 94 & \text { A-6.1 } & \text { A-34 } & 8 & 8\end{array} \quad$ Facility will be placed in Seismic Category 1; building will be classified as moderate hazard facility

$\begin{array}{lllllll}4 & 93 & 1.3 .2 & 10 & 8 & 7 & \text { System will incorporate minimum shielding; shielding not a factor in system performance }\end{array}$

$\begin{array}{llllll}5 & 469 & \text { A-5.3.2 } & \text { A-30 } & 7 & 7\end{array}$ Six vitrification technologies meet implementability requirements: joule, electric arc, direct current plasma torch, fossil fueled, slagging rotary kiln, high frequency induction melter; must meet 1450 to $1650 \mathrm{C}$ for aluminosilicate final waste form with minimal fluxing

$\begin{array}{rrrr}- & 105 \quad 3.3 \quad 96\end{array}$

Stabilization formulas consist of 1 part soil or glass forming additive to 2 parts waste (vitrification), 1 part polymer to 1 part waste (polymer stabilization), 2 parts grout to 1 part waste (grout stabilization)

d.5) System A5 - Rotary Kiln with Air and Polymer Stabilization

$\begin{array}{llllll}- & 133 & 2.1 .5 & 24 & 8 & 6\end{array}$ Bottom ash and fly ash stabilized residues kept separate for tracking transuranic activity

d-7) System B1 - Indirectly Heated Pyrolyzer with Oxygen and DryWet APC

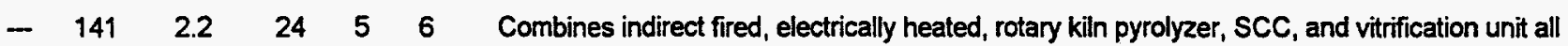

fired on oxygen

- $\quad 189 \quad 2.1 .1 .2 \quad 25 \quad 5 \quad 6 \quad$ Pyrolyzer, SCC, dryer are integrated with vitrification unit

e-1) Receiving and Preparation

$\begin{array}{llllll}6 & 175 & 2.1 .1 .1 & 18 & 9 & 8\end{array}$

7 report)

$\begin{array}{llllll}7 & 176 & 2.1 .1 .1 & 18 & 9 & 8\end{array}$ Systems B1 and D1: It is assumed that 100\% of the waste requires sorting (Table 3-9 Phase 2

report)

$\begin{array}{llllll}- & 177 & 2.1 .1 .1 & 18 & 9 & 8\end{array}$ System E1: It is assumed that $71 \%$ of the waste requires sorting (Table 3-9 Phase II report)

e-3) Air Pollution Control (APC)

$\begin{array}{lllllll}8 & 106 & 3.3 & 58 & 7 & 8 & \mathrm{CO} 2 \text { absorption, lime recycling is } 90 \% \text { and rejection is } 10 \%\end{array}$

$\begin{array}{lllllll}8 & 219 & 2.1 .1 .4 & 19 & 7 & 7 & \text { Lime or dolomite recycled up to ten times in calcining lime recovery system }\end{array}$

$\begin{array}{llllll}8 & 220 & 2.1 .1 .4 & 19 & 7 & 7\end{array}$ Lime disposed by secondary stabilization after ten cycles on premise that it contains RCRA

metals and is subject to disposal restrictions

$\begin{array}{lllllll}8 & 128 & 2.1 .4 & 23 & 7 & 7 & \text { Spent lime recycled as many as ten times by calcining }\end{array}$

$\begin{array}{lllllll}8 & 129 & 2.1 .4 & 23 & 7 & 7 & \mathrm{CO} 2 \text { is monitored and discharged; calcining can be done on or off site or spent lime can be }\end{array}$

$\begin{array}{lllllll}8 & 158 & 2.4 & 27 & 7 & 7 & \text { Lime recycled up to ten times; landfilling eliminates CO2 release }\end{array}$

e-485) Stabilization (Primary and Secondary)

$9 \quad 470$ A-5.3.2 A-30 $7 \quad 7 \quad$ Five low temperature stabilization agents meet implementability requirements: Portland cement, polymer (Dow Chemical), pozzolanic cement, polyethylene, and sulfur cement 
App D

\begin{tabular}{|c|c|c|c|c|c|c|}
\hline No. & No. & Sect. & Page & $\mathbf{U}^{*}$ & $\mathbf{S}^{* *}$ & ITTS Phase 1 - Critical Assumptions or Design Features \\
\hline e-18) & Dis & osal & & & & \\
\hline 1 & 311 & 4.3 & 82 & 9 & 9 & $\begin{array}{l}\text { Disposal costs - estimated from unit rate cost of } \$ 243 \text { per cubic foot for burial in engineered } \\
\text { above or below ground disposal }\end{array}$ \\
\hline 1 & 87 & A-4.4.1 & A-30 & 8 & 9 & Output LLW, MLLW, alpha LLW, alpha MLLW shipped to and disposed at Nevada Test Site \\
\hline 1 & 86 & & & 8 & 8 & Engineered disposal facility used for costing \\
\hline 1 & 92 & $A-4.4 .2$ & A-31 & 5 & 7 & $\begin{array}{l}\text { Final waste forms will meet contact handling requirements with no additional shielding besides } \\
\text { the container }\end{array}$ \\
\hline
\end{tabular}

f) Life Cycle Cost and Sensitivlty Analysis

$\begin{array}{llllll}10 & 302 & 4.2 .2 .5 & 79 & 9 & 9\end{array}$ Contingency - 25\% due to planning level estimate; applied to all components in production facility construction cost

$\begin{array}{llllll}11 & 310 & 4.2 .5 & 80 & 7 & 8\end{array} \quad$ Decontamination and decommissioning - estimated by multiplying $\$ 450$ square foot unit rate (from Schleuter) by total facility square feet.

$\begin{array}{llllll}12 & 291 & 4.2 .2 .4 & 78 & 9 & 6\end{array} \quad$ Building and structures - estimated by multiplying building unit costs by square feet for each subsystem

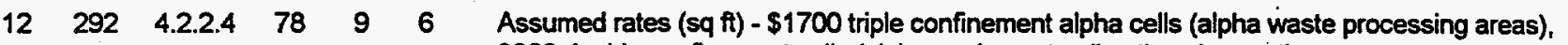
$\$ 800$ double confinement cells (alpha equipment pull out) and operating areas next to alpha cells, $\$ 420$ packaged waste handling (truck or drum bay) and nonalpha process, operator and packaged waste areas, $\$ 180$ for office areas, $\$ 420$ for analytical lab .

$\begin{array}{llllll}12 & 97 & 1.3 .4 & 15 & 8 & 5\end{array}$

Primary design requirement is triple containment of alpha contamination; tertiary containment will be used for waste sorting through waste stabilization; two levels of containment for processes with limited potential for airborne materials 
App E

No. No. Sect. Page $U^{*} S^{*} \quad$ ITTS Phase 2 - Critical Assumptions or Design Features

a) Regulations, Permitting and Stakeholder Input

$\begin{array}{llllll}1 & 67 & 1.5 .3 .5 & 1-21 & 7 & 8\end{array}$ Some final waste forms for LLW may be delistable to reduce the cost of disposal (Subtitle D versus Subtitle $C$ ). No credit appears to have been taken for such delisting in comparing different systems in this study.

$\begin{array}{llllll}1 & 243 & 4.3 & 4-4 & 8 & 7\end{array}$

The same unit disposal cost of $\$ 243$ per cubic foot is used for all waste disposal regardiess of form. This rate is based on the use of an engineered disposal facility, either above-ground or in a below-ground vault.

$\begin{array}{llllll}1 & 258 & 4.6 & 4-6 & 7 & 8\end{array}$

Sensitivity to the choice of stabilization technology was determined for vitrification, polymer solidification and grouting. Under the assumption that all waste forms bear the same disposal cost, the effect on PLCC was in proportion to the amount of waste produced, which increased in the order of vitrification, polymer, and grout.

$\begin{array}{llllll}1 & 259 & 4.7 & 4.7 & 7 & 8\end{array}$

Sensitivity to delisting was addressed for scrubber salts and for the entire vitrified waste. It was assumed that delisted salts could be disposed in a shallow-land burial facility without stabilization. Delisted vitrified waste was assumed to be disposed in a non-RCRA facility at a cost of $\$ 100 / \mathrm{cu} \mathrm{ft}$

d) General Design and Operating Assumptions

$\begin{array}{llllll}2 & 72 & 1.5 .3 .6 & 1-22 & 9 & 9\end{array}$ Facilities will be designed for a moderate -hazard classification and Seismic Category 1.

$\begin{array}{llllll}3 & 75 & 1.5 .3 .6 & 1.22 & 8 & 8\end{array}$

Operation of the treatment facility is assumed to be for 24 hours per day, 240 days per year, at $70 \%$ capacity during operation. This is equivalent to $\mathbf{4 0 3 2}$ hours per year at the design rate, or an overall capacity factor of $46 \%$.

$\begin{array}{llllll}4 & 74 & 1.5 .3 .6 & 1-22 & 8 & 7\end{array}$

Since systems are designed to handle both nonalpha and alpha waste up to $100 \mathrm{nCi} / \mathrm{g}$, triple containment will be used for all process steps from waste sorting through waste stabilization. Two levels of containment are used for other processes if there is limited potential for air emissions.

$\begin{array}{llllll}4 & 297 & 5.2 .1 .4 .1 & 5-7 & 8 & 6\end{array}$

The preconceptual system layouts are based on placing equipment in air-tight cells having three levels of confinement. Personnel access is through airlock doors, with large corridors provided next to each cell for equipment pull-out and maintenance. This approach "has seldom been used by DOE" and it needs further evaluation.

$\begin{array}{llllll}\text { FS } & 226 & 4 & 4 & 7 & 9\end{array} \quad$ PLCC estimates were based on a facility that incorporates a stringent alpha radiation confinement design. The alternative of providing separate facilities for alpha and nonalpha wastes was not costed.

d-2) System C2 - Plasma Furnace with $\mathrm{CO} 2$ Retention

$\begin{array}{llllll}5 & 330 & 5.4 .1 & 5-17 & 6 & 6\end{array}$ The technology risk of the oxygen plasma furnace system $(\mathrm{C} 2)$ is judged higher than the baseline due to lack of commercial experience, offgas recycling, short plasma torch lifetimes, problems of refractory lifetime, moving parts and complex seals in the centrifugal hearth.

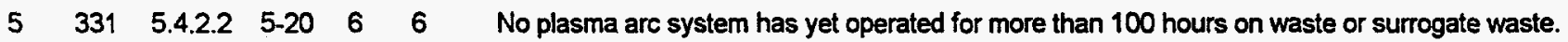
Electrode lifetime is very limited.

$5 \quad 336 \quad 5.4 .1 .4 \quad 5-18 \quad 6 \quad 6$

Implementation risks concern the lifetime of the plasma torch electrode, refractory lifetime and repair procedures (no repair experience for a radioactive environment exists), the near-zero air leakage requirement, separation of inert gases, and fate of radionuclides.

$\begin{array}{llllll}5 & 339 & 5.4 .1 .7 & 5-19 & 6 & 6\end{array}$

The plasma furnace is at an early stage of development, but the involvement of several vendors and the high level of developmental effort indicates that plasma arc systems will be commercially available within the ITSS time frame.

- $338 \quad 5.4 .1 .6 \quad 5-19 \quad 6 \quad 8 \quad$ Life-cycle costs for C2 cannot be estimated accurately at this stage of development.

d-3) System C3 -- Plasma Gasification
$\begin{array}{llllll}6 & 343 & 5.5 & 5-21 & 6 & 6\end{array}$
The technology risk of the plasma gasification system (C3) is higher than in the baseline owing to unproven operation for mixed organic/inorganic waste destruction, very limited electrode lifetime, volatilization of metals, uncertain refractory lifetime, and uncertainty concerning slag stability (5.5.2).
$\begin{array}{llllll}6 & 349 & 5.5 .1 .7 & 5-22 & 6 & 6\end{array}$
Technology development risk for $\mathrm{C} 3$ is high owing to the early stage of development. A plasma reactor is being designed for hospital waste at a feed rate of $1000 \mathrm{lb} / \mathrm{hr}$. Only pilot studies and research have been performed to data. Further development using DOE wastes is necessary.
$\begin{array}{lllll}347 & 5.5 .1 .5 & 5-22 & 6 & 6\end{array}$ Accurate life cycle costs cannot be estimated for plasma gasification. 


\begin{tabular}{|c|c|c|c|c|c|c|}
\hline No. & $\begin{array}{l}\text { App } E \\
\text { No. }\end{array}$ & Sect. & Page & $\mathbf{U}^{*}$ & $\mathbf{S}^{* \star \mathbf{t}}$ & ITTS Phase 2 - Critical Assumptions or Design Features \\
\hline d-4) & \multicolumn{2}{|c|}{ System F1 -- } & \multicolumn{4}{|c|}{ Molten Salt Oxidation } \\
\hline 7 & 143 & 2.3 & $2-15$ & 6 & 9 & $\begin{array}{l}\text { The Molten Salt Oxidation System (F1) consists of the MSO subsystem, an APC, salt recycle, } \\
\text { and primary stabilization with an independent APC. }\end{array}$ \\
\hline 7 & 145 & 2.3.1 & 2-16 & 6 & 8. & $\begin{array}{l}\text { Inorganic ash in the MSO unit will collect in the molten salt and will subsequently be filtered from } \\
\text { dissolved salt in the salt recycling subsystem and sent to primary stabilization. }\end{array}$ \\
\hline 7 & 146 & 2.3 .1 & $2-16$ & 6 & 7 & $\begin{array}{l}\text { Feed to the MSO will be sorted into combustible and noncombustible categories, with only the } \\
\text { combustible going to the MSO unit. }\end{array}$ \\
\hline 7 & 154 & 2.3.3 & $2-17$ & 6 & 6: & $\begin{array}{l}\text { Ash slurry from the salt recycling subsystem in } \mathrm{F} 1 \text { will be dried and sent to the primary } \\
\text { (vitrification) stabilization subsystem. }\end{array}$ \\
\hline 7 & 350 & 5.6 & $5-23$ & 6 & 6 & $\begin{array}{l}\text { The Molten Salt Oxidation (MSO) System (F1) has a greater technology risk than the baseline. } \\
\text { The technology oxidizes low-ash combustibles in molten sodium carbonate, which catalyzes the } \\
\text { oxidation and neutralizes acids. The viscosity of the melt must be controlled by removing ash } \\
\text { and inert materials. }\end{array}$ \\
\hline 7 & 351 & 5.6 & $5-23$ & 6 & 6 & $\begin{array}{l}\text { MSO technology has been developed over the last } 30 \text { years with little commercial application. } \\
\text { Most of the available data were obtained in bench scale tests. Technology risks pertain to the } \\
\text { removal of ash from the melt to control melt viscosity, the fate of radionuclides, and the effect of } \\
\text { carbon in ash from the MSO process in subsequent vitrification stabilization (5.6.2). }\end{array}$ \\
\hline 7 & 355 & 5.6 .1 .3 & $5-24$ & 6 & 6 & $\begin{array}{l}\text { Treatment effectiveness is reduced by the limitation of MSO to treat only combustibles. } \\
\text { Corrosion of the vessel is a concern. Ash in the molten bath is limited to } 20 \% \text { to control viscosity. } \\
\text { Excess ash is removed and the salt recycled by dissolution, filtration of ash, and evaporative } \\
\text { recrystallization of the salt. The aqueous stream is recycled to avoid waste generation. }\end{array}$ \\
\hline 7 & 360 & 5.6.1.6 & $5-25$ & 7 & 8 & $\begin{array}{l}\text { Life cycle cost and schedule for MSO may not meet DOE objectives. Further development will } \\
\text { be needed to evaluate treatment of MLLW, organic destruction rate and efficiency, and gaseous } \\
\text { emissions. }\end{array}$ \\
\hline d-5) & \multicolumn{2}{|c|}{ System G1 - } & \multicolumn{4}{|c|}{ Molten Metal Waste Destruction } \\
\hline 8 & 362 & 5.7 & $5-26$ & 6 & 8 & The technology risk of $\mathrm{G} 1$ is higher than the baseline because of lack of commercial experience. \\
\hline 8 & 365 & 5.7 .2 & $5-29$ & 6 & 6 & $\begin{array}{l}\text { Technology risks of the molten metal melter in G1 concern the effect of changes in feed } \\
\text { composition on the metal and slag produced, the residence time required to treat larger } \\
\text { particles, and the ability of the melter to destroy organic without a secondary combustion } \\
\text { chamber. }\end{array}$ \\
\hline 8 & 370 & 5.7 .1 .3 & $5-27$ & 6 & 6 & $\begin{array}{l}\text { The applicability of the G1 technology to MLLW has not yet been determined. Principal } \\
\text { technology risks for G1 are in reference to melter design and the removal and cooling of slag } \\
\text { and molten metal at high temperatures. }\end{array}$ \\
\hline 8 & 371 & 5.7.1.4 & $5-26$ & 6 & 6 & $\begin{array}{l}\text { Implementation risk for the molten metal system (G1) is high and development is needed for } \\
\text { reactor geometry, refractory, turbulence control, feeding, instrumentation, and slag/metal } \\
\text { removal. Radionuclide partitioning requires additional study. These uncertainties adversely } \\
\text { impact scaleup, cost and schedule. }\end{array}$ \\
\hline- & 374 & 5.7.1.7 & $5-28$ & 6 & 8 & Life-cycle cost cannot be accurately forecast for the $\mathrm{G} 1$ system. \\
\hline d-6) & \multicolumn{2}{|c|}{ System H1 .- } & \multicolumn{3}{|c|}{ Steam Gasification } & \\
\hline 9 & 377 & 5.8 .1 & $5-29$ & 5 & 5 & $\begin{array}{l}\text { The technology risk for steam gasification (H1) in treating MLLW is judged to be higher than for } \\
\text { the baseline despite the commercial use of the technology to treat biomass waste. General } \\
\text { areas of concern are the fate of radionuclides and the destruction efficiency for organics without } \\
\text { a secondary combustion chamber. }\end{array}$ \\
\hline 9 & 387 & 5.8 .2 & $5-31$ & 5 & 5 & $\begin{array}{l}\text { Technology risks for system } \mathrm{H} 1 \text { are concerned with system integration and include: the higher } \\
\text { demands placed on sorting; the destruction efficiency of low-temperature pyrolysis for MLLW; } \\
\text { slagging and plugging in the fluidized bed; fate of metals and radionuclides; and the effect of } \\
\text { carbon in ash on subsequent vitrification and the leaching properties of the disposed waste }\end{array}$ \\
\hline $\begin{array}{l}\text { See } \\
2\end{array}$ & 166 & 2.5 & $2-20$ & 7 & 8 & $\begin{array}{l}\text { Sorting requirements for the steam gasification system are larger than the baseline because of } \\
\text { the inability of the gasifier to accept large amounts of noncombustible. }\end{array}$ \\
\hline
\end{tabular}


App E

No. No. Sect. Page $U^{*} S^{*} \quad$ ITTS Phase 2 - Critical Assumptions or Design Features

d-7) System $\mathrm{J1}$ - Jousle Heated Vitrification

$\begin{array}{llllll}10 & 398 & 5.9 .1 .7 & 5-33 & 5 & 5\end{array}$ Some developmental risk exists for the joule melter system. Bench-scale tests have been performed using surrogate waste, but full-scale test remain to be performed. The flexibility of the system to process a variety of MLLW types has not been demonstrated.

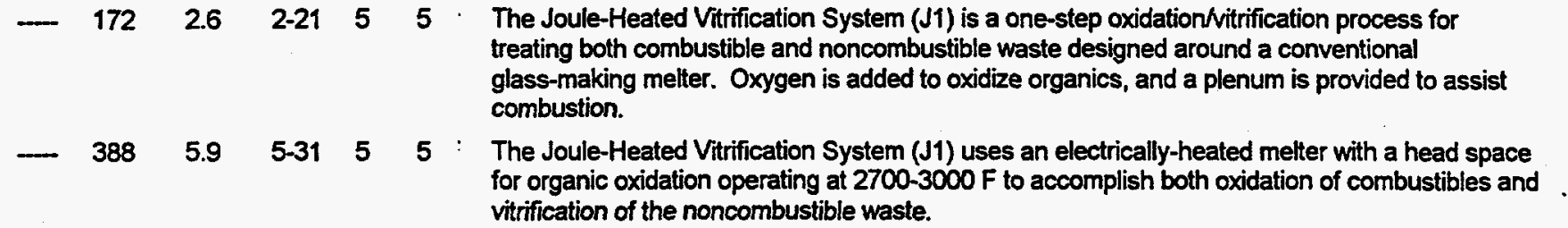

d-8) System K1 - Thermal Desorption and Mediated Electrochemical Oxidation

$\begin{array}{llllll}11 & 403 & 5.10 .1 & 5-34 & 7 & 7\end{array}$ The technology risks for for the TDMEO system are much higher than for the baseline. The TD and APC subsystems are less complex than those in the baseline, but only limited small-scale experience exists for the approach used in this system.

$\begin{array}{llllll} & 409 & 5.10 .1 .4 & 5-35 & 7 & 7\end{array}$ Implementability risks for $\mathrm{K} 1$ are high due to high sorting requirements, questions on processing plastics and combustibles, and the early developmental status of MEO at LLNL. A number of prototypes have been built using commercial electrochemical cells, but electrolyte replacement and regeneration need further development (5.10.2.2).

\begin{tabular}{|c|c|c|c|c|c|}
\hline 400 & 5.1 & $5-34$ & 7 & 8 & $\begin{array}{l}\text { Thermal Desorption (TD) and Mediated Electrochemical oxidation (MEO) in system K1 combine } \\
\text { low-temperature technologies to remove and destroy volatile organics in MLLW. This system } \\
\text { takes advantage of the EPS's debris rule for hazardous waste processing that allows minimum } \\
\text { stabilization of a certain category of MLLW debris. }\end{array}$ \\
\hline 411 & 5.10 .1 .6 & $5-35$ & 7 & 7 & $\begin{array}{l}\text { Life cycle cost for system K1 cannot be accurately forecast at this stage of development. } \\
\text { Disposal of a large volume of grouted waste adversely affects overall cost. }\end{array}$ \\
\hline
\end{tabular}

d-9) System L1 - Thermal Desorption and Supercritical Water Oxidation

$\begin{array}{cccccc}12 & 190 & 2.8 & 2-25 & 7 & 8 \\ 12 & 193 & 2.8 .3 & 2-25 & 7 & 7 \\ 12 & 413 & 5.11 .1 & 5-39 & 7 & 7 \\ 12 & 418 & 5.11 .1 .4 & 5-39 & 7 & 7 \\ 12 & 419 & 5.11 .2 .2 & 5-40 & 7 & 7\end{array}$

The Thermal Desorption and Supercritical Water Oxidation (TDSWO) System (L1) is designed to heat combustible and noncombustible waste to vaporize low-boiling VOCs at temperatures below $800 \mathrm{~F}$. The Thermal Desorber, APC and Primary Stabilization subsystems are similar to those used in the K1 TDMEO System.

SCWO reactants will be pressured and heated to above $220 \mathrm{~atm}$ and $705 \mathrm{~F}$ and reacted in a process vessel still being developed. Prototype reactors use metal alloys and may use ceramics.

Technology risk for the TDSCWO system (L1) is much higher than for the baseline.

Scaleup and implementability of SCWO remain to be demonstrated. Operational issues regarding salt buildup, reactor corrosion, and high pressure negatively affect availability.

The SCWO process operates at about $1000 \mathrm{~F}$ and $230 \mathrm{~atm}$, and significant problems with chloride-induced stress corrosion cracking are expected. Clogging of valves and lines with precipitated salts has hampered operation of pilot plants. Pressure reduction and gas/iquid/solid separations must be optimized.

$\begin{array}{llllll}12 & 421 & 5.11 .1 .6 & 5.39 & 7 & 7\end{array}$

Life cycle costs for system L1 cannot be accurately forecast because of the early stage of SCWO development.

$12 \cdot 422 \quad 5.11 .2 .2 \quad 5-40 \quad 7 \quad 7$

SCWO remains largely untested on DOE's MLLW. The first commercial SCWO plant was placed in operation in 1994 processing a petroleum based waste stream at the rate of 5 gallons per minute.

$\begin{array}{rrrrr}412 & 5.11 & 5-37 & 7 & 7\end{array}$

e-1) Receiving and Preparation

$\begin{array}{llllll}13 & 86 & 2.1 .1 .1 & 2-7 & 9 & 8\end{array}$ it is assumed that $50 \%$ of the waste requires sorting.

e-2) Primary Treatment

$14300 \quad 5.2 .1 .6 \quad 5-8 \quad 5 \quad 5 \quad$ The risk of cost overruns for incinerators is low for nonalpha MLLW, but it is high for alpha MLLW. Equipment engineering development will be needed for alpha MLLW (5.2.2.2). 
App E

No. No. Sect. Page $U^{*} S^{* *}$

e-3) Alr Polution Control (APC)

$\begin{array}{llllll}15 & 290 & 5.2 .1 .2 .3 & 5-6 & 7 & 7\end{array}$

$\begin{array}{llllll}15 & 291 & 5.2 .1 .2 .1 & 5-4 & 6 & 8\end{array}$

$15 \quad 320 \quad 5.2 .2 .10 \quad 5-13 \quad 7 \quad 8$

$\begin{array}{lllll}-\quad & 125 & 2.2 .1 & 2-12 & 6\end{array}$

$\begin{array}{rrrrr}-\quad 366 \quad 5.7 .2 & 5-29 \quad 6 \quad 8\end{array}$

e-4) Primary Stabilization

$\begin{array}{lllll}- & 278 & 5.2 & 5-3 & 6\end{array}$

$\begin{array}{lllll}- & 317 & 5.2 .2 .10 & 5.13 & 6\end{array}$

e-9) Aqueous Waste Treatment

$\begin{array}{lllll}-\quad 181 & 2.7 & 2-22 & 6 & 8\end{array}$

\section{t) Life Cycle Cost and Sensitivity Analysis}

\begin{tabular}{cccccc}
16 & 227 & 4.1 & $4-1$ & 6 & 7 \\
16 & 233 & 4.2 .2 .1 & $4-2$ & 7 & 8 \\
16 & 235 & 4.2 .2 .3 & $4-2$ & 6 & 7 \\
16 & 236 & 4.2 .2 .4 & $4-2$ & 6 & 8 \\
& & & & & \\
16 & 237 & 4.2 .2 .5 & $4-2$ & 6 & 7 \\
16 & 238 & 4.2 .2 .5 & $4-3$ & 6 & 7 \\
\hline & $X-255$ & 4.5 & $4-5$ & 6 & 7 \\
- & $X-256$ & 4.5 & $4-5$ & 6 & 7 \\
\hline & $X-257$ & 4.5 & $4-5$ & 6 & 7
\end{tabular}

\section{ITTS Phase 2 - Critical Assumptions or Design Features}

Actinide volatilization and potential release is the greatest ES\&H concern when treating alpha MLLW, which may contain the toxic radionuclides uranium, plutonium and americium. Actinide volatilization and capture require further study.

Actinide removals in APC modules are unknown. For compliance, actinides discharge from APCs should be very low and perhaps below detection limits. Most of the actinides are thought to remain in the incinerator bottom ash, but they may be volatilized in the stabilization vitrifier. Aluminosilicates have been shown to decrease actinide volatility.

A method to prevent volatilization of metals and actinides must be developed. A cold sand trap is proposed in the offgas duct to absorb volatilized metals.

The APC subsystem for the oxygen plasma furnace will include a fluidized bed of lime to remove $\mathrm{CO} 2$, chlorides and water from the offgas. The spent lime will be calcined for recycling; the released $\mathrm{CO} 2$ will be discharged to the atmosphere.

The control of particulates, radionuclides, toxic metals and acid gases, and the leaching resistance of slag and metal products, remain to be demonstrated for MLLW.

Baseline primary stabilization was designed using a melter of unspecified type and a standard dry APC unit. For estimating cost, a centrifugal hearth plasma melter was assumed.

Primary stabilization by vitrification is assigned a moderate technology risk.

The condensed organic liquids from TDMEO are destroyed in a low-temperature (50-60 C) Mediated Electrochemical Oxidation (MEO) process using an aqueous sulfuric acid/cobalt sulfate electrolyte.
PLCC estimates assume a government owned and contractor operated (GOCO) facility. Cost
Design was estimated at $25 \%$ of construction cost.
Project management was $10 \%$ of construction cost multipliers appropriate to this business relationship were used.
Construction costs were estimated for buildings ( $\$ 180$ for offices to $\$ 1700 / \mathrm{sq} \mathrm{ft}$ for triple containment areas); equipment (suppliers cost plus allowance for installation, electrical, instrumentation and mechanical); and indirect cost ( $29 \%$ of buildings and equipment).
Construction management was estimated as percent of equipment, building and indirect and Contingency was assumed to be $25 \%$ of total facility construction cost.
Risk level 2 assumed full operation in two years and increased overall system costs by $4 \%$. Risk level 3 assumed full operation in three years and increased overall system costs by $7 \%$.
Risk level 4 for technologies in an early stage of development increased overall system costs by $11 \%$. included - $17 \%$ for management and $10 \%$ for project scope changes and management reserve. 
App F

No. No. Sect. Page $\mathbf{U}^{*} \mathbf{S}^{* *}$

INTS - Critical Assumptions or Design Features

a) Regulations, Permitting and Stakeholder Input

$\begin{array}{cccccc}1 & 3 & 1.9 .1 & 15 & 7 & 8 \\ 2 & 7 & 1.9 .1 & 16 & 6 & 6 \\ 2 & 8 & 1.9 .1 & 16 & 6 & 6 \\ 2 & 9 & 1.9 .1 & 16 & 6 & 6 \\ 2 & 10 & 1.9 .1 & 16 & 6 & 6 \\ 2 & 11 & 1.9 .1 & 16 & 6 & 6\end{array}$

Facilities are placed in seismic category 1.

The facility consists of four radiation zones that house the treatment subsystems and other support systems. These zones are as follows:

d) General Design and Operating Assumptions

\begin{tabular}{|c|c|c|c|c|c|c|}
\hline FS & 22 & 1.10 .1 & 20 & 8 & 9 & The facility will process all of the RCRA waste stored at all DOE installations. \\
\hline FS & 105 & 5.3 & 166 & 8 & 8 & $\begin{array}{l}\text { Issues regarding single versus multiple facility options and transportation of waste to such } \\
\text { facilities were not considered in this study ( they were addressed in the draft DOE Programmatic } \\
\text { Environmental Impact Statement (PEIS)). }\end{array}$ \\
\hline FS & 106 & 5.3 & 166 & 8 & 8 & $\begin{array}{l}\text { Premise was that a single facility will treat all existing DOE mixed waste in } 20 \text { yrs (excluding } \\
\text { Hanford tank wastes and Rocky Flats pondcrete). }\end{array}$ \\
\hline FS & 260 & 4 & 125 & 8 & 6 & $\begin{array}{l}\text { The facility includes alpha confinement rather than build two smaller facilities (one for alpha and } \\
\text { one for non-alpha MLLW). }\end{array}$ \\
\hline FS & 111 & 6.7 & 224 & 9 & 7 & $\begin{array}{l}\text { Hybrid systems that combine the best elements of thermal and non-thermal technologies were } \\
\text { not considered. }\end{array}$ \\
\hline- & 65 & 1.7 & 12 & 9 & 9 & $\begin{array}{l}\text { Over } 200 \text { non-thermal technologies were screened; only five systems were selected (WPI, } 1966 \\
\text { - see Appendix D) }\end{array}$ \\
\hline 2 & 87 & 1.10 .3 & 27 & 5 & 6 & $\begin{array}{l}\text { The system for treating alpha LLW and alpha MLLW will accommodate TRU waste (triple } \\
\text { containment of contaminated waste). }\end{array}$ \\
\hline 2 & 88 & 1.10 .3 & 28 & 5 & 6 & $\begin{array}{l}\text { Double containment will be used for processes involving materials with limited potential for } \\
\text { becoming airborne. }\end{array}$ \\
\hline 2 & 104 & 5.1 .3 & 163 & 5 & 6 & $\begin{array}{l}\text { Process containment - Double or triple containment is standard for systems treating radioactive } \\
\text { waste and is not a significant discriminator between systems. }\end{array}$ \\
\hline 3 & 70 & 1.9 .2 & 17 & 8 & 8 & $\begin{array}{l}\text { The facility is designed to operate three shifts per day, seven days per week, } 40 \text { weeks per year } \\
\text { at } 60 \% \text { operating efficiency for a total of } 4,032 \text { hrs per year. }\end{array}$ \\
\hline 3 & 85 & 1.10 .3 & 27 & 8 & 6 & The subsystems will handle at least $125 \%$ of the expected flow rates. \\
\hline 4 & 96 & 3.3 & 100 & 6 & 8 & $\begin{array}{l}\text { Stabilization formulas (mass basis): Polymer = } 1 \text { part polymer to } 1 \text { part waste; Phosphate } \\
\text { bonded ceramic = } 1 \text { part ceramic additives to } 1 \text { part waste; Grout }=2 \text { parts grout to } 1 \text { part waste. }\end{array}$ \\
\hline
\end{tabular}

d-1) System 1 -. Grout Debris

$\begin{array}{llllll}5 & 112 & 2 & 31 & 7 & 6 \\ 6 & 113 & 2 & 31 & 7 & 6\end{array}$

Low hazard areas: the zone that houses offices. and packaged waste handling areas.

Moderate hazard areas: the zone that houses operating galleries and analytical laboratory.

Double confined alpha cells: the zone that houses maintenance galleries.

Triple confined alpha cells: the zone that houses alpha MLLW processing equipment.

d-2) System 2 - Desorption

$\begin{array}{cccccc}6 & 118 & 2 & 31 & 7 & 6 \\ 6 & 123 & 6.3 & 199 & 7 & 6 \\ 7 & 119 & 2 & 31 & 7 & 6 \\ 11 & 121 & 4.8 & 132 & 7 & 7\end{array}$

System 1 (Grout Debris) uses mediated electrochemical oxidation (MEO) for primary organic destruction

System 1 (Grout Debris) uses vacuum desorption for volatile organic separation of process residue and soil.

System 2 (Desorption) uses vacuum desorption (followed by stabilization) for debris waste as well as process residue and soil.

The vacuum desorption tech. does not remove heavy and radioactive metals. Stabilization of these materials in grout in the presence of debris has not been demonstrated.

System 2 (Desorption) uses catalytic wet oxidation (CWO) for primary organic destruction.

The excess water generated by the system may need to be grout stabilized (rather than discharged), which would increase the grout system by $60 \%(\$ 450 \mathrm{k})$ and increase disposal cost by $\$ 250 \mathrm{M}$.

$\begin{array}{llllll}12 & 122 & 6.3 & 199 & 7 & 6\end{array}$

Sorting requirements for System 2 are more strenuous than System 1 because debris must be separated. BUT sorting and preparation was considered to be the same for all systems; this is not consistent. 
App F

No. No. Sect. Page $\mathbf{U}^{*} \mathbf{S}^{* *}$

d-3) System 3 - Wash

$\begin{array}{llllll}5 & 128 & 2 & 31 & 7 & 6\end{array}$

$\begin{array}{llllll}5 & 136 & 6.4 & 207 & 6 & 6\end{array}$

$\begin{array}{llllll}8 & 126 & 2 & 31 & 7 & 6\end{array}$

d-4) System 4 - Acid Digestion

$\begin{array}{cccccc}6 & 140 & 2 & 31 & 7 & 6 \\ 8 & 138 & 2 & 31 & 7 & 6 \\ 8 & 144 & 2 & 31 & 7 & 6 \\ 9 & 143 & 2 & 31 & 7 & 6 \\ 9 & 149 & 6.5 & 208 & 7 & 6 \\ 9 & 153 & 6.5 & 212 & 7 & 6 \\ 10 & 142 & 2 & 31 & 7 & 6 \\ 10 & 148 & 6.5 & 208 & 7 & 6 \\ 10 & 150 & 6.5 & 209 & 5 & 5 \\ 10 & 151 & 6.5 & 210 & 7 & 6\end{array}$

INTS - Critical Assumptions or Design Features

System 3 (Washing) uses MEO for primary organic destruction.

If surfactant cannot be recycled (due to poor partitioning) treatment of the surfactant would increase the cost to the MEO organic destruction subsystem by approximately $50 \%$, or $\$ 100$ million in PLCC, and surfactant costs would increase by $<1$ million.

System 3 (Washing) uses aqueous wash for soil, process residue, and inorganic sludge treatment; and high pressure wash for soft, open and complex debris.

System 4 (Acid Digestion) uses vacuum thermal desorption for process residue and inorganic System 4 (Acid Digestion) uses aqueous wash for soil.

System 4 (Acid Digestion) uses high pressure spray wash for open debris. sludge.

System 4 (Acid Digestion) uses phosphoric-nitric acid digestion for primary organic destruction and soft debris treatment.

The response of the acid digestion system to complex feed streams is not known.

Volatile organics could vaporize prior to destruction.

System 4 (Acid Digestion) uses phosphate bonded ceramic for stabilization of treated soil and insoluble residues.

Phosphate bonded cement stabilization (which uses the waste phosphoric acid) is a bench scale process whose effectiveness needs to be determined.

Failure of phosphate bonded ceramic waste may occur, with subsequent reprocessing required curing may be slower than anticipated which will impact production rate.

Phosphate bonded ceramic is assumed to be as stable as polymer and more stable than grout.

d-5) System 5 - Catalyzed Wet Oxidation

\begin{tabular}{|c|c|c|c|c|c|c|}
\hline 6 & 160 & 2 & 31 & 7 & 6 & $\begin{array}{l}\text { System } 5 \text { (Catalytic Wet Oxidation) uses vacuum thermal desorption for process residue and } \\
\text { inorganic sludge. }\end{array}$ \\
\hline 7 & 157 & 2. & 31 & 7 & 6 & $\begin{array}{l}\text { System } 5 \text { (Catalytic Wet Oxidation) uses CWO for primary organic destruction and soft debris } \\
\text { treatment. }\end{array}$ \\
\hline 7 & 163 & 2.5 .3 & 55 & 7 & 6 & $\begin{array}{l}\text { The CWO subsystem for treating soft debris is the same as for treating organics except that an } \\
\text { extra shredder in needed and a larger ( } 2500 \text { gal) vessel is used since a slower reaction is } \\
\text { expected }\end{array}$ \\
\hline 7 & 164 & 6.6 & 214 & 7 & 6 & $\begin{array}{l}\text { The organic destruction efficiency of CWO is } 99.99 \% \text { for organics, and soil rinsed with CWO } \\
\text { solution has metal removal to nondetect levels. }\end{array}$ \\
\hline 8 & 158 & 2 & 31 & 7 & 6 & System 5 (Catalytic Wet Oxidation) uses aqueous wash for soil. \\
\hline 8 & 161 & 2 & 31 & 7 & 6 & System 5 (Catalytic Wet Oxidation) uses high pressure spray wash for open debris. \\
\hline-1$)$ & \multicolumn{6}{|c|}{ Receiving and Preparation } \\
\hline 12 & 167 & 1.10 .3 & 24 & 5 & 8 & $\begin{array}{l}\text { Extensive sorting is required to divide the waste into appropriate categories } \\
\text { (as given in Table } 3-1 \text { ). }\end{array}$ \\
\hline 12 & 168 & 2 & 30 & 5 & 8 & All systems use extensive characterization and sorting. \\
\hline 12 & 169 & 2.1 .2 & 34 & 6 & 8 & $\begin{array}{l}\text { The Receiving and Preparation subsystem (the highest cost subsystem) is the same for all } \\
\text { alternative INTS systems. }\end{array}$ \\
\hline 12 & 170 & 1.9 .2 & 17 & 6 & 8 & $\begin{array}{l}75 \% \text { of all the waste received by the facility will require sorting to meet the Waste Acceptance } \\
\text { Criteria (WAC) for the processes. }\end{array}$ \\
\hline 12 & $171^{\circ}$ & 1.9 .2 & 17 & 6 & 8 & $\begin{array}{l}25 \% \text { of all the waste received by the facility meets the WAC of the treatment processes and will } \\
\text { not require further sorting. }\end{array}$ \\
\hline 12 & 172 & 6.2 & 187 & 8 & 8 & $\begin{array}{l}\text { The feedstock characterization and preparation process has not been tested; it will require } \\
\text { further engineering development and demonstration. }\end{array}$ \\
\hline 12 & 173 & 6.2 & 194 & 8 & 8 & $\begin{array}{l}\text { Assay \& non-destructive examination of incoming containers and decapping, dumping, \& sorting } \\
\text { of the waste require extensive concept development, component development, hardware } \\
\text { engineering and system integration. }\end{array}$ \\
\hline
\end{tabular}




\begin{tabular}{|c|c|c|c|c|c|}
\hline No. & $\begin{array}{c}\text { App F } \\
\text { No. }\end{array}$ & Sect. & Page & $U^{*}$ & $\mathbf{S}^{* *}$ \\
\hline e-2) & \multicolumn{5}{|c|}{ Organic Destruction } \\
\hline $5 \& 7$ & 174 & 1.10 .3 & 25 & 7 & 6 \\
\hline $5 \& 7$ & 177 & 6.2 & 187 & 7 & 6 \\
\hline 5 & 180 & $\mathrm{C}-3$ & $\mathrm{C}-7$ & 7 & 6 \\
\hline \multirow[t]{2}{*}{9} & 181 & $\mathrm{C}-3$ & C-8 & 7 & 6 \\
\hline & & & - & & \\
\hline e-4) & \multicolumn{5}{|c|}{ Primary Stabillzation (Grout) } \\
\hline 4 & 193 & 2.1 .14 & 43 & 6 & 6 \\
\hline
\end{tabular}

INTS - Critical Assumptions or Design Features

Organic liquid and sludge waste will be oxidized or decomposed at temperatures below $660 \mathrm{~F}$ to achieve destruction of RCRA controlled materials.

The organic destruction subsystems may be affected by the presence of non-organic compounds present in DOE wastes; the impact of non-organics on performance, reliability and availability must be addressed.

Catalytic Wet Oxidation, CWO, (used for Systems 2 and 5) treats organic liquids and sludges at $302 \mathrm{~F}$ and 35 psi; the reactions taking place are assumed to go to $99 \%$ completion. The liquid stream is neutralized, which is also assumed to operate at a conversion of $99 \%$.

Phosphoric Acid Digestion, (used for System 4) treats organic liquids and sludges at $392 \mathrm{~F}$ and $1 \mathrm{~atm}$; the reactions taking place are assumed to go to $95 \%$ completion. The recovery of $\mathrm{HNO} 3$ is also assumed to operate at a conversion of $99 \%$.

The Grout Stabilization subsystem mixes two parts of grout (cement, sand, \& water) with one part of waste.

e-14) Process Residue and inorganic Sludge
$6 \quad 227 \quad 2.15$
1.5
e-15) Bulk Soil

$\begin{array}{llllll}6 & 231 & 2.1 .6 & 40 & 7 & 6\end{array}$
The Process Residue and Inorganic Sludge Treatment subsystem employs vacuum desorption at $500 \mathrm{~F}$ to remove volatile compounds.
The bulk soil is treated (in campaigns) in the vacuum desorption process, and then sent to the grout stabilization subsystem.'

e-18) Disposal

$\begin{array}{llllll}13 & 239 & 1.10 .3 & 27 & 5 & 6 \\ 13 & 240 & 2.1 .17 & 46 & 5 & 6\end{array}$

Costs for shallow land disposal facilities have been used for all wastes. The Disposal subsystem consists of disposal units based on an earth mound and concrete cell
concept.

\section{ก) Life Cycle Cost and Sensitivity Analysis}

\begin{tabular}{|c|c|c|c|c|c|c|}
\hline 13 & 298 & 4.3 & 129 & 8 & 6 & Disposal costs are based on a unit rate of $\$ 243 / \mathrm{tt} 3$ for burial in an engineered disposal facility \\
\hline 14 & 241 & 1.8 & 15 & 8 & 9 & $\begin{array}{l}\text { Costs have been estimated assuming the system is a government owned and contractor } \\
\text { operated }(\mathrm{GOCO}) \text { facility. }\end{array}$ \\
\hline 14 & 248 & 1.9 .3 & 18 & 8 & 8 & $\begin{array}{l}\text { PLCC estimates for facility construction are based on conditions at Idaho National Engineering } \\
\text { Laboratory (INEL), in Idaho Falls, Idaho, including utilities, labor and related design, construction, } \\
\text { operation, and management factors. }\end{array}$ \\
\hline 14 & 242 & 1.9 .3 & 18 & 8 & 9 & $\begin{array}{l}\text { Design, inspection, project administration, indirect, construction management, and contingency } \\
\text { costs subcomponents are developed using percentage guidelines provided by INEL. }\end{array}$ \\
\hline 14 & 254 & 1.9 .3 & 19 & 8 & 8 & $\begin{array}{l}\text { The allowance percentages are historical averages experienced by DOE contractors at INEL } \\
\text { for the types of activities covered by waste management facilities. }\end{array}$ \\
\hline 14 & 265 & 4.2 .2 & 126 & 8 & 6 & Design (preliminary plus detailed) is estimated at $25 \%$ of facility construction costs (FCC). \\
\hline 14 & 266 & 4.2 .2 & 126 & 8 & 6 & Project management for construction (DOE and $\mathrm{M} \& \mathrm{O}$ ) is estimated at $10 \%$ of FCC \\
\hline 14 & 268 & 4.2 .2 & 126 & 8 & 6 & Inspection (engineering support during construction) is estimated at $7 \%$ of FCC \\
\hline 14 & 284 & 4.2 .2 & 128 & 8 & 6 & $\begin{array}{l}\text { A } 25 \% \text { contingency was added to the total construction cost (because the costs are a planning } \\
\text { level estimate). }\end{array}$ \\
\hline 14 & 285 & 4.2 .2 & 128 & 8 & 6 & Allowances for project scope change $=10 \%$ of construction cost. \\
\hline 14 & 286 & 4.2 .2 & 128 & 8 & 6 & Construction management $=17 \%$ of construction costs (equipment + buildings + indirect costs). \\
\hline 14815 & 307 & 4.2 .4 & 135 & 8 & 6 & A contingency of $25 \%$ was added for O\&M costs. \\
\hline 16 & 244 & 1.9 .3 & 18 & 5 & 5 & $\begin{array}{l}\text { Equipment cost estimates are based on the use of stainless steel material for process vessels } \\
\text { selected for ease of decontamination and maintenance, unless otherwise discussed. }\end{array}$ \\
\hline- & 302 & 4.6 & 131 & 8 & 6 & $\begin{array}{l}\text { Uncertain subsystems (receiving and prep, organic destr. [MEO, CWO, and acid digestion], } \\
\text { process residue [vacuum desorption, aqueous washing], soil treatment [aq. washing], and } \\
\text { debris treatment [high press washing, agitation washing, acid digestion, CWO]) were given a } \\
50 \% \text { contingency. }\end{array}$ \\
\hline- & 262 & 4.1 & 125 & 8 & 6 & The time value of money was ignored in this analysis. \\
\hline
\end{tabular}

Note: $U$ The uncertainty in an assumption (on a scale of $1-10$ with 10 being the most uncertain)

* $\mathrm{S}$ The sensitivity of the Total PLCC to changes in the assumption (on a scale of $1-10$ with 10 being the most sensitive) 
APPENDIX H

\section{ASSUMPTIONS OF INTEREST FROM THE ITTS PHASE 2 ANALYSIS OF PERFORMANCE MEASURES}


NO. SEC PAGE $\ldots . . . . . .$. . CRITERIA $\ldots . . . . .$.

48 1.5.3.3 1-18 $\quad 1 \quad 9 \quad 1 \quad|\quad| \quad|\quad| \quad \mid$ Analysis for RCRA metals will not be needed since the waste is already assumed to be hazardous.

290 5.2.1.2.35-6 $\quad 7 \quad 711|1|$ Actinide volatilization and potential release is the greatest ES\&H concern when treating alpha MLLW, which may contain the toxic radionuclides uranium, plutonium and americium. Actinide volatilization and capture require further study.

291 5.2.1.2.1 5-4

Actinide removals in APC modules are unknown. For compliance, actinides discharge from APCs should be very low and perhaps below detection limits. Most of the actinides are thought to remain in the incinerator bottom ash, but they may be volatilized in the stabilization vitrifier. Aluminosilicates have been shown to decrease actinide volatility.

44 1.5.3.2 1-17 492 ～～～| | | System G1 (molten metal) may not require RCRA permitting if it can be classified as a recycling facility. The report casts doubt on this possibility, and it is presumed that the study does not treat it in that manner.

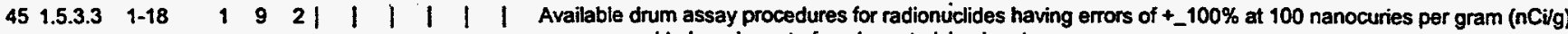
are assumed to be adequate for characterizing input.

15 1.5.1 $1-11 \quad 36 \quad 3 \quad|\quad| \quad|\quad| \quad$ Limited quantities of buried waste covered by the Comprehensive Environmental Response, Compensation and Liability Act (CERCLA) may be retrieved for treatment.

50 1.5.3.3 $\quad 1-18 \quad 1531 \quad|\quad| \quad|\quad| \quad$ TCLP leaching tests will be used to demonstrate compliance with EPA requirements for burial in a mixed waste disposal facility.

$1002.1 .1 .8 \quad 2-8$

$2831|1| 11$

No conceptual design has been developed for "special wastes", which will be dealt with on a case-by-case basis. A cost allowance of $\$ 3$ million is included in cost estimates.

$1612.4 .2 \quad 2-19 \quad|\quad 3|$ cooler.

$\begin{array}{lllllllllll}19 & 1.5 .1 & 1-11 & 4 & 6 & 4 & \mid & \mid & \mid & \mid\end{array} \quad$ Some regulatory guidelines have been published by the EPA, as for example in the document entitled Quality Assurance and Quality Control for Waste Containment Facilities, September 1993. However, specific permitting requirements may depend on the characterization of the final waste form obtained from pilot tests or demonstrations.

70 1.5.3.5 1-22 $\quad|\quad| \quad 4 \quad|\quad| \quad|\quad| \quad \mid$ Final waste forms are assumed to meet stability requirements for acceptance at surface disposal facifities at various major DOE installations.

81 2.1.1.1 2-7 | | $4|\quad| \quad|\quad|$ A passive/active neutron (PAN) assay unit will determine the level of TRU contamination.

$1232.2 .1 \quad 2-12 \quad|\quad 4| \quad|\quad| \quad|\quad| \quad$ | | | | | | | Contaminated soil or olher additives are added to control the properties of the slag.

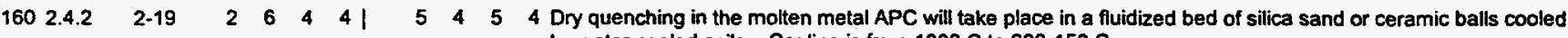
by water-cooled coils. Cooling is from $1800 \mathrm{C}$ to $200-150 \mathrm{C}$.

$\begin{array}{llllllll}182 & 27 & 2-22 & \mid & 4 & \mid\end{array}$

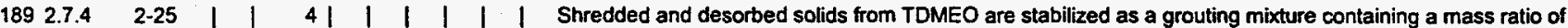
waste to grout of $50 \%$ by weight. The stabilized process residues will be required to pass the EPA TCLP test.

$2203.3 \quad 3-5 \quad 1 \quad 8 \quad 4 \quad|1| 1 \quad 1$

The 0.5:1 mass ratio of soil to waste is assumed to apply to the Joule-heated melter despite the relatively narrower range of operating temperature for the borosilicate glass usually formed in this system (when compared to alumino-silicate based basalt).

284 5.2.1.2.15-3 | | $|\quad| \quad|\quad| \quad \mid \quad$ The low temperature required for mercury capture on activated carbon (150 F) creates a design problem concerning removal of condensate from flue gas ahead of the HEPA filters.

289 5.2.1.2.15-4 $\quad 3 \quad 5 \quad 4|| \quad|\quad| \quad \mid \quad$ Lead expected to bed volatilized in an incinerator or other thermal treatment technology is not specifically addressed in the preconceptual design. Between $5 \%$ and $80 \%$ of lead input has been reported in scrubber exit gas, indicating a need for further study.

$\begin{array}{lllllllllll}302 & 5.2 .2 .1 & 5-8 & 1 & 6 & 4 & 6 & 7 & 6 & 6 & 7\end{array} \quad$ Real-time radiography for assay has been used experimentally at INEL, but work is needed on design and data interpretation.

$\begin{array}{lllllllllll}303 & 5.2 .2 .1 & 5-8 & 1 & 7 & 4 & \mid & \mid & \mid & \mid\end{array} \quad$ Alpha-radialion assay based on PAN is the current technology bas for DOE facilities. The method is suitable for TRU waste $>100 \mathrm{nCi} / \mathrm{g}$, but the accuracy is questionable at lower levels.

318 5.2.2.10.5-13 | | 1 | | | | | - | Melt chemistry and formulation requires additional work on a prototype unit to assure :high-integrity. leach-resistant vitrified product.

$\begin{array}{llllllll}320 & 5.2 .2 .10 .5-13 & 7 & 8 & 4 & 6 & 6 & 5\end{array}$ proposed in the offgas duct to absorb volatilized metals.

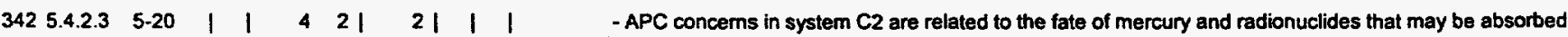
in the lime bed and released in the calciner.

$3505.6 \quad 5-23 \quad 6 \quad 6 \quad 4 \quad|\quad| \quad|\quad| \quad \mid$ The Molten Salt Oxidation (MSO) System (F1) has a greater technology risk than the baseline. The technology oxidizes low-ash combustibles in molten sodium carbonate, which catalyzes the oxidation and neutralizes acids. The viscosity of the melt must be controlled by removing ash and inert materials.

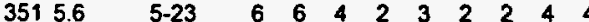

- MSO technology has been developed over the last 30 years with little commercial application. Most of the available data were obtained in bench scale tests. Technology risks pertain to the removal of ash from the melt to control melt viscosity, the fate of radionuclides, and the effect of carbon in ash from the MSO process in 
NO. SEC PAGE $\ldots . . . . .$. "CRITERIA $\ldots . . . . .$.

subsequent vitrification stabilization (5.6.2).

$3525.6 \quad 5-23 \quad|\quad| \quad 4|23|$

- Feed to the MSO consists of low-ash solid combustibles and organic liquids. Sorting the combustible from the noncombustible requires an extensive receiving and preparation subsystem. Large bulk items must be excluded. Because of the large heat sink, gradual changes in the feed's heating value can be tolerated (5.6.2).

353 5.6.1.1 5-23 | | $\quad 4 \quad|\quad| \quad|\quad| \quad|\quad| \quad$ | treatment. Permitting is expected to be under industrial furnace or miscellaneous RCRA categories.

$\begin{array}{lllllllllll}354 & 5.6 .1 .2 & 5-24 & \mid & \mid & 4 & 1 & \mid & \mid & \mid & 1\end{array}$

- EH\&S risks of worker exposure are increased due to additional waste separation and processing for salt recycling. Small MSO systems have been operated at Oak Ridge and Lawrence Livermore. NOx is reduced and the volume of emissions is halved compared to the baseline. The fate of radionuclides remains to be evaluated.

$\begin{array}{llllllllllll}355 & 5.6 .1 .3 & 5-24 & 6 & 6 & 4 & 2 & 2 & 2 & 1 & \mid & 1\end{array}$

- Treatment effectiveness is reduced by the limitation of MSO to treat only combustibles. Corrosion of the vessel is a concem. Ash in the molten bath is limited to $20 \%$ to control viscosity. Excess ash is removed and the salt recycled by dissolution, fittration of ash, and evaporative recrystallization of the salt. The aqueous stream is recycled to avoid waste generation.

$\begin{array}{lllllllllll}357 & 5.6 .1 .3 & 5-25 & \mid & \mid & 4 & 5 & 6 & 4 & \mid & 1\end{array}$

- Both the separated noncombustible waste and the ash from the MSO are sent to the primary stabilization vitrifier. Vitrifier concerns include organics in the separated noncombustible material and carbon in the ash from the MSO.

$4025.10 \quad 5-34|| 4||||||$

$4045.10 .1 .15-34|14||1|||$

$4145.11 .1 .45-39 \quad|\quad| \quad 4||||||$
- Solids leaving the TD unit are stabilized by grouting.

- Regulatory Compliance depends on evaluating the acceptability of grout stabilization for TD residues under EPA and DOE standards. Grouting produces a less stable waste form than vitrification. "Permitting ... may not be possible." TD has been permitted for hazardous waste treatment, and MEO as an aqueous treatment method is a less sensitive technology.

- Regulatory compliance risk is increased by the less stabilized final waste form and the larger volume produced by grouting. compared to the baseline. TD has been permitted for hazardous waste treatment, and SCWO would be permitted as a simpler aqueous method.

\begin{tabular}{llllll|lll|l|l|l|l|l|l}
419 & 5.11 .2 .2 & $5-40$ & 7 & 7 & 4 & 2 & 3 & 1 & 3
\end{tabular}

- The SCWO process operates at about $1000 \mathrm{~F}$ and $230 \mathrm{~atm}$. and significant problems with chloride-induced stress corrosion cracking are expected. Clogging of valves and lines with precipitated salts has hampered operation of pilot plants. Pressure reduction and gas/iquid/solid separations must be optimized. 


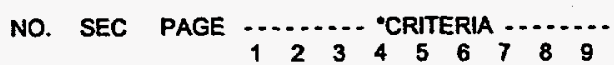

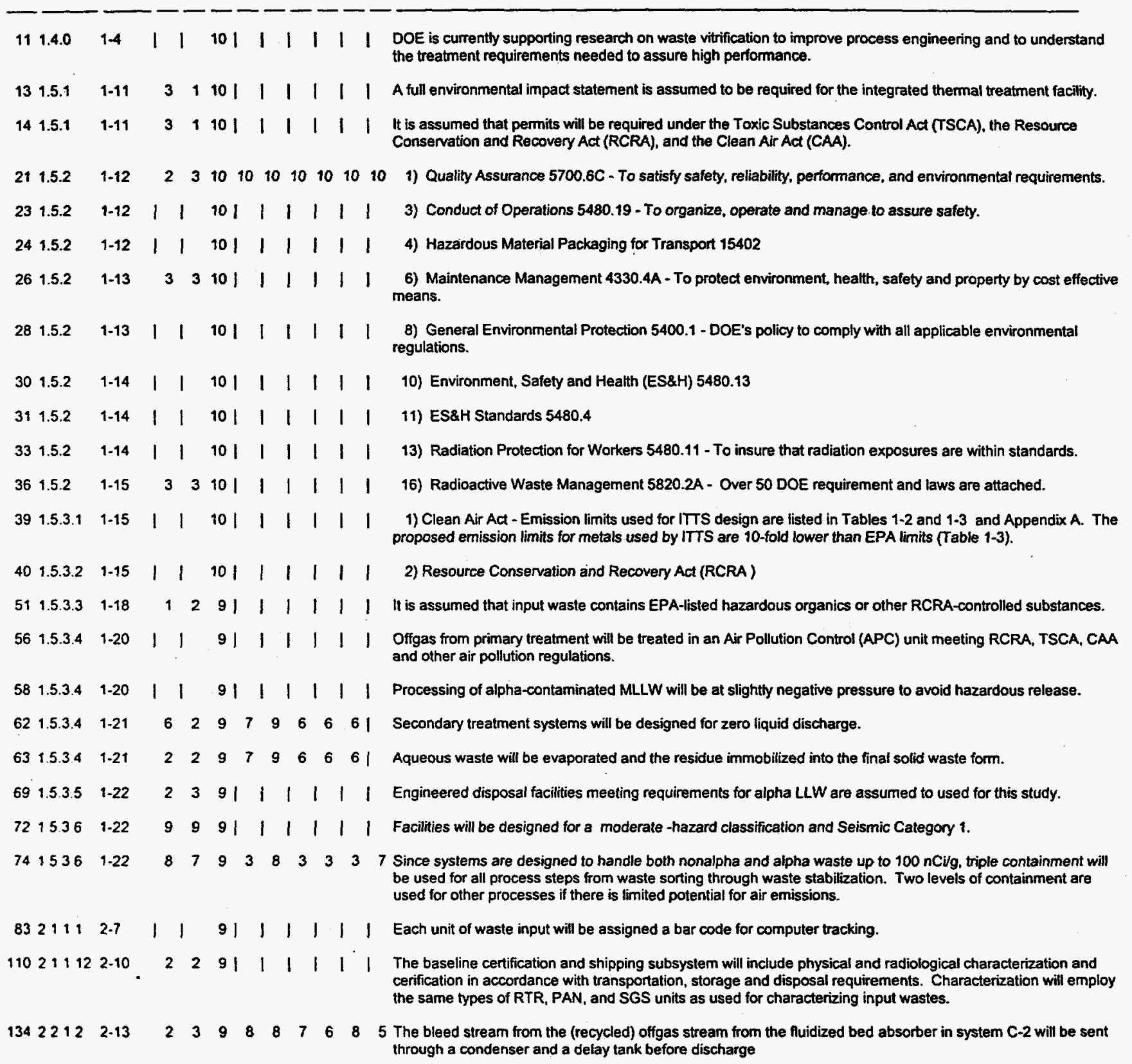

